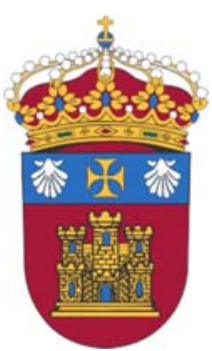

DEPARTAMENTO DE INGENIERÍA CIVIL

UNIVERSIDAD DE BURGOS

\title{
ANÁLISIS Y OPTIMIZACIÓN DE MODELOS DE ROTOR DE MOTOR SINCRONO PARA VEHÍCULOS HIBRIDOS CON LA INCORPORACIÓN DE NUEVOS MATERIALES MAGNÉTICOS
}

TESIS DOCTORAL

Doña Victoria Abad San Martín

Ingeniera Industrial por la UNED 



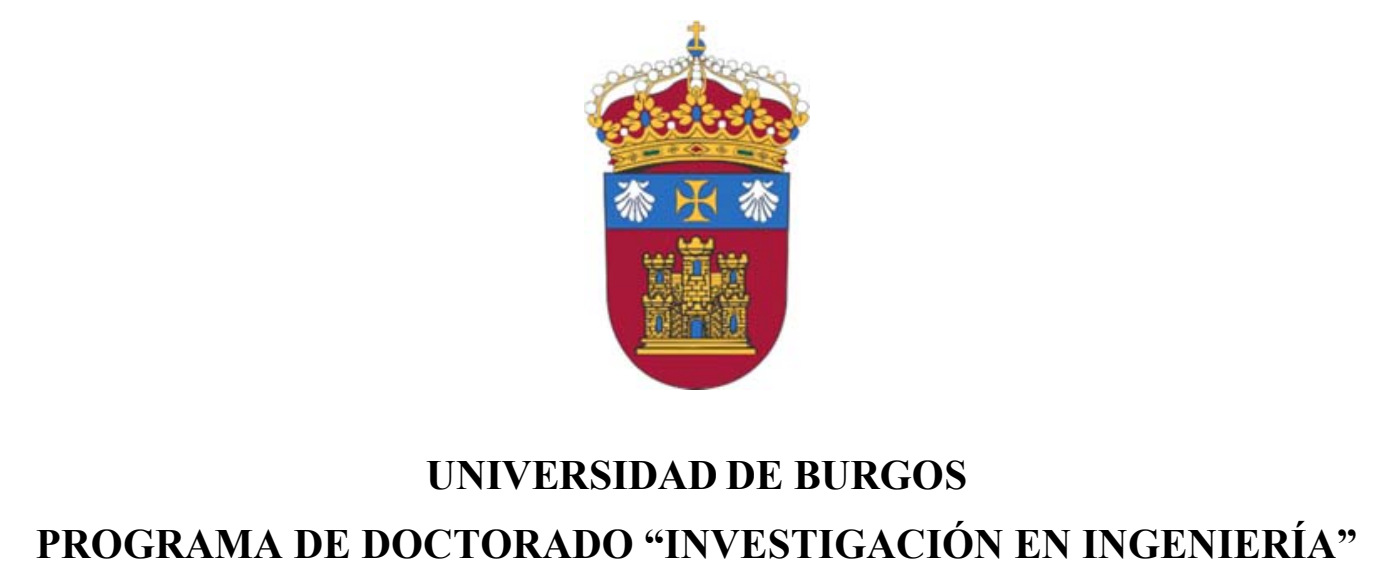

ESCUELA POLITÉCNICA SUPERIOR

TESIS DOCTORAL

\section{TÍTULO: ANÁLISIS Y OPTIMIZACIÓN DE MODELOS DE ROTOR DE MOTOR SINCRONO PARA VEHÍCULOS HIBRIDOS CON LA INCORPORACIÓN DE NUEVOS MATERIALES MAGNÉTICOS}

\section{AUTOR: Doña VICTORIA ABAD SAN MARTÍN \\ DIRECTOR: Dr. Don JESÚS SAGREDO GONZÁLEZ}

RESUMEN: En la presente tesis, por un lado, se estudian las tecnologías de fabricación de imanes permanentes de tierras raras para determinar una alternativa viable a los imanes NdFeB sinterizados, monopolizados por China, y por otro lado se estudian los distintos tipos de motores eléctricos más idóneos para su aplicación en vehículos eléctricos. Una vez determinado que los motores síncronos de imanes permanentes son actualmente los más apropiados, y tomando el motor MG2 del Toyota Prius como base, se desarrolla un nuevo modelo de rotor que utilice eficazmente imanes permanentes aglomerados, con más posibilidades de conformación que los sinterizados.

PALABRAS CLAVE:

Motor Síncrono de Imanes Permanentes, Análisis por Elementos Finitos, Vehículo Eléctrico Híbrido, Tierras raras 



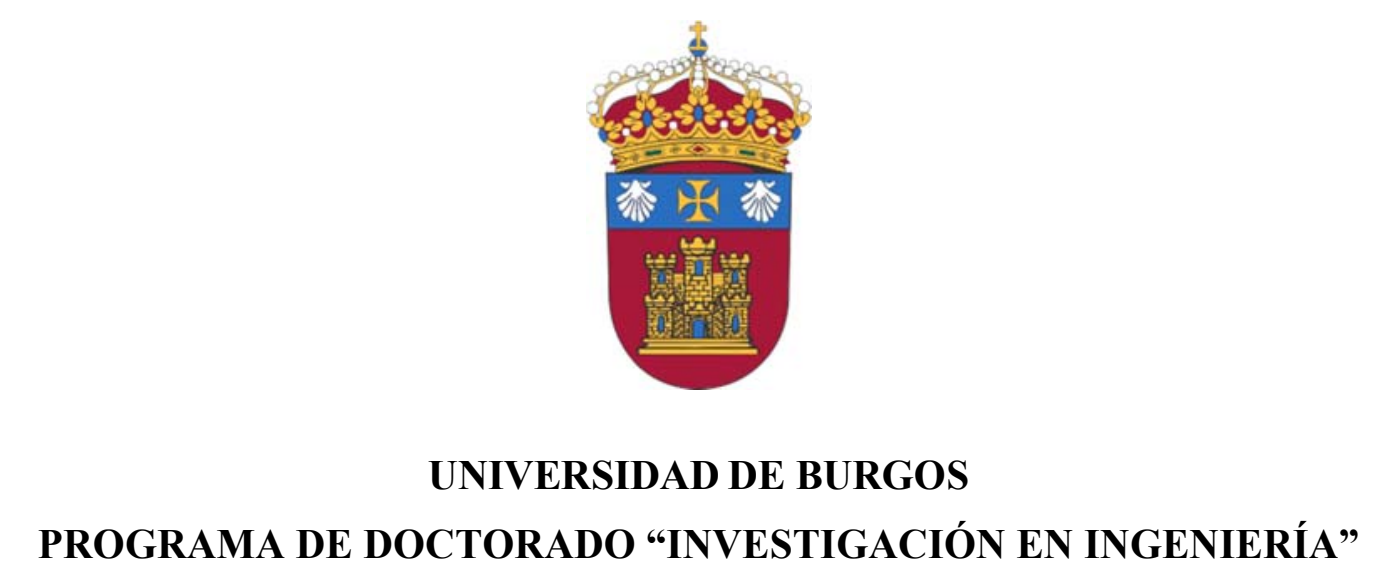

\author{
ESCUELA POLITÉCNICA SUPERIOR
}

\title{
PHD TESIS
}

\section{TITLE: ANALYSIS AND OPTIMIZATION OF ROTOR MODELS IN SYNCHRONOUS MOTORS FOR HYBRID VEHICLES WITH THE INCLUSION OF NEW MAGNETIC MATERIALS}

\section{AUTHOR: VICTORIA ABAD SAN MARTÍN \\ DIRECTOR: Dr. Mr. JESÚS SAGREDO GONZÁLEZ}

ABSTRACT: In this Thesis, on the one hand, manufacturing technologies of rare earth permanent magnets are studied to determine a viable alternative to sintered $\mathrm{NdFeB}$ magnets monopolized by China, and, on the other hand, the most suitable types of electric motors are also studied for its implementation in electric vehicles. Once having determined that the synchronous permanent magnet motors are, at the present time, the most convenient option, and taking Toyota Prius MG2 motor as a basis, a new rotor model efficiently using agglomerate permanent magnets is developed with more conformation possibilities than the sintered ones.

KEYWORDS:

Permanent Magnet Synchronous Machine, Finite Elements Analysis, Hybrid Electrical Vehicle, Rare Earths 



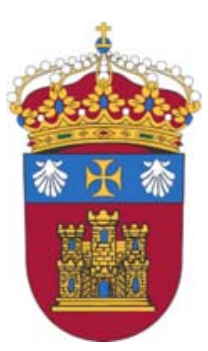

UNIVERSIDAD DE BURGOS

DEPARTAMENTO DE INGENIERÍA ELECTROMECÁNICA

JESÚS SAGREDO GONZÁLEZ, DOCTOR INGENIERO INDUSTRIAL, PROFESOR TITULAR DE ESCUELA UNIVERSITARIA EN EL ÁREA DE INGENIERÍA ELÉCTRICA DE LA UNIVERSIDAD DE BURGOS, EN CONFORMIDAD CON LAS NORMAS VIGENTES DE ESTA UNIVERSIDAD PARA LA PRESENTACIÓN DE TESIS DOCTORALES,

AUTORIZA:

A Doña VICTORIA ABAD SAN MARTÍN a que presente la Tesis Doctoral titulada: "Análisis y optimización de modelos de rotor de motor síncrono para vehículos híbridos con la incorporación de nuevos materiales magnéticos” para la obtención del grado de Doctor.

Burgos, 9 de Junio de 2015

El Director de la Tesis

Fdo: Jesús Sagredo González 



\section{AGRADECIMIENTO}

Son muchas las personas que de una $u$ otra forma me han ayudado en el largo camino recorrido que significa la realización de este trabajo. Unos, con su apoyo técnico, permitieron vencer las dificultades que entorpecían el camino. Otros, con su Amistad, inyectaron su energía en mi espíritu para poder continuar. A todos ellos les quiero manifestar mi más profundo agradecimiento.

Pero, sin duda, la persona que merece todo mi agradecimiento es el director de la misma, Jesús, por estar siempre corrigiéndome y apoyándome.

Por último, a mi padre, que ha estado a mi lado toda la vida. 



\section{ÍNDICE}

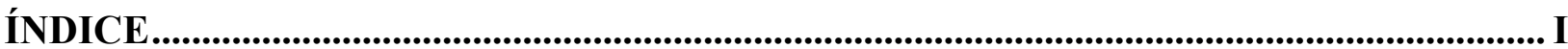

LISTA DE FIGURAS............................................................................................ IV

LISTA DE TABLAS............................................................................................................... VIII

LISTA DE ACRÓNIMOS Y ABREVIATURAS ……............................................................ IX

LISTA DE SÍMBOLOS .................................................................................................. XI

1 Introducción.................................................................................................................................

$1.1 \quad$ Justificación e importancia de la presente Tesis ...............................................................1

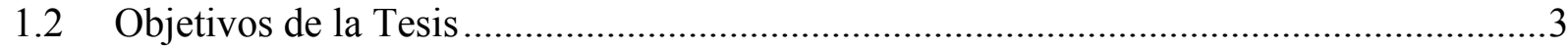

1.3 Metodología y estructura de la Tesis ...............................................................................

2 Estado de la Tecnología ............................................................................................................5

$2.1 \quad$ Introducción. Tipos de Vehículos híbridos [4, 5] ........................................................

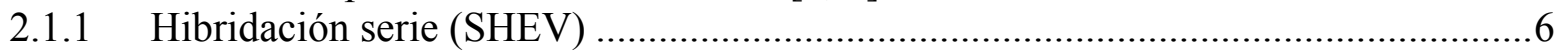

2.1.2 Hibridación paralelo (PHEV) ………………….................................................

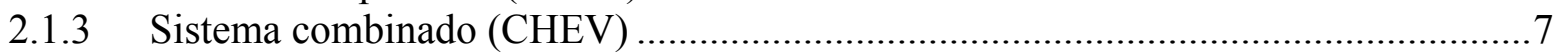

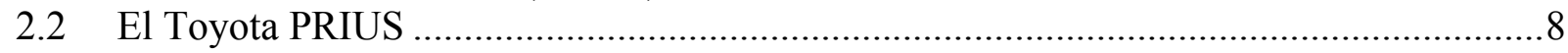

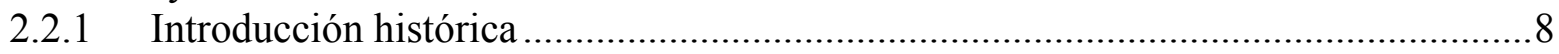

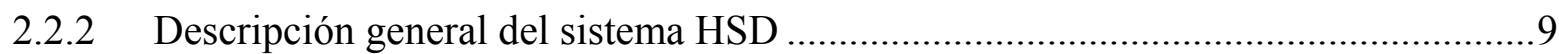

2.3 El motor MG2 del Toyota Prius [10-16]................................................................

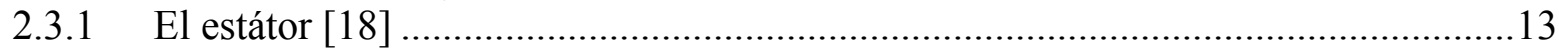

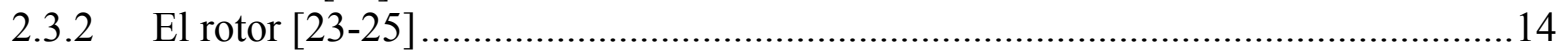

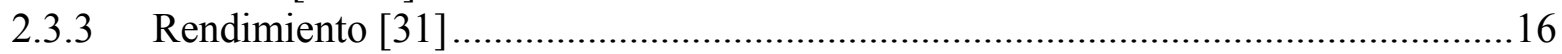

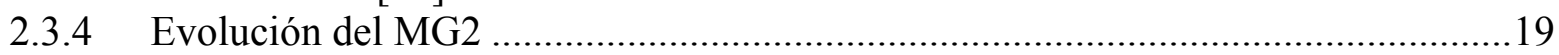

3 Materiales magnéticos para vehículos eléctricos....................................................................23

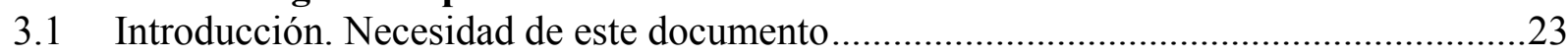

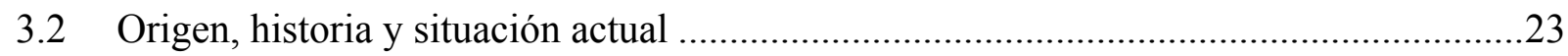

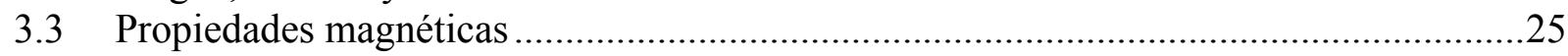

3.3.1 Características magnéticas...............................................................................2

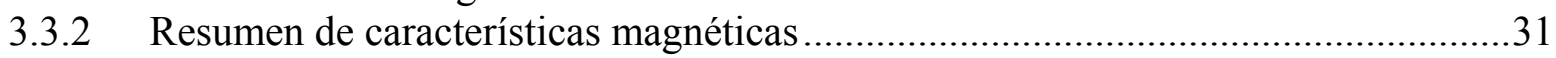

3.4 Clasificación de materiales magnéticos ....................................................................32

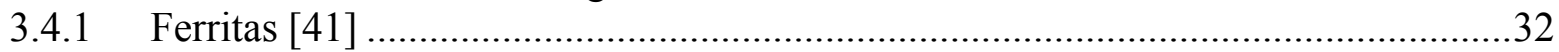

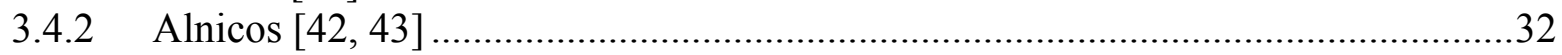

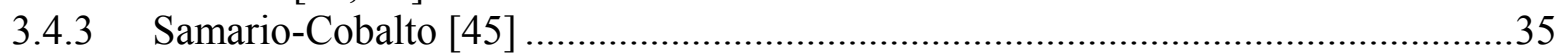

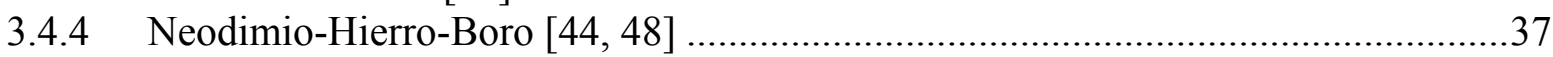

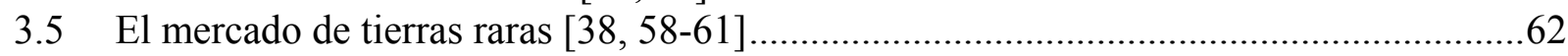

3.5.1 Demanda de estos materiales. ¿Por qué son tan importantes estos materiales? ........62

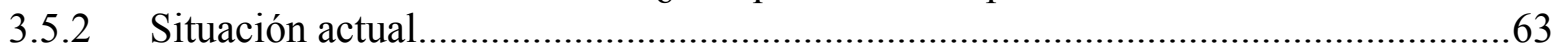

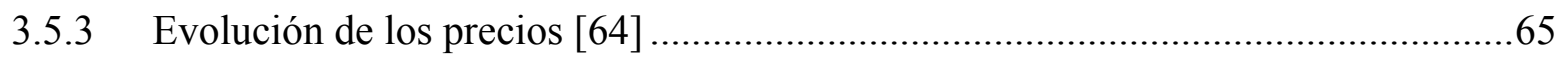

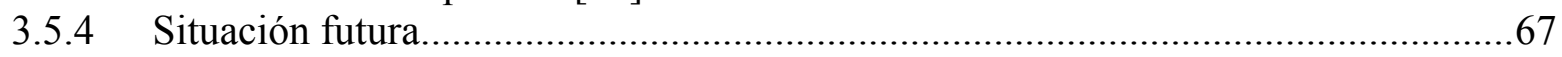

4 Motores eléctricos en tracción eléctrica ligera ……………………………………………......71

$4.1 \quad$ Selección del motor eléctrico .................................................................................

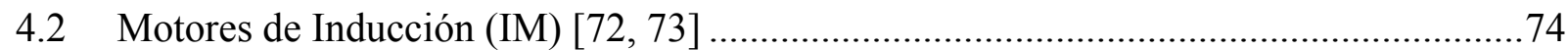

4.3 Motores de Corriente Continua (BDC) .......................................................................... 


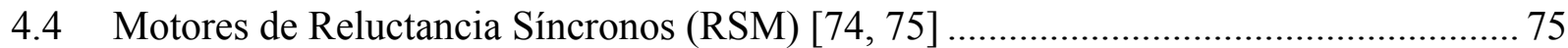

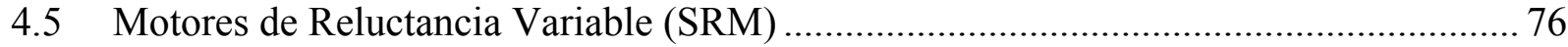

4.6 Motores Síncronos de Imanes Permanentes (IPM) [34, 77-83] .................................. 76

4.6.1 Motores de imanes permanentes en superficie (SPM) [84] .................................... 76

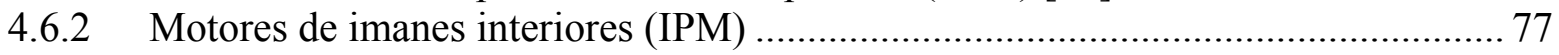

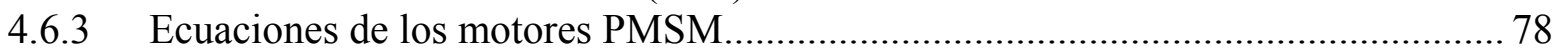

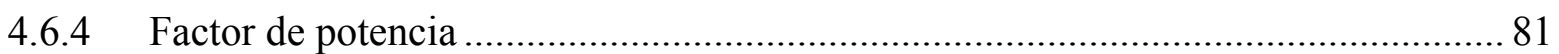

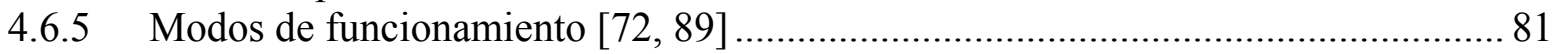

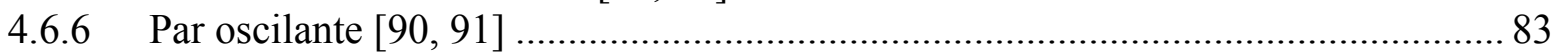

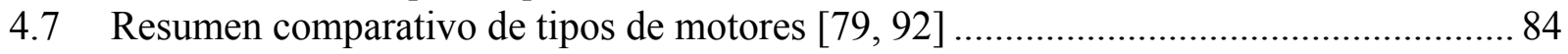

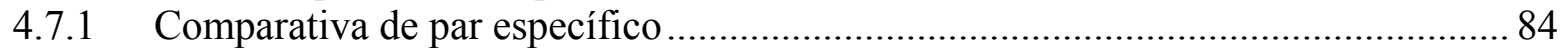

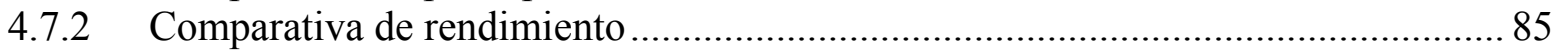

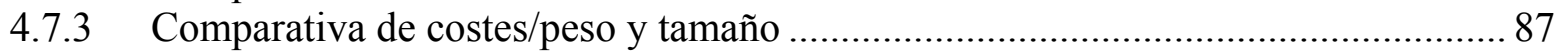

5 Análisis de modelos mediante elementos finitos ............................................................ 91

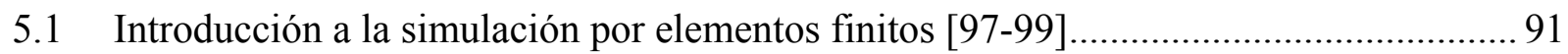

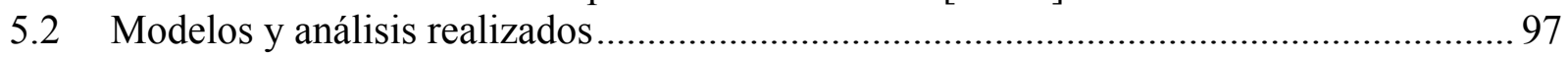

5.2.1 Curva de par Magnetostática de Corriente Continua ............................................. 98

5.2.2 Optimización de la geometría del rotor............................................................. 99

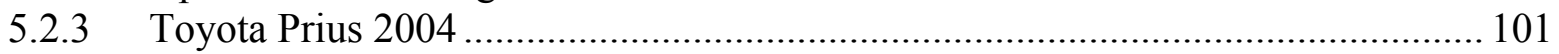

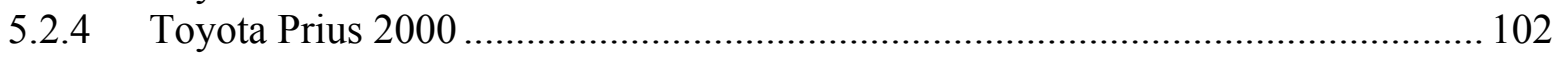

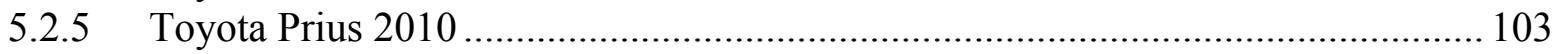

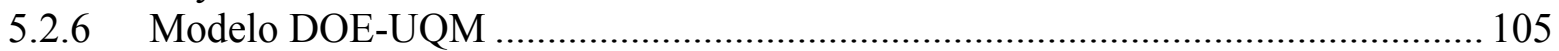

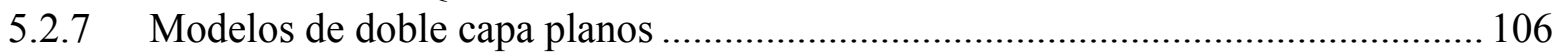

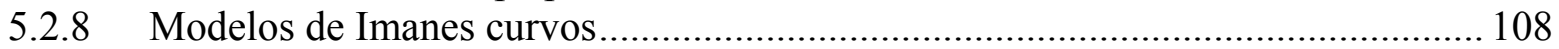

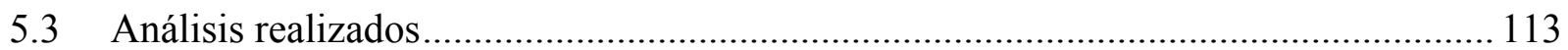

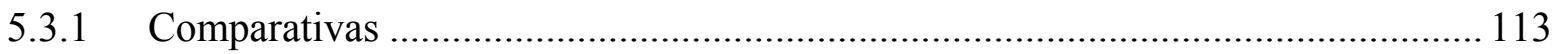

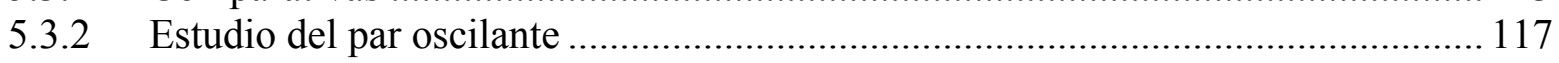

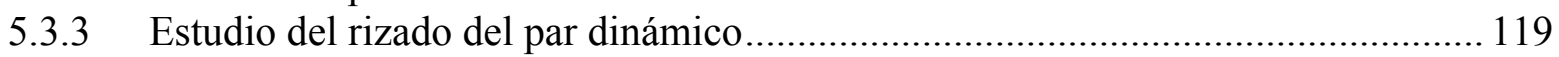

5.3.4 Imanes aglomerados moldeados por compresión ............................................... 120

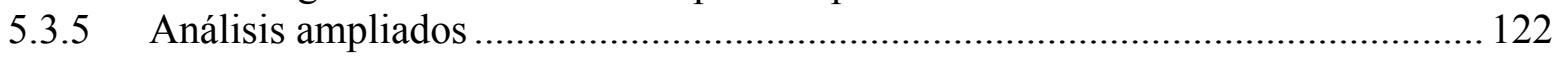

5.4 Resumen final del modelo propuesto y sus valores específicos................................. 126

6 Resumen, conclusiones y desarrollos y trabajos futuros.................................................... 127

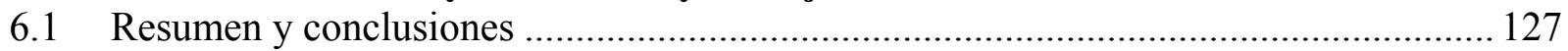

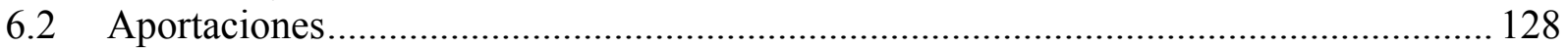

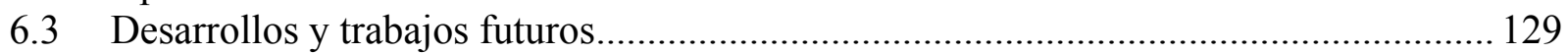

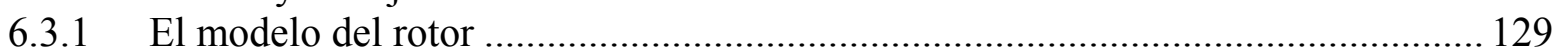

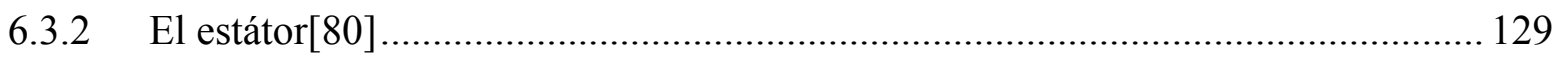

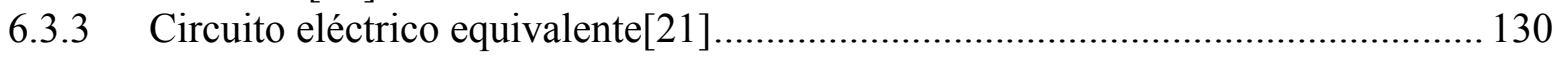

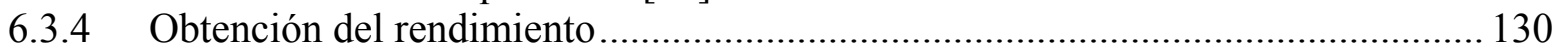

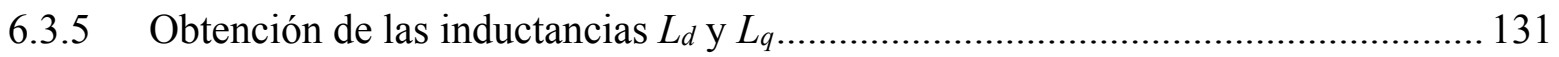

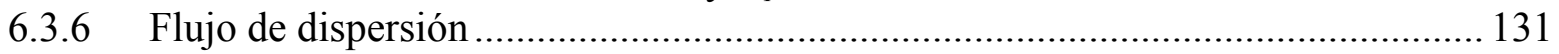

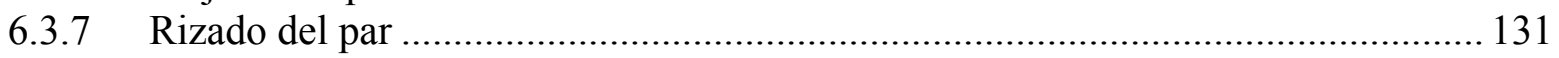

6.3.8 Desarrollo de técnicas de técnicas CPSR (Constant Power Speed Ratio).............. 132

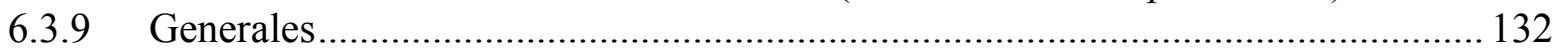

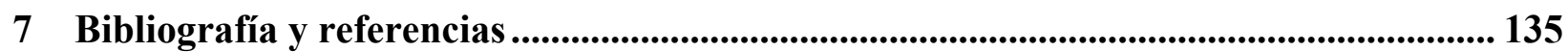

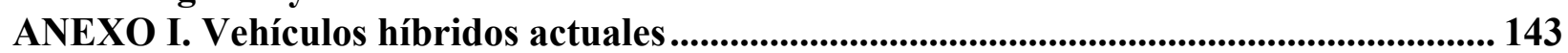

ANEXO II. Datos del MG2 del Toyota Prius ................................................................... 147

ANEXO III. Contrastación de resultados de FEA del MG2 del Toyota Prius 2004 .......... 151

III.1 Curvas de par magnetostático................................................................................ 153

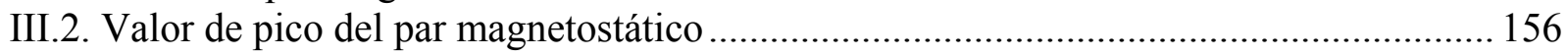




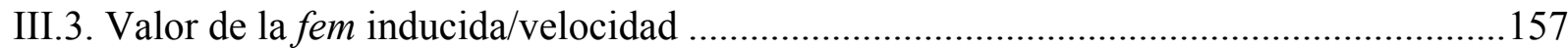

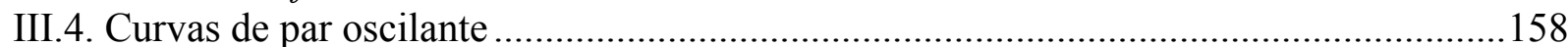

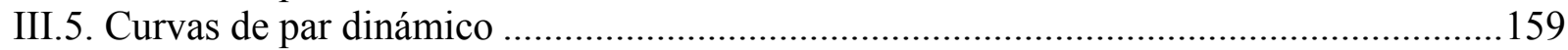

ANEXO IV. Vector de potencial magnético............................................................................161 


\section{LISTA DE FIGURAS}

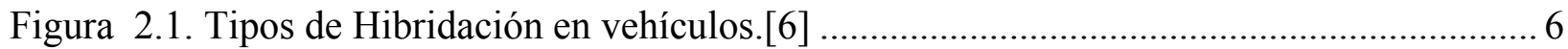

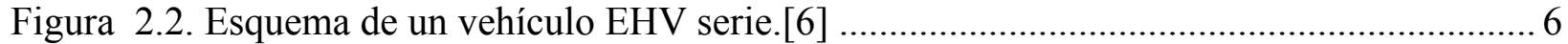

Figura 2.3. Esquema de un vehículo EHV paralelo.[6] .......................................................... 7

Figura 2.4. Esquema de sistema combinado CHEV.[6] ....................................................... 7

Figura 2.5. Sistema híbrido combinado del Prius.[7] ......................................................... 8

Figura 2.6. Esquema del sistema de transmisión del Prius. [7] ................................................... 9

Figura 2.7. Componentes y conjunto del PSD del Prius. [7] ..................................................... 10

Figura 2.8. PCU del Prius y esquema de funciones del inversor. [7] ....................................... 11

Figura 2.9. Disposición de la batería y vista exterior de la misma. [7]..................................... 12

Figura 2.10. Vistas del MG2 del Toyota Prius 2004.[17]..................................................... 13

Figura 2.11. Detalle de ranura del estátor del MG2.[20] .......................................................... 13

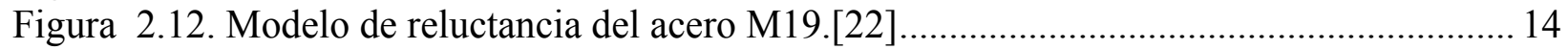

Figura 2.13. Disposición de los imanes en el rotor del MG2 del 2004.[27] .............................. 15

Figura 2.14. Puentes y esfuerzos de los modelos Prius 2000 y 2004.[30]................................ 16

Figura 2.15. Zonas de funcionamiento en conducción urbana (izda.) y distribución de pérdidas en

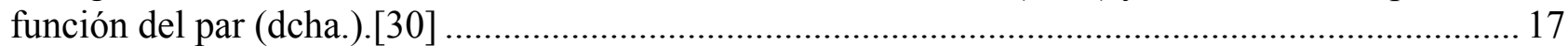

Figura 2.16. Pérdidas específicas de corrientes de Foucault versus espesor de laminación para una aleación acero de alta saturación de cobalto a $1.200 \mathrm{~Hz}$ y 2 T.[33] ............................................. 18

Figura 2.17. Mapa de pérdidas magnéticas del estátor de un motor IPM.[12] ......................... 18

Figura 2.18. Mapas de eficiencia del MG2-inversor a 500 V CC. [34] ................................... 19

Figura 2.19. Distribución general de pérdidas. [30] ............................................................. 19

Figura 2.20. Curvas de potencia y par del MG2 del 2000 (THS) y 2004 (THSII). [20]............ 20

Figura 2.21. Chapas del rotor del Prius 2000 y Prius 2004.[17] ............................................ 20

Figura 2.22. Evolución de las dimensiones de los imanes. [17] ........................................... 20

Figura 2.23. Conjunto MG2 del Prius 2004 (izda.) y del 2010 (dcha.). ................................... 21

Figura 2.24. Modelo de rotor del modelo Prius 2010 (izda.) y LS 600H 2008 (dcha.). [22]:.... 21

Figura 2.25. Sección de los conductores de distintos modelos de Toyota.[22]........................ 22

Figura 3.1. Evolución de los materiales magnéticos.[36] ...................................................... 24

Figura 3.2. Tamaño y forma relativa de imán para generar 1.000 gauss desde la cara del imán.[37]

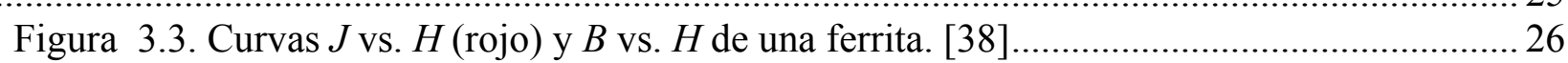

Figura 3.4. Curvas de carga, de desmagnetización y punto de trabajo de un imán.[39].............. 27

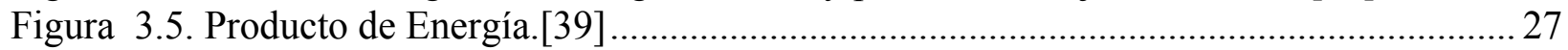

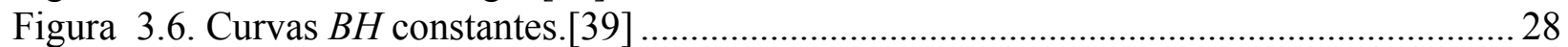

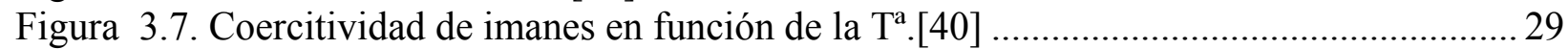

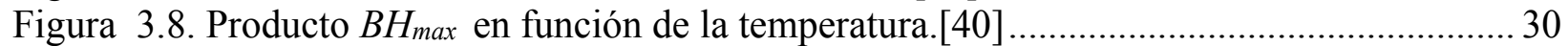

Figura 3.9. Curvas $J$ vs. $H$ (rojo) y $B$ vs. $H$ (azul) de una ferrita.[39] ...................................... 32

Figura 3.10. Curvas B vs. H de diversos grados de comerciales Alnico.[39] ............................ 33

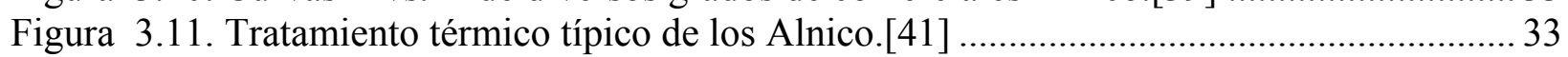

Figura 3.12. Curvas de magnetización de maetriales Alnico. [43] .......................................... 34

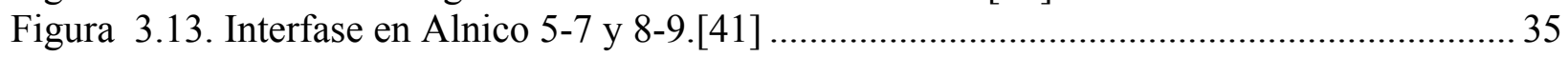

Figura 3.14. Curvas de magnetización de SmCo.[46] ........................................................... 36

Figura 3.15. Comparación entre imanes NdFeB y SmCo.[47] ............................................... 37

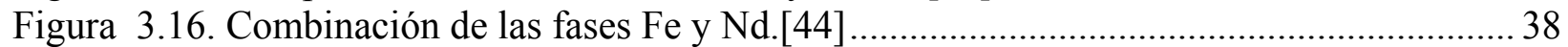

Figura 3.17. Curvas de desmagnetización típica de N38SH y comparativa con Ferrita y

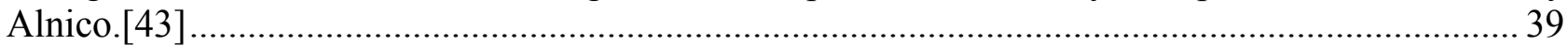

Figura 3.18. Clasificación comercial de neodimio.[37] ..................................................... 40 


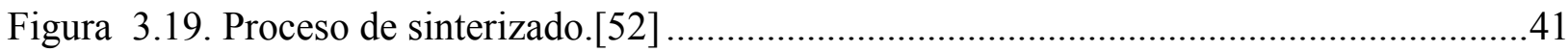

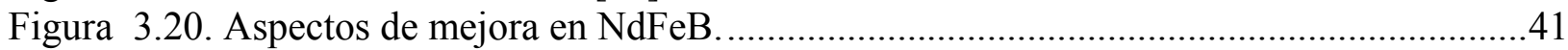

Figura 3.21. Posibilidades de prensado.[41] .......................................................................42

Figura 3.22. Variación de las características magnéticas con la proporción de disprosio.[45]...43

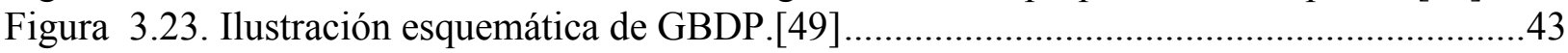

Figura 3.24. Comparativa del procesotradicional-mezcla-difusión.[44] ...................................44

Figura 3.25. Métodos para la mejora de $H_{C}$ en neodimios. [49] ...............................................44

Figura 3.26. a) Momento magnético (remanencia) y b) energía de la isotropía (coercitividad).

Dependencia de la temperatura en cada $\mathrm{RE}_{2} \mathrm{Fe}_{14}$.B.[53] ...........................................................45

Figura 3.27. Efecto de la sustitución de Co en la temeperatura de Curie.[53] ..........................46

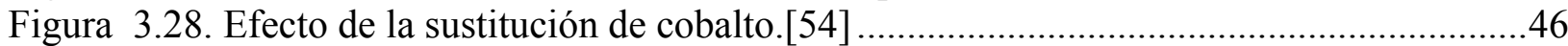

Figura 3.29. Curvas de desmagnetización de MQP 14-12.[56]................................................48

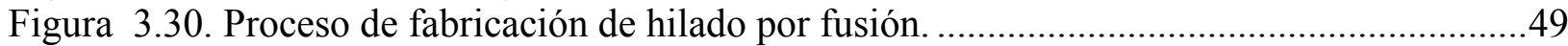

Figura 3.31. SEM de GA-1-66 con recubrimiento de fluor.[54] ................................................50

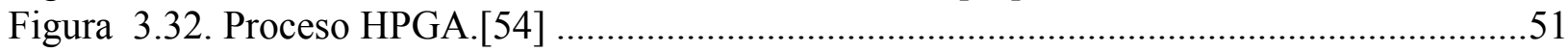

Figura 3.33. Comparativa de energía entre morfología de copo y esférica.[54] ........................52

Figura 3.34. Comparativa del WT-096 en versión de laboratorio y comercial.[53] ...................53

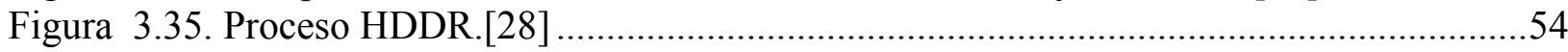

Figura 3.36. Energía del MF-25 y tamaño de grano por hilado por fusión (izda.) y por HDDR

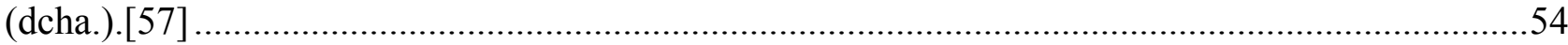

Figura 3.37. Característica de desmagnetización de MF-25 moldeado por compresión.[57]......55

Figura 3.38. Comparativa de los distintos BPM según proceso de fabricación.[55] ..................56

Figura 3.39. Proceso y resultado de imanes aglomerados por compresión.[47] ........................57

Figura 3.40. Proceso y resultado de imanes aglomerados por inyección.[47] ............................58

Figura 3.41. Comparativa de la energía obtenida por compresión e inyección.[47]...................59

Figura 3.42. Descomposición de pérdidas en función de la temperatura.[47] ............................60

Figura 3.43. Comparativa de STILT de distintos imanes.[47] ................................................61

Figura 3.44. Comparativa de pérdidas a corto plazo de distintos imanes.[47] ..........................61

Figura 3.45. Obtención de pérdidas con distintas lineas de carga.[47] ..................................62

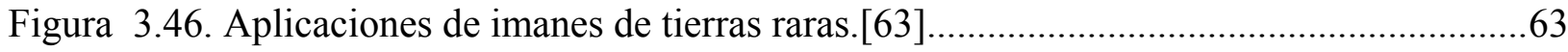

Figura 3.47. Producción mundial de óxidos de tierras raras.[47] ...........................................64

Figura 3.48. Evolución de los precios de los óxidos hasta 2010.[45] .....................................65

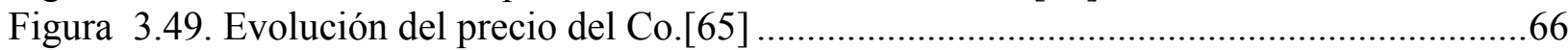

Figura 3.50. Precio de imanes en función de la $\mathrm{t}^{\mathrm{a}}$ de trabajo.[38] ...........................................67

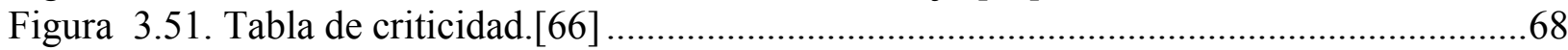

Figura 4.1. Característica par/velocidad de motores eléctricos y de combustión.[67]................71

Figura 4.2. Motores eléctricos para VE/HEV.[21] ............................................................. 73

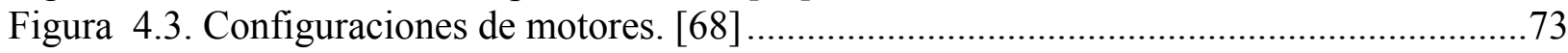

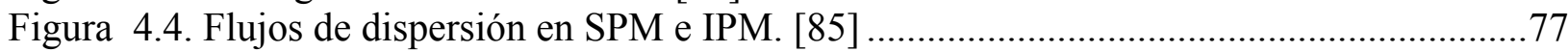

Figura 4.5. Diagrama fasorial de la máquina PMSM............................................................. 78

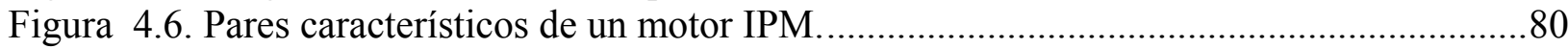

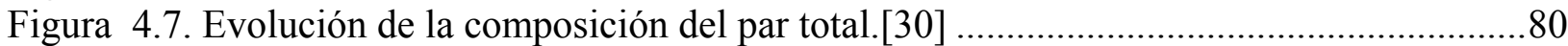

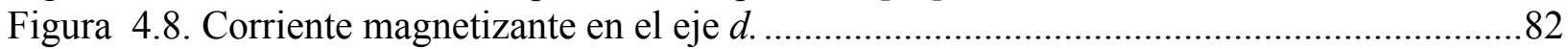

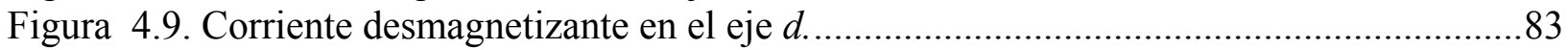

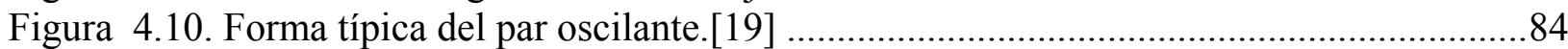

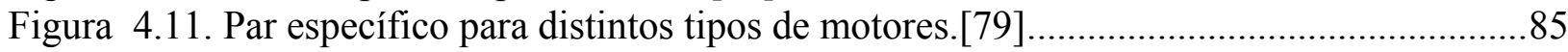

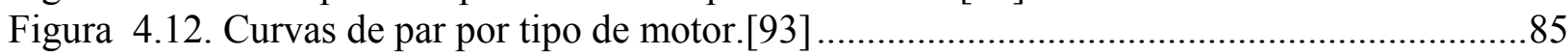

Figura 4.13. Eficiencia de motores IPM (encima) e IM en distintos puntos de funcionamiento.[94]

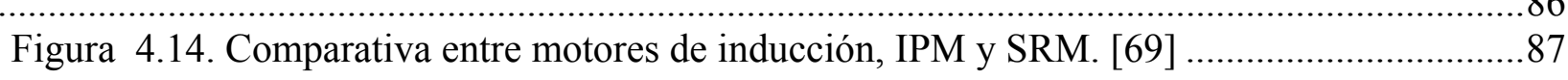


Figura 4.15. Ventajas de los motores PM respecto a los de inducción.[95] .............................. 87

Figura 4.16. Motor eléctrico Audi Q7 e-tron.[96] ............................................................... 89

Figura 5.1. Motor MG2 del Toyota Prius 2004: a) real y su modelado b) completo en 3D y c)

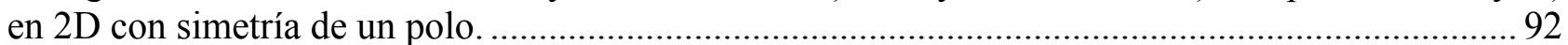

Figura 5.2. Curva de magnetización no lineal del acero M19-29G. [98] .................................. 93

Figura 5.3. Definición de material para imanes permanentes. [98] ......................................... 93

Figura 5.4. Sistemas de coordenadas relativos en los imanes................................................ 94

Figura 5.5. Excitación trifásica en las bobinas. Ejes d y q y magnetización de los imanes. [98] 94

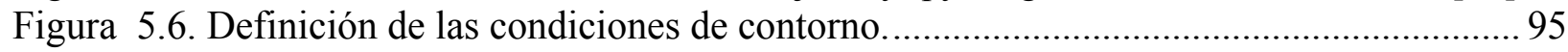

Figura 5.7. Diferentes niveles de mallado de elementos finitos. ............................................ 95

Figura 5.8. Flujo magnético $B$, líneas de flujo $A$ y elementos finitos en un motor PMSM. ....... 96

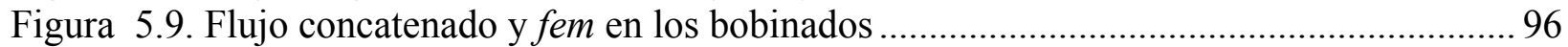

Figura 5.10. Curva de par motriz/tiempo y de par oscilante................................................. 97

Figura 5.11. Intensidades de excitación para análisis magnetostático [34] .............................. 99

Figura 5.12. Pares síncrono y reluctante de un motor IPM a) teóricos b) reales[34] c) del modelo Prius 2000 .

Figura 5.13. Inclusión de variables con sus límites en el proceso de optimización y definición de función objetivo para modelo de imán curvo.

Figura 5.14. Óptimos global y locales en curvas del par magnetostático en función de 2 parámetros geométricos en 3D y en 2D. 100

Figura 5.15. Sección y parametrización del modelo Prius 2004............................................ 101

Figura 5.16. Curvas de par a rotor bloqueado del modelo Prius 2004 con distintas intensidades de excitación. 102

Figura 5.17. Sección y parametrización del modelo Prius 2000 ............................................. 102

Figura 5.18. Curvas de par a rotor bloqueado del Prius 2000 ................................................ 103

Figura 5.19. Sección y parametrización del modelo Prius 2010............................................ 103

Figura 5.20. Curvas de para a rotor bloqueado del Prius 2010 para distintas intensidades....... 104

Figura 5.21. a) Sección del modelo del DOE-UQM [100], b) sección del modelo adaptado y c)

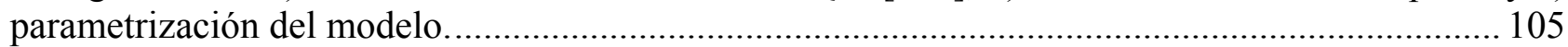

Figura 5.22. Curva de par del modelo DOE-UQM para distintas intensidades........................ 106

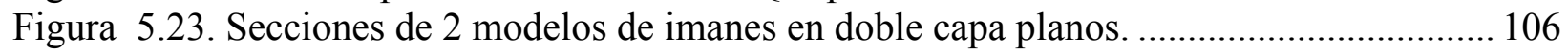

Figura 5.24. Parametrización de modelo de doble capa plano en V ........................................ 107

Figura 5.25. Curvas de par del modelo Doble Capa en V para varias intensidades.................. 107

Figura 5.26. Sección del modelo de imán curvo Tipo 1......................................................... 108

Figura 5.27. Sección del modelo de imán curvo Tipo 2 ...................................................... 108

Figura 5.28. Variación del par magnetostático en función del radio de curvatura \$ri de los imanes.

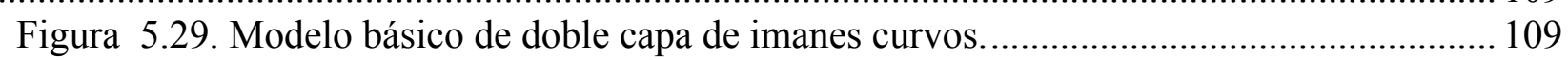

Figura 5.30. Formas de los extremos de los imanes curvos del modelo................................... 109

Figura 5.31. Curvas de par variando la forma de los extremos. .............................................. 110

Figura 5.32. Dirección de magnetización de imanes curvos: a) lineal y b) radial saliente del material.

Figura 5.33. Líneas de flujo según la magnetización lineal y radial...................................... 112

Figura 5.34. Curvas de para a rotor bloqueado de imanes curvos. Magnetización lineal y radial.

Figura 5.35. Comparativa del par máximo en función de la intensidad y dirección de

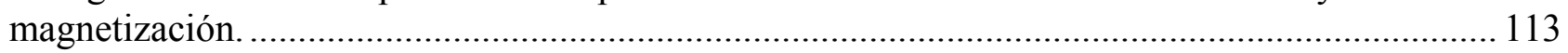

Figura 5.36. Curvas de par magnetostático de los modelos analizados................................. 114

Figura 5.37. Curvas de par al variar el ángulo del imán inferior betar2 ................................. 115

Figura 5.38. Valores de par máximo y par/área en las curvas magnetostáticas........................ 116 
Figura 5.39. Par y densidad de potencia en función del espesor de los imanes........................117

Figura 5.40. Curvas de par oscilante para distintos modelos ..................................................118

Figura 5.41. Valor eficaz (Rms) y de pico del par oscilante de los modelos. ...........................118

Figura 5.42. Modelos optimizados de doble capa en V y doble curvo. ....................................119

Figura 5.43. Curvas de par dinámico para 3.000 rpm. Prius 2004 y doble curvo en ala............119

Figura 5.44. Curvas de par magnetostático para el modelo con sinterizados (N36) y aglomerados (NB-10H).

Figura 5.45. Par oscilante del modelo de imanes curvos en ala con material sinterizado (N36) y aglomerado (N-10-BH).

Figura 5.46. Efecto de la temperatura en desmagnetización de imanes permanentes. [109].....123

Figura 5.47. Curvas de par magnetostático. Material N10-B-H para $20^{\circ} \mathrm{C}$ y $140{ }^{\circ} \mathrm{C} \ldots \ldots \ldots \ldots . . . . .123$

Figura 5.48. Curvas de par dinámico a $3.000 \mathrm{rpm}$. Material N10-B-H para $20^{\circ} \mathrm{C}$ y $140{ }^{\circ} \mathrm{C} \ldots 124$

Figura 5.49. Curvas de para para el modelo Prius 2000 (izda) y doble capa curvo (dcha).......125

Figura 5.50. Intensidades y pérdidas en el hierro del modelo 2004 (azul) y ala con N10-BH (rojo) para $\mathrm{n}=3.000 \mathrm{rpm}$.

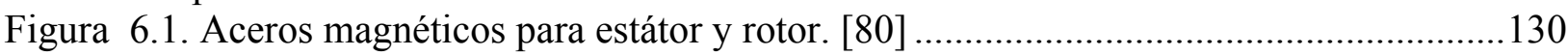

Figura 6.2. Circuito equivalente de un motor derivado de su análisis FEA..............................130

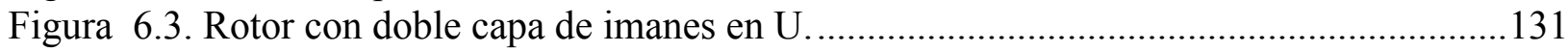

Figura II. 1. Curvas par-velocidad de las versiones del MG2 ...............................................150

Figura II.2. Dimensiones del MG2 del Prius 2004............................................................ 150

Figura II.3. Dimensiones de los imanes y huecos del Prius 2004 .........................................150

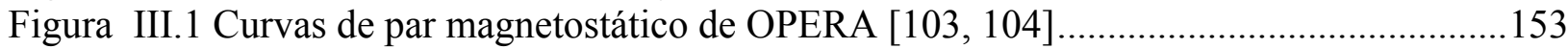

Figura III.2. Curvas de par magnetostático de nuestro modelo ............................................... 154

Figura III.3. Curvas de par magnetostático de nuestro modelo....................................................154

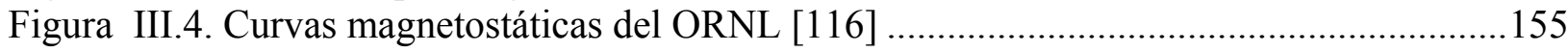

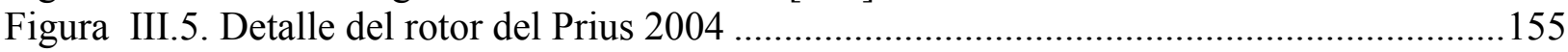

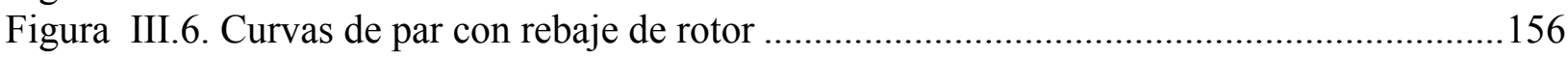

Figura III.7. Valor de pico del par en función de la intensidad. [116] .....................................156

Figura III.8. Valor de pico del par en función de la intensidad. ORNL[116] y modelo ............157

Figura III.9. Comparativa de fem a distintas revoluciones: ORNL[116] y del modelo ..............158

Figura III.10. Curvas de par oscilante a) OPERA[103] y b) Modelo.......................................158

Figura III.11. Curvas de para 250 A y $3.000 \mathrm{rpm}$. OPERA[103] y modelo...............................159

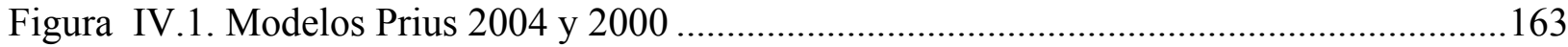

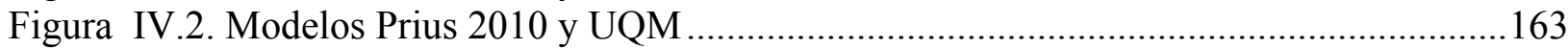

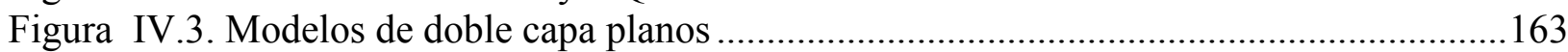

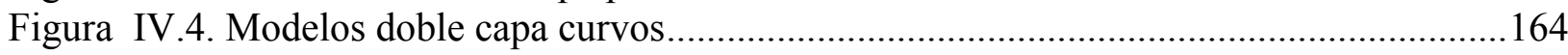




\section{LISTA DE TABLAS}

Tabla 2-1. Configuración de las baterías de los vehículos híbridos de Toyota. ......................... 12

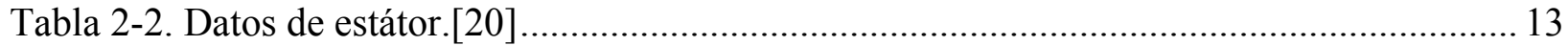

Tabla 2-3. Comparación de características del MG2 2004 y 2010 [5]..................................... 22

Tabla 3-1. Objetivos de la APEEM para materiales magnéticos en el 2020.[35]...................... 24

Tabla 3-2. Coeficientes y temperaturas típicos de materiales magnéticos ................................ 30

Tabla 3-3. Grados de los materiales Alnico................................................................................. 33

Tabla 3-4. Características de los componentes NdFeB ............................................................ 38

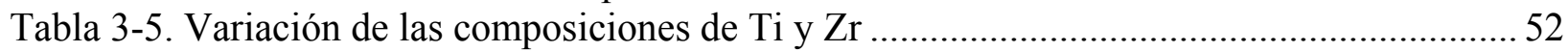

Tabla 3-6. Materiales magnéticos de Magnequench[55] ...................................................... 56

Tabla 3-7. Ventajas e incovenientes de los imanes sinterizados y aglomerados.......................59

Tabla 3-8. Comparativa entre imanes sinterizados y aglomerados........................................59

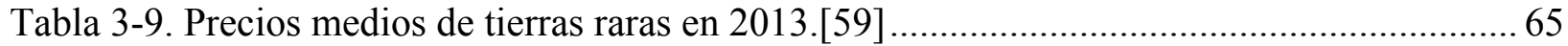

Tabla 3-10. Composición de imanes de tierras raras y precios.[40] ......................................... 67

Tabla 4-1. Objetivos sobre motores eléctricos de la APEEM[35] ............................................ 71

Tabla 4-2. Comparativa de eficiencia de tipos de motores eléctricos....................................... 85

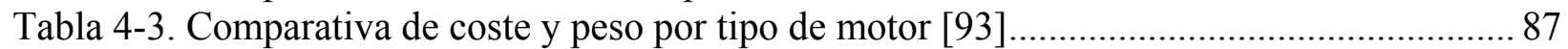

Tabla 4-4. Ventajas e inconvenientes de motores utilizados en vehículos eléctricos.................. 88

Tabla 4-5. Valoración de tipos de motores eléctricos para HEV. [93] ..................................... 88

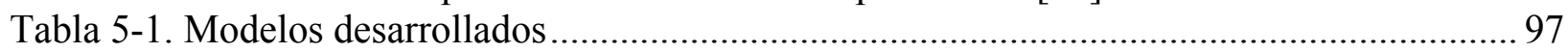

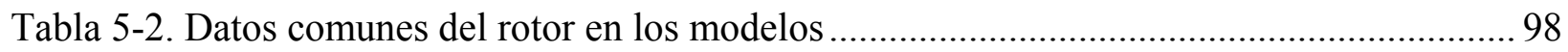

Tabla 5-3. Parámetros del modelo del Prius 2004 .................................................................... 101

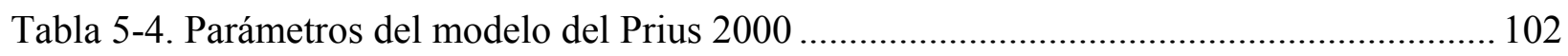

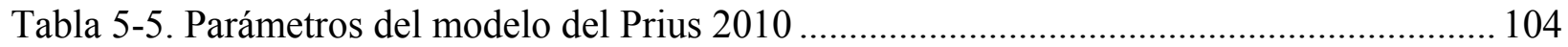

Tabla 5-6. Parámetros del modelo del modelo UQM ............................................................ 105

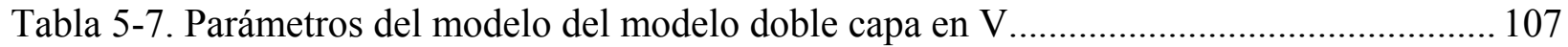

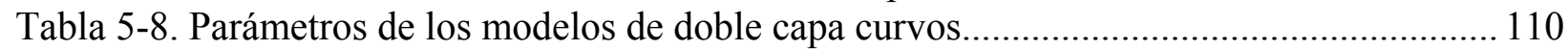

Tabla 5-9. Parámetros óptimos según la dirección de magnetización ......................................... 111

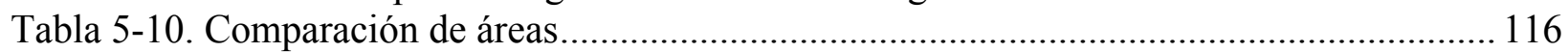

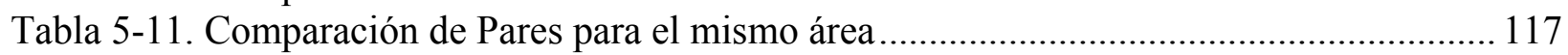

Tabla 5-12. Valores de rizado para el modelo 2004 y doble curvo en ala................................ 120

Tabla 5-13. Características de imanes NdFeB aglomerados por compresión............................ 120

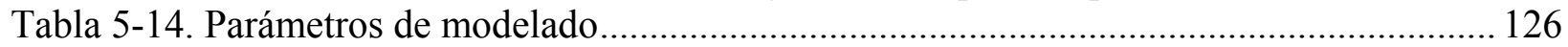

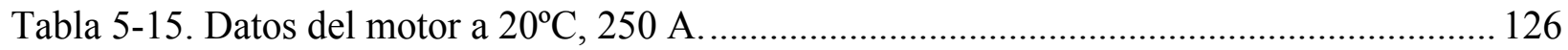

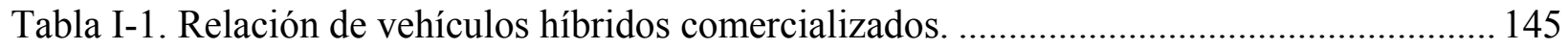

Tabla II-1. Datos y características de los motores MG2 de Toyota Prius ................................ 149

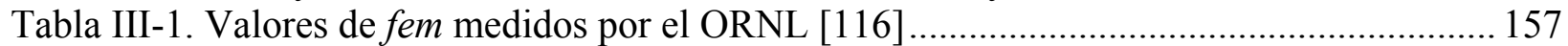




\section{LISTA DE ACRÓNIMOS Y ABREVIATURAS}

\begin{tabular}{|c|c|}
\hline APEEM & $\begin{array}{l}\text { Advanced Power Electronics and Electric Machines } \\
\text { Agencia de Electrónica de Potencia y Máquinas eléctricas del } D O E\end{array}$ \\
\hline ARPA-E & $\begin{array}{l}\text { Advanced Research Projects Agency-Energy } \\
\text { Agencia de Proyectos de Investigación Avanzados en Energía }\end{array}$ \\
\hline BDC & $\begin{array}{l}\text { Brushless Direct Current Motor } \\
\text { Motor de corriente continua sin escobillas }\end{array}$ \\
\hline BPM & $\begin{array}{l}\text { Bonded Permanent Magnet } \\
\text { Imán Permanente aglomerado }\end{array}$ \\
\hline CA & Corriente Alterna \\
\hline CC & Corriente Continua \\
\hline CHEV & $\begin{array}{l}\text { Combinated Hybrid Electric Vehicle } \\
\text { Vehículo Eléctrico Híbrido combinado (serie-paralelo) }\end{array}$ \\
\hline CPSR & $\begin{array}{l}\text { Constant Power Speed Ratio } \\
\text { Relación par/velocidad constante }\end{array}$ \\
\hline CVT & $\begin{array}{l}\text { Continue Variable Transmission } \\
\text { Transmisión variable continua }\end{array}$ \\
\hline$\overline{D O E}$ & $\begin{array}{l}\text { Department Of Energy } \\
\text { Departamento de Energía de los EEUU }\end{array}$ \\
\hline ECU & $\begin{array}{l}\text { Electronic Control Unit } \\
\text { Unidad Electrónica de Control }\end{array}$ \\
\hline ECVT & $\begin{array}{l}\text { Electronically-controlled Continuously Variable Transmission } \\
\text { Transmisión variable continua electrónicamente controlada }\end{array}$ \\
\hline $\mathbf{E V}$ & $\begin{array}{l}\text { Electrical Vehicle } \\
\text { Vehículo eléctrico }\end{array}$ \\
\hline FEA & $\begin{array}{l}\text { Finite Elements Analysis } \\
\text { Análisis mediante Elementos Finitos }\end{array}$ \\
\hline FW & $\begin{array}{l}\text { Field Weakening } \\
\text { Debilitamiento de campo }\end{array}$ \\
\hline HDDR & $\begin{array}{l}\text { Hydrogenation disproportionation desorption recombination } \\
\text { hidrogenación - descomposición - desorción - recombinación }\end{array}$ \\
\hline GBDP & $\begin{array}{l}\text { Grain Boundary Difusion Process } \\
\text { Proceso de difusión en la frontera de grano }\end{array}$ \\
\hline HEV & $\begin{array}{l}\text { Hybrid Electric Vehicle } \\
\text { Vehículo Eléctrico Híbrido } \\
\end{array}$ \\
\hline HPGA & $\begin{array}{l}\text { High Pressure Gas Atomization } \\
\text { Atomización de gas a elevada presión }\end{array}$ \\
\hline HSD & $\begin{array}{l}\text { Hybrid Synergy Drive } \\
\text { Motor de sinergia híbrida }\end{array}$ \\
\hline ICE & $\begin{array}{l}\text { Internal Combustion Engine } \\
\text { Motor de combustión interna }\end{array}$ \\
\hline IM & $\begin{array}{l}\text { Induction Machine } \\
\text { Máquina de inducción }\end{array}$ \\
\hline IPM & $\begin{array}{l}\text { Interior Permanent Motor } \\
\text { Motor de imanes interiores (similar a IPMSM) }\end{array}$ \\
\hline IPMSM & $\begin{array}{l}\text { Interior Permanent Magnet Synchronous Motor } \\
\text { Motor síncrono de imanes permanentes interiores }\end{array}$ \\
\hline
\end{tabular}




\begin{tabular}{|c|c|}
\hline LTILT & $\begin{array}{l}\text { Long Term Irreversible Loss Temperature } \\
\text { Perdidas irreversibles por temperatura de larga duración }\end{array}$ \\
\hline MG1 & $\begin{array}{l}\text { Motor-generator 1. Secondary Electric Motor } \\
\text { Motor-generador1. Motor eléctrico secundario }\end{array}$ \\
\hline MG2 & $\begin{array}{l}\text { Motor-generator 2. Primary Electric Motor } \\
\text { Motor-generador 2. Motor eléctrico principal }\end{array}$ \\
\hline MTPA & $\begin{array}{l}\text { Maximun Torque Per Ampere } \\
\text { Par Máximo por Amperio }\end{array}$ \\
\hline ONRL & $\begin{array}{l}\text { Oak National Transportation Research Center Laboratory } \\
\text { Laboratorio del Centro de Nacional de Investigación en transporte }\end{array}$ \\
\hline $\mathbf{P C U}$ & $\begin{array}{l}\text { Power Control Unit } \\
\text { Unidad de Control de Potencia }\end{array}$ \\
\hline PD & $\begin{array}{l}\text { Power Density } \\
\text { Densidad de Potencia }\end{array}$ \\
\hline $\mathbf{P E}$ & $\begin{array}{l}\text { Power Electronics } \\
\text { Electrónica de potencia }\end{array}$ \\
\hline PHEV & $\begin{array}{l}\text { Parallel Hybrid Electric Vehicle } \\
\text { Vehículo Eléctrico Híbrido Paralelo }\end{array}$ \\
\hline PM & $\begin{array}{l}\text { Permanent Magnet } \\
\text { Imán Permanente }\end{array}$ \\
\hline PMSM & $\begin{array}{l}\text { Permanent Magnet Synchronous Motor } \\
\text { Motor síncrono de imanes permanentes. }\end{array}$ \\
\hline PSD & $\begin{array}{l}\text { Power System Drive } \\
\text { Sistema de Transmisión de Potencia }\end{array}$ \\
\hline $\mathbf{R E}$ & $\begin{array}{l}\text { Rare Earth } \\
\text { Tierras raras }\end{array}$ \\
\hline$\overline{\text { SEM }}$ & $\begin{array}{l}\text { Scanning Electronic Microscope } \\
\text { Microscopio Electrónico de Rastreo }\end{array}$ \\
\hline SHEV & $\begin{array}{l}\text { Serial Hybrid Electric Vehicle } \\
\text { Vehículo Eléctrico Híbrido Serie }\end{array}$ \\
\hline SOA & $\begin{array}{l}\text { State of The Art } \\
\text { Estado del Arte }\end{array}$ \\
\hline$\overline{\text { SOC }}$ & $\begin{array}{l}\text { State Of Charge } \\
\text { Estado de carga de la batería }\end{array}$ \\
\hline SP & $\begin{array}{l}\text { Specific Power } \\
\text { Potencia específica }\end{array}$ \\
\hline SPM & $\begin{array}{l}\text { Surface Permanent Magnets } \\
\text { Imanes permanentes en superficie }\end{array}$ \\
\hline SRM & $\begin{array}{l}\text { Switched Reluctance Motor } \\
\text { Motor de reluctancia variable }\end{array}$ \\
\hline STILT & $\begin{array}{l}\text { Short Term Irreversible Loss Temperature } \\
\text { Pérdidas Irreversibles por temperatura de corta duración }\end{array}$ \\
\hline SUV & $\begin{array}{l}\text { Sub Urban Vehicle } \\
\text { Vehículo sub-urbano }\end{array}$ \\
\hline THS & $\begin{array}{l}\text { Toyota Hibrid System } \\
\text { Sistema Híbrido de Toyota }\end{array}$ \\
\hline
\end{tabular}




\section{LISTA DE SÍMBOLOS}

\begin{tabular}{|c|c|}
\hline$\delta$ & Ángulo de potencia. Desfase entre $V$ y $E\left({ }^{\circ}\right)$ \\
\hline$\gamma$ & Desfase entre $V$ e $I$. Desfase entre $E$ e $I\left(^{\circ}\right)$ \\
\hline$\lambda$ & Flujo común (Wb) \\
\hline$\lambda_{p m}$ & Flujo común en el eje $d$ debido al imán permanente (Wb) \\
\hline$\varphi$ & Factor de potencia. Desfase entre $V$ e $I\left(^{\circ}\right)$ \\
\hline$\mu$ & Permeabilidad relativa \\
\hline$\xi$ & Saliencia \\
\hline$\omega$ & Velocidad de sincronismo (rad/s) \\
\hline$B H_{\max }$ & Producto de Energía (MGOe) \\
\hline$B_{r}$ & Remanencia magnética $(T, G)$ \\
\hline$E$ & Fuerza electromotriz por fase $(\mathrm{V})$ \\
\hline$E_{q}$ & Fuerza electromotriz por fase en el eje $q(\mathrm{~V})$ \\
\hline$f$ & Frecuencia $(\mathrm{Hz})$ \\
\hline fem & Fuerza electromotriz $(\mathrm{V})$ \\
\hline$H_{C}$ & Coercitividad (Am,Oe) \\
\hline$I$ & Intensidad de corriente (A) \\
\hline$I_{d}$ & Componente de la intensidad en el eje $d$ (A) \\
\hline$I_{q}$ & Componente de la intensidad en el eje $q$ (A) \\
\hline$L_{d}$ & Inductancia en el eje $d(\mathrm{H})$ \\
\hline$L_{q}$ & Inductancia en el eje $q(\mathrm{H})$ \\
\hline$p$ & Pares de polos de la máquina \\
\hline$P$ & Potencia activa (W) \\
\hline$Q$ & Potencia reactiva (Var) \\
\hline$X_{d}$ & Reactancia en el eje directo $(\Omega)$ \\
\hline$X_{q}$ & Reactancia en el eje $q(\Omega)$ \\
\hline$X_{s}$ & Reactancia síncrona $(\Omega)$ \\
\hline$V$ & Tensión (V) \\
\hline$\vec{S}$ & Potencia compleja $(\mathrm{VA})=P+\mathrm{j} Q$ \\
\hline$T$ & Par (Nm) \\
\hline
\end{tabular}





\section{Introducción}

El proceso de elaboración de esta tesis ha sido un largo proceso motivado por el interés personal en investigar en una rama de la ingeniería que llamaba mi atención: los motores eléctricos de los vehículos híbridos.

Cuando empecé a leer información sobre ambos tipos de vehículos eléctricos e híbridos rápidamente me decanté por los segundos por dos razones: los niveles de rendimiento obtenidos y las posibilidades de autonomía del vehículo.

El vehículo insignia de estos modelos es el renombrado Toyota Prius. Llevaba tiempo investigando sobre los motores eléctricos de este vehículo, pero no había mucha información publicada. Entonces encontré los documentos del ORNL (un instituto de investigación dependiente del Departamento de Energía de los Estados Unidos) que se dedicó a analizar detalladamente cómo son sus motores y la evolución desarrollada y publicó los primeros datos técnicos. Esta ha sido sin duda, al igual que para muchos investigadores en este campo, mi principal fuente de información.

Así pues, inicialmente comencé a conocer las particularidades y ecuaciones que rigen el funcionamiento de los motores síncronos de imanes permanentes, grupo al que pertenece el motor MG2 del Prius. Posteriormente al irrumpir más modelos híbridos en el mercado analicé qué otros tipos de motores eléctricos incorporaban y las diferencias que pudiesen hacerlos más interesantes sobre los del Prius.

Tras analizar las variaciones sobre devanados en los motores síncronos y múltiples configuraciones de motores eléctricos deduje que el aspecto que marca la diferencia en éstos son los imanes permanentes de tierras raras que incorporan, y que la situación del mercado de estas tierras raras ha impulsado varios estudios para adaptarlos a las nuevas condiciones actuales.

Los primeros pasos se dedicaron a conocer los modos de funcionamiento y la nueva tecnología que incorporan los sistemas híbridos, a desgranar los componentes con todos los parámetros que incorporan los fabricantes de vehículos eléctricos híbridos.

También ha sido objeto de este trabajo conocer con detalle el acotado y diseño mecánico de las piezas del estátor y rotor, el tipo de devanado y sus materiales para poder posteriormente establecer qué variaciones se pueden llevar a cabo en su disposición que permitan mejorar datos de interés como el par efectivo suministrado y la variación del mismo.

Asimismo, ha sido necesario profundizar en los múltiples procesos de fabricación de imanes que actualmente se están probando, así como las posibles mejoras que puedan ofrecer los nuevos materiales magnéticos.

\subsection{Justificación e importancia de la presente Tesis}

Con el objetivo de prevenir el calentamiento global y preservar los recursos energéticos y naturales, la industria automovilística está dando un fuerte empuje en los últimos años a la investigación en los vehículos eléctricos. Un 4\% de las ventas actuales de vehículos mundiales actualmente corresponde a vehículos híbridos y se estima que será al menos un $15 \%$ de las ventas en $2020[1]$. 
Los primeros vehículos eléctricos puros datan de la década de 1830, pero ha sido en los años 90 cuando muchos fabricantes, como Citroën, Ford, Honda, GM, Peugeot o Toyota, han llevado a cabo programas de fabricación de este tipo de vehículos. Sin embargo, las ventas nunca han dejado de ser muy limitadas, y desde finales de esa misma década se ha transferido gran parte del interés y de los recursos destinados a investigación de los vehículos eléctricos puros a los híbridos, que combinan motores eléctricos con motores de combustión interna, lo que les confiere más potencia y mayor autonomía, que es el punto débil de los vehículos eléctricos puros.

Los vehículos híbridos casi no producen $\mathrm{CO}_{2}$, tienen un mayor rendimiento energético que los de combustión interna de gasolina o diésel y se presentan como una clara alternativa a dichos motores, o al menos como una tecnología que los apoye, obteniendo vehículos más "limpios y ecológicos".

Esto hace que actualmente los vehículos eléctricos se encuentren en fase de pleno desarrollo debido a la política internacional de ahorro energético y de protección del medio ambiente mencionada. Así, casi todos los fabricantes de automóviles disponen de un vehículo que utiliza la electricidad como fuente de energía principal o secundaria. Como se ha comentado, el Toyota Prius es el vehículo híbrido líder.

Por otro lado, el éxito del Prius ha provocado que las grandes compañías automovilísticas creen su modelo propio, con distintas tecnologías de motor eléctrico. Todos utilizan principalmente imanes permanentes de tierras raras $\mathrm{NdFeB}$ fabricados mediante sinterización en su conformación. Pero el 99\% de las tierras raras se encuentra en China, que monopoliza este recurso. La creciente necesidad de este material ha hecho que gobiernos como estados Unidos y Japón dediquen proyectos propios a contrarrestar este monopolio. Es, por tanto, también muy importante estudiar la evolución de estos materiales magnéticos de tierras raras y las nuevas posibilidades que permitan disminuir la dependencia de los imanes NdFeB.

Por último es necesario probar estos cambios mediante simulaciones y optimizar el diseño del imán para maximizar el par con la mínima cantidad del mismo. Otros aspectos de menor importancia como pérdidas y análisis térmico se citan como futura líneas.

La Tesis que se presenta se centra en dos campos:

1.- Estudiar los tipos y las tecnologías de fabricación de los imanes de tierras raras y sus avances para disminuir la fuerte dependencia actual de los imanes sinterizados NdFeB.

2.- Analizar la evolución de los motores eléctricos aplicados a vehículos híbridos y su posible mejora. En concreto, a través de estas páginas se intentará determinar los parámetros de diseño eléctricos utilizados en los motores síncronos de imanes permanentes utilizados en el Prius y de los materiales utilizados desarrollando varios modelos de rotor para su análisis mediante elementos finitos.

Toda la información que he recabado apunta en esta dirección: obtener mediante una geometría diferente un alto par reluctante que permite compensar su menor valor de par magnético...

Estos dos aspectos combinados tienen como resultado esta tesis, que presenta un nuevo modelo de rotor para motores síncronos de imanes permanentes que emplea imanes aglomerados como alternativa viable a los actuales imanes NdFeB sinterizados. 


\subsection{Objetivos de la Tesis}

La presente tesis tiene como objetivos generales:

- Completar, en cumplimiento de la normativa de programas de doctorado, el trabajo de investigación correspondiente al programa de doctorado "Investigación en Ingeniería" perteneciente al Departamento de Ingeniería Civil de la Universidad de Burgos.

- Utilizar los conocimientos adquiridos sobre investigación en los cursos de doctorado.

Y los objetivos concretos para su desarrollo son:

- Determinar qué tipo de motores eléctricos utilizan los fabricantes de vehículos.

- Seleccionar el más importante, en este caso el motor síncrono de imanes permanentes del Toyota Prius, para establecer el estado actual de la tecnología y aplicación de estos motores.

- Estudiar la estructura, funcionamiento y características de los motores síncronos de imanes permanentes, comparándolos con tecnologías competitivas.

- Estudiar los diseños y materiales utilizados en las distintas versiones del motor del Prius lanzadas al mercado. Para ello utilizaremos principalmente los estudios realizados sobre dicho motor y modelos de elementos finitos.

- Estudiar las tecnologías de fabricación de los materiales magnéticos utilizados para construir imanes permanentes y las características magnéticas obtenidas. Especial importancia tiene en este apartado el estudio de los imanes NdFeB aglomerados, que amplía enormemente el rango de posibilidades de fabricación de los imanes.

- Obtener un modelo de rotor para utilizar los últimos desarrollos y tecnologías y evitar el uso de imanes sinterizados.

\subsection{Metodología y estructura de la Tesis}

Básicamente la primera parte del trabajo consiste en la recopilación de información (SOA) y documentación de distintos temas:

- Sobre vehículos eléctricos, especialmente híbridos, y sobre los motores que utilizan.

- Sobre los motores eléctricos de imanes permanentes.

- Sobre los distintos tipos de materiales magnéticos, especialmente los de tierras raras NdFeB.

Una vez recopilada y estudiada esta información se decidió seleccionar el estudio del motorgenerador MG2 del Toyota Prius como objetivo del trabajo por ser el motor más desarrollado en sus tres versiones. Para ello se estudia su evolución y se desarrollan los modelos correspondientes para su análisis mediante elementos finitos. A través de la modificación de la geometría, se desarrollan varios modelos de rotor con geometrías complejas, determinando el más óptimo para su aplicación en vehículos híbridos. Para ello se ha determinado la siguiente estructura de la tesis: 
El capítulo 2 incluye una introducción a los vehículos eléctricos híbridos para presentar los sistemas utilizados en el Toyota Prius y se describe a fondo el motor MG2, especialmente la geometría de su rotor que ha sido el elemento que más modificaciones y mejoras ha sufrido a lo largo de sus distintas versiones.

El capítulo 3, sin duda el más complejo e innovador por su importancia capital, estudia las tecnologías de fabricación de materiales magnéticos de tierras raras en vías de investigación y las posibilidades que ofrecerán.

En el capítulo 4 se estudian los distintos tipos de motores eléctricos utilizados en tracción ligera de vehículos híbridos, comparándolos entre sí y seleccionando los de imanes permanentes y estableciendo sus características principales.

Es en el capítulo 5 donde se exponen los modelos de elementos finitos desarrollados y se aglutinan todos los conocimientos teóricos para obtener resultados experimentales.

En el capítulo 6 se indican las conclusiones obtenidas y las futuras líneas de trabajo que pueden continuar la presente tesis.

Finalmente en el capítulo 7 se recoge la bibliografía y otras fuentes de documentación utilizadas en la elaboración de este documento. 


\section{Estado de la Tecnología}

En el presente capítulo se introducen los vehículos eléctricos, la hibridación y el motor MG2 utilizado en el Toyota Prius, objetivo de los estudios posteriores.

Su funcionamiento básico es simple: hasta aproximadamente $35 \mathrm{~km} / \mathrm{h}$, el Prius marcha casi silencioso utilizando su motor eléctrico. Si se acelera más se activa un motor impulsado por gasolina, resultando en un ahorro de gasolina medio de unos 5,1 litros por cada 100 kilómetros recorridos. La energía del motor de combustión y su recuperación cuando frena recargan las baterías de manera que no es necesario conectar el vehículo a la red eléctrica para su carga. Alcanza los $170 \mathrm{~km} / \mathrm{h}$ y acelera hasta de 0 a los $100 \mathrm{~km} / \mathrm{h}$ en unos 11 segundos.

Actualmente el Toyota Prius se vende en más de 70 países, con Japón y Estados Unidos representando los mayores mercados [2]. En mayo de 2008, las ventas acumuladas a nivel mundial alcanzaron el hito de 1 millón de Prius vendidos. En los Estados Unidos las ventas alcanzaron 1 millón de Prius vendidos en abril de 2011, y en Japón la misma marca se alcanzó en agosto. En octubre de 2014 las ventas mundiales desde 1997 alcanzaron los 3,8 millones de unidades [3].

\subsection{Introducción. Tipos de Vehículos híbridos [4, 5]}

Básicamente, y en función del uso de la energía eléctrica en el vehículo, existen dos tipos de vehículos eléctricos: puros e híbridos.

Los vehículos eléctricos "puros" o Electrical Vehicle (EV) no disponen de motor térmico de combustión interna. Cargan sus baterías directamente de la red eléctrica y su única fuente de energía es la electricidad que mueve uno o varios motores eléctricos.

Por otro lado, los vehículos eléctricos "híbridos" o Hybrid Electrical Vehicle (HEV) disponen al menos de dos fuentes de energía que tendrán como función alimentar el tren de transmisión, siendo una de ellas la electricidad y, usualmente, la otra un motor de combustión interna (ICE). Un depósito de combustible sería la fuente primaria de energía y las baterías de alta tensión serían la fuente secundaria.

A su vez, dentro de los vehículos híbridos se puede hacer una primera clasificación básica en medios y puros, por su capacidad de funcionamiento, como muestra la Figura 2.1. 


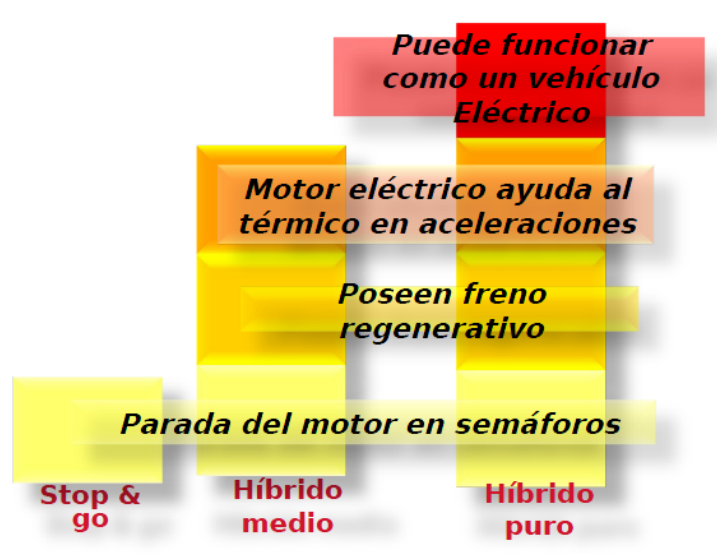

Figura 2.1. Tipos de Hibridación en vehículos.[6]

Atendiendo al flujo de energías entre motores y ruedas se clasifican en Serie, Paralelo y Combinado. El tipo de hibridación es importante pues marca el comportamiento y necesidades de los motores que, dependiendo del régimen de marcha del vehículo, pueden funcionar como motor $\mathrm{o}$ generador eléctrico alternativamente.

\subsubsection{Hibridación serie (SHEV)}

La fuente principal de energía es la energía eléctrica proveniente, por un lado, de un generador eléctrico acoplado al motor de combustión interna, y por otro de un sistema de baterías, como muestra la Figura 2.2. Las ruedas son accionadas por un motor eléctrico. El eje del motor térmico y el de las ruedas no están unidos mecánicamente y el motor térmico se limita a generar electricidad.

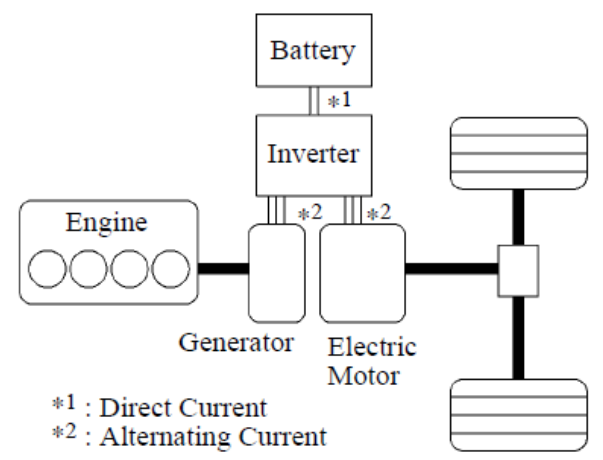

Figura 2.2. Esquema de un vehículo EHV serie.[6]

\subsubsection{Hibridación paralelo (PHEV)}

En este caso la fuente principal de energía en este caso es la energía del motor térmico y se dispone un motor eléctrico que apoya al motor térmico. Ambos motores están unidos mecánicamente e impulsan al vehículo, pero el motor eléctrico sólo colabora en momentos puntuales. Ver Figura 2.3. 


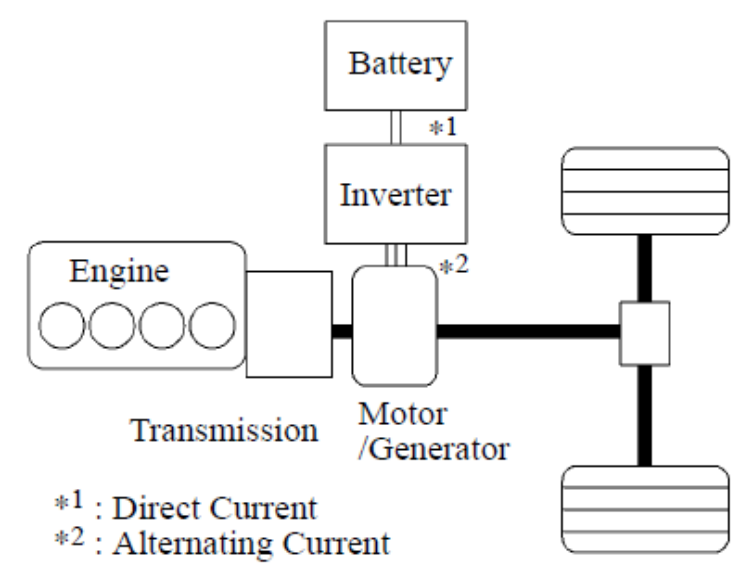

Figura 2.3. Esquema de un vehículo EHV paralelo.[6]

\subsubsection{Sistema combinado (CHEV)}

Las ruedas pueden ser impulsadas por cualquiera de los dos motores, independientemente o en conjunto. El sistema eléctrico puede ser alimentado desde una red eléctrica o desde un generador accionado por el motor térmico. Este sistema elimina la limitación de la potencia y disponibilidad de la energía de la batería (y por tanto de la autonomía) y de los tiempos de carga y aprovecha el mejor rendimiento del motor eléctrico. Es necesario disponer de un mecanismo transeje que una mecánicamente los ejes de los motores en un sistema de transmisión híbrido repartiendo, normalmente mediante trenes epicicloidales, la energía de ambos sistemas a las ruedas, como muestra la Figura 2.4. El Toyota Prius pertenece a esta categoría.

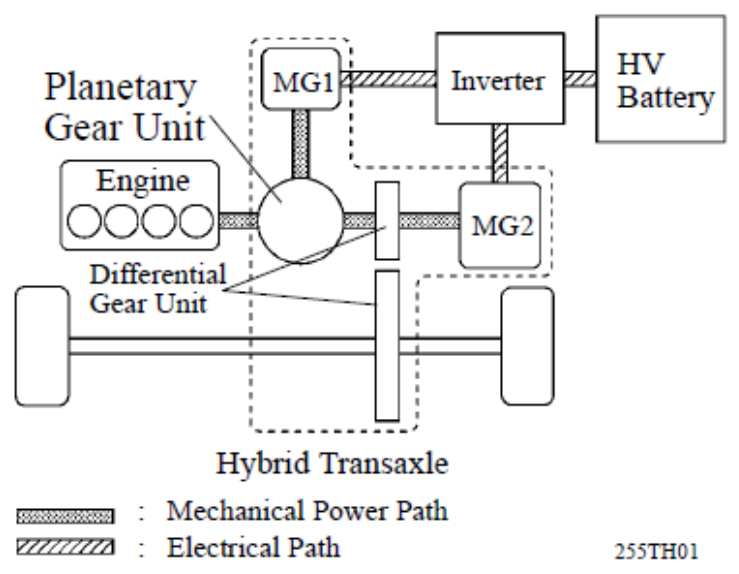

Figura 2.4. Esquema de sistema combinado CHEV.[6] 


\subsection{El Toyota PRIUS}

\subsubsection{Introducción histórica}

El Toyota Prius original es puesto en el mercado japonés en el año 1997, a Europa llegaría en el año 2000. Disponía de $110 \mathrm{CV}$ de potencia combinada, con un consumo medio de 3,9 1/100 km y un $90 \%$ menos de emisiones respecto de un vehículo similar de combustión interna. Se considera la primera producción en el mercado de propulsión híbrida. El sistema motriz del vehículo dispone básicamente, como muestra la Figura 2.5, de:

- Un motor de combustión interna de gasolina.

- Dos motores/generadores eléctricos MG1 y MG2. Funcionan de forma contraria dependiendo del régimen de marcha. Este conjunto $\mathrm{MG} /$ inversor es trifásico, de imanes permanentes y $\sin$ escobillas.

- Un sistema de baterías de alta potencia de Ni-Mh. Normalmente se carga mediante el generador y mueve el motor eléctrico.

- Un sistema de transmisión de potencia (PSD).

- Un sistema de control de Potencia (PCU).

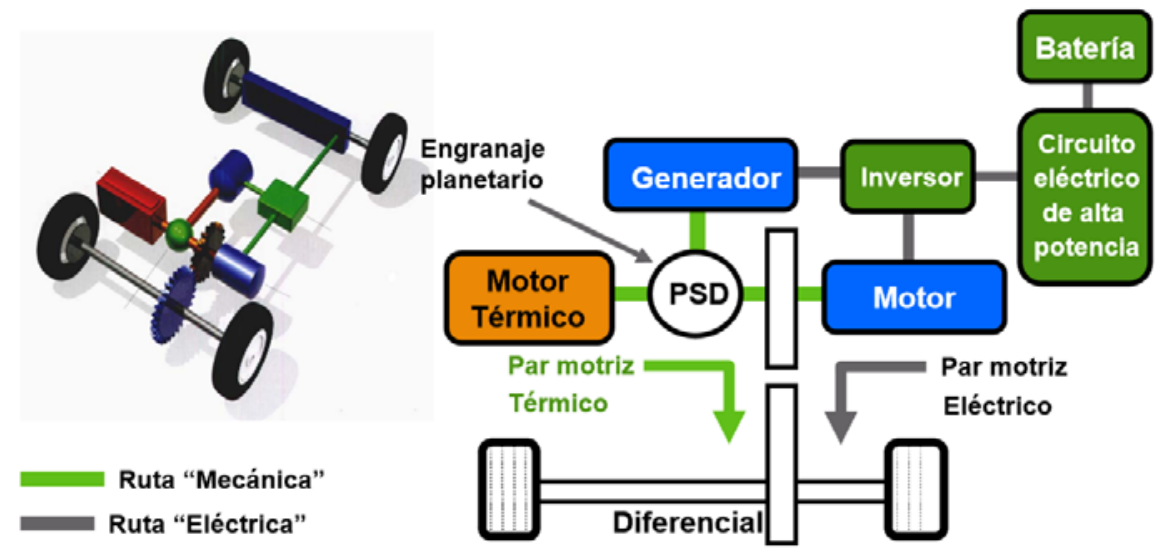

Figura 2.5. Sistema híbrido combinado del Prius.[7]

Como se ha indicado, la primera versión apareció en 1997 y su sistema de hibridación se denominó Toyota Hybrid System (THS). La segunda generación del Prius se denominó THS II y apareció el año 2004. Una de las mejoras conseguidas es que se logra reducir los costes del sistema en un $70 \%$. También se modifica el diseño del motor MG2 pasando de un imán permanente plano a dos con forma de "V" y se consigue un motor del que se obtiene un 50\% más de potencia con la elevación de la tensión del inversor de $500 \mathrm{~V}$ a $650 \mathrm{~V}$ y un nuevo sistema de control. Previendo la implantación de esta tecnología en otras marcas de vehículos, 2 años después de la aparición del THS II, Toyota crea la actual denominación Hybrid Synergy Drive (HSD)

A partir del 2006 derivó de esta denominación HSD la de Lexus Hybrid Drive. Actualmente esta tecnología está implantada en los modelos Auris, Prius, Highlander Hybrid, Camry Hybrid, Estima, Alphard, Lexus CT, Lexus RX 400h/RX 450h, Lexus GS 450h, Lexus LS 600/h/LS 600hL y Lexus HS 250h.

La tercera generación del Prius llegó en junio de 2009 y, además de mejoras en los sistemas de control. Incluye una nueva versión del HSD, denominadas PlugHD, que permite que se puedan cargar directamente las baterías desde una toma de corriente. En esta versión se disminuye el par máximo del motor MG2 y se aumenta su régimen de funcionamiento. 
El alto grado de desarrollo de este sistema híbrido HSD de Toyota ha conseguido que otros fabricantes de automóviles lo implanten en sus modelos, como el caso de Mazda o Nissan y el reciente acuerdo con BMW para que estos últimos ellos empleen la tecnología HSD y Toyota se beneficie de los motores diésel más eficientes desarrollados en Alemania. Conjuntamente van a desarrollar las baterías de Li-ion paras las nuevas generaciones de HEV.

Cada una de las versiones del Prius ha sido incluida en el Top 10 Tech Cars [8] [9] del IEEE el año de su aparición.

\subsubsection{Descripción general del sistema HSD}

Como punto principal, la tecnología HSD remplaza la transmisión clásica embrague/engranajes por un conjunto electromecánico (PSD), capaz de repartir la potencia en varios sentidos entre los sistemas mecánico y eléctrico totalmente controlados por un ordenador (PCU) como muestra la Figura 2.6. Al motor de combustión interna, el cual desarrolla su mejor rendimiento en un corto rango de pares y velocidades, le acompaña un grupo eléctrico generador-motor (MG1 y MG2 respectivamente).

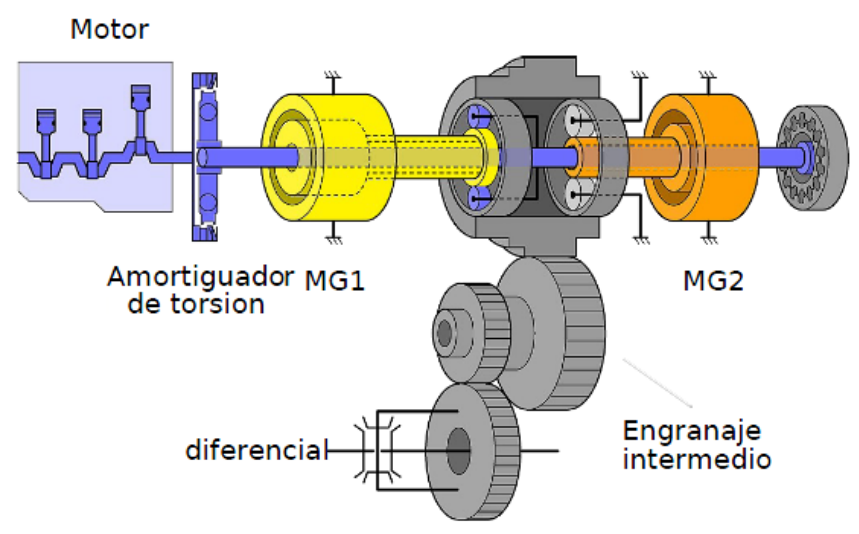

Figura 2.6. Esquema del sistema de transmisión del Prius. [7]

\subsubsection{Generador MG1}

Es una máquina de imanes permanentes interiores (IPM) de 8 polos y tiene la función principal de generador eléctrico, cargando el sistema de baterías a través del inversor. Al ser reversible (de ahí su denominación Motor-Generador), se utiliza también como motor de arranque del motor de combustión cuando el vehículo está parado. Proporciona una relación de transmisión continuamente variable y dispone de refrigeración líquida. Ver Figura 2.7.

\subsubsection{Motor MG2}

El estudio de esta máquina es una parte importante de este trabajo. En el apartado 2.3 se exponen las características técnicas a fondo. Ver Figura 2.7. 


\subsubsection{Sistema de transmisión}

En el corazón del sistema HSD se encuentra el conjunto de transmisión transeje, auténtica obra de ingeniería, que interconecta las distintas fuentes de energía y controla los flujos de potencias de los 3 motores dependiendo del régimen de funcionamiento del vehículo. Su sistema de reparto de potencia es el encargado de aunar la potencia del motor térmico y del eléctrico y mover el eje motriz a través de un sistema de engranajes epicicloidales, donde los motores MG1 y MG2 son los soles del tren epicicloidal como muestran la Figura 2.6 y la Figura 2.7.
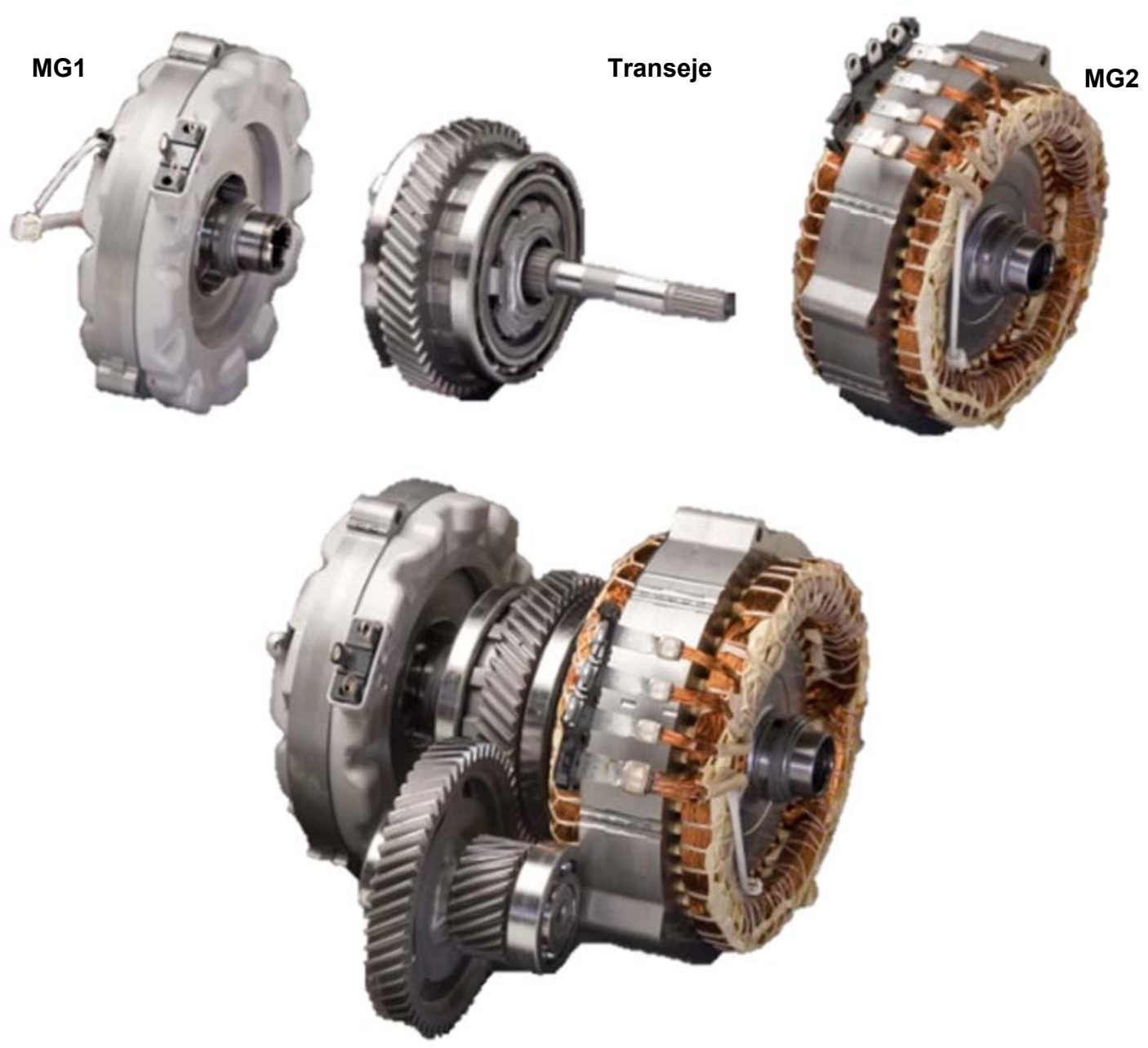

Figura 2.7. Componentes y conjunto del PSD del Prius. [7]

A efectos prácticos es como una transmisión de tipo variable continua, pero con ciertas características particulares:

- No tiene ruidosas cadenas.

- No hay saltos de marcha.

- Toda la transferencia de par se efectúa a través del sistema de reparto de potencia que se sitúa entre el motor térmico, el generador eléctrico MG1, el motor eléctrico MG2 y las ruedas. 


\subsubsection{Sistema Control de Potencia (PCU)}

Comprende dos conversores CC-CC y el inversor CC-CA trifásico para controlar los motores MG1 y MG2. Todo el sistema de electrónica de potencia del vehículo es controlado por el ordenador central. Tanto MG1 como MG2 funcionan en CA trifásica, mientras que las baterías eléctricas funcionan en corriente continua. Por tanto, para interconectar ambos sistemas es necesario un inversor.

En concreto, este dispositivo inversor realiza las siguientes funciones (ver Figura 2.8):

- Transforma la corriente eléctrica de 201,6V CC de la batería HV a 650 CC.

- Convierte los 650V CC a 650V CA trifásica para el motor y generador eléctricos.

Uno de los conversores transforma los 201,6V CC en 14V CC para recargar la batería auxiliar de $12 \mathrm{~V}$, dada la ausencia de alternador. El otro conversor, denominado booster, transforma los $650 \mathrm{~V}$ CC en 201V CC para alimentar las baterías HV, y en su primera versión, el compresor del aire acondicionado, que ahora se conecta en $\mathrm{CA}$.
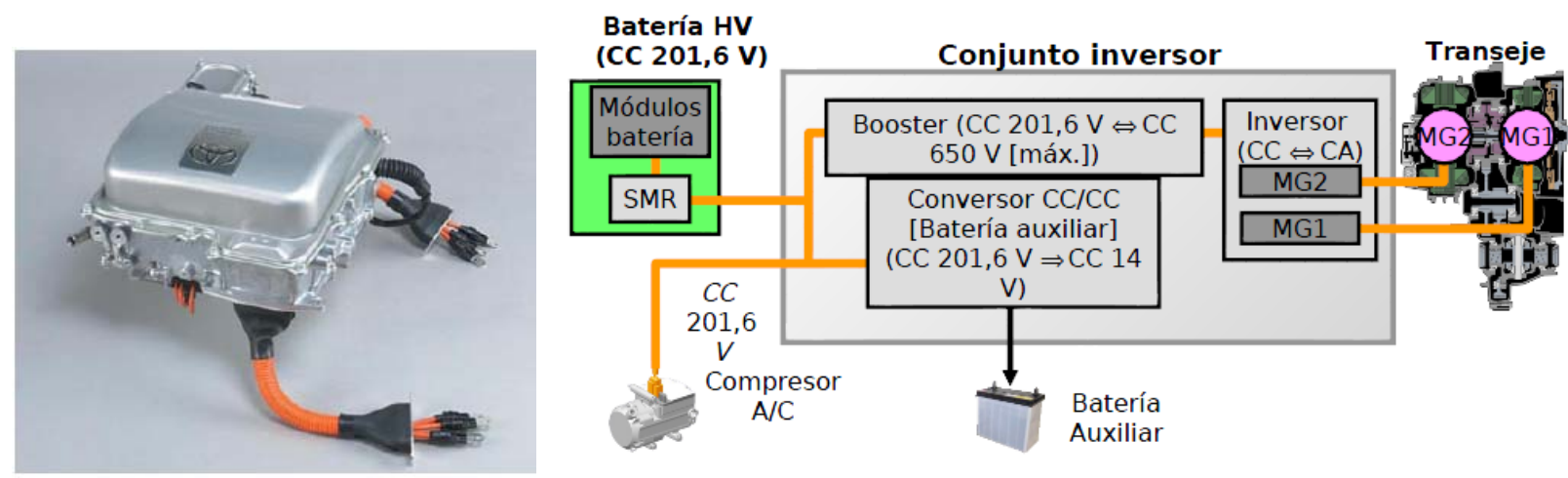

Figura 2.8. PCU del Prius y esquema de funciones del inversor. [7]

\subsubsection{Batería de alta tensión}

La energía eléctrica generada por MG1 puede aplicarse directamente a MG2 o pasar a cargar las baterías para su posterior uso. El sistema de baterías está construido por Panasonic y está formado por 38 módulos de $202 \mathrm{~V}$ de Níquel Hidruro metálico (Ni-Mh), con una capacidad de 6,5 Ah, un peso de $42 \mathrm{~kg}$ y unas dimensiones de 279x19x102 mm.

Se ha optado por esta tecnología por presentar la densidad de energía más alta entre las baterías de su tamaño. No tiene «efecto memoria», está hecha para que nunca baje de un cierto nivel de carga, mientras el vehículo está funcionando. Cuando el vehículo queda parado y desconectado, el proceso de descarga es muy lento. Todo el cableado del sistema de baterías se realiza con conductores de aluminio en vez de cobre para reducir peso y precio.

La batería se coloca en el maletero, como muestra la Figura 2.9, bajo el piso, detrás del asiento trasero y aún permite 4081 de capacidad de maletero. Esto es así para menor riesgo de deformación por impacto. 

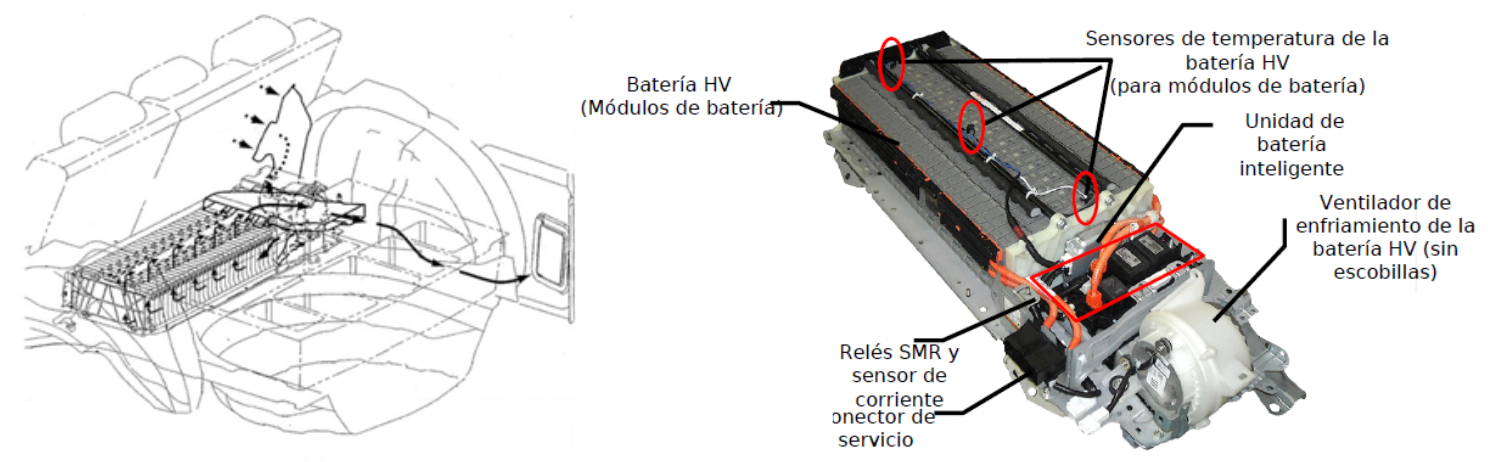

Figura 2.9. Disposición de la batería y vista exterior de la misma. [7]

A medida que han aparecido las distintas versiones del Prius y de otros vehículos híbridos de Toyota ha habido ligeras variaciones en la batería, que se resumen en la Tabla 2-1:

Tabla 2-1. Configuración de las baterías de los vehículos híbridos de Toyota.

\begin{tabular}{lccccc}
\hline & Prius 1 & Prius 2 y 3 & GS 450-h & RS 400-h & LS 600 h \\
\hline Tipo & Ni-Mh & Ni-Mh & Ni-Mh & Ni-Mh & Ni-Mh \\
Celdas & $1,2 \mathrm{~V}$ & $1,2 \mathrm{~V}$ & $1,2 \mathrm{~V}$ & $1,2 \mathrm{~V}$ & $1,2 \mathrm{~V}$ \\
$\mathrm{~N}^{\mathrm{o}}$ celdas/módulo & 6 & 6 & 6 & 8 & 12 \\
Tensión/módulo & $7,2 \mathrm{~V}$ & $7,2 \mathrm{~V}$ & $7,2 \mathrm{~V}$ & $9,6 \mathrm{~V}$ & $14,4 \mathrm{~V}$ \\
$\mathrm{~N}^{\mathrm{o}}$ módulos & 38 & 28 & 40 & 12 & 20 \\
$\mathrm{~N}^{\mathrm{o}}$ de grupos & 1 & 1 & 1 & 3 & 1 \\
Tensión total & $273,6 \mathrm{~V}$ & $201,6 \mathrm{~V}$ & $288 \mathrm{~V}$ & $288 \mathrm{~V}$ & $288 \mathrm{~V}$ \\
\hline
\end{tabular}

\subsection{El motor MG2 del Toyota Prius [10-16]}

El motor-generador MG2, es uno de los elementos fundamentales del Toyota Prius. Ha tenido tres versiones en sus más de 15 años de vida. El motor elegido para su análisis en esta Tesis es el desarrollado en el año 2004, un motor totalmente probado y consolidado. Al final del capítulo se detalla su evolución respecto a su predecesor del año 2000 y las modificaciones sufridas hasta su última versión en 2010, y en los siguientes subcapítulos se describen sus características y comportamiento.

Al igual que el MG1, es un motor IPM reversible. Su función principal es actuar como motor eléctrico en combinación con el motor térmico. Funciona a $500 \mathrm{~V}$ trifásicos y puede proporcionar una potencia de $50 \mathrm{~kW}$ con un rendimiento del $97 \%$ entre 1.200 y $1.540 \mathrm{rpm}$ con un par máximo de 400 $\mathrm{Nm}$, hasta $1.200 \mathrm{rpm}$. Cuando el vehículo frena se convierte en generador y recarga las baterías. Pesa unos $36 \mathrm{~kg}$, un tercio del conjunto mecánico, y su régimen máximo es $6.150 \mathrm{rpm}$. Su aspecto exterior puede verse en la Figura 2.10. 


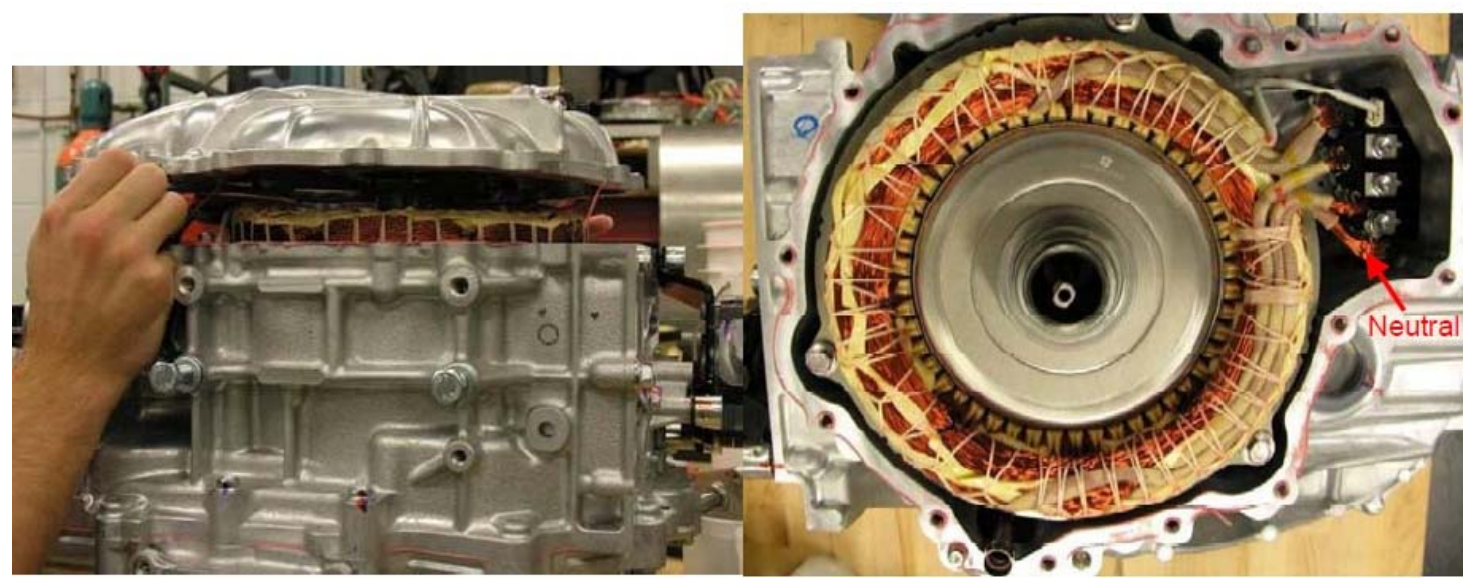

Figura 2.10. Vistas del MG2 del Toyota Prius 2004.[17].

\subsubsection{El estátor [18]}

El estátor del MG2 dispone de 48 ranuras como la mostrada en la Figura 2.11, número que no ha cambiado en sus tres versiones, al igual que tampoco lo ha hecho el diseño básico de las chapas.

Dispone de devanados imbricados de simple capa con paso polar de 6 y de bobina de 7.

Cada una de las tres fases de los bobinados del estátor del motor consiste en 12 cables con 8 bobinas (polos) de unos $66 \mathrm{~mm}^{2}$ y cada bobina tiene 11 espiras. Cada fase pesa alrededor de 1,644 $\mathrm{kg}$, con un total de $4,93 \mathrm{~kg}$ de cobre.

La forma de la boca de la ranura [19] no tiene que cumplir los requerimientos de un motor de inducción de obtener un par máximo, por lo que se pueden definir otros diseños que permitan un mayor paso de flujo del imán.
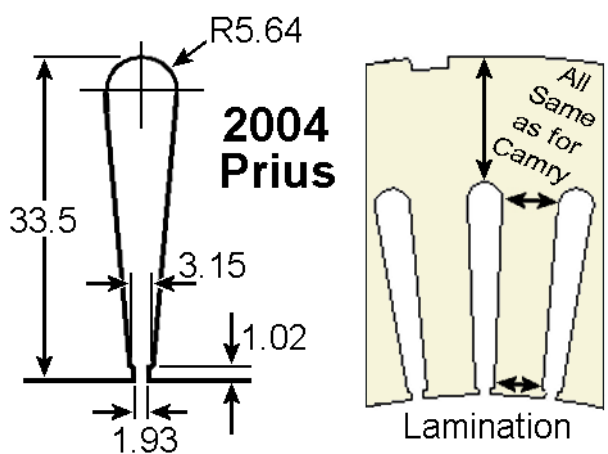

Figura 2.11. Detalle de ranura del estátor del MG2.[20].

Tabla 2-2. Datos de estátor.[20]

\begin{tabular}{lc}
\hline Peso de los bobinados de cobre & $\mathbf{6 , 9} \mathbf{~ k g}$ \\
\hline Peso de las chapas & $19,05 \mathrm{~kg}$ \\
Número de ranuras & 48 \\
Vueltas por bobina & 9 \\
$\mathrm{~N}^{\circ}$ de circuitos en paralelo por fas & 0 \\
$\mathrm{~N}^{\circ}$ de bobinas en serie & 8 \\
Número de cables en paralelo & 13 \\
Sección del conductor & $11 \mathrm{~mm}^{2}$ \\
Resistencia por fase & $0,069 \Omega$ \\
\hline
\end{tabular}


El material empleado para fabricar las chapas es el popular acero M19 con un espesor de 0,33 mm, en este caso de grado magnético JFE35JN250 "non oriented electrical Steel”[21]. La Figura 2.12 ilustra la intensidad del campo magnético de dicho grado (en azul) y la curva del material suministrada por el fabricante (marcadores de diamante en curva roja). El ajuste es excelente, especialmente en la región de la curva, altamente no lineal, donde el motor opera principalmente.

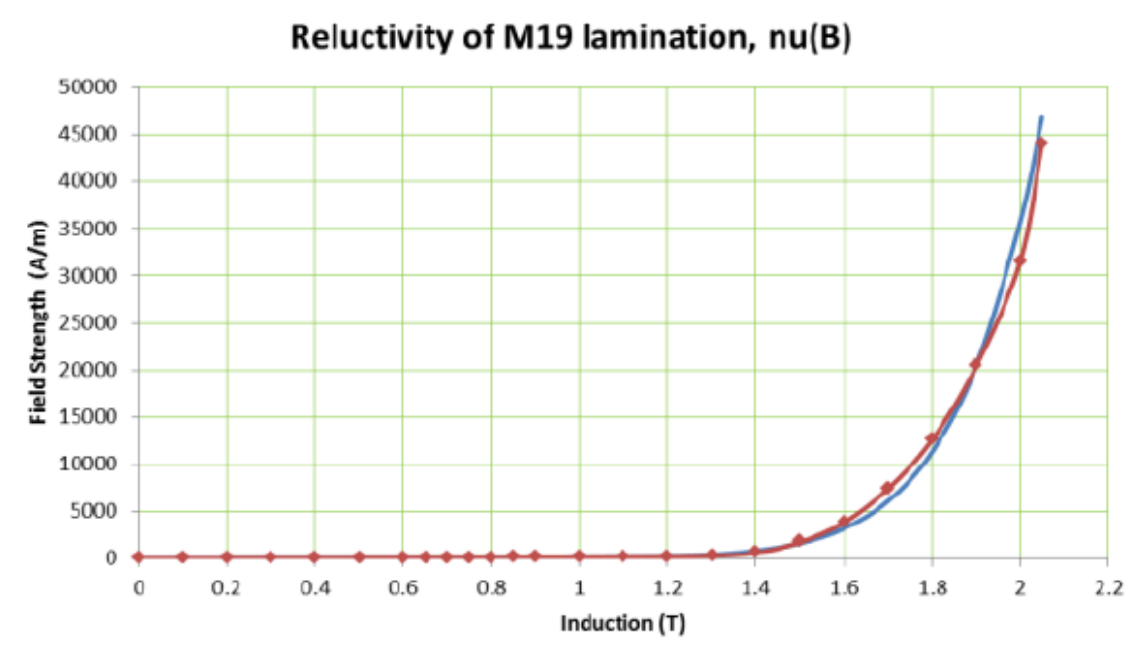

Figura 2.12. Modelo de reluctancia del acero M19.[22]

Los devanados de este tipo de motores han sido estudiados por [17, 29, 30] quien ha considerado la posibilidad de sustituirlos por devanados concentrados con paso fraccional, este tipo de devanado es mucho más económico porque se bobinan automáticamente, pero no permiten la combinación de polos y ranuras que nos proporcionan los devanados distribuidos. Tienen el inconveniente de generar más armónicos y mayor par oscilante. Las referencias indicadas también han considerado el uso de devanados distribuidos con un número fraccional de ranuras por polo. Las posibilidades de variación que ofrecen los devanados no tienen gran influencia en el funcionamiento del motor.

\subsubsection{El rotor $[23-25]$}

A la hora de diseñar el rotor del motor en cuestión hay cuatro aspectos fundamentales a considerar para mejorar su densidad de potencia.

1.- La robustez mecánica a altas velocidades de giro.

2.- Minimizar la cantidad de imán.

3.- El uso eficaz del par reluctante.

4.- La reducción de pérdidas en el hierro.

Para ello se puede actuar sobre el $\mathrm{n}^{\mathrm{o}}$ de polos, la geometría y los materiales de los imanes y de las chapas. 


\subsubsection{1 $\mathrm{N}^{\mathrm{o}}$ de polos}

En términos generales, no es conveniente seleccionar un gran número de polos, teniendo en cuenta la mayor resistencia mecánica posible del rotor y la minimización del volumen del imán. También, a mayor $\mathrm{n}^{\mathrm{o}}$ de polos, aumentan las pérdidas a altas velocidades de giro.

El rotor de los motores de imanes permanentes ha experimentado un sinfín de estudios comenzando por el número de polos, y todos concluyen en que el número que mejor se adapta a estas aplicaciones está entre 8 y 12, aunque se han probado todas las posibilidades de 6 a 24 [26]. Como solución de compromiso obtenida por la experiencia, Toyota utiliza 8 polos en todos sus motores MG1 y MG2.

\subsubsection{Disposición de los imanes}

En su primera versión el MG2 disponía imanes planos de una sola pieza, pero en sus versiones posteriores utiliza 2 imanes en $\mathrm{V}$. Esta disposición en $\mathrm{V}$ permite el uso de materiales más delgados y un aumento de la longitud, para el mismo arco polar, y por tanto abarcan un mayor flujo magnético. Las zonas de aire en los extremos sirven para reducir la saturación magnética, que de otra forma sería un camino para el flujo de dispersión y supone una pérdida de flujo.

Por parte de otros fabricantes se han diseñado infinidad de modelos con polos en $\mathrm{U}$, en $\mathrm{V}$ y de variadas formas y combinación de ellos en simple capa o en doble capa.

Como suele ser habitual es necesario llegar a una solución de compromiso por lo que se refiere al ángulo que ocupan los imanes. $\mathrm{Al}$ aumentar éste crece el par, pero también lo hacen las pérdidas en el hierro y las tensiones inducidas en vacío. Este valor del ángulo está comprendido entre los $133^{\circ}$ y los $150^{\circ}$, habiéndose elegido por Toyota el valor de $145^{\circ}$ para el diseño que analizamos como muestra la Figura 2.13.

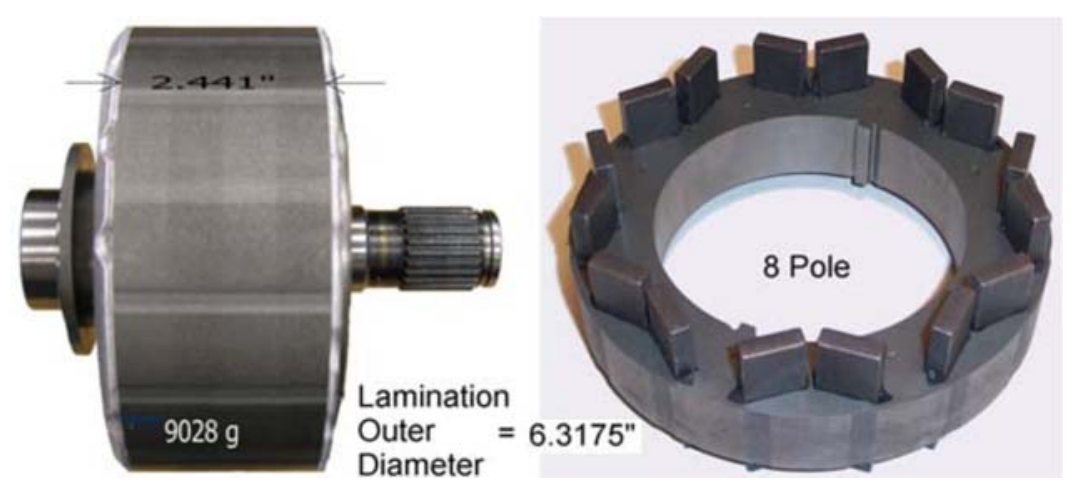

Figura 2.13. Disposición de los imanes en el rotor del MG2 del 2004.[27]

La estructura en $\mathrm{V}$ es la dominante para aprovechar el flujo de los imanes por eso se ha analizado el mejor ángulo de curvatura [23] considerando la altura desde el vértice de la $\mathrm{V}$ hasta el diámetro exterior del rotor. El valor que se obtiene como óptimo es $\mathrm{h}=10,9 \mathrm{~mm}$, prácticamente coincidente con los $11,3 \mathrm{~mm}$ que corresponden a los $145^{\circ}$ del MG2.

La forma de los imanes está limitada a rectángulos. Rápidamente la idea de emplear imanes curvos [28] empezaba a tener más interés para lo que era necesario emplear otros materiales. 


\subsubsection{Puentes[29]}

En los motores PMSM, se denomina puente a la zona que fija el imán en la chapa y por tanto asegura la resistencia mecánica del rotor y cumple la función adicional de establecer las barreras de flujo. Cuanto mayor sea su espesor mayor será el flujo de dispersión que se cierra sobre los mismos, por lo que se busca el mínimo número y lo más pequeños posible dentro del rango aceptable para mantener la rigidez mecánica.

El diseño del puente óptimo del MG2 se examina por uno de sus desarrolladores en [30], se analiza también que al aumentar el número de puentes disminuye la saliencia del motor . El motor MG2 del 2000 incorporaba sólo 2 puentes pero se detectaron problemas mecánicos por lo que en la versión del 2004, como muestra la Figura 2.14, pasaron a ser 3 y en la última versión de 2010 ha aumentado a 4. También debido a problemas mecánicos, en la zona próxima a los imanes se aumenta el diámetro exterior del rotor.
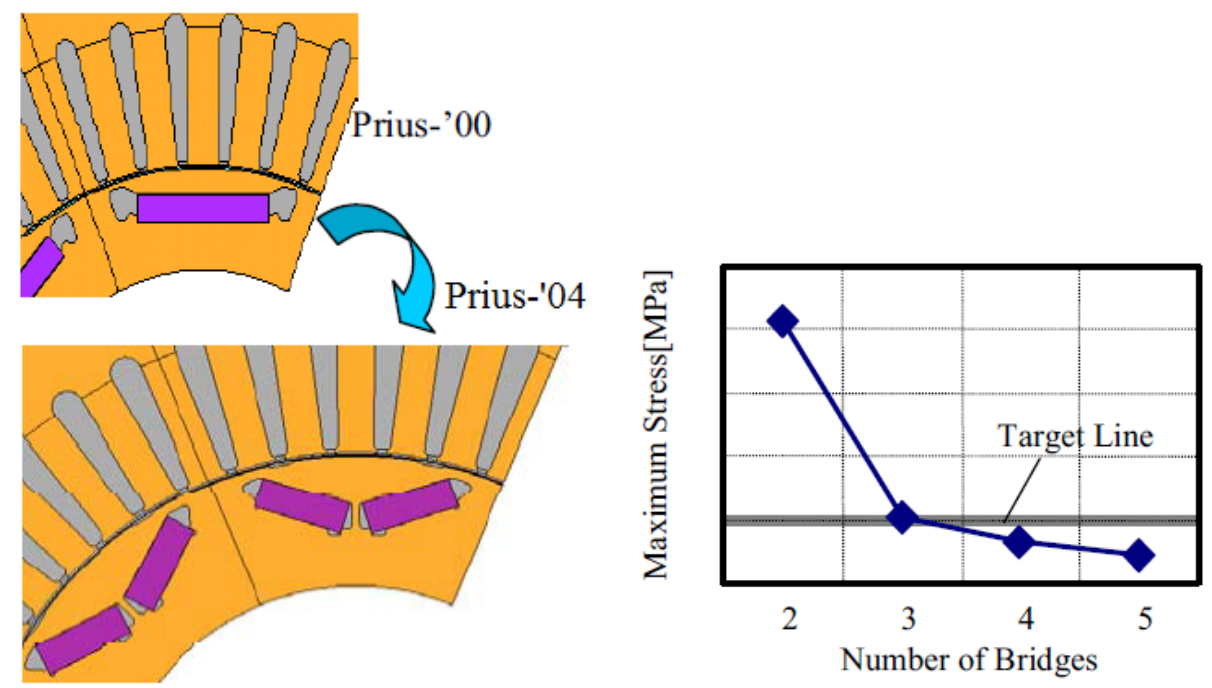

Figura 2.14. Puentes y esfuerzos de los modelos Prius 2000 y 2004.[30]

Asimismo se puede apreciar que al haber estrechado los puentes se reduce el flujo que se cierra sobre ellos haciendo más eficaz el motor.

Además de estos parámetros de diseño en las chapas del rotor también se hace necesario incorporar otros huecos o rebajes a veces con pequeñas piezas de sujeción de imanes que además de minimizar el flujo de dispersión, aligeran su peso y mejoren el comportamiento mecánico con la idea de poder aumentar el régimen de velocidad del motor.

\subsubsection{Rendimiento [31]}

Como es conocido, las pérdidas de un motor eléctrico se dividen en pérdidas en el cobre y pérdidas en el hierro. Las pérdidas en el cobre tienen poco margen de mejora, por lo que se sólo se investigan las producidas en el hierro. Además, en las zonas de mayor funcionamiento del motor, ver Figura 2.15, en conducción urbana, es donde las pérdidas en el hierro son superiores a las del cobre. 

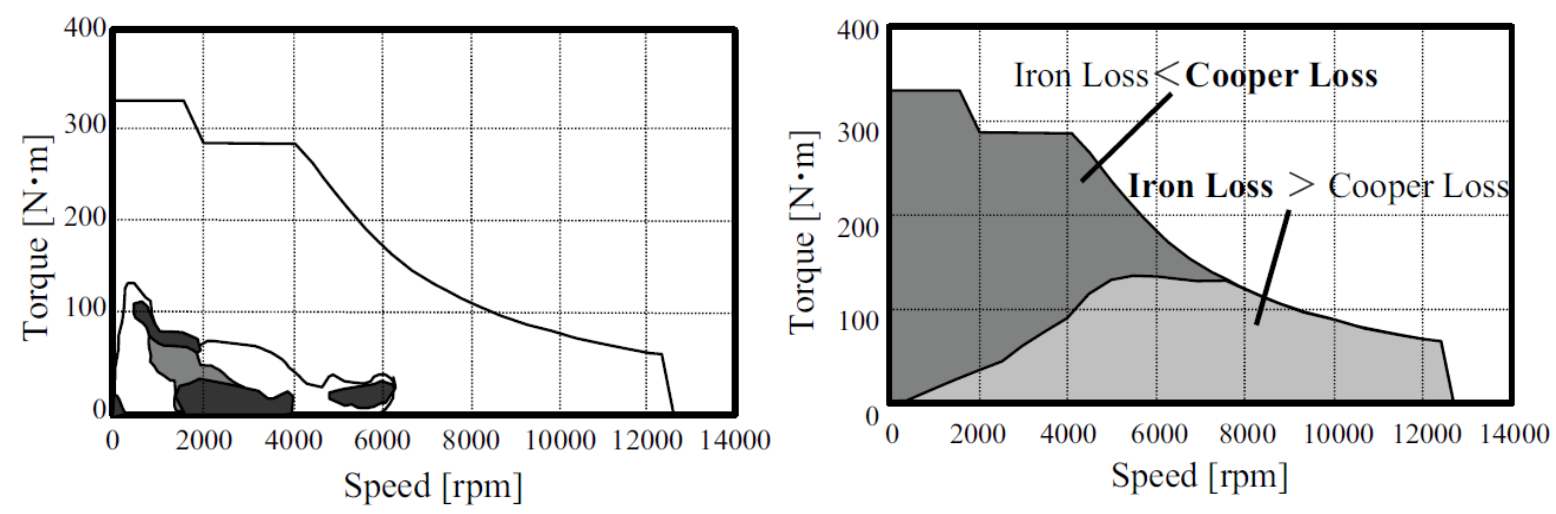

Figura 2.15. Zonas de funcionamiento en conducción urbana (izda.) y distribución de pérdidas en función del par (dcha.).[30]

Dada la importancia de las pérdidas en el hierro en los motores PMSM, se han cuantificado matemáticamente mediante la fórmula (2.1) [32]. En ella se incluyen las pérdidas por histéresis directamente proporcionales a la frecuencia $f$ y por corrientes de Foucault proporcional a una potencia de la frecuencia.

$$
P_{\text {nucleo }}=\{\underbrace{k_{h} B_{m}^{2} f}_{\text {(a) }}+\underbrace{\frac{\pi^{2} \sigma d^{2}}{6 \rho}\left(B_{m} f^{2}\right)}_{\text {(b) }}+\underbrace{\left.k_{g}\left(B_{m} f\right)^{3 / 2}\right\} M_{g}(W)}_{\text {(c) }}
$$

Esta ecuación es empírica y está formada por 3 términos correspondientes a:

(a) Pérdidas por histéresis.

(b) Anómalas, dependientes del material magnético.

(c) Corrientes de Foucault o Eddy currents

Donde:

$\sigma=$ conductividad eléctrica de la chapa $\left(\Omega^{-1}\right)$

$d=$ espesor de la chapa $(\mathrm{mm})$

$\rho=$ densidad del material $\left(\mathrm{kg} / \mathrm{m}^{3}\right)$

$f=$ frecuencia $(\mathrm{Hz})$

$M_{g}=$ masa de material magnético $(\mathrm{kg})$

$B_{m}=$ Inducción magnética (T)

$k_{h}$ y $k_{g}$ son constantes empíricas determinadas experimentalmente

La componente (c) de corrientes de Foucault de la pérdida total del núcleo aumenta con el espesor de la laminación. La Figura 2.16 muestra las pérdidas en el núcleo como una función del espesor de las chapas magnéticas de las distintas versiones. En color naranja se representa el caso de las chapas del Prius, 0,013 pulgadas, que corresponde a unas pérdidas bastante elevadas, de casi $200 \mathrm{~W} / \mathrm{kg}$. 


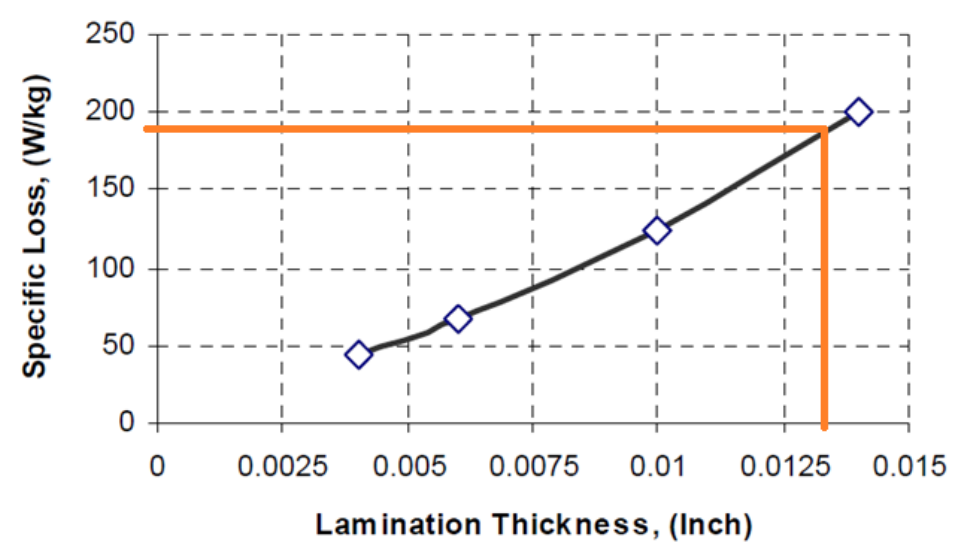

Figura 2.16. Pérdidas específicas de corrientes de Foucault versus espesor de laminación para una aleación acero de alta saturación de cobalto a $1.200 \mathrm{~Hz}$ y 2 T.[33]

Un estudio más profundo sobre las pérdidas en el hierro se debería de centrar en las chapas de estátor, ya que las pérdidas magnéticas del rotor son menores y las del cobre no admiten apenas variaciones. En dicho estudio partiendo de la ecuación de pérdidas (2.1) se fijarían una serie de puntos característicos en los caminos seguidos por el flujo como muestra la figura. De este modo se obtendrían valores detallados de flujo y perdidas en el estátor con distintos valores de intensidad asignados por zonas (ver Figura 2.17).

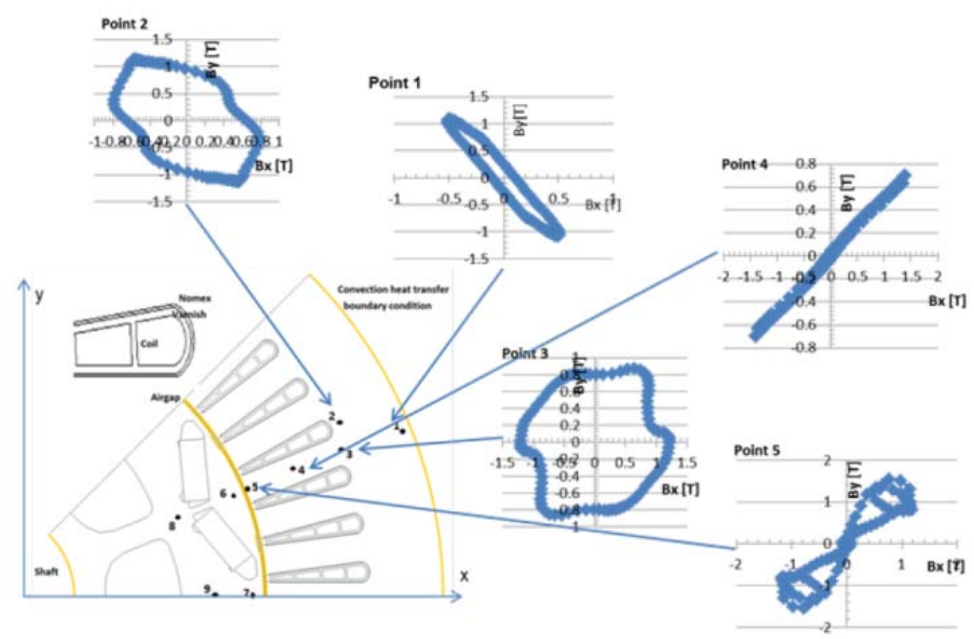

Figura 2.17. Mapa de pérdidas magnéticas del estátor de un motor IPM.[12]

En todo el conjunto inversor-motor, el mapa de rendimiento en función del par y la velocidad es el mostrado en la Figura 2.18. En las zonas de conducción de travesía los rendimientos superan el $94 \%$. 


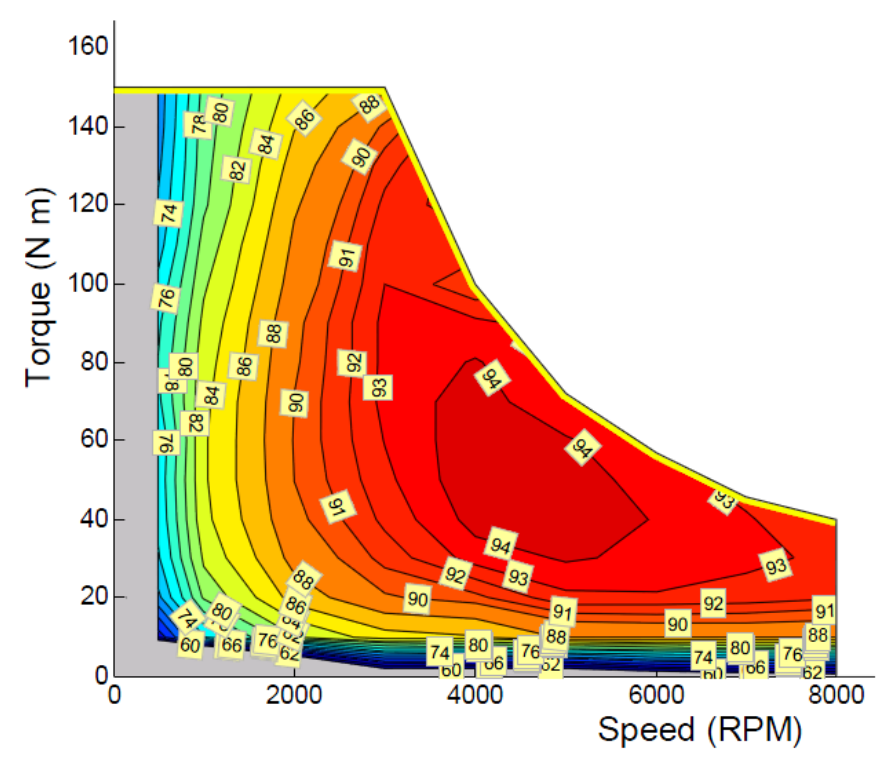

Figura 2.18. Mapas de eficiencia del MG2-inversor a $500 \mathrm{~V}$ CC. [34]

Los resultados para disminuir las pérdidas a lo largo de las distintas evoluciones del motor se muestran en la Figura 2.19, donde se observa una disminución de las mismas de hasta el 34\% en su régimen nominal de $6.000 \mathrm{rpm}$.

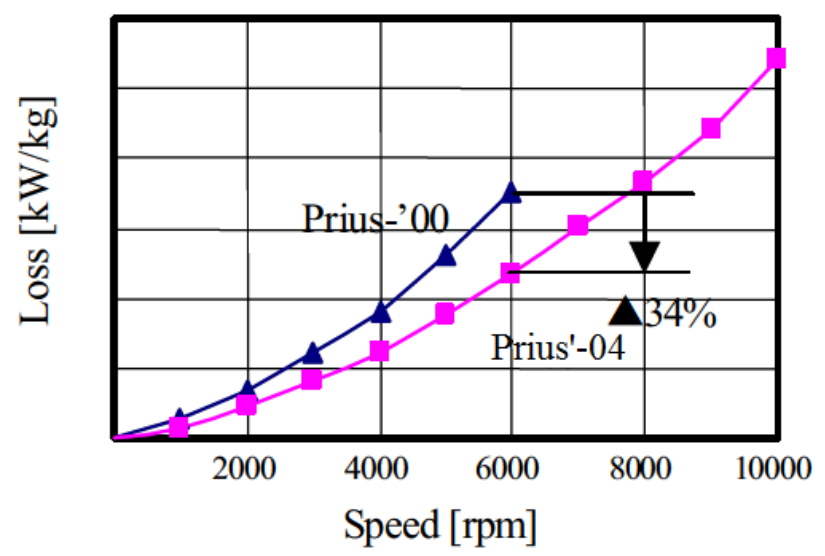

Figura 2.19. Distribución general de pérdidas. [30]

\subsubsection{Evolución del MG2}

A continuación se describen las modificaciones del motor MG2 en sus distintas versiones.

El estátor se mantiene casi constante en su geometría, mientras que es en el rotor donde se realizan los cambios que proporcionan mejoras al motor.

\subsubsection{Del 2000 al 2004}

Si lo comparamos con su predecesor del 2000 (THS), la principal diferencia en los devanados del estátor del modelo del 2004 (THS II) es que en los iniciales los devanados están conectados en 
paralelo y posteriormente se conectan en serie. Al duplicar el número de vueltas de los bobinados se duplica el par y la potencia y por ello se requiere mayor tensión de alimentación, pasando de $280 \mathrm{~V}$ a $500 \mathrm{~V}$, aunque esto ha producido un aumento de la reactancia del eje $q$.

En la Figura 2.20 se aprecia que el motor ha pasado de suministrar una potencia de $33 \mathrm{~kW}$ a otra de $50 \mathrm{~kW}$ y en la Figura III.3 del anexo que el par ha pasado de ser de $350 \mathrm{Nm}$ a $400 \mathrm{Nm}$.

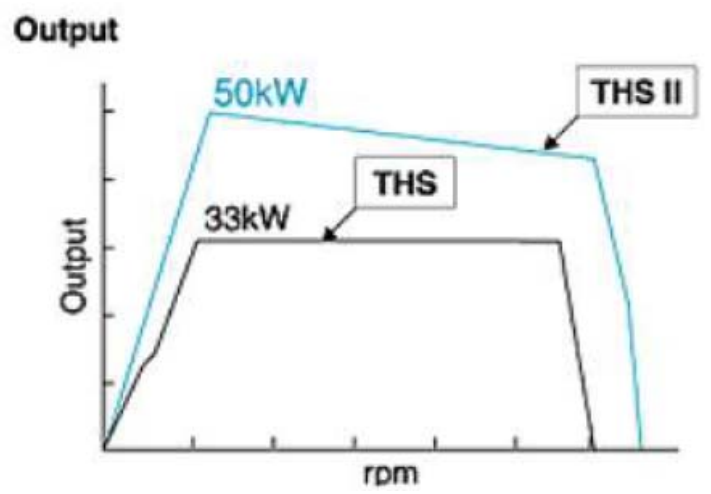

Figura 2.20. Curvas de potencia y par del MG2 del 2000 (THS) y 2004 (THSII). [20].

En el rotor, se pasa de 1 imán recto por polo a 2 imanes en V, como se muestra en la Figura 2.21 y la Figura 2.22. También se disminuye la longitud del motor en unos $5 \mathrm{~mm}$, de esta manera se disminuye la cantidad de material magnético y por tanto su peso, pero manteniendo la densidad de flujo.
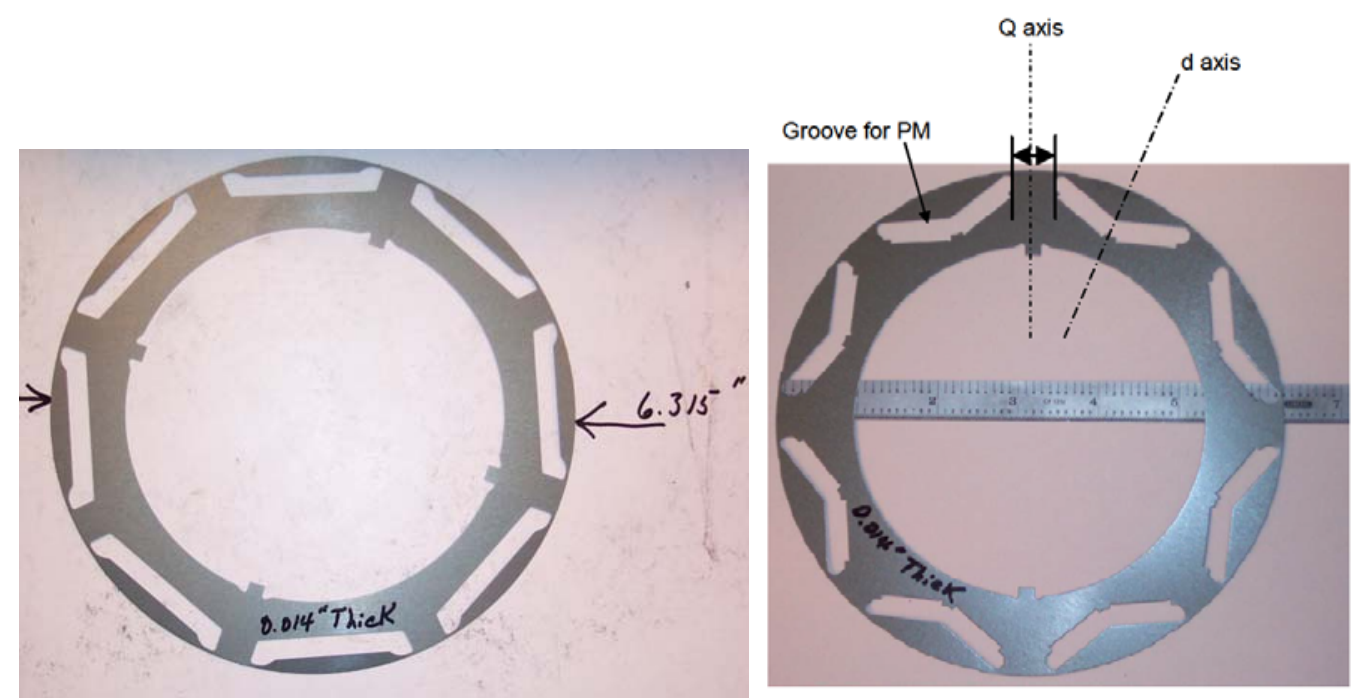

Figura 2.21. Chapas del rotor del Prius 2000 y Prius 2004.[17]

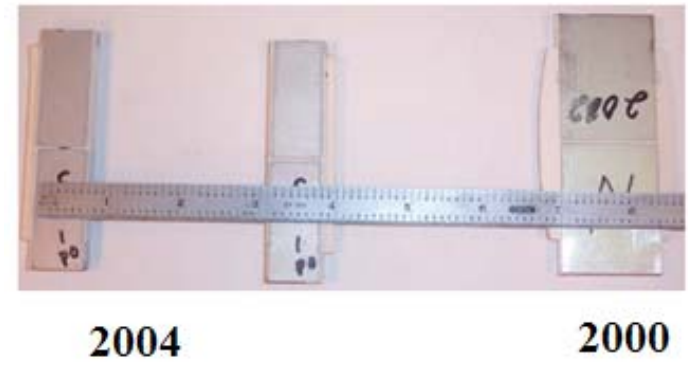

Figura 2.22. Evolución de las dimensiones de los imanes. [17]. 


\subsubsection{Del 2004 al 2010}

La primera modificación observable es la reducción de longitud del motor de 88,3 a casi $50 \mathrm{~mm}$, como se muestra en la Figura 2.23, lo que supone un motor más compacto y ligero con una disminución del peso de 45 a $36 \mathrm{~kg}$, pero un aumento de potencia de 50 a $60 \mathrm{KW}$.

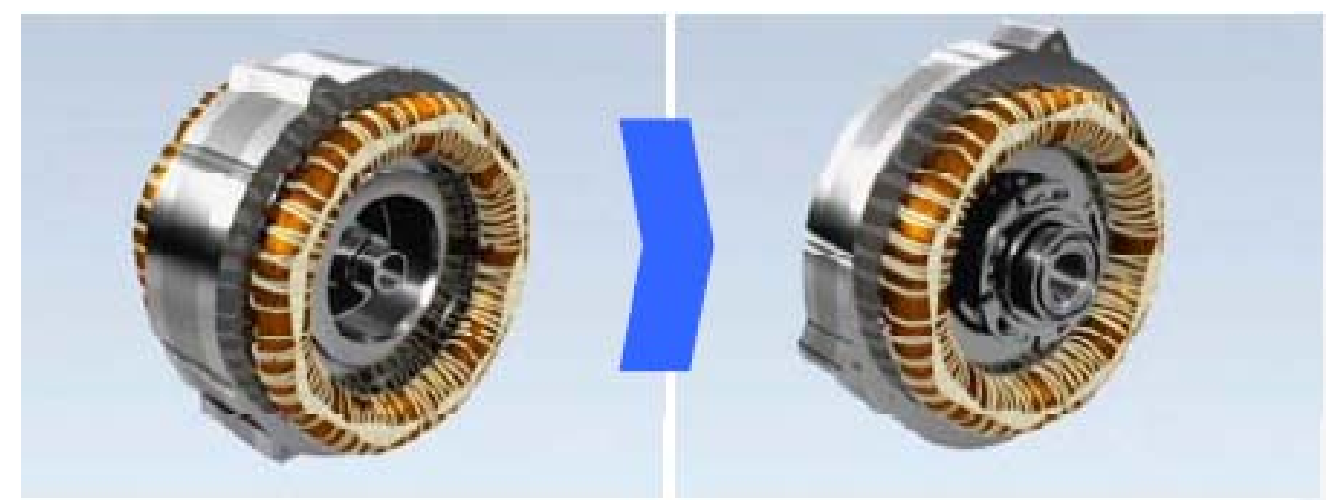

Figura 2.23. Conjunto MG2 del Prius 2004 (izda.) y del 2010 (dcha.).

Mientras que en los motores de los Prius 2010 los imanes permanentes mantienen la orientación en forma de una " $V$ ", se aprecian pequeñas diferencias al disminuir ligeramente su tamaño y aumentar el número de puentes. Además aparece la inclusión de grandes aberturas en las laminaciones en la parte interior del rotor. Estas aberturas reducen el peso total del rotor y aumentan el par motor. Esta configuración es una simplificación del rotor del Lexus $600 \mathrm{H}$ del 2008 , que añade un imán horizontal más, como se ve en la Figura 2.24.
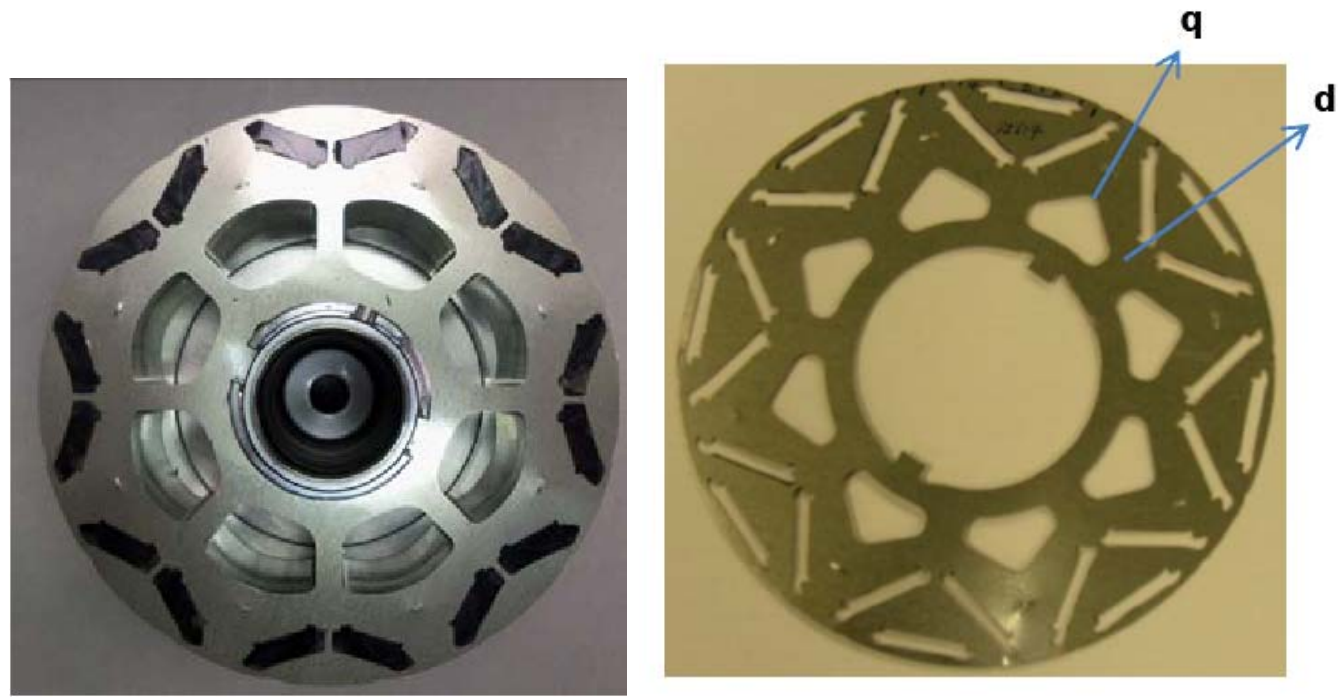

Figura 2.24. Modelo de rotor del modelo Prius 2010 (izda.) y LS 600H 2008 (dcha.). [22]:.

Además, el nuevo diseño reduce las pérdidas por corrientes parásitas en el eje, ya que los grandes huecos dificultan los transitorios del flujo magnético que se produzcan en esta área. También se disponen unas pequeñas muescas (que también se observan en los diseños anteriores) en la superficie exterior radial del rotor para cerrar los imanes, cerca de los puentes de apoyo, como se puede ver en el Anexo II. 
En cuanto a los imanes del motor del Prius 2010, pesan 48 gramos y miden 49,3x17,88x7,16 mm en comparación con los 77 gramos del 2004. Al aumentar el espesor del imán disminuye la inductancia asociada al eje $d$.

En lo referente a los conductores del motor, en la Figura 2.25 se muestra una comparación de los conductores utilizados para transportar energía entre la UCP y el sistema de transmisión continua. El diámetro del conductor se ha ido reduciendo significativamente como resultado del aumento de la tensión de alimentación (de 500 a $600 \mathrm{~V}$ ) y de la velocidad de giro (de 6.000 a $13.000 \mathrm{rpm}$ ). Los conductores de Prius 2010 contienen 50 hilos de 0,45 mm de diámetro, y es aproximadamente equivalente a un cable de $11 \mathrm{~mm}^{2}$ de sección.

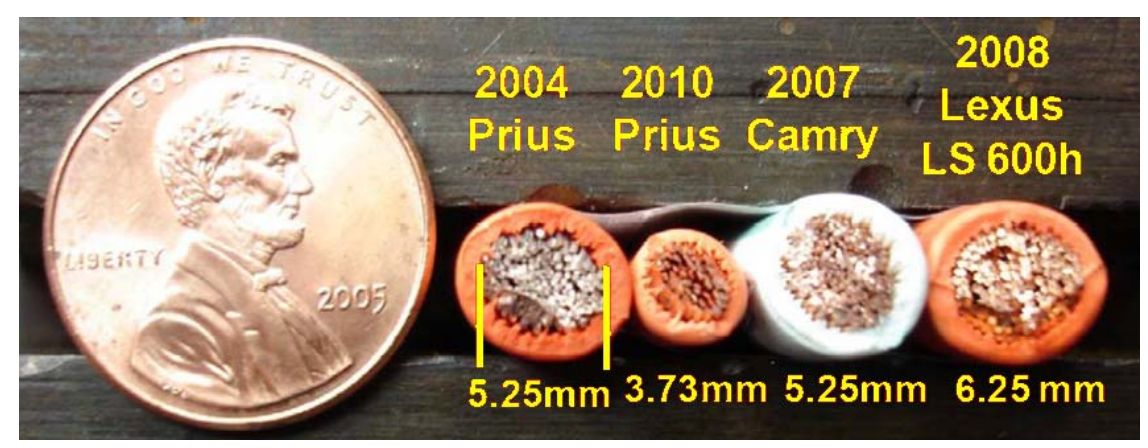

Figura 2.25. Sección de los conductores de distintos modelos de Toyota.[22].

La Tabla 2-3 muestra los datos más importantes para estas versiones.

Tabla 2-3. Comparación de características del MG2 2004 y 2010 [5].

\begin{tabular}{lr|r}
\hline & Prius 2004 & Prius 2010 \\
\hline Potencia (kW) & 50 & 60 \\
Tensión alimentación (V) & 500 & 600 \\
Velocidad (rpm) & 6.000 & 13.500 \\
Potencia específica (kW/kg) & 1,1 & 1,6 \\
Densidad de potencia (kW/l) & 3,25 & 4,8 \\
\hline
\end{tabular}




\section{Materiales magnéticos para vehículos eléctricos}

\subsection{Introducción. Necesidad de este documento}

En este capítulo se pretende hacer una revisión de la evolución que han sufrido los materiales magnéticos y del crecimiento tan importante que han tenido en las aplicaciones industriales actuales. Se repasan las características principales que se busca en estos materiales y la evolución que han tenido a lo largo del tiempo centrándonos en las modificaciones de los imanes $\mathrm{NdFeB}$.

Uno de los objetivos finales de esta tesis es comparar las posibilidades que aporta la sustitución de imanes aglomerados por los sinterizados actuales, que permiten formas geométricas complejas, más apropiadas para concentrar el flujo magnético y aprovechar las importantes variaciones que han tenido estos materiales.

Me ha sido inevitable extenderme tanto en este capítulo porque son muchas las alternativas que han manejado todos los implicados (desde organismos gubernamentales a institutos de investigación, fabricantes de imanes y vehículos) y muy poca la transparencia e información.

Para cada tecnología, se analizan los siguientes temas:

- El estado de la técnica actual y el coste.

- Últimas tendencias en tecnología.

- Características inherentes de cada imán.

- Los aspectos que la investigación y el desarrollo (I+D) deberían desarrollar para alcanzar los objetivos.

\subsection{Origen, historia y situación actual}

Curiosamente la primera aplicación del imán magnético es la brújula, procede de China y está datada de unos 2.500 años antes de Cristo, pero no fue hasta finales de los años ochenta, cuando se desarrollaron imanes permanentes con un material de alto flujo magnético. Inicialmente fueron los de SmCo, pero el alto precio que se pagaba por ellos inició la investigación de otros nuevos desarrollando una mezcla de tierras raras o "Rare Earth" (RE) principalmente neodimio con hierro y boro. Esta composición presenta casi un orden de magnitud mayor de flujo que otros tipos de imanes permanentes del momento. Esto creó una revolución para muchos productos que necesitan los pequeños imanes de alto flujo, incluyendo altavoces, discos duros, etc. 
La aplicación lógica de utilizar los imanes RE en un motor eléctrico llegó en la década de los 90. Se eligió la máquina síncrona en la que se sustituyen los devanados del rotor, que requieren alimentación en corriente continua, por los imanes permanentes.

Cuando los fabricantes de automóviles eléctricos ya habían elegido el motor síncrono de imanes permanentes como motor más idóneo a sus requerimientos, se provoca una creciente escasez mundial de materiales de tierras raras utilizados en la fabricación de los imanes. En 2010 estalla la guerra de los precios de las tierras raras y el costo de estos materiales se ha ido incrementando dramáticamente desde entonces, especialmente el precio del disprosio. A partir de esto todos los productores de imanes empezaron a desarrollar nuevos procesos de fabricación para evitar este componente sin perder valor en el producto de energía.

La demanda de tecnologías que emplean tierras raras, en temas tan críticos como el desarrollo de HEV y la energía eólica, sigue aumentando en un mercado abastecido por el monopolio de China.

Hoy en día las perspectivas mundiales empiezan a ampliarse y muchos países, pero especialmente USA y Japón, están financiando tecnologías alternativas que reducen o eliminan la necesidad de tierras raras ARPA -E.

La agencia Advanced Power Electronics and Electric Machines (APEEM) establece una serie de objetivos generales para los motores, que se indicarán en el capítulo siguiente, y otros específicos para materiales magnéticos que son los indicados en la Tabla 3-1.

Tabla 3-1. Objetivos de la APEEM para materiales magnéticos en el 2020.[35]

\begin{tabular}{lr}
\hline Potencia de Pico (KW/kg) & $>\mathbf{2 , 7 5}$ \\
\hline Coste de material activo (\$/KW) & $<3,2$ \\
Coste para motor 55 KW (\$) & 259 \\
\hline
\end{tabular}

En la Figura 3.1 se muestra la evolución de los imanes permanentes con la cantidad de energía que suministran.

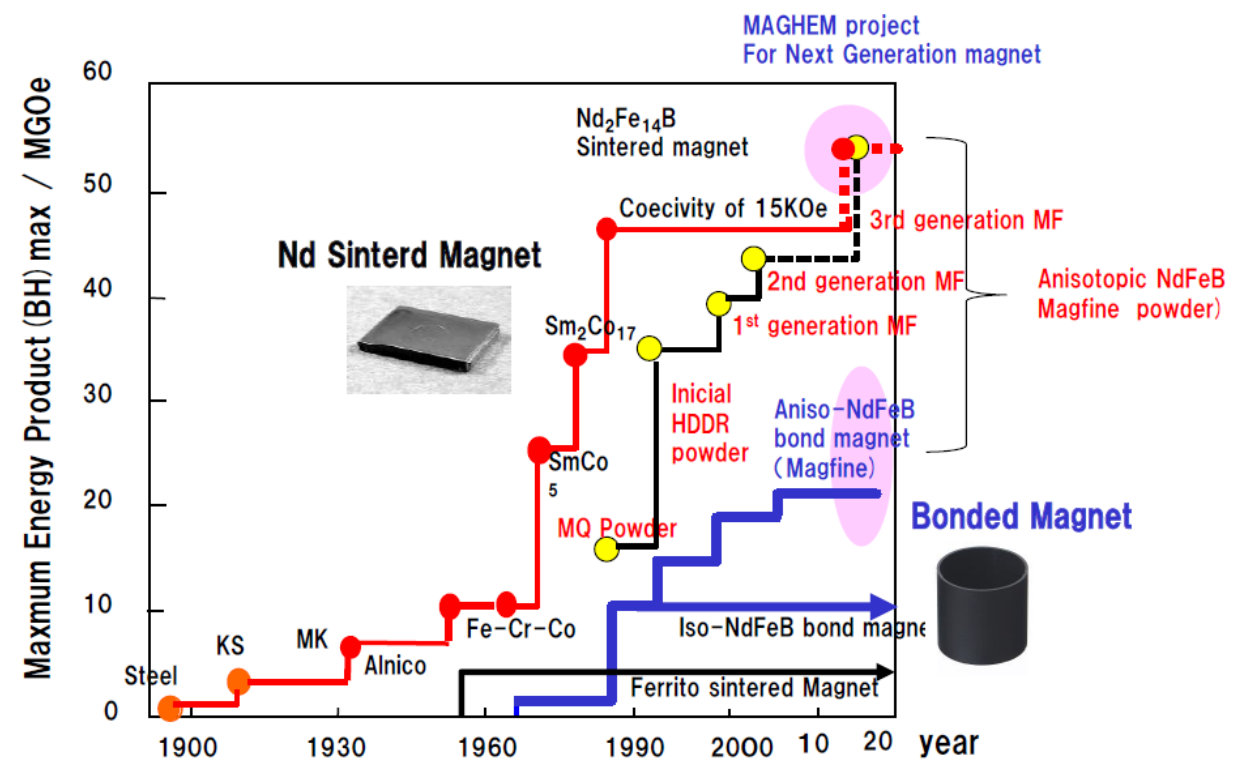

Figura 3.1. Evolución de los materiales magnéticos.[36]

En la Figura 3.2 se muestran las cantidades necesarias de imán y su evolución en el tiempo de los distintos imanes fijas ciertas características magnéticas. 


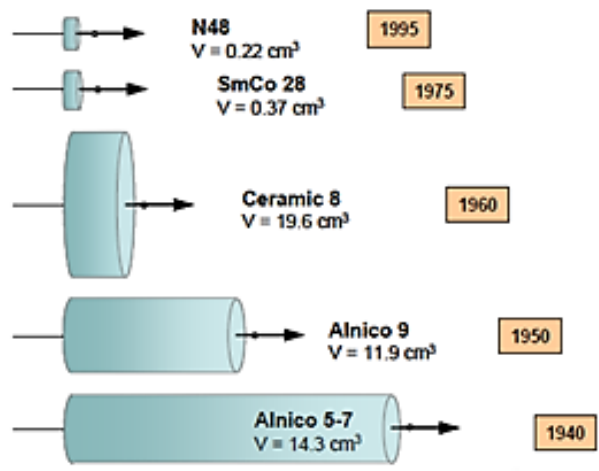

Figura 3.2. Tamaño y forma relativa de imán para generar 1.000 gauss desde la cara del imán.[37]

\subsection{Propiedades magnéticas}

Las características de un material magnético pueden clasificarse en:

\section{Magnéticas:}

Las más importantes son coercitividad, remanencia, producto de energía y comportamiento ante la temperatura.

\section{Físicas:}

Corrosión, ductilidad, dureza, en definitiva las posibilidades de fabricación que ofrezca el material.

\section{Económicas:}

Coste, disponibilidad y facilidad de ensamblaje.

La suma del conjunto de estas propiedades debe ser constante, es decir debe existir un compromiso/equilibrio entre calidad/precio. Actualmente esta suma es más favorable en los imanes $\mathrm{NdFeB}$ sinterizados y la alternativa sería los imanes aglomerados.

\subsubsection{Características magnéticas}

\subsubsection{Curva de magnetización}

En los imanes permanentes el cuadrante de la curva de histéresis de mayor interés es el segundo, correspondiente a la desmagnetización del material. La curva de desmagnetización mostrada en la Figura 3.3 es propia del material con el que está construido el imán y expresa cual será la densidad de flujo magnético $B$ para cada campo $H$. En ella se distinguen dos curvas, una en rojo, que representa las propiedades dentro del imán, conocida como intrínseca y la otra azul representa el comportamiento incluyendo el medio que lo rodea, denominada normal. 


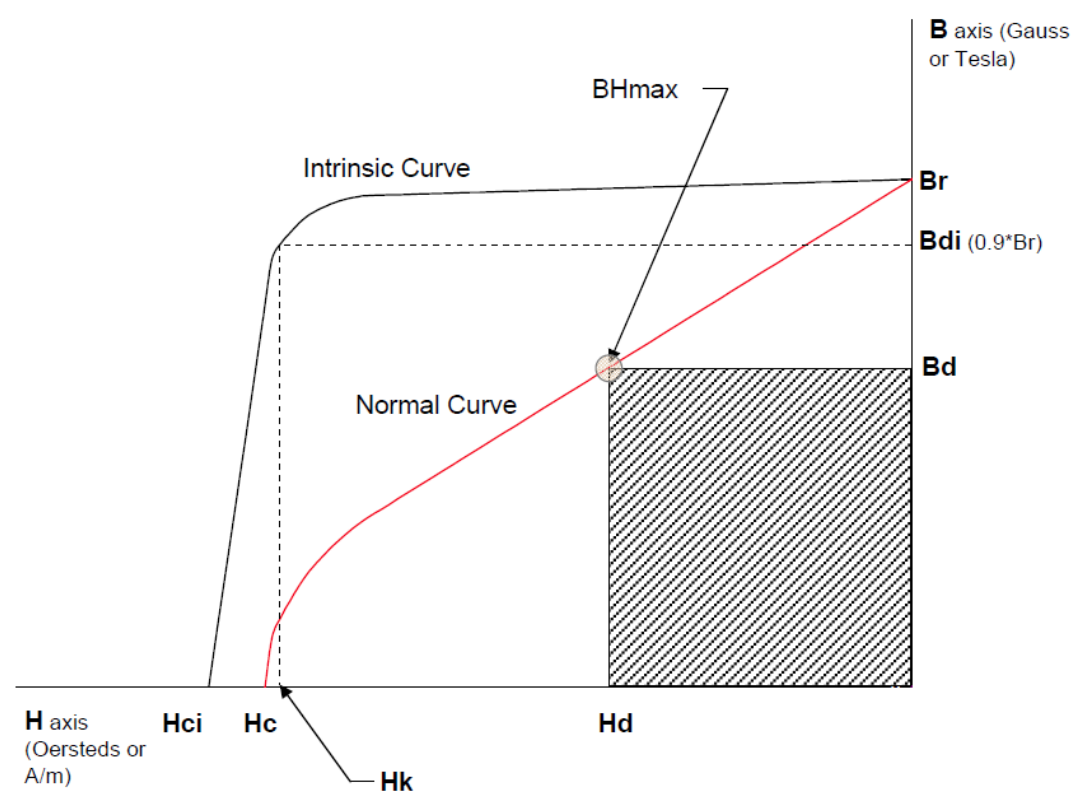

Figura 3.3. Curvas $J$ vs. $H$ (rojo) y $B$ vs. $H$ de una ferrita. [38]

La relación $H_{k} / H_{c i}$ es una medida de la cuadratura del ciclo y de la localización del codo.

La ecuación de la curva intrínseca es:

$$
B=\mu_{0} H
$$

Y de la normal es:

$$
\begin{aligned}
& B=\mu_{r} \mu_{0} H+\mu_{0} M \\
& \mu_{r}=\left(1+\chi_{m}\right)
\end{aligned}
$$

Siendo $M$ la magnetización que cuantifica las características del medio material incluyendo si es isótropo u homogéneo.

Se define Remanencia $\boldsymbol{B}_{\boldsymbol{r}}$ como el valor residual de flujo magnético cuando la intensidad de campo es nula.

$$
\begin{aligned}
& H=0: \quad B_{r}=\mu_{0} M \\
& B=0: H_{c}=-\frac{M}{\mu_{r}}
\end{aligned}
$$

Este valor es el mismo en ambas curvas.

Se define coercitividad $H_{c}$ como la intensidad de campo magnético necesaria para anular el flujo de imán. 


\subsubsection{Concepto de recta de carga}

El punto de trabajo del imán es la intersección de la curva de desmagnetización del imán con la recta de carga. La recta de carga introduce la geometría del circuito magnético en general, incluyendo medidas propias del imán (área y longitud) y las del entrehierro (área y longitud). El punto de trabajo fija los parámetros magnéticos que se establecerán dentro del imán en una situación de trabajo determinada. Del gráfico de la Figura 3.4 puede deducirse cuáles son las condiciones que "alivian" el trabajo del imán y cuales la complican:

1) Cuanto mayor sea la longitud del entrehierro y el área del imán, menor el flujo aportado al circuito.

2) Cuanto mayor sea el área del entrehierro y la longitud del imán, mayor el flujo que el imán aportará al circuito.

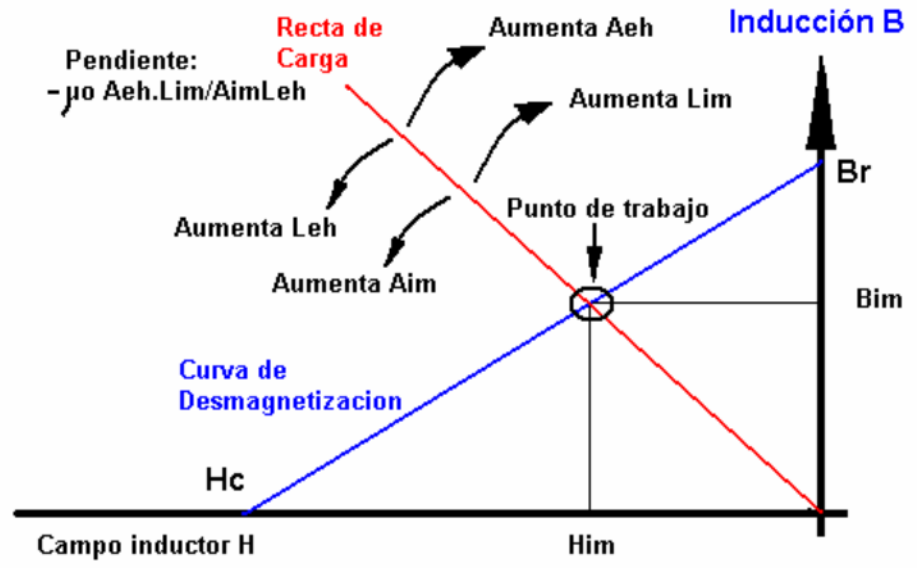

Figura 3.4. Curvas de carga, de desmagnetización y punto de trabajo de un imán.[39]

\subsubsection{Concepto de "Producto de Energía"}

Para cualquier punto de la curva de desmagnetización de un material magnético, el producto de las coordenadas $B$ y $H$ de dicho punto indica la cantidad de energía que $1 \mathrm{~m}^{3}$ de dicho material puede imponer al espacio.

El producto de energía asociado a un punto de la curva de desmagnetización puede representarse gráficamente como el área del rectángulo determinado por dicho punto y los ejes de coordenadas. A medida que el punto de trabajo se acerca a uno de los ejes, el área del rectángulo tiende a ser nula. El área máxima de rectángulo estará asociada a un punto intermedio de la curva, por ejemplo el punto P2 de la Figura 3.5.

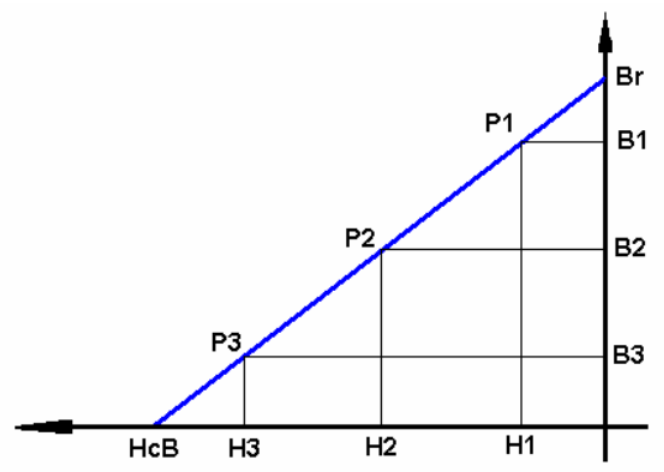

Figura 3.5. Producto de Energía.[39] 
Las curvas de desmagnetización de los imanes comerciales contienen un conjunto de hipérbolas sobre cada una de las cuales el producto $B H$ es constante. En la Figura 3.6, la curva de desmagnetización intersecta a la hipérbola de $B H$ en el punto $\mathrm{C} 2$. El producto de energía máximo con que puede trabajar este material es $\mathrm{C} 2\left[\mathrm{~J} / \mathrm{m}^{3}\right]$, siendo Ba y Ha las coordenadas de dicho punto.

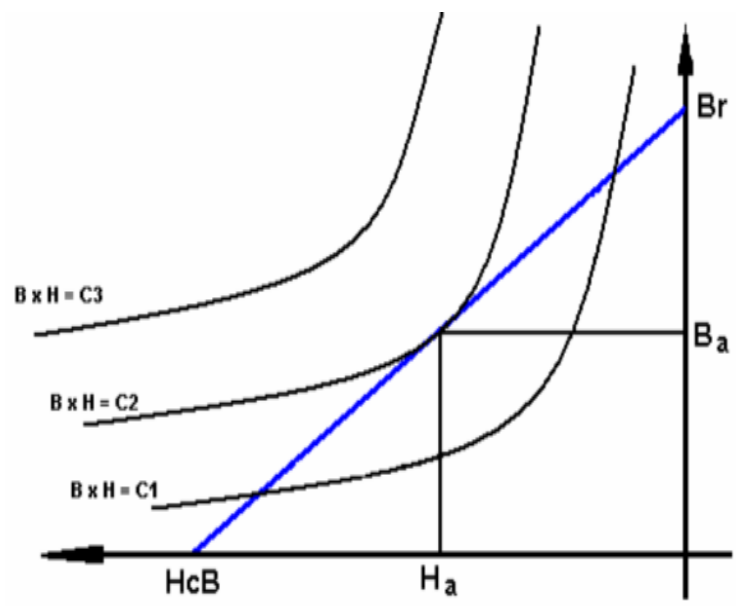

Figura 3.6. Curvas $B H$ constantes.[39]

La expresión general del producto de energía:

$$
W_{m}=\frac{1}{2} B H=\frac{\mu_{r} \mu_{0}}{2} H^{2}+\frac{\mu_{0}}{2} M H
$$

Los valores medios valen:

$$
B_{d}=\frac{\mu_{0} M}{2} \quad H_{d}=-\frac{M}{2 \mu_{r}}
$$

Analizando el producto dimensionalmente se llega a la siguiente conclusión:

$$
B\left(\frac{\mathrm{Wb}}{\mathrm{m}^{2}}\right) \cdot H\left(\frac{\mathrm{A}}{\mathrm{m}}\right)=B H\left(\frac{\mathrm{Wb} \cdot \mathrm{A}}{\mathrm{m}^{3}}\right)
$$

Pero $\mathrm{Wb}=\mathrm{V} \cdot \mathrm{s}$, entonces:

$$
B H\left(\frac{\mathrm{Wb} \cdot \mathrm{A}}{\mathrm{m}^{3}}\right)=B H\left(\frac{\mathrm{V} \cdot \mathrm{A} \cdot \mathrm{s}}{\mathrm{m}^{3}}\right)=B H\left(\frac{\mathrm{W} \cdot \mathrm{s}}{\mathrm{m}^{3}}\right)=B H\left(\frac{\mathrm{J}}{\mathrm{m}^{3}}\right)
$$

El producto $B H$ tiene dimensión de energía por unidad de volumen.

\subsubsection{Comportamiento ante la temperatura}

La temperatura es una de las características de funcionamiento que más importancia tiene en este tipo de materiales, sobre todo si tenemos en cuenta la aplicación, ya que en funcionamiento el motor 
puede alcanzar elevadas temperaturas (entre $150{ }^{\circ} \mathrm{C}$ y $200{ }^{\circ} \mathrm{C}$ ) peligrando el mantenimiento de las propiedades del imán.

\section{Coeficientes $\alpha$ y $\beta$ y temperatura de Curie}

Coeficiente $\alpha$ : Este parámetro se conoce como coeficiente de temperatura reversible de inducción magnética.

$$
\alpha=\frac{\Delta B_{r}}{B_{r}} \frac{1}{\Delta T} 100 \%
$$

Coeficiente $\boldsymbol{\beta}$ : Aún más crítico que el anterior es el coeficiente reversible de temperatura referida a la intensidad de campo magnético.

$$
\beta=\frac{\Delta H_{c}}{H_{c}} \frac{1}{\Delta T} 100 \%
$$

Interesa obtener los valores más bajos posibles de $\alpha$ y $\beta$ siendo valores aceptables en torno a 0,1 y $-0,5$ respectivamente.

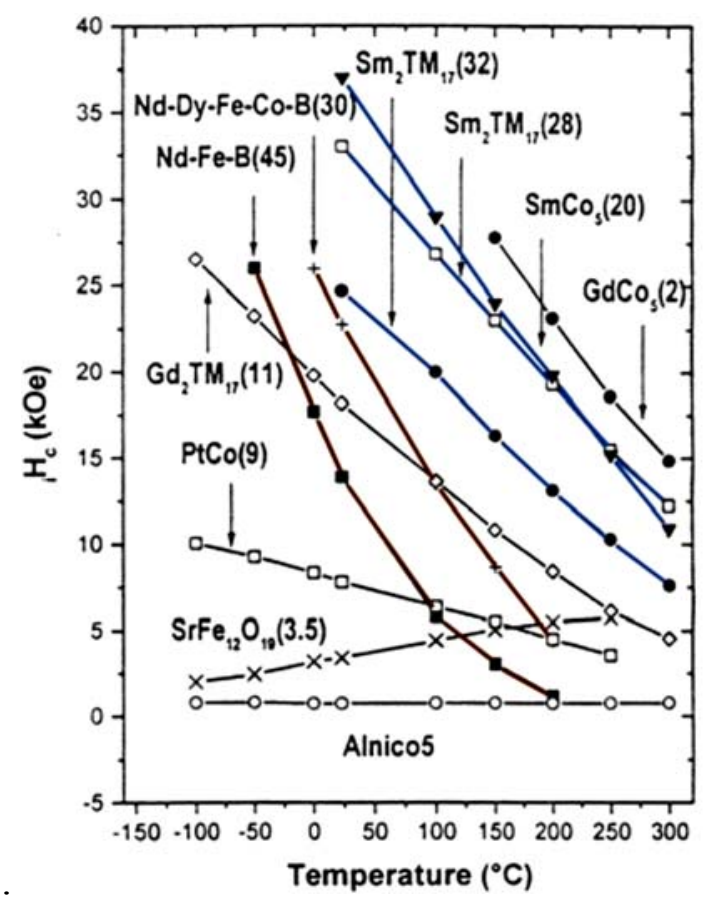

Figura 3.7. Coercitividad de imanes en función de la $T^{\mathrm{a}}$.[40] 
La temperatura de Curie se define como la temperatura de transición a la cual se destruye la ordenación magnética y se pasa de un material con comportamiento ferromagnético a paramagnético, degradándose de forma irreversible las propiedades magnéticas.

En la Tabla 3-2 se incluyen los datos habituales anteriores de los imanes junto con la máxima de trabajo que nos fija la máxima $t^{\mathrm{a}}$ a la que se puede llegar a trabajar sin ver alterado ningún parámetro mecánico o magnético cuando se retorne a la temperatura ambiente.

Tabla 3-2. Coeficientes y temperaturas típicos de materiales magnéticos

\begin{tabular}{|c|c|c|c|c|}
\hline Material & $\alpha\left(\% /{ }^{\circ} \mathrm{C}\right) \operatorname{de} B_{r}$ & $\beta\left(\% /{ }^{\circ} \mathrm{C}\right)$ de $H_{c}$ & $T^{a}$ de Curie $\left({ }^{\circ} \mathrm{C}\right)$ & $T^{a} \operatorname{Máx}\left({ }^{\circ} \mathrm{C}\right)$ \\
\hline Neodimio & $-0,11$ & $-0,6$ & 320 & 180 \\
\hline Samario-Cobalto & $-0,03$ & $-0,3$ & 800 & 300 \\
\hline Alnico & $-0,02$ & $+0,01$ & 760 & 550 \\
\hline Ferrita & $-0,18$ & $+0,30$ & 450 & 250 \\
\hline
\end{tabular}

\section{Producto energía vs. Temperatura}

Otro de los parámetros claves de los materiales magnéticos es la variación que presenta el producto de energía $\mathrm{BH}_{\max }$ de los materiales con la temperatura. Los imanes de SmCo son más estables que los $\mathrm{NdFeB}$, que presentan una caída brusca a partir de $150^{\circ} \mathrm{C}$.

Esto ha reabierto la posibilidad de hacer rentables imanes como el SmCo, porque al disminuir tanto el valor de $\mathrm{BH}_{\max }$ con la temperatura, la única manera de mantenerlo es elevar la proporción de disprosio o terbio que se añade, lo que dispara el precio enormemente.

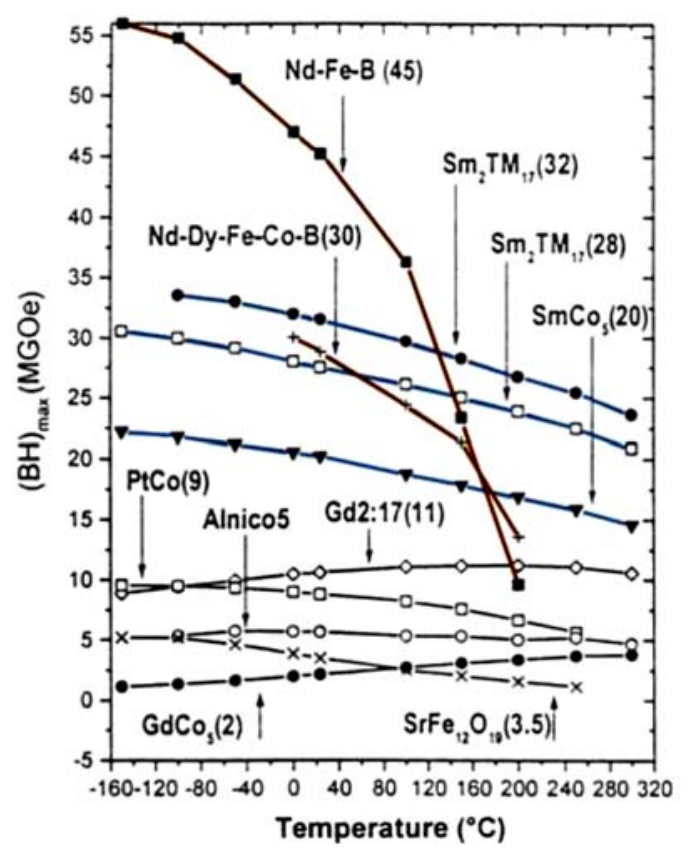

Figura 3.8. Producto $\mathrm{BH}_{\max }$ en función de la temperatura.[40]

Independientemente del parámetro que se analice lo que es evidente es que a partir de $120^{\circ} \mathrm{C}$ los imanes permanentes basados en neodimio presentan un pésimo comportamiento ante la temperatura. 


\subsubsection{Resumen de características magnéticas}

En resumen, las propiedades que se requieren de un material magnético son:

- Elevada coercitividad $H_{c}$ y remanencia $B_{r}$.

- Alta energía magnética $B H_{\max }$.

- Soportar bien altas temperaturas de operación.

- Alto poder de corrosión

- Obtener materiales que presenten una alta anisotropía.

Los objetivos finales que se persiguen para los imanes son:

- Aumentar la temperatura de funcionamiento entre 150 y $200{ }^{\circ} \mathrm{C}$ y aumentar el tiempo de vida por encima de los 15 años.

- Alcanzar los objetivos fijados en la Tabla 3-1.

- Favorecer el aumento el rendimiento de los motores por encima del 93\%. 


\subsection{Clasificación de materiales magnéticos}

\subsubsection{Ferritas [41]}

Las ferritas son materiales cerámicos ferromagnéticos compuestos por hierro, cobalto y bario con buenas propiedades magnéticas, entre otras alta permeabilidad magnética. Tradicionalmente se han utilizado para la construcción de núcleos magnéticos e imanes permanentes.

Si analizamos la producción por toneladas incluso actualmente constituyen con diferencia la mayor producción de imanes permanentes. Los minerales son baratos en mina pero presentan bajos valores de producto de energía de tal forma que actualmente sea imposible su aplicación en las aplicaciones de interés.

Ya en los años 50 se probó a hacer sustituciones con estroncio y bario en los óxidos de ferrita, pero sin mucho éxito Al contrario que en los imanes de tierras raras, en las ferritas la coercitividad aumenta con la temperatura, con el valor de $\beta$ más positivo. En la Figura 3.9 se muestran las curvas magnéticas típicas de una Ferrita.
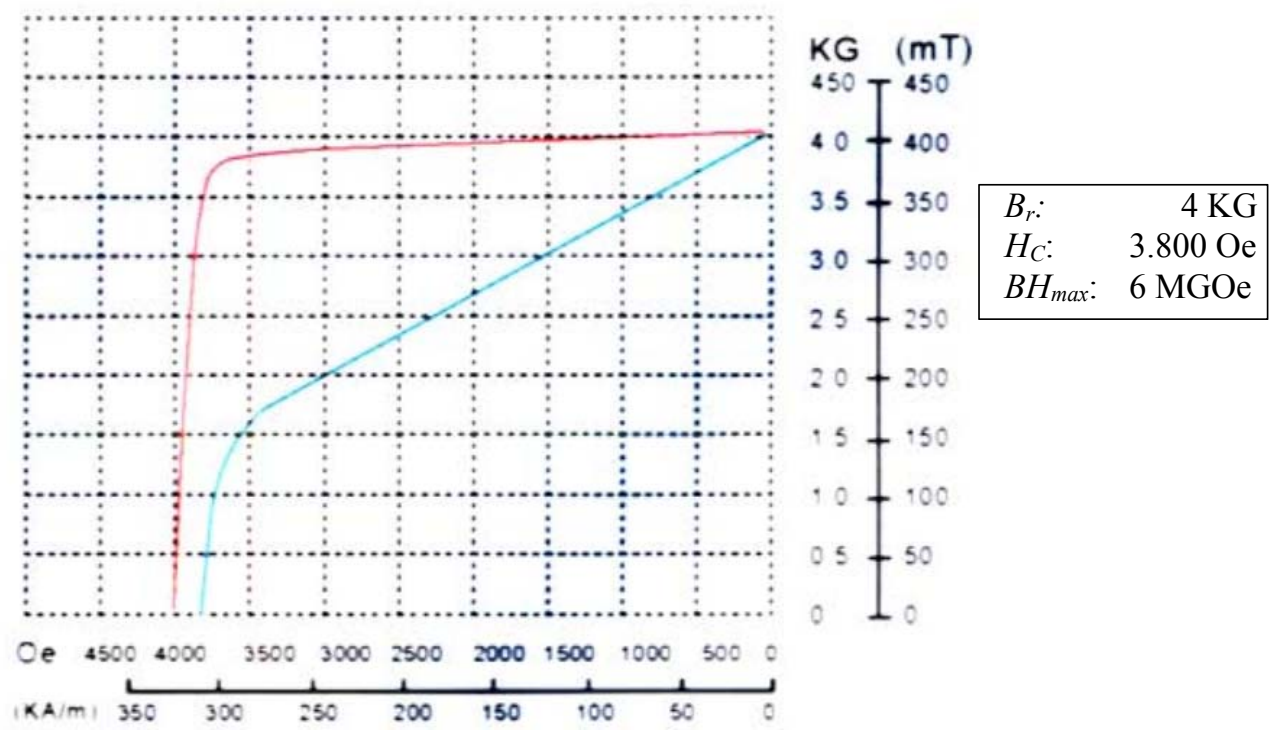

Figura 3.9. Curvas $J$ vs. $H$ (rojo) y $B$ vs. $H$ (azul) de una ferrita.[39]

\subsubsection{Alnicos [42, 43]}

Estos imanes permanentes forman una familia de aleaciones cuyos componentes principales son: el hierro, el aluminio, el níquel y el cobalto, aunque pueden estar incluidos en cantidades menores otros elementos como cobre y titanio.

Se emplearon mucho en los años 1940, pero su desarrollo ha quedado en espera desde entonces al ser reemplazado por otros como $\mathrm{NdFeB}$ con un producto de energía de unas cinco veces superior a temperatura ambiente. Desde entonces no han sufrido ningún desarrollo. En la Figura 3.10 se muestras las curvas de magnetización típicas de un Alnico. 


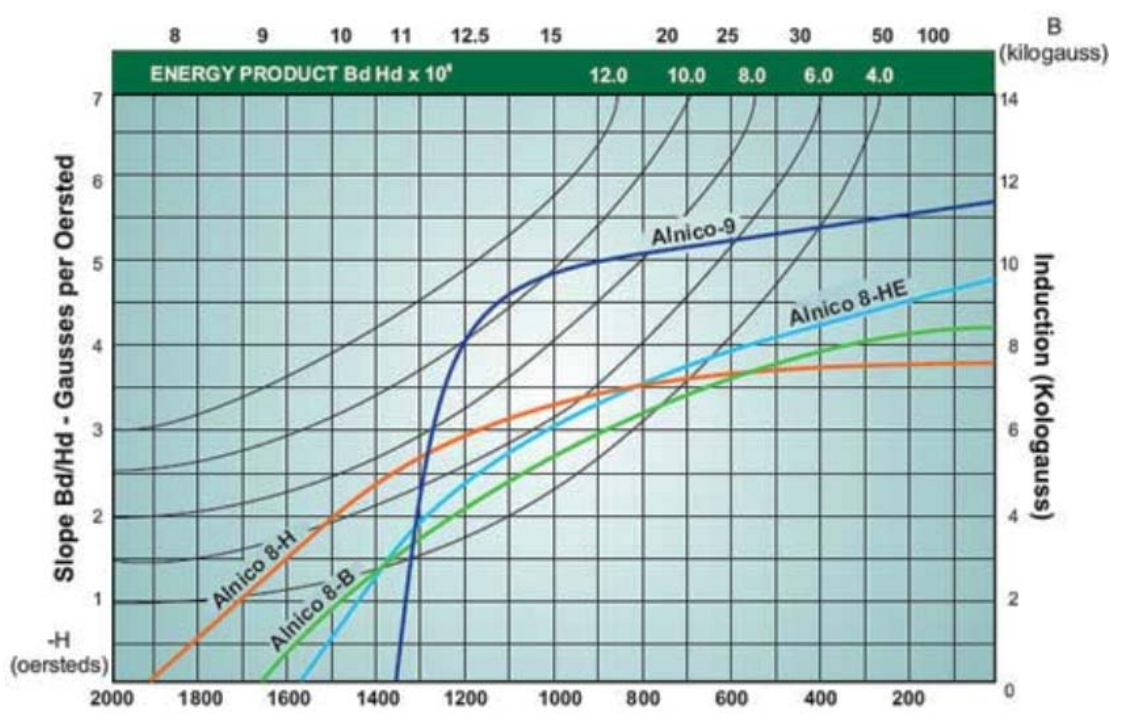

\begin{tabular}{|lc|}
\hline$B_{r:}:$ & $11,4 \mathrm{KG}$ \\
$H_{C}:$ & $1350 \mathrm{Oe}$ \\
$B H_{\max }:$ & $10,5 \mathrm{MGOe}$ \\
\hline
\end{tabular}

Figura 3.10. Curvas B vs. H de diversos grados de comerciales Alnico.[39]

Los grados de estos materiales varían con el contenido de cobalto, que va de cero (Alnico 3) a 40\% (Alnico 8).

Tabla 3-3. Grados de los materiales Alnico

\begin{tabular}{lrrrr}
\hline & $\begin{array}{c}\text { Alnico } \\
\text { 5-7 }\end{array}$ & Alnico 8 & Alnico 9 & Alnico 8H \\
\hline $\boldsymbol{B}_{\boldsymbol{r}}(\mathbf{K G})$ & 13,5 & 7,4 & 11,4 & 6,7 \\
$\boldsymbol{H}_{\boldsymbol{c i}}(\mathbf{O e})$ & 740 & 1.690 & 1.350 & 2.020 \\
$\boldsymbol{B}_{\max }$ (MGOe) & 7,5 & 4 & 10,5 & 4,5 \\
\hline
\end{tabular}

Los grados inferiores $(2,3$ y 4) son isotrópicos con propiedades magnéticas iguales en todas las direcciones, su producción es relativamente baja. Los grados anisotrópicas (Alnico 5, 6, 8 y 9) están diseñados para producir un alto rendimiento magnético en una dirección especificada. Las aleaciones anisótropas en general tienen una mayor capacidad magnética. La orientación se consigue durante el tratamiento térmico, mediante el enfriamiento del producto a partir de una temperatura de aproximadamente $1.093^{\circ} \mathrm{C}$ a una velocidad controlada, dentro de un campo magnético que se ajusta a la dirección preferida de la magnetización, de este modo se obtiene un material de precipitación que está formado por hierro y cobalto precipitados en una matriz rica en Ni y Al. El esquema de la Figura 3.11 muestra los pasos.

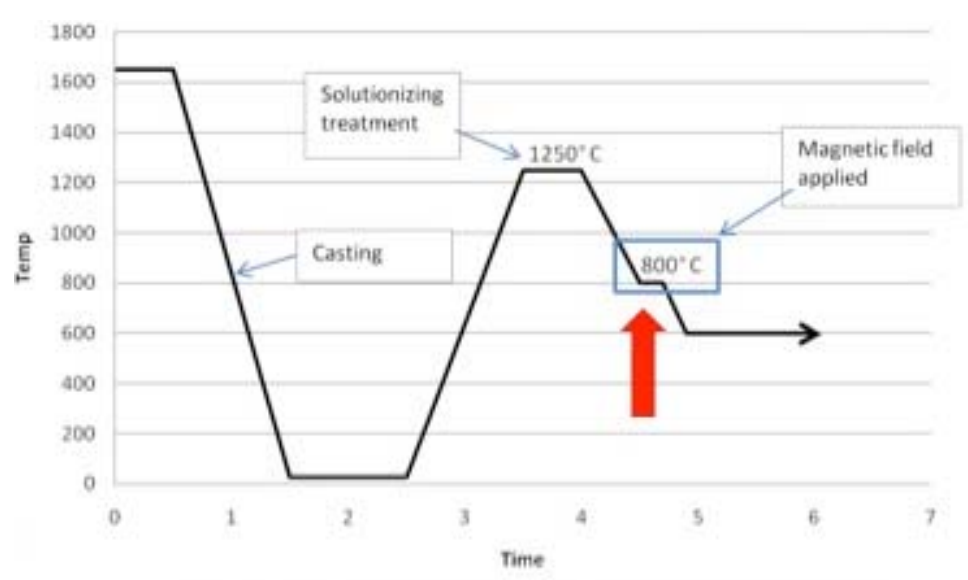

Figura 3.11. Tratamiento térmico típico de los Alnico.[41] 
Los alnicos presentan buena resistencia a la corrosión, tienen alta remanencia y podrían igualar a los imanes de tierras raras si se mejorara su valor de $H_{C}$. Su fragilidad y alto punto de fusión son el resultado de la fuerte tendencia hacia el orden, debido a los enlaces intermetálicos. Son también uno de los imanes más estables si se manejan adecuadamente.

Sus componentes se consiguen fácilmente, y su precio es relativamente bajo (alrededor de $44 \$ / \mathrm{kg}$ ) a pesar del alto coste del cobalto.

Los imanes de Alnico tienen un excelente comportamiento a altas temperaturas, como se muestra en la Figura 3.12, y temperaturas de Curie más altas que cualquier material magnético (alrededor de $800{ }^{\circ} \mathrm{C}$ ), aunque su temperatura máxima de trabajo se limita normalmente a unos $538{ }^{\circ} \mathrm{C}$. Son los únicos imanes que tienen magnetismo útil incluso cuando se calientan al rojo vivo.

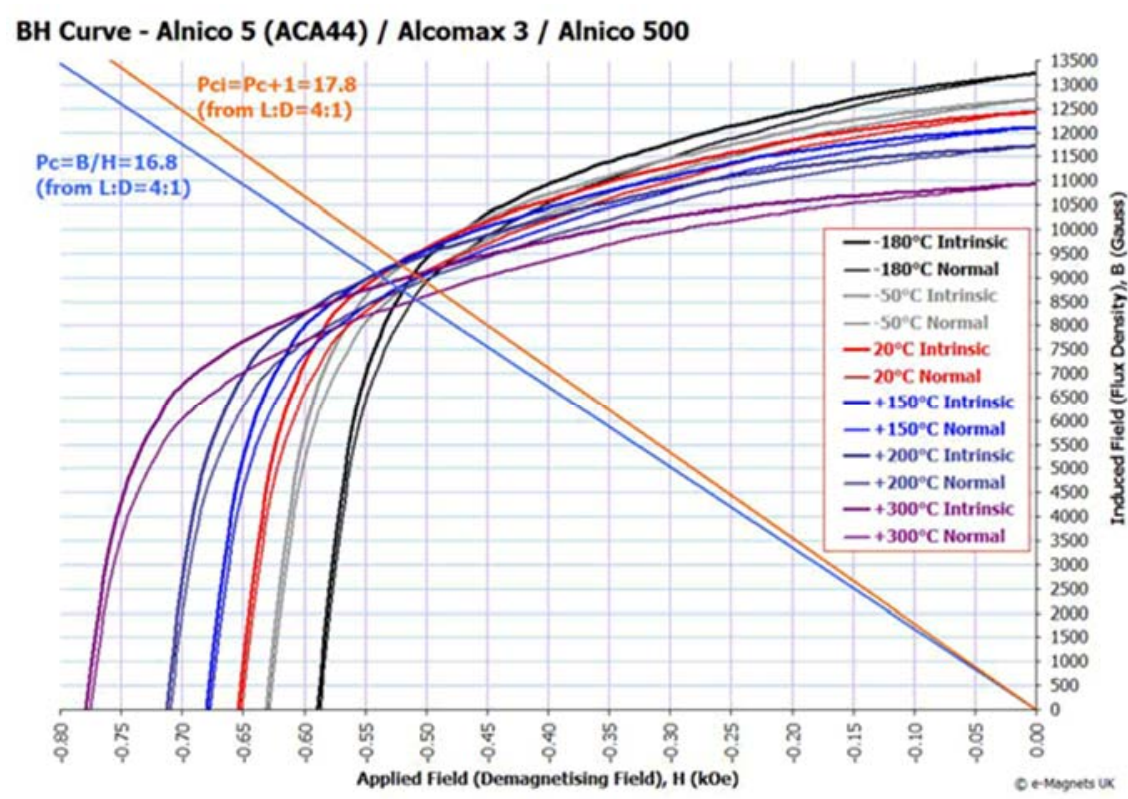

Figura 3.12. Curvas de magnetización de maetriales Alnico. [43]

Por estas propiedades los imanes de Alnico han sido seleccionados por Ames Laboratory como un buen candidato para obtener imanes sin tierras raras para todas aquellas aplicaciones que requieren temperaturas por encima de los $180^{\circ}$.

Se estudian dos mecanismos diferenciados para potenciar la coercitividad:

- El anclaje (pinning). El movimiento de las paredes del dominio se ha relacionado con la existencia de no-homogeneidades magnéticas dentro de los granos, actuando estas como centros de anclaje para el movimiento de dichas paredes y aumentando $H_{c}$. Estos centros de anclaje son más eficaces cuando el área entera de la pared está involucrada, como ocurre en el caso de las precipitaciones.

- Cuando el movimiento de la pared del dominio cruza los límites de grano, lo sitúa en oposición al resto de tal modo que su valor de coercitividad se reduce. Para disminuir este problema se trabaja en las dislocaciones e inclusiones de material no magnético, que desplazan dichas paredes. Es deseable tener un movimiento libre de dominio dentro de las estructuras del grano para mejorar la coercitividad.

Los Laboratorios Ames han encontrado una correlación directa entre el tamaño de grano y este movimiento de las paredes de dominio. En la Figura 3.13 se aprecian las precipitaciones de Cu entre 
las losas de Fe-Co con una mejora importante en la anisotropía y en el valor de $H_{c}$ al favorecer los 2 mecanismos anteriores.

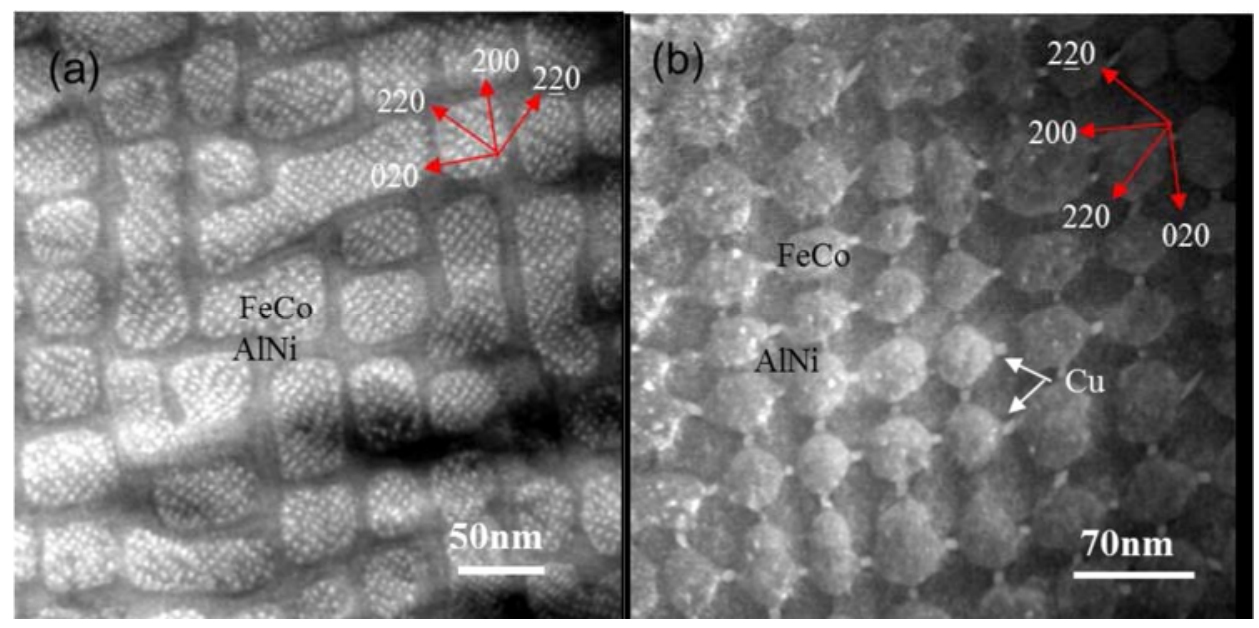

Figura 3.13. Interfase en Alnico 5-7 y 8-9.[41]

Los análisis a nivel de micro estructura demuestran que del contenido actual de Co se desaprovecha la mitad de la composición, porque es atrapado en la etapa de la matriz y puede llegar incluso a degradar las características magnéticas. Si se elimina el exceso de cobalto innecesario se reduce hasta un $20 \%$ su costo[44].

Tradicionalmente las piezas de Alnico se producen mediante procesos de moldeado o sinterización. A nivel de laboratorio se está produciendo gas atomizado de alnico denominado $8 \mathrm{H}$ con resultados positivos. Se intenta generar granos finos isotrópicos. En la última columna de la Tabla 3-3 están incluidas sus propiedades, mejorando considerablemente su coercitividad y energía, disminuyendo un poco la remanencia.

\subsubsection{Resumen de características de Alnico}

- Materia prima abundante y barata.

- Los imanes fabricados de menor coste.

- La tecnología de fabricación está bien establecida.

- Propiedades magnéticas peores que los materiales de tierras raras

- Excelente rendimiento a alta temperatura con grados disponibles para su uso a $250{ }^{\circ} \mathrm{C}$.

- Mal rendimiento a baja temperatura, (en general, a $-40{ }^{\circ} \mathrm{C}$ )

- Resistencia a la corrosión es excepcional

- China es el fabricante y proveedor de los imanes de ferrita más grande del mundo.

\subsubsection{Samario-Cobalto [45]}

Estos imanes fueron desarrollados a principio de la década de 1970. Están constituidos por una aleación de hierro, cobalto y una tierra rara ligera: el samario. Son de manera general el segundo tipo más fuerte de imanes (15 y 30 MGOe), pero menos fuertes que los imanes de neodimio, en cambio 
tienen mayores temperaturas de trabajo $\left(300{ }^{\circ} \mathrm{C}\right)$ y relativamente grandes coercitividades, que son ventajas insustituibles. Son frágiles, y propensos a agrietarse pero en cambio no tienen problemas de corrosión. Los valores de los coeficientes de temperatura $\alpha$ y $\beta$ son inmejorables.

El proceso de fabricación incluye los siguientes pasos el material aleado se muele hasta obtener un polvo fino, este se alinea mediante un campo magnético externo. La pieza se sinteriza entonces a una temperatura elevada, seguido de otro tratamiento térmico para la mejora de las propiedades magnéticas. El coste de estos imanes es elevado por los procesos de refinamiento, pero especialmente por el coste de los productos de las minas

Los precios rondan $180 \$ / \mathrm{kg}$, cada vez más próximos a los $200 \$ / \mathrm{kg}$ de los de Neodimio.

Hay dos familias de materiales de SmCo: La serie SmCo 5 ofrece una fácil magnetización en campos moderados y la mejor resistencia a la corrosión de todos los imanes de tierras raras. Los imanes de la otra serie, $\mathrm{Sm}_{2} \mathrm{Co}_{17}$, muestran el rendimiento magnético más alta a temperaturas elevadas. Se pueden obtener mayoritariamente sinterizados y también aunque en menor cantidad como aglomerados. La Figura 3.14 muestra los valores típicos de magnetización de los SmCo.

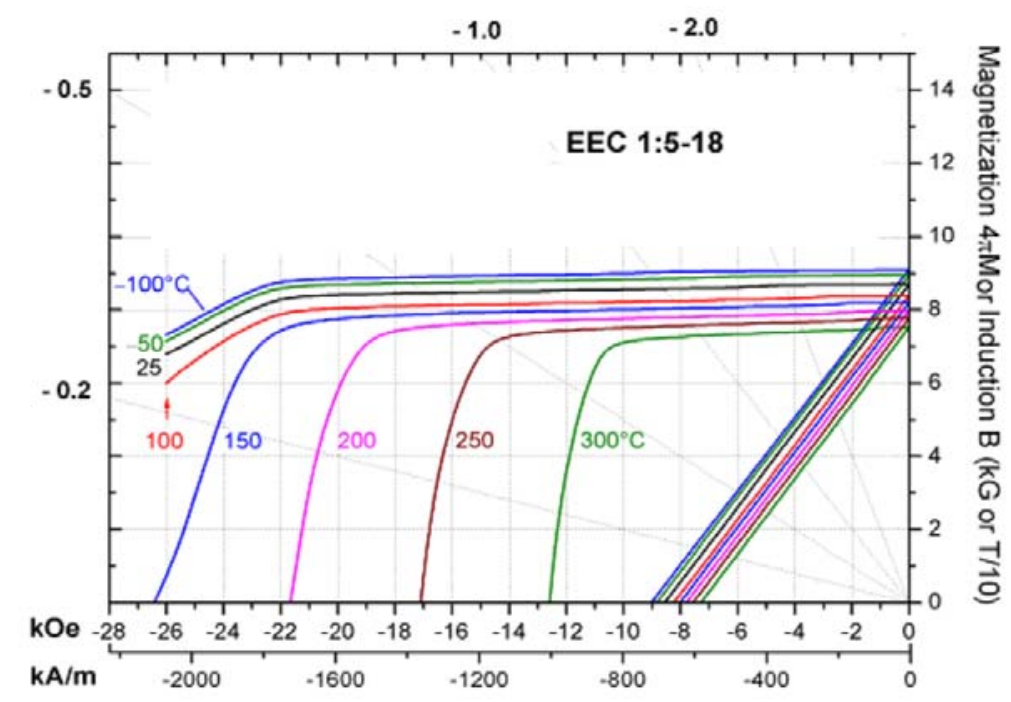

\begin{tabular}{|lc|}
\hline$B_{r}:$ & $8,71 \mathrm{KG}$ \\
$H_{C}:$ & $8.550 \mathrm{Oe}$ \\
$B H_{\max }:$ & $35,3 \mathrm{MGOe}$ \\
\hline
\end{tabular}

Figura 3.14. Curvas de magnetización de SmCo.[46]

Debido al elevado coste del cobalto, se está sustituyendo éste por otros metales como Cobre, Zirconio, hierro y tulio. Con la sustitución de gadolinio por samario se mantiene el flujo prácticamente constante entre -40 y $150{ }^{\circ} \mathrm{C}$. Una de las variaciones que más éxito ha tenido ha sido $\mathrm{SmFeN}$, el nitrógeno tiene una función parecida al hidrogeno, el fino polvo solo es válido para formar aglomerados. En la Figura 3.15 se muestra una comparativa de las curvas de SmCo (26HE) y de $\mathrm{NdFeB}(\mathrm{L} 30 \mathrm{EHT})$ para 20 y $220^{\circ} \mathrm{C}$. 


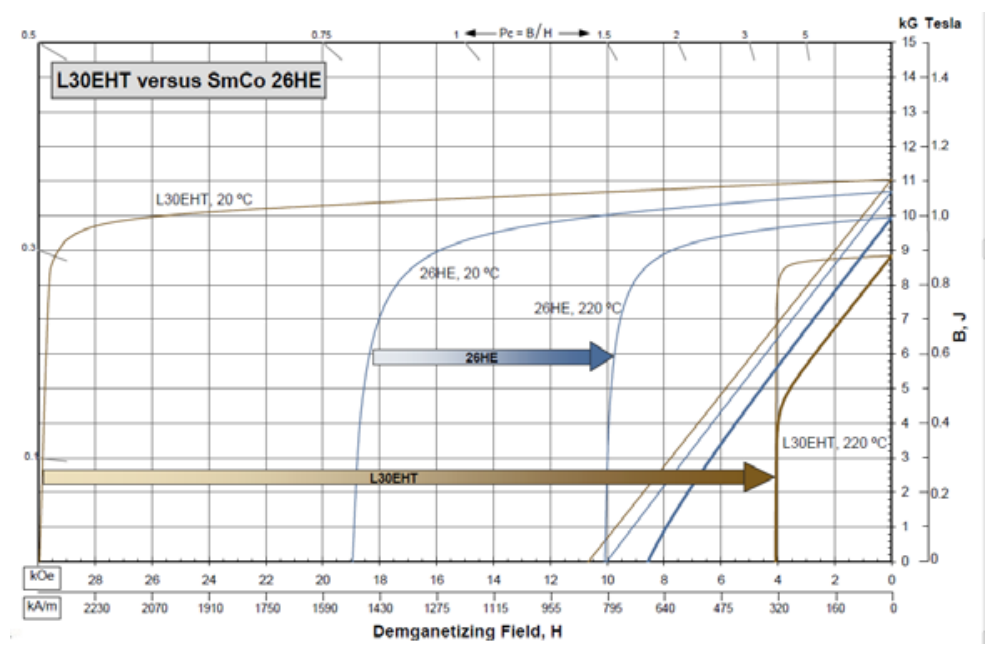

Figura 3.15. Comparación entre imanes NdFeB y SmCo.[47]

\subsubsection{Resumen de características de SmCo}

Como resumen de las propiedades de los imanes SmCo podemos decir:

- Presentan aproximadamente cinco veces el valor de energía que los alnicos y algo menos que los de Neodimio para el mismo volumen.

- Materia prima excesivamente cara.

- Los procesos de fabricación también son costosos.

- Excelente resistencia a la corrosión.

- Son ideales para aplicaciones en miniatura.

\subsubsection{Neodimio-Hierro-Boro $[44,48]$}

Este material se obtuvo simultáneamente a través de dos rutas de procesamiento separadas: Una basada en la sinterización de polvo fue desarrollado por Sagawa en Sumitomo Special Metals Research Laboratories (Hitachi) de Japón y la otra con enfriamiento rápido y aglomerante comercializado por General Motors de U.SA (Magnequench) en 1984. La ventaja de esta aleación fue que sus principales componentes, $\mathrm{Fe}$ y $\mathrm{Nd}$, eran fáciles de obtener en mina y tenían reservas más abundantes que las de los imanes de tipo SmCo, permitiendo la reducción significativa de costos de materia prima.

La mezcla de tierras raras con metales de transición forma compuestos intermetálicos que permiten valores elevados de anisotropía, y por tanto, productos elevados de energía. Son, con diferencia, los imanes más potentes conocidos hasta el momento. Con esta mezcla se combinan y equilibran las características de ambos materiales (Tabla 3-4), como muestra la Figura 3.16. 


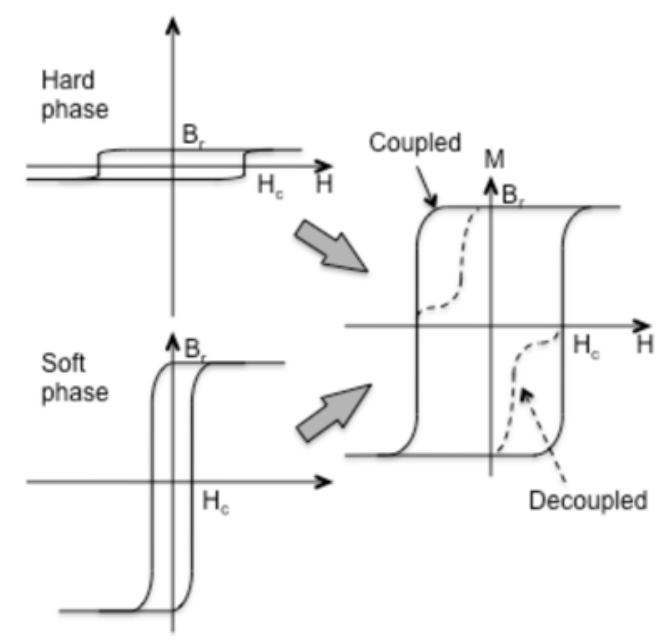

Figura 3.16. Combinación de las fases Fe y Nd.[44]

Tabla 3-4. Características de los componentes NdFeB

\begin{tabular}{cccc}
\hline Material & Función & Propiedad deseada & Debilidad \\
\hline $\mathrm{Nd}$ & Fase dura & Alta coercitividad & Baja Saturación \\
$\mathrm{Fe}$ & Fase blanda & Alta Saturación & Baja Coercitividad \\
\hline
\end{tabular}

El principal inconveniente que presentan es su dependencia con la temperatura, con un valor de temperatura de Curie de tan solo $312^{\circ} \mathrm{C}$ y una temperatura máxima de trabajo de 125 a $150{ }^{\circ} \mathrm{C}$. Otro de los problemas que presentan es la baja resistencia a la corrosión, especialmente cuando las condiciones de temperatura y humedad son elevadas. Necesitan, por tanto, una cubierta protectora. Para ello existen varias posibilidades en el mercado, aunque lo más frecuente es usar plata, níquel o incluso el recubrimiento con una capa epoxi.

Los imanes convencionales se componen de tres fases: a) $\mathrm{Nd}_{2} \mathrm{Fe}_{14} \mathrm{~B}$ (composición estequiométrica), b) fase Nd-rica y c) B-rica. La combinación en la proporción adecuada entre las tres fases junto con las mejoras en las técnicas de fabricación es lo que proporciona tan buenas características.

Las fases ricas en $\mathrm{Nd}$ y su distribución son críticas para el $H_{C}$ de los imanes, alcanzando actualmente sus valores sólo el 20 a 30\% del máximo teórico.[40]

El mecanismo de coercitividad de estos imanes depende de la fijación de dominios inversos. La fase rica en $\mathrm{Nd}$ es la responsable de reforzar las paredes de estos dominios. Si se analizara el diagrama de fases, el neodimio enriquecido se comporta como fase líquida por encima de los $665^{\circ} \mathrm{C}$, mejorando la densificación durante el proceso de sinterizado y limpiando de impurezas la superficie de los dominios $\mathrm{y}$, por tanto, disminuyendo el número de nucleaciones

Esta fase Nd-rica, al no ser magnética, precipita al Fe a la superficie, con el inconveniente de facilitar la oxidación. Por todo ello la fracción de enriquecimiento en $\mathrm{Nd}$, donde se produce la nucleación de los dominios inversos, ha de estar proporcionada frente a la cantidad de Fe precipitado. A medida que se produce la formación de óxido de $\mathrm{Nd}$ decrece la capa enriquecida en el límite del grano y disminuye rápidamente el valor de $H_{C}$. 
La adición de disprosio mejora en gran manera la coercitividad, ya que su momento magnético se acopla en antiparalelo con el de hierro, siendo de nuevo necesario que la proporción sea la apropiada para que no se produzca un efecto adverso de disminución de coercitividad.

Han pasado 25 años desde el desarrollo de los primeros NdFeB y aún actualmente son muchas las líneas de investigación y desarrollo abiertas debido al interés y a la fuerte demanda que despiertan.

\subsubsection{Resumen de características}

Las características que presenta este tipo de material se resumen

- Los productos de energía más elevados

- Existen suficientes reservas probadas

- China es ahora el fabricante dominante y proveedor de imanes de NdFeB.

- Aplicaciones de alta temperatura requieren un compromiso en materia de energía.

- Tendencia a la corrosión. Requiere revestimientos protectores.

\subsubsection{Sinterizados o de densidad completa [21, 49-51]}

Se denominan así por el proceso de fabricación que más adelante se detalla. Todos los imanes sinterizados son anisotrópicos lo que favorece sus altos productos de energía alcanzando valores de 52 MGOe. Es por este motivo el que sean los elegidos para la construcción de motores eléctricos.

Actualmente se producen entre 45.000 y 50.000 toneladas de imanes de $\mathrm{Nd}$ sinterizados cada año. Desde 2011 China produce más de $95 \%$ de los elementos de tierras raras, y produce $76 \%$ de los imanes de tierras raras del mundo.

Se muestran en la Figura 3.17 las curvas comerciales de magnetización del N38SH superpuestas con las de un ALNICO (en azul) y de una ferrita (en rojo), representándolas en la misma escala para poder compararlas.

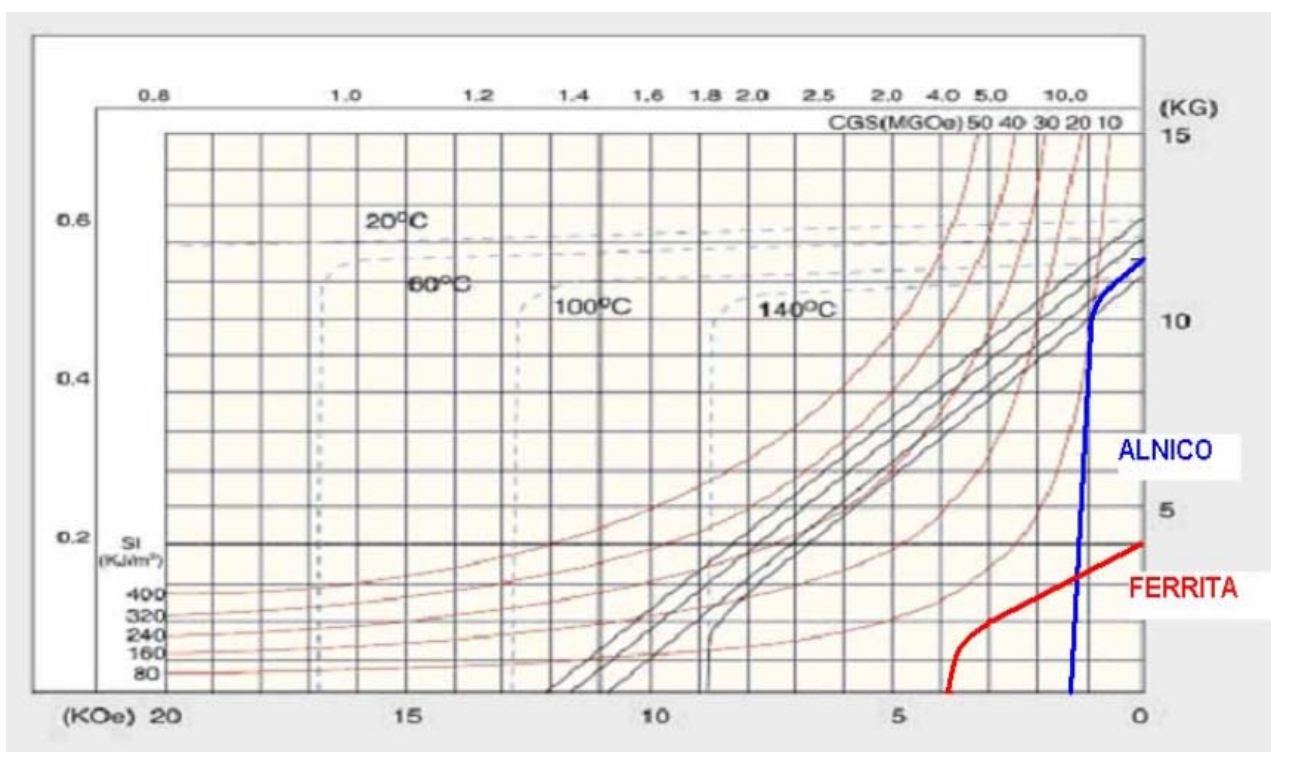

Figura 3.17. Curvas de desmagnetización típica de N38SH y comparativa con Ferrita y Alnico.[43] 
Como se observa en la Figura 3.18, los valores de energía disminuyen rápidamente cuando se eleva la temperatura y se establecen una clasificación estándar que relaciona el compromiso entre energía y la máxima temperatura de trabajo.

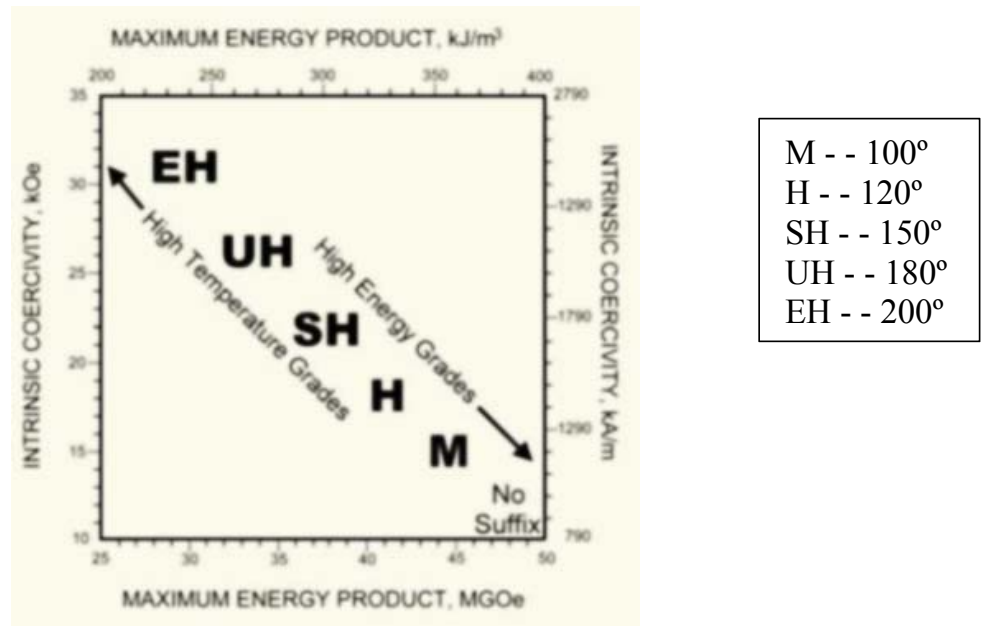

Figura 3.18. Clasificación comercial de neodimio.[37]

En el material tomado como ejemplo de la Figura 3.17, la letra $\mathbf{N}$ indica que es $\mathrm{NdFeB}, \mathbf{3 8}$ es el valor de energía y SH la máxima temperatura que soporta, que es $150^{\circ} \mathrm{C}$.

En las simulaciones de los modelos del capítulo 5 se ha utilizado un material magnético $\mathrm{N} 36 \mathrm{H}$, para que sus valores sean más parecidos al aglomerado con el que se compara.

\subsection{Proceso de fabricación}

Los imanes de neodimio sinterizados se preparan fundiendo las materias primas en un horno, colando el material fundido en moldes y enfriándolo para formar lingotes. Luego se produce un polvo extremadamente fino a partir de estos lingotes. Este polvo es sometido más tarde a un proceso de sinterizado en fase líquida por medio del cual las partículas se alinean magnéticamente y se unen entre sí para formar bloques densos, los cuales son tratados térmicamente, cortados con la forma deseada, sometidos a un tratamiento superficial para prevenir la corrosión, y magnetizados.

La tecnología de fabricación de estos imanes está bien establecida (ver Figura 3.19) y los costos del proceso son moderados. Estos son los pasos del proceso esquematizados:

- Fundición de la aleación

- Decrepitación hidrógeno (para hacer la molienda más fácil y efectiva)

- Moler partículas finas (2-3 micras de diámetro)

- Compactación mediante prensado

- Sinterización y recocido

- Rectificado del perímetro de los imanes

- Revestimiento al vacío con Ni y Al.

El aglutinante en estos imanes no supera un 5\% de la composición total y se emplean elastómeros como: caucho nitrilo, polietileno y vinilo. 


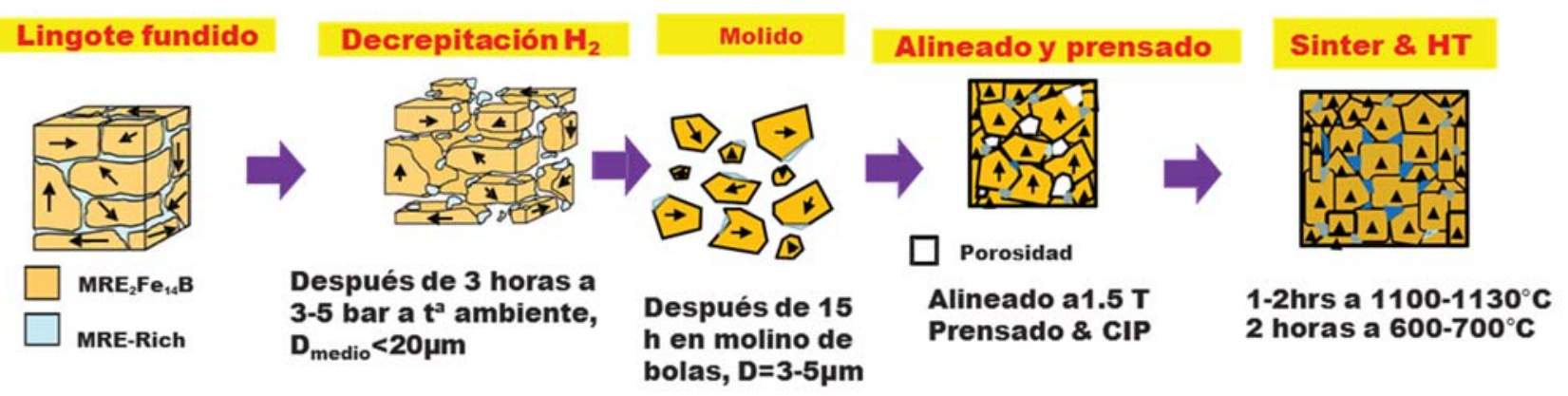

Figura 3.19. Proceso de sinterizado.[52]

\subsection{Mejoras de sinterizados}

Las variaciones que han experimentado los imanes tienen que ver con dos aspectos indicados en la Figura 3.20:

- El que se refiere a los procesos de fabricación que sufre el material hasta la obtención última de los imanes. Dado que el control de la microestructura y de la textura es crítico en la formación de este tipo de imanes, se trata de controlar el tamaño del grano, la dirección de crecimiento del mismo y disminuir la aspereza del grano durante el recocido.

- El otro aspecto que analizaremos son las variaciones químicas que ha sufrido la fórmula base de NdFeB. Una de las primeras posibilidades que se ha tenido en cuenta es sustituir el neodimio por una terna de Neodimio -Disprosio-Itrio.

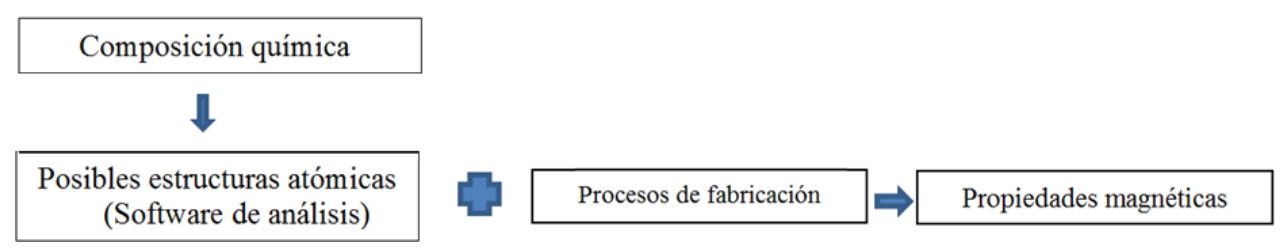

Figura 3.20. Aspectos de mejora en NdFeB.

\subsection{Variaciones en los procesos de fabricación}

\section{a. Proceso de sinterizado}

Una de las mejoras más fáciles de adoptar se refiere al proceso combinado de sinterizado y alineado, con diversas combinaciones posibles.

El método más básico incorpora un campo de alineación axial como se muestra en la Figura 3.21.a. Una simple bobina toroidal rodea el recipiente para proporcionar un campo relativamente uniforme dentro de él, sin afectar a la acción de los punzones superior e inferior de la prensa. Este método es adecuado para el uso de recipientes simples que produzcan bloques rectangulares, siendo el método más común, barato y fiable. 


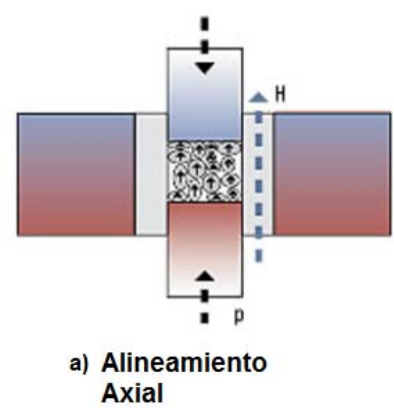

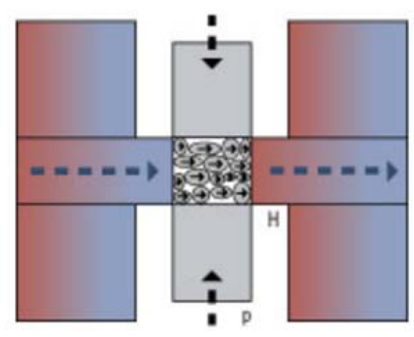

b) Alineamiento transversal

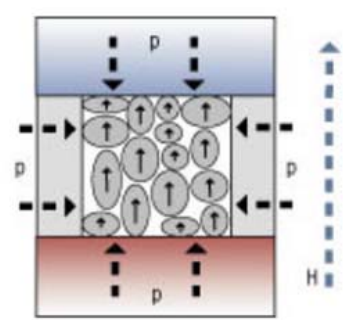

c) Prensado isostático con polvo pre-alineado

Figura 3.21. Posibilidades de prensado.[41]

Se podría lograr una mejor alineación y/o densificación magnética utilizando los siguientes métodos b) y c), que proporcionan aproximadamente el $6 \%$ mayor remanencia para cualquier aleación dada en comparación con los imanes anteriores.

1. La prensa de estampar utiliza un campo de alineación transversal creado por un par de bobinas toroidales externos como se muestra en la Figura 3.21.b. Esto permite una mejor saturación de la cavidad de la matriz.

2. La prensa isostática se ilustra en la Figura 3.21.c logra mejor densificación del polvo, minimizando las cavidades flexibles. Se ha aplicado un campo de pre-alineado en la misma dirección que el primero.

Ninguno de estos dos métodos puede producir bloques rectangulares relativamente delgados adecuados para motores IPM, por lo que habría que mecanizarlos posteriormente para tener partes más delgadas.

\section{b.- HD (Hidrogenación - Desorción)}

Cuando se inyecta con hidrogeno un lingote de imán los metales de transición y las tierras raras se vuelven frágiles después de su absorción. Al calentarlo se produce una gran expansión de volumen de la retícula del metal que con la ebullición facilita la rotura y permite ser molidos en forma de polvo. Con este método se refina el tamaño del grano de $100-500 \mu \mathrm{m}$ a $0,3 \mu \mathrm{m}$. Este procedimiento en ocasiones se desarrolla en una atmosfera inerte habitualmente de argón para evitar la oxidación.

La fase rica en neodimio facilita la absorción de hidrogeno a temperatura ambiente, en cambio cuando se emplea la fase estequiométrica es necesario calentar hasta los $150^{\circ} \mathrm{C}$.

Aunque esta técnica ha mejorado algunos de los parámetros magnéticos, se le pueden achacar también inconvenientes como el empeoramiento de la estabilidad térmica y la complejidad propia del proceso, con reacciones exotérmicas y endotérmicas, lo que ha limitado en parte la expansión comercial de esta técnica. A principios del 2000 Aichi Steel retomó este proceso, mejorándolo y consiguiendo uno de los polvos aglomerados de mayor energía.

\section{c.- Incorporación de Dy y sustitución por DyF3}

Para poder soportar las temperaturas de funcionamiento de estos motores sin que disminuya drásticamente su valor de coercitividad se añade Disprosio, lo que aumenta la anisotropía del material y provoca el aumento la $H_{C}$ y $\beta$ (relación $H / \mathrm{t}^{\mathrm{a}}$ ). 
Actualmente el contenido de disprosio es de un $10 \%$, un valor demasiado elevado dada de la rareza del material, disparándose su precio (el 99,5\% del Dy lo produce China).

La Figura 3.22 muestra como varían las propiedades de los imanes con el porcentaje de Dy y su relación con la clasificación anterior de los materiales.

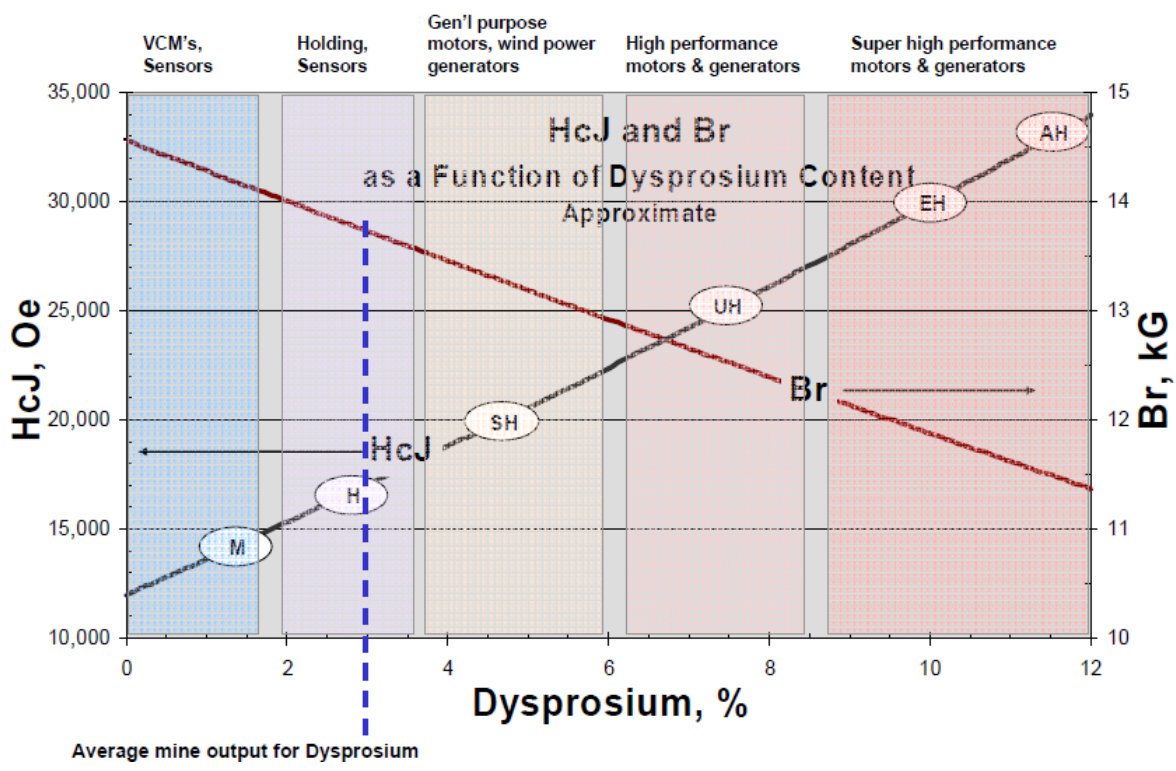

Figura 3.22. Variación de las características magnéticas con la proporción de disprosio.[45]

Inicialmente el Dy se mezclaba molido con los polvos del imán y después se difundía. El método que mejores resultados está proporcionando para disminuir la proporción de Dy es el denominado GBDP (Grain Boundary Difusion Process) con dos posibilidades:

Por Difusion. Se introduce $\mathrm{DyF}_{3}$ en forma de pintura basada en etil-alcohol, se calienta a $900{ }^{\circ} \mathrm{C}$, de esta forma se difunde hacia el interior del imán hasta la las frontera de grano. También se ha probado con tierras raras más pesadas como el terbio en formando óxidos o fluoruros.

Otra versión emplea la tecnología de vacío, con la que se obtiene vapor de metal de Dy para su difusión.

El ahorro de Dy puede alcanzar hasta un $20 \%$.

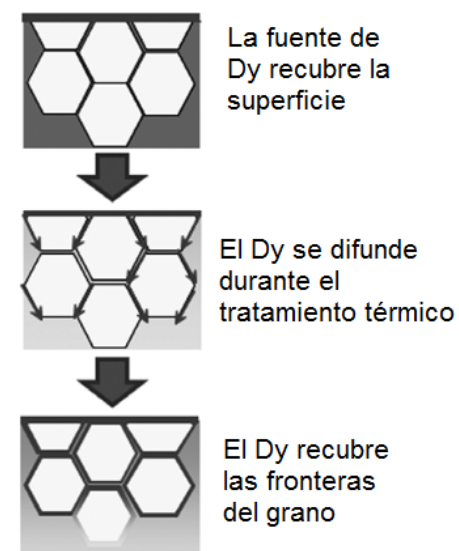

Figura 3.23. Ilustración esquemática de GBDP.[49] 
En la Figura 3.24 puede verse la diferencia de comportamiento entre las modalidades de fabricación. Se observa que los valores de energía son mayores por mezcla pero en cambio la $\beta$ es menor que por difusión.
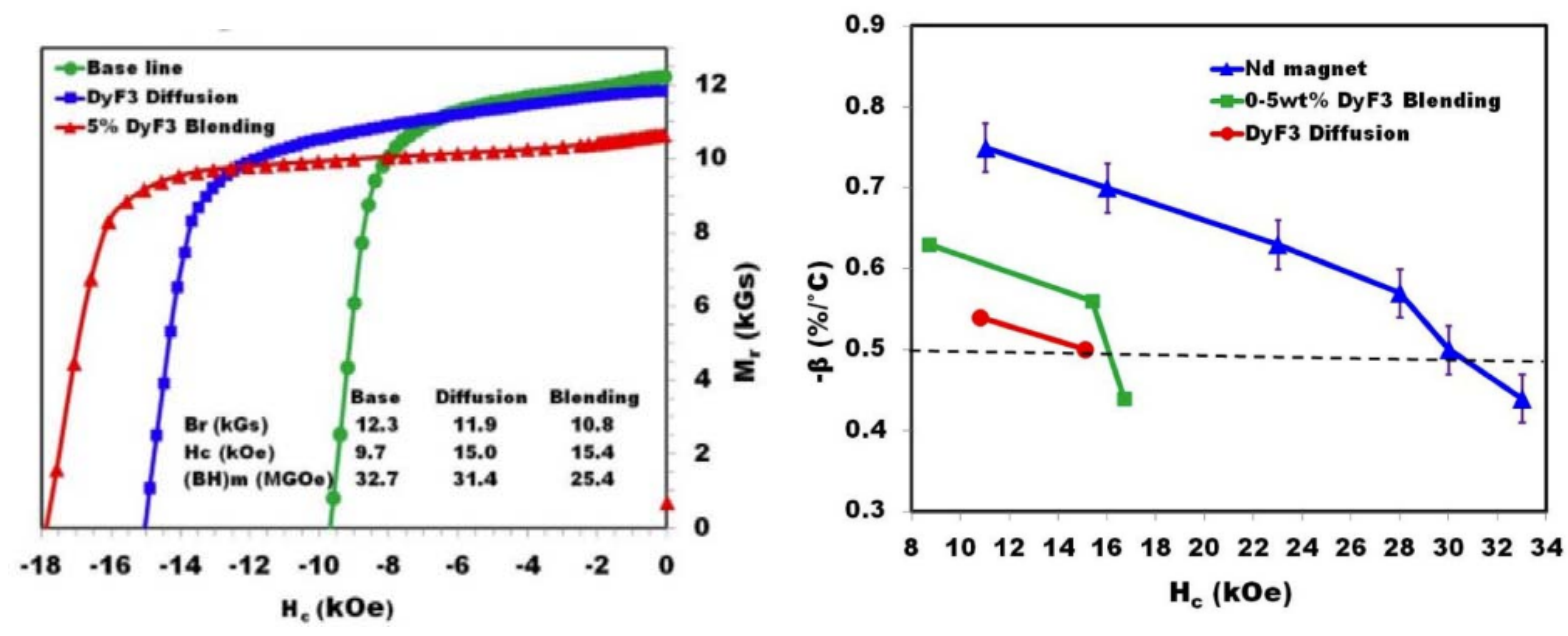

Figura 3.24. Comparativa del procesotradicional-mezcla-difusión.[44]

Otras posibilidades para mejorar $H_{c}$ sin utilizar Dy son:

1.- Refinamiento de grano. Al disminuir el tamaño del grano se disminuye exponencialmente la posibilidad de multidominio (ver Figura 3.25.1).

2.- Control del dominio. El otro método se basa en el recubrimiento de la pared del grano con la fase Nd-rica que elimina los posibles defectos que puedan aparecer en la superficie del mismo, evitando así los dominios en retroceso (ver Figura 3.25.2).

\section{Refinamiento de grano}

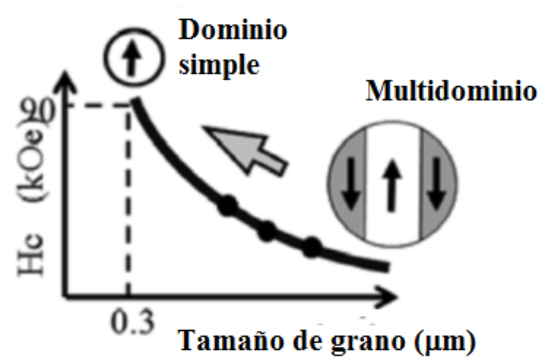

2. Control del dominio

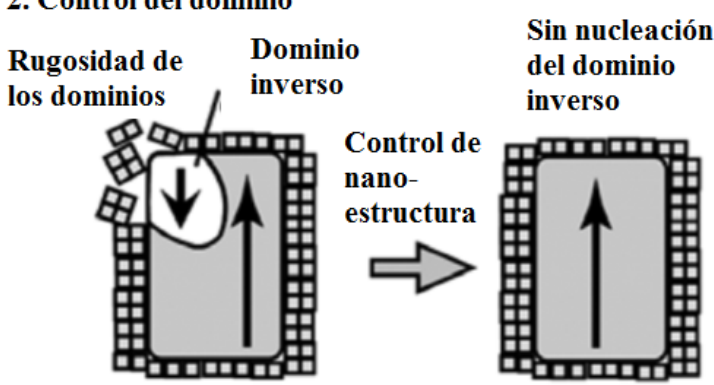

Figura 3.25. Métodos para la mejora de $H_{C}$ en neodimios.[49] 


\subsection{Variaciones de la composición química}

\section{Progreso en los compuestos MRE-2-14-1}

Con el objetivo de mantener los valores magnéticos, especialmente un $B H_{\max }$, adecuados a las temperaturas de operación; se propone una primera modificación con una mezcla de tierras raras MRE-Fe-B $(\mathrm{MRE}=\mathrm{Nd}, \mathrm{Y}, \mathrm{Dy})$ en la proporción adecuada.

La Figura 3.26 muestra la evolución de la remanencia en la gráfica (a) y la coercitividad, energía anisotrópica en la (b). Se observa como la de $\mathrm{Nd}$ presenta la máxima remanencia y en la coercitividad hace máximo el Dy.

Este mix de tierras raras, en los márgenes de temperatura de funcionamiento del motor, mejora la media del parámetro de energía, pero en cambio disminuye a temperatura ambiente. Se emplea también en los aglomerados.
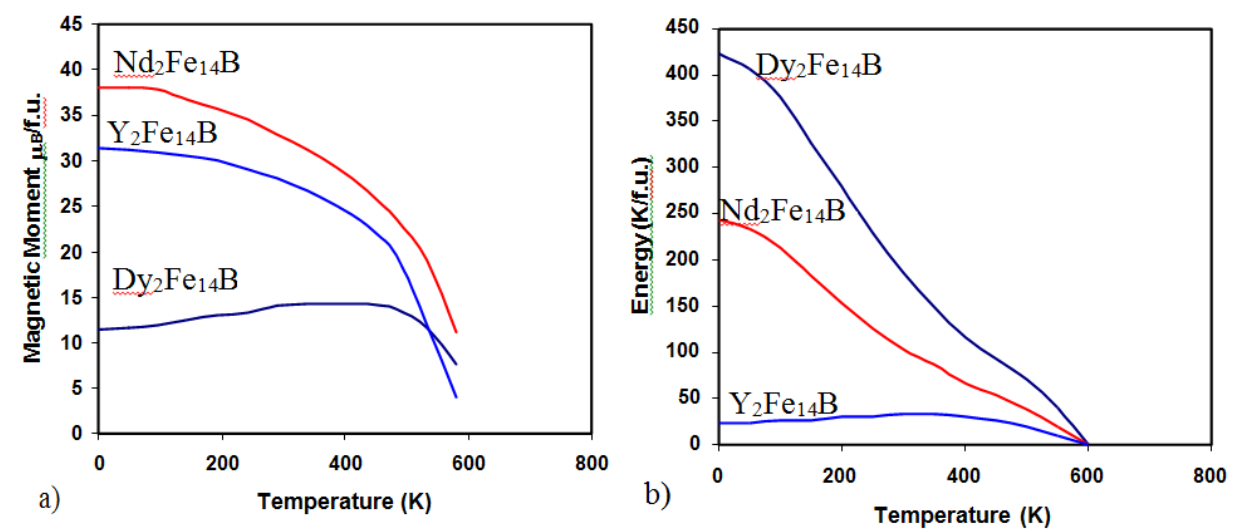

Figura 3.26. a) Momento magnético (remanencia) y b) energía de la isotropía (coercitividad). Dependencia de la temperatura en cada $\mathrm{RE}_{2} \mathrm{Fe}_{14 .}$.B.[53]

El laboratorio AMES también ha probado a variar la composición del Nd, al aumentar mejora $B_{r}$, a costa del valor $H_{c}$, el efecto es el mismo a diferentes valores de la temperatura.

\section{El cobalto}

Con pequeñas sustituciones de Co por Fe se mejora sustancialmente la $\mathrm{T}^{\mathrm{a}}$ de Curie. En la Figura 3.27 se observa que del 0,1 al 0,3 la mejora es muy importante, luego se aplana. A cambio se produce una disminución de la coercitividad intrínseca, lo que se compensa con Dy; desafortunadamente hay un acoplamiento anti ferromagnético entre el Co y el Dy que hace que se reduzca, aunque levemente, el producto de energía. Por tanto hay que buscar una sustitución adecuada de Co y Dy que minimice los efectos adversos y mejore la estabilidad térmica. 


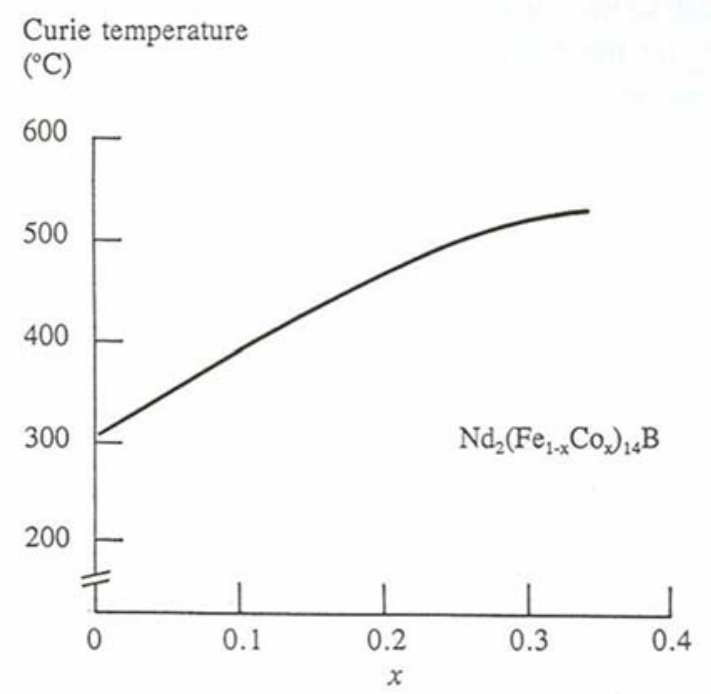

Figura 3.27. Efecto de la sustitución de Co en la temeperatura de Curie.[53]

En la Figura 3.28 se observa como varía el producto $B H$ con la composición de Co. Crece hasta una concentración del $1.5 \%$ a partir de ese punto empieza a disminuir.[36]

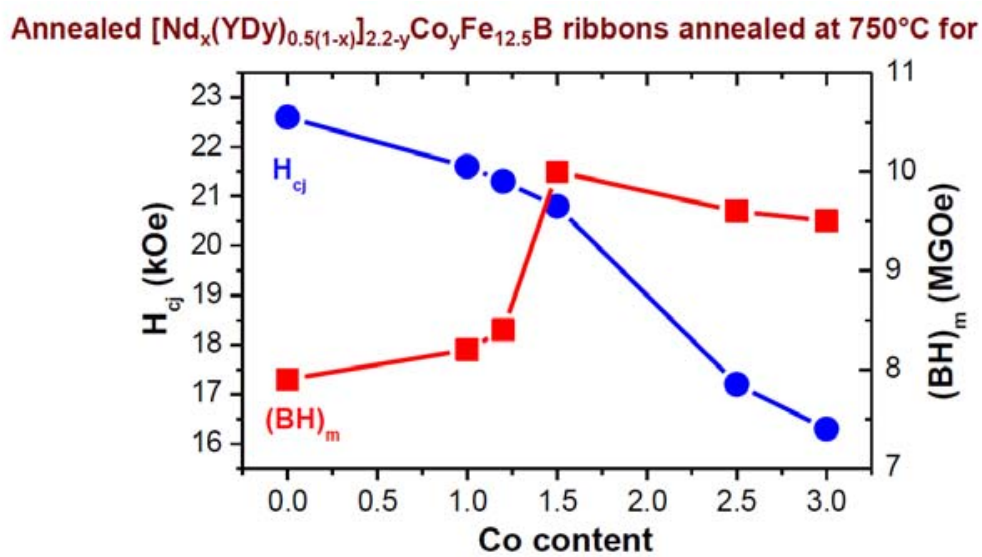

Figura 3.28. Efecto de la sustitución de cobalto.[54]

\section{El zirconio}

Otro de los efectos que presenta la adición de Co así como los enriquecimientos de $\mathrm{Nd}$ es el incremento del crecimiento de las fases suaves $\alpha$-Fe, para contrarrestar este efecto se añade circonio $\mathrm{Zr}$ que es bien conocido por su capacidad para formar cristales de vidrio. Inhibe eficazmente el crecimiento de granos durante la solidificación, impide la nucleación de fases suaves y promover la formación de la fase dura 2-14-1.

Además disminuye la viscosidad de los copos y facilita las operaciones de prensado y por tanto reduce sustancialmente los costes de manufactura finales. El valor óptimo se logró mediante la adición de $0,4 \%$ en peso de $\mathrm{Zr}$.

\section{El carburo de titanio $\mathrm{TiC}$}

No tiene solubilidad en el MRE2-14-1, formando precipitados en los límites del grano. Tiene una función similar a la de circonio Estos precipitados proporcionaron un lugar de nucleación para la fase 
magnético duro, así como un mecanismo eficaz que impida el crecimiento de grano durante el recocido, por lo que se consigue una microestructura refinada..

El conjunto de $\mathrm{Zr}$ y TiC proporciona cristalizaciones uniformes.

\section{La plata}

Otra de las mejoras introducidas reducir la velocidad de solidificación y usar aditivos muy solubles como plata Ag. Se han hecho pruebas incorporando hasta el 0,3\%, la proporción óptima es del 0,1\% presentando buenos resultados tanto en su comportamiento ante la temperatura, como ante la oxidación. [21]

\section{Una nueva posibilidad: EI cerio.}

Con el objetivo "No es el mejor imán de tierras raras, pero mucho mejor que cualquier imán sin tierras raras", se pretende diseñar un nuevo compuesto en el que el material principal sea el Cerio.

Los motivos por los que se ha elegido este elemento es que es una tierra rara muy abundante con una estructura y distribución electrónica interesante. Es un elemento que tiene una valencia entre $4 \mathrm{y}$ 3 , cuanto más se aproxime a la valencia 3 mejor consigue una anisotropía estructural o magnetocristalina

La fórmula propuesta es: $(\mathrm{Ce} 1-\mathrm{xNdx})_{2} \mathrm{Fe}_{14} \mathrm{~B}$

Las modificaciones indicadas se han dirigido a mejorar la vida útil y reducir el costo de los imanes sinterizados, manteniendo los productos energéticos deseables,

\subsubsection{Aglomerados o ligados (BPM) $[37,53,55]$}

Estos imanes tienen la misma constitución que los anteriores, con la diferencia de que los granos finos de tierras raras que constituyen el imán permanente se obtienen por procesos de templado muy rápidos obteniendo polvos isotrópicos. Éstos se mezclan con una determinada proporción de aglomerante (entre un 20-40\%) formando una estructura reticular. Posteriormente se constituye el imán mediante un proceso de compresión o de inyección. Estos imanes también son conocidos como de solidificación rápida.

Inicialmente estos compuestos se habían relegado a un segundo plano porque ofrecen un flujo magnético menor, o lo que es lo mismo, presentan un menor producto de energía que el de los imanes sinterizados. Sin embargo, en los últimos años el interés por los BPM ha crecido, especialmente en aquellas aplicaciones que tienen que ver con los motores. Cada año se producen aproximadamente unas 5.500 Tns de imanes de neodimio aglomerados frente a las 45.000 Tns de imanes sinterizados.

La gran versatilidad que permite en sus procesos de fabricación ha conseguido aumentar el valor del producto, de tal forma que bajo determinadas condiciones son competitivos respecto a los sinterizados. Además, pueden ser moldeados en formas muy intrincadas para obtener la potencia específica requerida. Se pueden construir polos con formas circulares, incluso con diseños multicapa, que requieren espesores menores.

Como es mayor la cantidad de aglomerante que incorporan se minimizan las pérdidas Joule en el material magnético. La elevada resistencia eléctrica que presenta la matriz polimérica limita la 
inestabilidad que producen las elevadas corrientes de Foucault. También se solucionan los problemas de oxidación sin que sea necesario recubrir con una capa protectora.

El polvo obtenido en la actualidad es tan fino que permite mayor grado de compactación que los sinterizados.

En general, los costes de fabricación son menores siempre que hablamos de producción elevada. Si además se eliminan los elevados costes de montaje que conllevan las formas prismáticas las cuentas a favor de los BPM empiezan a salir. Permiten magnetizarlos después de que el rotor esté ensamblado, lo que supone una ventaja en su transporte y almacenaje.

General Motors desarrolló los primeros polvos de BPM en 1986, posteriormente se transformó en Magnequench para la producción y comercialización en grandes cantidades importantes y actualmente se denomina Molycorp, que ha sido adquirida por China en 1995. Por otro lado, la compañía Aichi Steel, perteneciente al grupo Toyota, son su competencia directa.

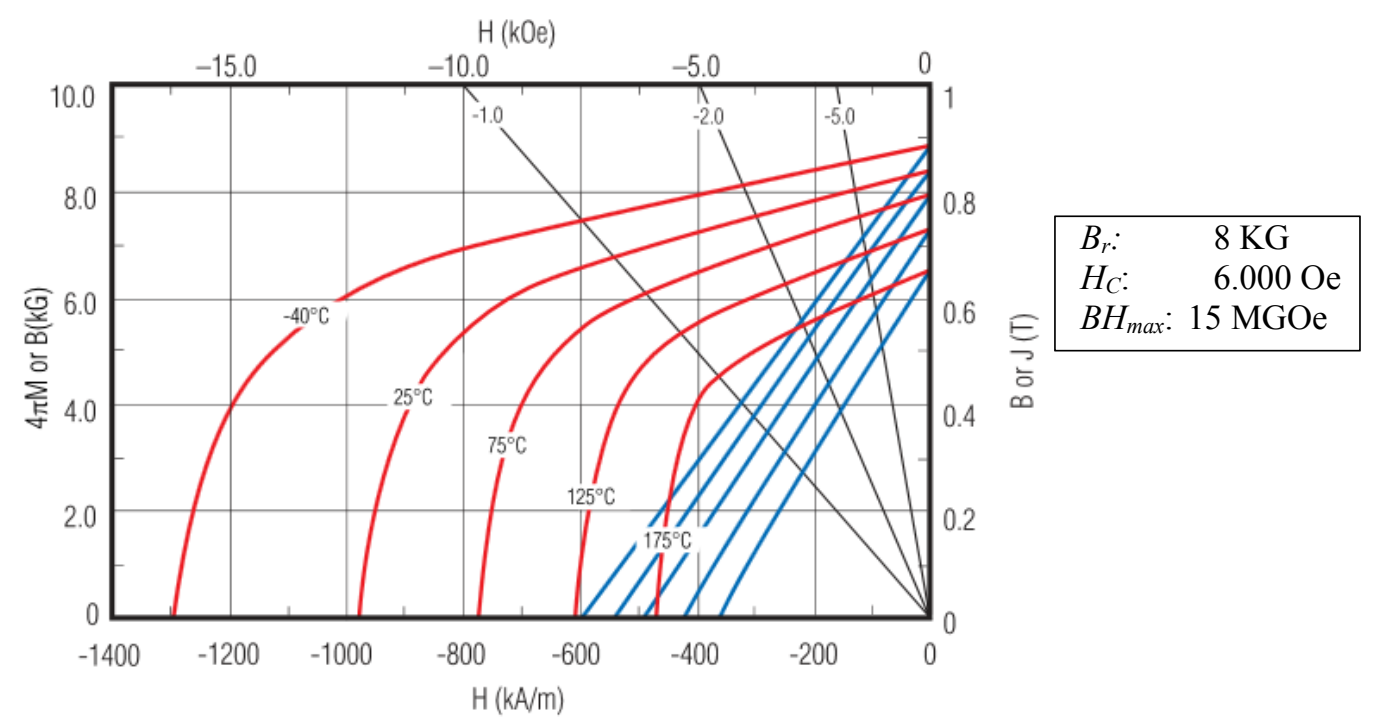

Figura 3.29. Curvas de desmagnetización de MQP 14-12.[56]

\subsection{Proceso de fabricación del polvo magnético.}

Presentan gran flexibilidad en los procesos de fabricación

\section{a) Hilado por fusión (Melt Spinning)}

Los imanes de neodimio ligados se preparan a partir de una delgada cinta de aleación de Nd-Fe-B obtenida por medio de hilado por fusión. Es el primer método, empleado en la producción de estos imanes.

Esta cinta se obtiene al inyectar material fusionado sobre un rodillo muy frio con nitrógeno líquido, el proceso de enfriamiento combina la conductividad de la rueda con el delgado espesor del material en una primera fase y posteriormente al abandonar el rodillo sufre un recocido lento por convección con la atmosfera estancada (ver Figura 3.30). 
Cuando la velocidad de la rueda es alta, el líquido en contacto con la superficie se enfría por debajo de su punto de fusión pero puede continuar en forma de líquido durante una cierta distancia antes de que ocurra la nucleación. Esto permite un subenfriamiento sustancial de la masa fundida y la transformación en una estructura amorfa. Optimizando la velocidad de la rueda se mejora, la velocidad de enfriamiento y se consigue producir una microestructura homogénea de nanocristales finos dispersos dentro de una matriz amorfa.

La cinta se pulveriza para producir pequeñas partículas, que son mezcladas con un polímero con una proporción que varía entre el 25 y $40 \%$.

La mezcla resultante se somete a un campo en una determinada dirección, consiguiendo una remanencia realzada en esa dirección. Luego se aplica un nuevo tratamiento térmico y es moldeada ya sea por forjado o extrusión para obtener imanes anisotrópicos de alta energía.

Sin embargo, las principales deficiencias de esta técnica de procesamiento surgen de la forma del producto solidificado, los copos por su geometría reducen el factor de relleno y aumentan la viscosidad

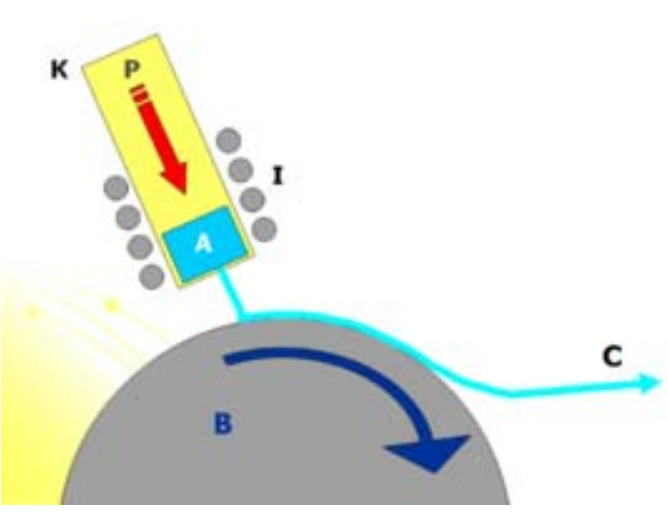

Figura 3.30. Proceso de fabricación de hilado por fusión.

La hilatura por fusión es el método comercialmente más empleado debido a su amplia gama de velocidades de enfriamiento y por la capacidad para suministrar microestructuras uniformes en una variedad de aleaciones.

\section{b) Atomización por gas (HPGA)}

Se pensó que el procesamiento mediante atomización de gas a alta presión (High Pressure Gas Atomization) podría llegar a convertirse en un sustituto beneficioso para el hilado por fusión en la producción de partículas nanocristalinas de $\mathrm{NdFeB}$.

El gas, habitualmente helio, se introduce con una velocidad de Mach 2-3, lo que provoca un cizallamiento muy energético de la corriente de masa fundida, obteniéndose partículas finas y esféricas (ver Figura 3.31) en vez de los copos obtenidos por hilado por fusión. Esto es debido a las diferencias en los mecanismos de transferencia de calor y direccionalidad durante la solidificación.

La geometría esférica de polvos obtenida por HPGA es más apropiada para el procesamiento de imanes permanentes, ya que evita el proceso de molido y permite un aumento de la carga en la inyección o moldeo. La viscosidad de los copos del hilado requiere de valores de temperatura y presión muy elevados que no son necesarios con las esferas obtenidas vía HPGA. Se habían realizado pruebas anteriores disminuyendo la velocidad del rodillo en el proceso de hiladura que proporcionaban copos más finos, pero sin llegar a las esferas del HPGA. 


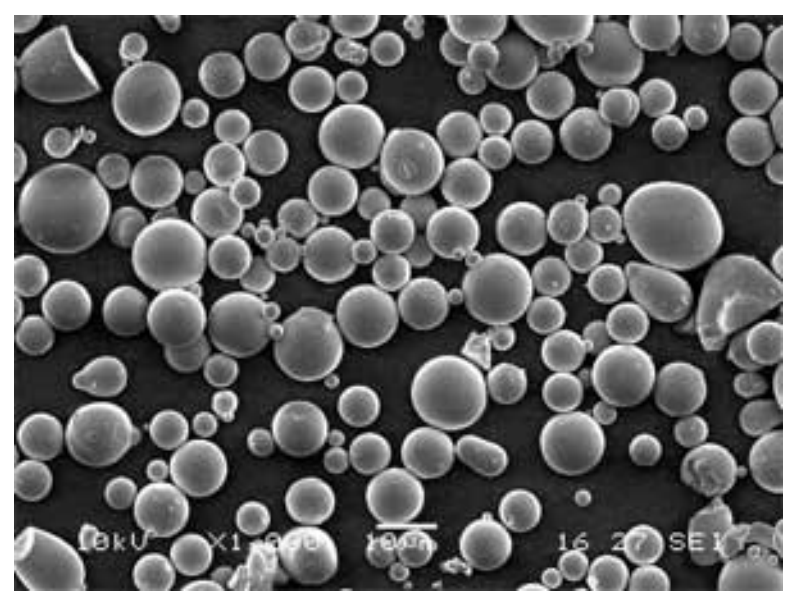

Figura 3.31. SEM de GA-1-66 con recubrimiento de fluor.[54]

\section{Recubrimiento de partículas.}

Las pérdidas magnéticas irreversibles debido a la oxidación y corrosión son un inconveniente importante de este tipo de polvos. Los medios más habituales para evitarlas consisten en aplicar recubrimientos de níquel-plata con un espesor de capa entre 10 y $15 \mu \mathrm{m}$.

El siguiente paso ha sido incorporar el proceso de fluoración en la formación de los polvos. La capacidad de recubrir las partículas mientras están "en vuelo" puede eliminar la necesidad de tratamiento posterior a la atomización.

El procedimiento se ha renovado con la inyección de trifluoruro de nitrógeno $\left(\mathrm{NF}_{3}\right)$ mezclado con un $20 \%$ de argón para conseguir una capa adherente, como muestra la Figura 3.32. De este modo mejora aún más el comportamiento de estos materiales ante posibles incrementos de temperaturas y exposición a la humedad. Las concentraciones relativas empleadas son pequeñas del orden del 0,05\% a $185^{\circ}$.

Otra posibilidad que se está probando es la fluoración en lecho fluido lo que permite el control de la capa de recubrimiento mejorando la protección de cada bola y la adherencia a la misma. Últimamente se emplean aparatos de fluoración en lecho fluido de menor escala que permite aplicar este sistema de recubrimiento a los copos. 


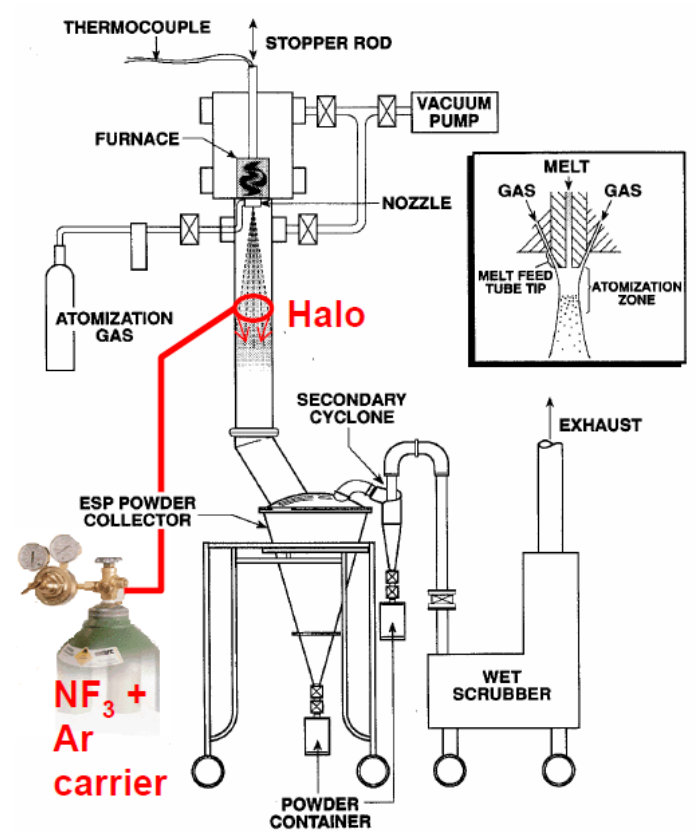

Figura 3.32. Proceso HPGA.[54]

Los beneficios que presenta este proceso son:

- Reducción de los costes de post-procesado en la atomización

- Aumento de la Resistencia a la corrosión

- Mejoran las características magnéticas entre 120 y $200{ }^{\circ} \mathrm{C}$

Los inconvenientes para el desarrollo de polvo fino de imanes obtenido por atomización con gas son los siguientes:

- La microestructura que presenta depende de la composición de la que se parte.

- Las pérdidas en la composición de tierras raras durante la atomización son similares a las que se tienen el proceso de hiladura por fusión a gran escala.

- Se tiene el riesgo de perder propiedades debido a un recalentamiento elevado tanto de la mezcla como de los elementos reactivos cuando se encuentran en estado de fundición.

- Superficie significativamente mayor de polvo esférico fino en comparación con la escama molida cuando alcanza estado solidificado.

- Sensibilidad a la oxidación.

- Presenta explosividad moderada.

- Protección corrosión/oxidación mejorada.

\section{Costes de Procesamiento:}

En los procesos experimentales se requiere 40 veces más cantidad de material y 10 veces más elevados el precio de los procesos de elaboración comparado con el de hilado por fusión.

Aunque potencialmente la producción industrial a gran escala se prevé que sea mucho más barato. 


\section{Variaciones con estos procesos}

Se han realizado varias pruebas de laboratorio variando la composición con adiciones de carburo de titanio y de circonio ( $\mathrm{TiC}, \mathrm{TiC}-\mathrm{Zr}$ y de $\mathrm{Zr}-\mathrm{ZrC}$ ). El cobalto se incorpora para mejorar su comportamiento con la temperatura.

A través de la adición de un formador de vidrio, $(\mathrm{Zr})$ y de un inhibidor del crecimiento del grano como el Ti, la alta velocidad de enfriamiento que se requiere para formar los copos ya no se convierte en una necesidad, por lo que es posible otro procesamiento con velocidad de enfriamiento menor como el HPGA.

Se ha probado el procesamiento de estos compuestos con los dos métodos indicados anteriormente, son denominados WT cuando se procesan en hilado por fusión y GA en la modalidad de gas atomizado (Tabla 3 5). Los resultados son los que se muestran en la Figura 3.33.

Tabla 3-5. Variación de las composiciones de $\mathrm{Ti}$ y $\mathrm{Zr}$

\begin{tabular}{lll}
\hline Hilado por fusión & HPGA & \multicolumn{1}{c}{ Fórmula } \\
\hline WT-096 & GA-1-52 & {$[\mathrm{Nd} 0.45(\mathrm{Y} 0.66, \mathrm{Dy} 0.33) 0.55] 2-0.1 \mathrm{Zr} 0.1(\mathrm{Fe} 0.89, \mathrm{Co} 0.11) 14 \mathrm{~B}+\mathrm{Ti} 0.02 \mathrm{C} 0.02$} \\
WT-102 & GA-1-66 & {$[\mathrm{Nd} 0.45(\mathrm{Y} 0.66, \mathrm{Dy} 0.33) 0.55] 2.3-0.1 \mathrm{Zr} 0.1(\mathrm{Fe} 0.89, \mathrm{Co} 0.11) 14 \mathrm{~B}+\mathrm{Ti} 0.02 \mathrm{C} 0.02$} \\
WT-127 & GA-1-100 & {$[\mathrm{Nd} 0.45(\mathrm{Y} 0.66, \mathrm{Dy} 0.33) 0.55] 2.3-0.3 \mathrm{Zr} 0.3(\mathrm{Fe} 0.93, \mathrm{Co} 0.07) 14 \mathrm{~B}+\mathrm{Zr} 0.01 \mathrm{C} 0.01$} \\
WT-131 & GA-1-106 & {$[\mathrm{Nd} 0.45(\mathrm{Y} 0.66, \mathrm{Dy} 0.33) 0.55] 2.3-0.3 \mathrm{Zr} 0.3(\mathrm{Fe} 0.93, \mathrm{Co} 0.07) 14 \mathrm{~B}+\mathrm{Zr} 0.01 \mathrm{C} 0.01$} \\
\hline
\end{tabular}

Las gráficas con marcadores cuadrados son producidas mediante hilado por fusión y los circulares por atomización con gas, los rellenos representan modelos comerciales frente a los huecos que son de laboratorio.

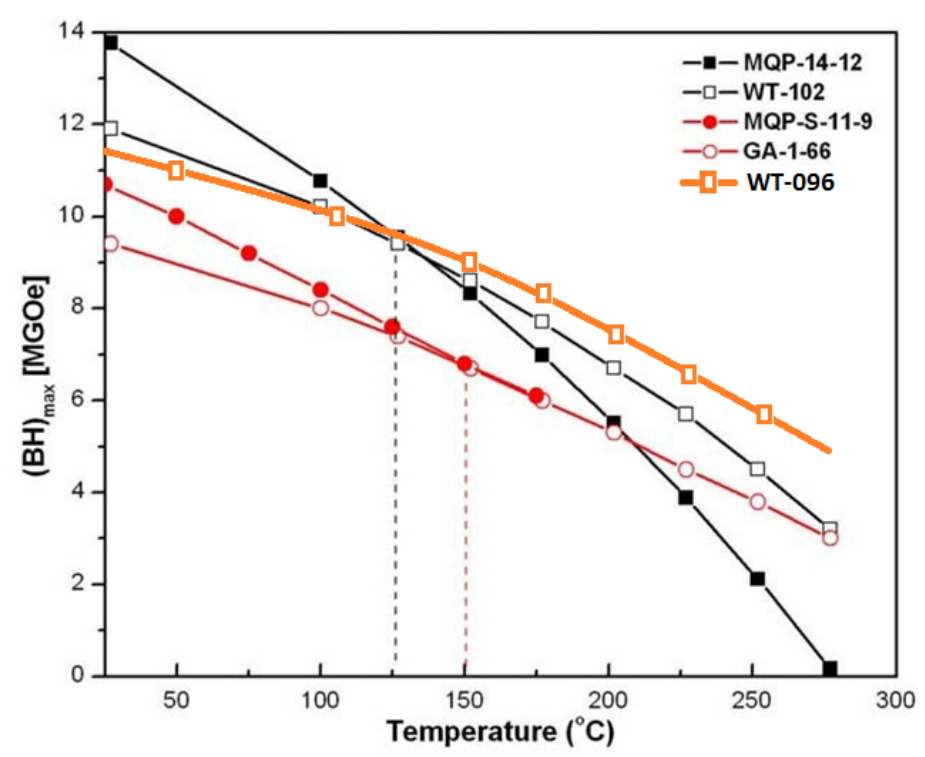

Figura 3.33. Comparativa de energía entre morfología de copo y esférica.[54]

Se puede comprobar que cuando el tratamiento elegido es HPGA el denominado WT-102 mejora el comportamiento con la temperatura respecto al original MQP 14-12, y todavía es más plana la curva del GA-1-66, pero en cambio el valor de energía a temperatura ambiente es mucho menor (7,6 frente a 11,5 MGOe). 
El WT-102 parte de valores más elevados de energía que WT-096; es imprescindible este valor de partida cuando posteriormente se va a gasificar, como se observa en las gráficas.

En la primera prueba de WT-096 se incorporó Zr que ofrece buenos resultados, especialmente cuando el compuesto va a ser gasificado. Los mejores resultados se han obtenido con una reducción de cobalto del 33\% pasando de un producto de energía de 11,66 a 1,7 MGOe en el WT-102. Estos son datos de laboratorio y el único que se ha comercializado es el WT-096 con denominación. MQP11HTP (ver Figura 3.34).

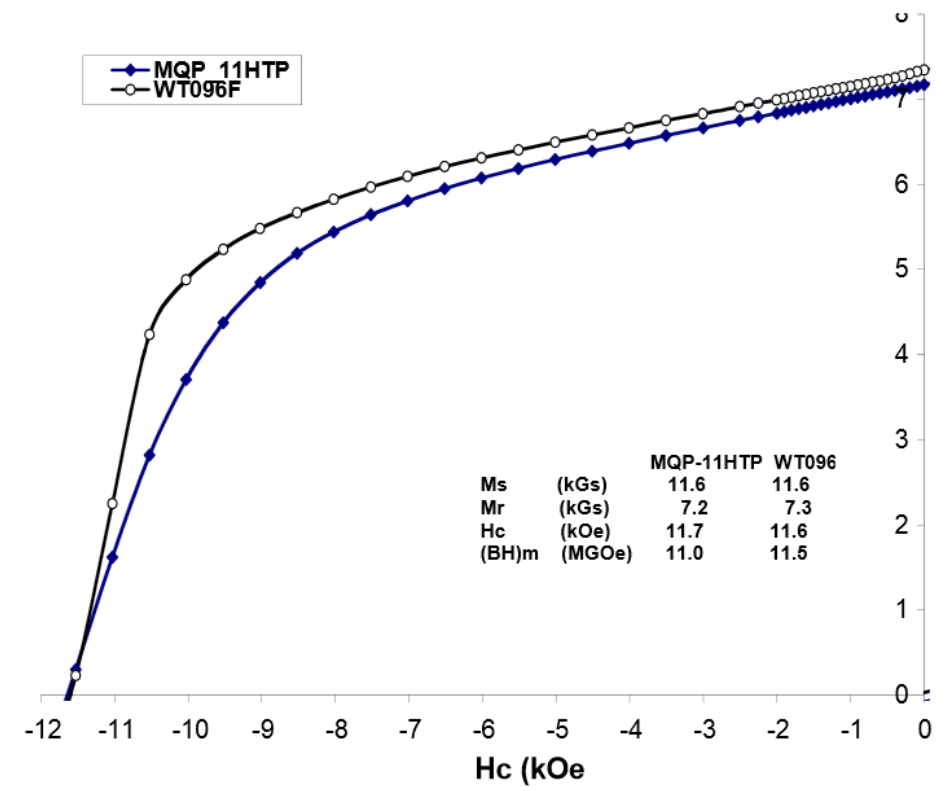

Figura 3.34. Comparativa del WT-096 en versión de laboratorio y comercial.[53]

No se han encontrado imanes comerciales fabricados mediante este proceso.

\section{c) MAGFINE. HDDR (Hidrogenación-Descomposición-Desorción-Recombinación) [57]}

El método procede del HD empleado con los sinterizados. Fue desarrollado en el 2000 por Aichi Steel Company, que es la única compañía que lo comercializa, y el nombre proviene de MAGNET (de imán) y FINE (de la microestructura fina). Existen tres versiones de $B H_{\max }: 15,20$ y 25 y es el imán aglomerado con la fuerza magnética más alta. Actualmente el MF-25 alcanza 43MGOe en polvo, que se convierten entre los 23 y los 17 MGOe cuando se moldea por compresión e inyección respectivamente. Presenta una resistencia a la temperatura hasta $150{ }^{\circ} \mathrm{C}$ y se puede inyectar directamente en los huecos de los polos. En el 2014 se han diseñado el primer prototipo para motores auxiliares de 50W.

El proceso utiliza una serie de cuatro transformaciones dependientes de la temperatura y de la presión en una atmósfera de hidrógeno controlando la velocidad de absorción-desorción. De este modo se minimiza el tamaño de los cristales y se eleva la anisotropía de los mismos (Ver Figura 3.35). El material se descompone en $\mathrm{NdH}_{2}, \mathrm{Fe}_{\text {y }} \mathrm{Fe}_{2} \mathrm{~B}$ durante el primer tratamiento térmico cuando se calienta a aproximadamente $840^{\circ} \mathrm{C}$ bajo una presión elevada de gas de hidrógeno. 


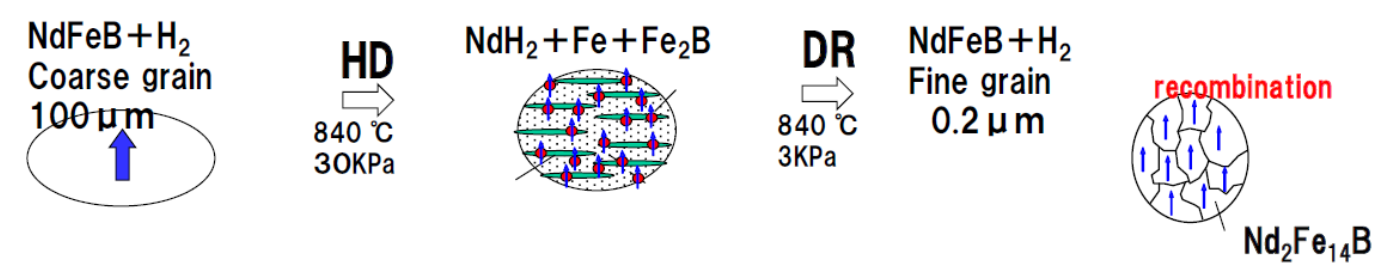

Figura 3.35. Proceso HDDR.[28]

Durante el siguiente tratamiento manteniendo la temperatura entre $750-900{ }^{\circ} \mathrm{C}$ durante 2 - $3 \mathrm{~h}$ el hidrogeno es liberado del hidruro de Neodimio $(\mathrm{NdH})$, lo que se conoce como desorción. Luego éste se recombina con $\mathrm{Fe}_{2} \mathrm{~B}$ para formar el compuesto original, pero con un tamaño de grano más fino. Estos procesos se realizan en atmosfera de vacío

La ventaja respecto al tipo de polvo obtenida mediante hilado por fusión es la obtención directamente de material anisotrópico (ver Figura 3.36). Controlando la presión y la temperatura durante el proceso, el tamaño de grano se reduce a un valor de $0,3 \mu$.
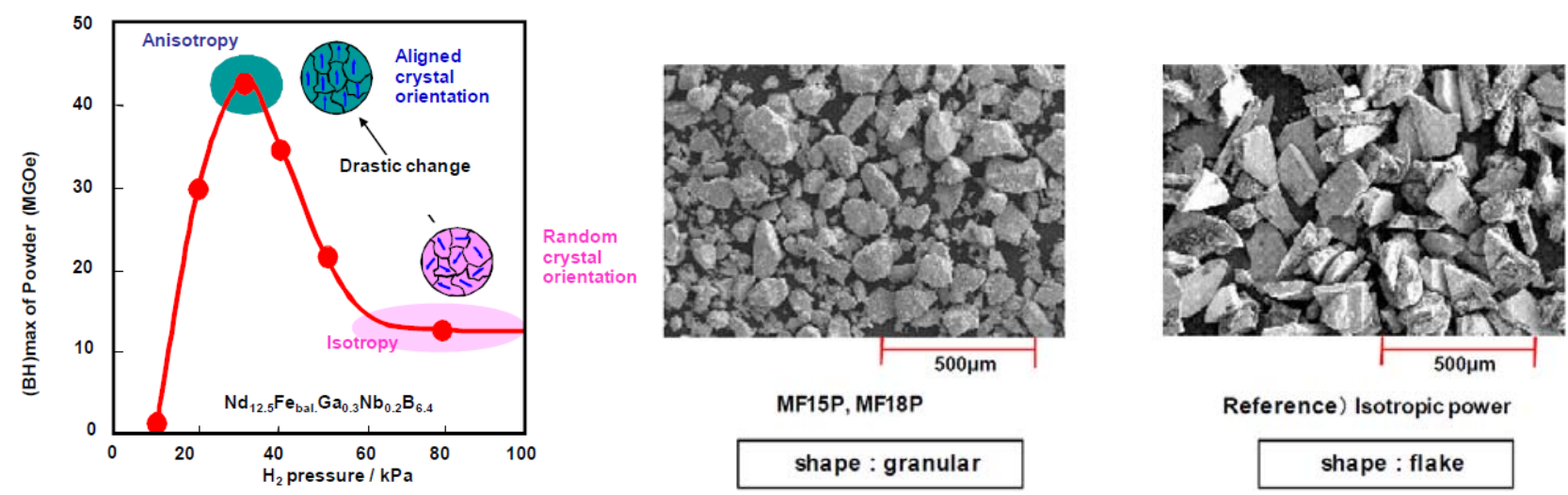

Figura 3.36. Energía del MF-25 y tamaño de grano por hilado por fusión (izda.) y por HDDR (dcha.).[57]

Los polvos de imán isotrópicos presentan curvas con más cuadratura en la curva intrínseca, lo que le confiere mayor estabilidad. En cambio, los obtenidos mediante este proceso exhiben curvas más redondeadas. El principal inconveniente que conlleva es su deterioro con la temperatura (hasta un 14\% el MF-15), debido a la poca uniformidad en la distribución del tamaño del grano.

En la tercera generación, el MF-25 (ver Figura 3.37) ha mejorado este aspecto. Para ello es necesario una nueva etapa con tratamiento de calor adicional para difundir Dy en el polvo, que luego se recombina en $(\mathrm{Nd}, \mathrm{Dy})_{2} \mathrm{Fe}_{14} \mathrm{~B}$. Otra de las posibilidades empleadas es mezclar con polvos de $\mathrm{Nd}$ $\mathrm{Cu}-\mathrm{Al}$, que al pasar a fase líquida, recubren los granos con un enriquecimiento de $\mathrm{Nd}$. 


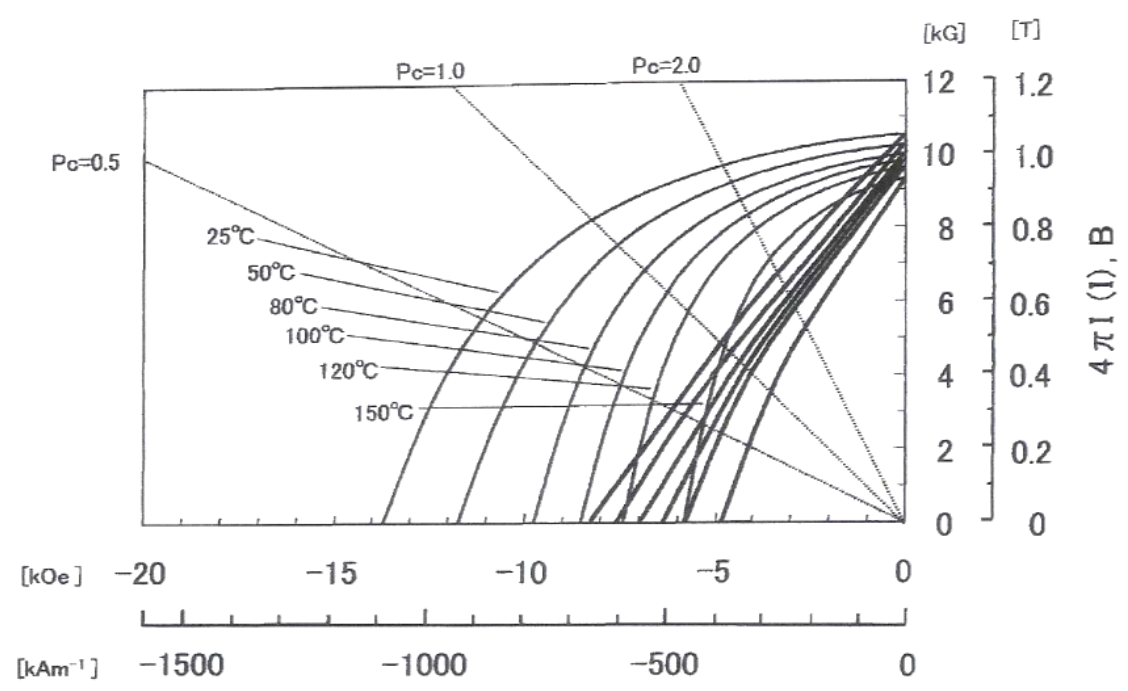

Figura 3.37. Característica de desmagnetización de MF-25 moldeado por compresión.[57]

Si bien este proceso HDDR es relativamente complejo, el polvo producido es susceptible de técnicas de conformación y moldeo bastante comunes. Para que sea adecuado para la compresión el polvo MF-25 se mezcla con resina epoxi, obteniendo un compuesto termoestable que puede ser moldeado en prensa, que además se oxida menos que con otros aglomerantes.

El uso de MAGFINE permitirá reducir el peso y tamaño de un motor considerablemente. De hecho, es el único material que consigue cumplir los objetivos del APEEM 2020, sin que en su composición se incluya el cotizado disprosio.

\section{d) Deformación en caliente}

En la carrera entre las compañías Aichi y Molycorp por alcanzar las mejores propiedades de estos imanes, la compañía americana desarrolla esta técnica emergente de deformación en caliente directa de los copos.

Se obtienen mediante un proceso de calandrado. El polvo de imán se derrite previamente a $260{ }^{\circ} \mathrm{C}$ bajo la presencia de un campo axial de $20 \mathrm{kOe}$ y se somete a altas presiones para evitar las reacciones gas-sólido. De esta forma se obtienen polvos muy anisotrópicos y con una mejora importante en la estabilidad térmica.

Los fabricantes de estos imanes deformed $\boldsymbol{M Q U}^{\mathbf{T M}} \mathbf{- F}$ han informado que tienen una energía de 22 MGOe. Mejorar la estabilidad térmica de estos imanes es tan sencillo como incorporar Dy en su composición, consiguiendo así deformed $\boldsymbol{M Q U} \boldsymbol{U}^{\mathbf{T M}} \mathbf{G}$ con valores de energía de $17 \mathrm{kOe}$ y temperatura de operación de $120^{\circ} \mathrm{C}$ sin pérdida de flujo.

El coeficiente de estabilidad de temperatura de coercitividad, $\beta$, se consigue reducir de 0,63 en los MAGFINE a los 0,52 en deformed G (ver Figura 3.38). 


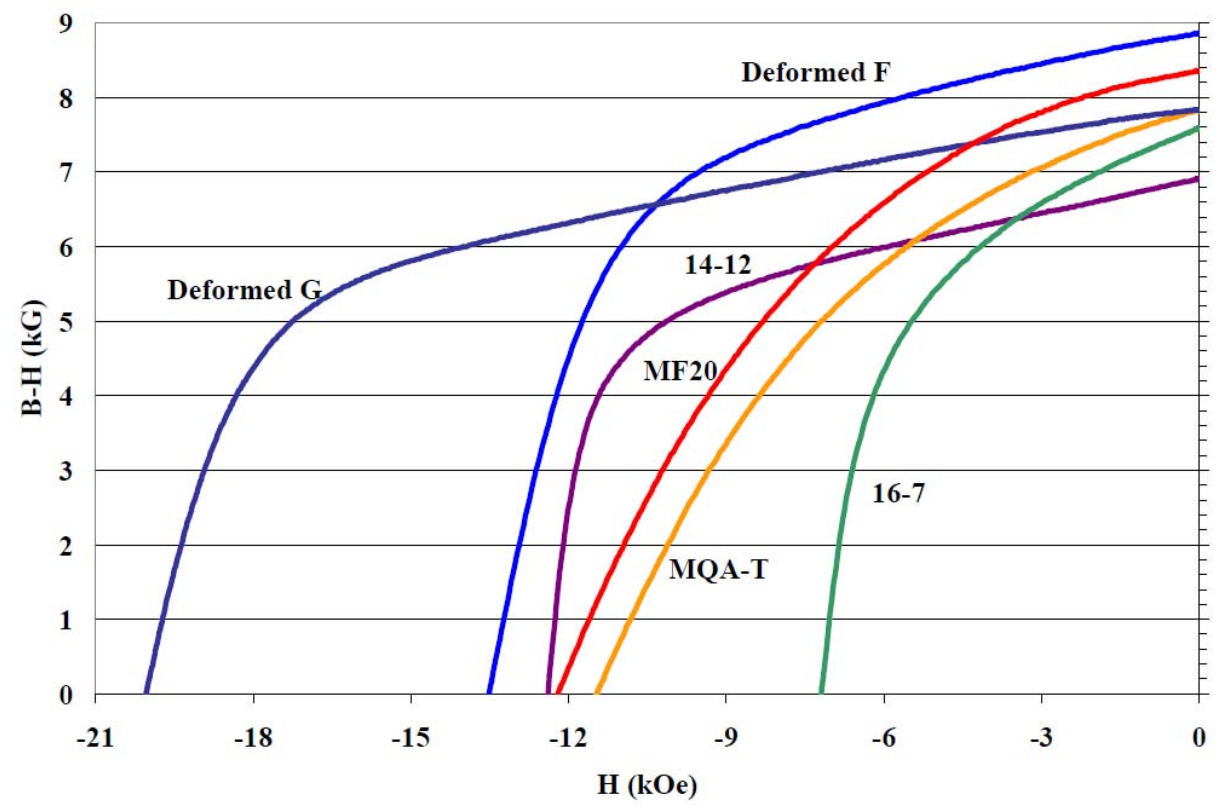

Figura 3.38. Comparativa de los distintos BPM según proceso de fabricación.[55]

Como conclusión, los imanes de última generación MQU basados en el proceso de deformación en caliente obtienen estabilidad térmica y altos productos de energía.

\subsection{Posibilidades comerciales de polvo magnético}

En una primera clasificación existen los polvos isotrópicos y los anisotrópicos. Estos últimos acaparan todo el interés, ya que tiene un mayor producto de energía. Existen varios métodos para transformarlos de isotrópicos en anisotrópicos, como ser prensados en un campo de $20 \mathrm{kOe}$ a $135^{\circ} \mathrm{C}$ de temperatura. La principal promotora de estos imanes BPM es Magnequench, que los denomina según las siglas:

- MQP- Isotrópicos

- MQPS de grano esférico (HPGA).

- MQPHTP Alta temperatura y presión.

- MQA- Anisotrópicos.

- MQF- Fine particle.

- MQU-Hot deformed.

Algunos de los comercialmente más conocidos se muestran en la Tabla 3-6.

Tabla 3-6. Materiales magnéticos de Magnequench[55]

\begin{tabular}{lll}
\hline Sample Code & Composition & Character \\
\hline MQPTM-14-12 & RE-Fe-B- & Melt spun isotropic thermal stable nanostructured material \\
MQPTM-16-7 & RE-Fe-B-type & Melt spun isotropic, high remanence nanostructured material \\
Deformed F MQU & Nd-Fe-Co-B-Ga & Hot deformed melt spun material with high remanence \\
Deformed G MQU & Nd-Dy-Fe-Co-B-Ga & Hot deformed melt spun material with high coercivity \\
MF20/ MF15 AICHI Steel & Nd-Fe-B-Nb-Ga & HDDR processed anisotropic material anisotropic material \\
MQPTM-A-T & Nd-Fe-Co-B-Ga & Original grade of HDDR processed material developed in 1990s \\
\hline
\end{tabular}


Podemos resumir ahora el comportamiento que presentan a elevadas temperaturas las diferentes posibilidades de aglomerados. Los polvos isotrópicos de MQP14-12 y 16-17 se comportan con buena estabilidad térmica y escasa variación de las propiedades magnéticas, en contraste con los HDDR, que son los que presentan el peor comportamiento con $\alpha$ de $-0,14 \% /{ }^{\circ} \mathrm{C}$ para el MF-20 y $\beta$ de $-0,63$ $\% /{ }^{\circ} \mathrm{C}$ en el MF-15. Los últimos compuestos MQU presentan una magnífica estabilidad térmica, incluso cuando las temperaturas son elevadas, aunque no consiguen alcanzar los valores obtenidos en los polvos isotrópicos. En cambio los mejores valores de energía corresponden a MAGFINE.

\subsection{Fabricación del imán}

\section{Compresión}

Tiene características magnéticas intermedias, entre los imanes obtenidos por inyección y el sinterizado de alta densidad.

Las geometrías obtenidas son simples (ver Figura 3.39): rectángulos, formas cilíndricas y arcos pero ofrece otras posibilidades que los prismas sinterizados, pudiéndose obtener espesores más delgados.

- En general presenta buenos niveles de tolerancia.

- Como inconveniente es quebradizo y requiere tratarlo con cuidado.

- La palabra clave es bajo coste de fabricación.

- Nivel de compactación del 75\%.
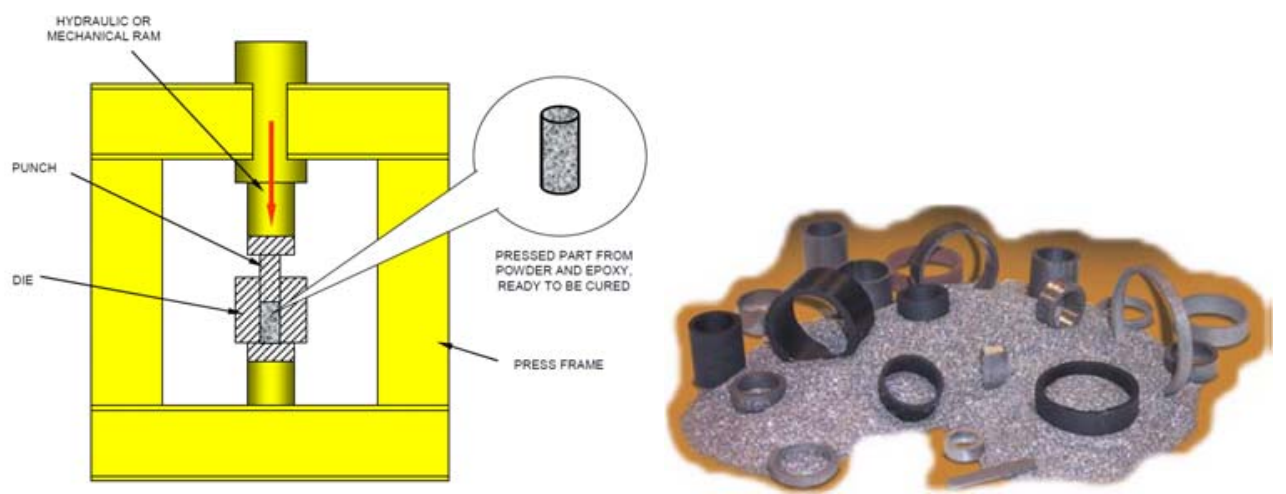

Figura 3.39. Proceso y resultado de imanes aglomerados por compresión.[47]

Los aglomerantes utilizados en BPM son polímeros termoestables y termoendurecibles. La cantidad oscila entre un 15 y un $25 \%$ con un punto de fusión de $150^{\circ} \mathrm{C}$, siendo los más habituales:

- Resinas epoxi

- Resinas fenólicas

- Novalac 


\section{Inyección}

Los imanes obtenidos así tienen una mayor dureza mecánica y pueden ser moldeados con otras piezas insertadas con ellos. Tienen formas geométricas complejas (ver Figura 3.38) con valores de tolerancia muy ajustados sin necesidad de procesos posteriores de acabado, aunque en ocasiones puede resultar áspero.

- Se reducen los costes de ensamblaje siempre y cuando el volumen de piezas sea lo suficientemente elevado.

- No necesita ningún proceso posterior.

- La palabra clave es flexibilidad en las formas.

- Nivel de compactación de 65\%.

Los aglomerantes son termoplásticos, en una proporción del 40\%.Los nombres comerciales empleados con sus puntos de fusión son:

- Poliamidas $\left(200^{\circ} \mathrm{C}\right)$

- PPS polifenileno sulfido $\left(290^{\circ} \mathrm{C}\right)$
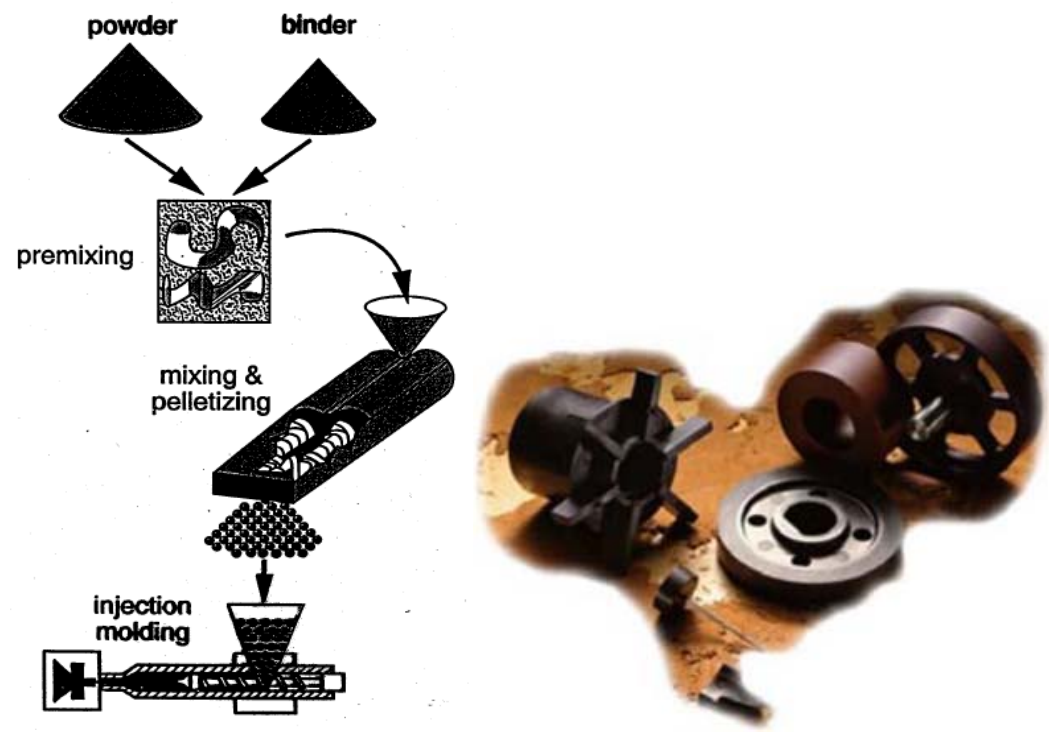

Figura 3.40. Proceso y resultado de imanes aglomerados por inyección.[47]

La Figura 3.41 muestra los valores $B H_{\max }$. Son más altos lógicamente en los imanes obtenidos por compresión, y por tanto los que compiten con los sinterizados en los modelos de motor propuestos en esta Tesis. 


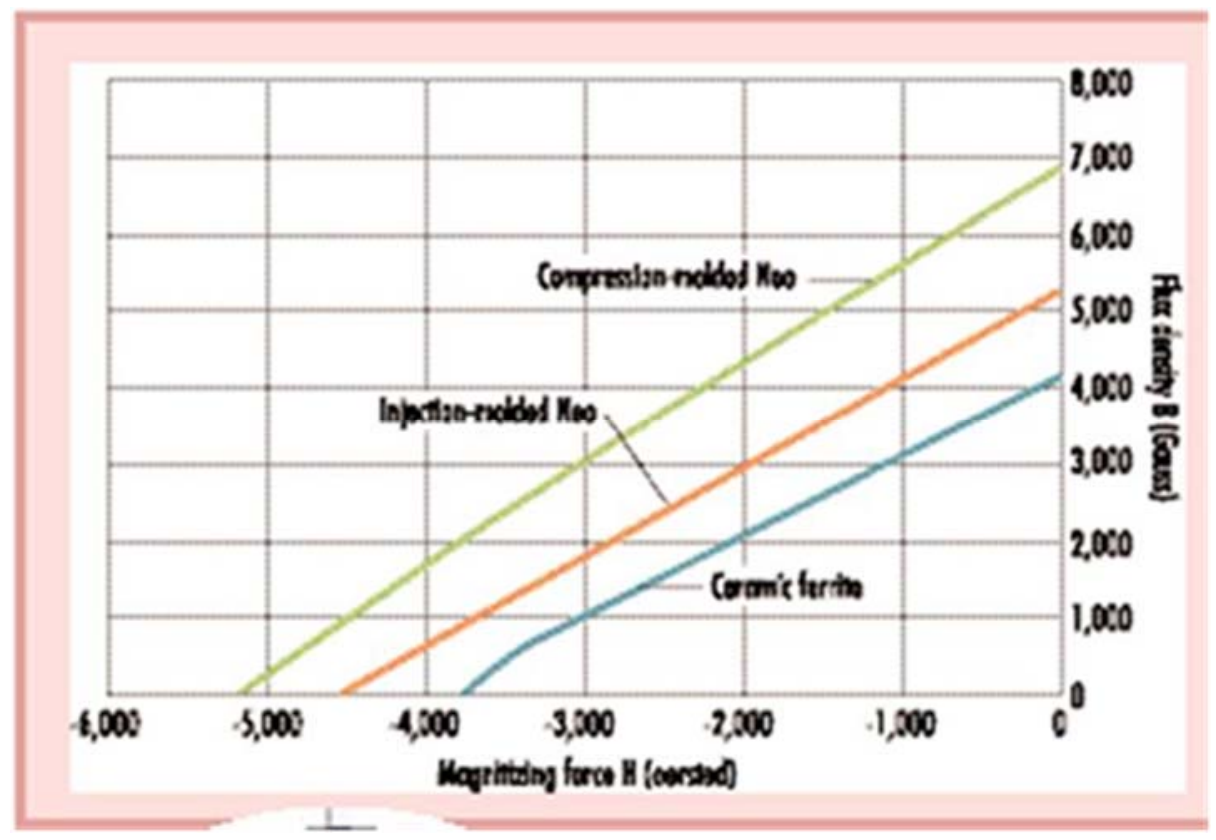

Figura 3.41. Comparativa de la energía obtenida por compresión e inyección.[47]

\subsubsection{Comparación entre imanes sinterizados y aglomerados}

La Tabla 3-7 muestra como la evolución experimentada en la última década por los imanes aglomerados que permite que sean competitivos. Además presentan otra serie de ventajas.

Tabla 3-7. Ventajas e incovenientes de los imanes sinterizados y aglomerados.

\begin{tabular}{lll}
\hline & \multicolumn{1}{c}{ Sinterizados } & \multicolumn{1}{c}{ Aglomerados } \\
\hline A favor & Alto producto de energía & $\begin{array}{l}\text { Bajo costo con elevadas producciones montaje } \\
\text { sencillo, magnetización montados, mejor resistencia } \\
\text { corrosión }\end{array}$ \\
\hline En contra & $\begin{array}{l}\text { Alto coste, perdidas al moler, frágil, Producto de energía reducido } \\
\text { magnetización individual, ensamblaje } \\
\text { complicado }\end{array}$ \\
\hline
\end{tabular}

Como ejemplo, en la Tabla 3-8 se pueden contrastar los datos obtenidos cuando se aplican al prototipo de motor doble capa en $\mathrm{V}$ para una misma potencia específica. Este modelo se explicará en el capítulo 5. Puede observarse que aunque aumenta la cantidad requerida de material magnético, el coste de materiales activos es ligeramente inferior.

Tabla 3-8. Comparativa entre imanes sinterizados y aglomerados.

\begin{tabular}{lrr}
\hline & NdFeB Sinterizado & NdFeB aglomerado \\
\hline Peso de imanes & $0,65 \mathrm{~kg}$ & $1,39 \mathrm{~kg}$ \\
Potencia específica pico para materiales activos & $2,88 \mathrm{KW} / \mathrm{kg}$ & $2,88 \mathrm{KW} / \mathrm{kg}$ \\
Coste de imanes & $59,26 \$$ & $54,45 \$$ \\
Coste de materiales (montaje de material incluido) & $172,92 \$$ & $163,68 \$$ \\
\hline
\end{tabular}




\subsubsection{Vida útil de los imanes Neo.}

Uno de los datos para medir el envejecimiento en el comportamiento de un material magnético es la pérdida de flujo en tanto por ciento en un periodo a una determinada temperatura de operación.

Las pérdidas de flujo magnético se pueden clasificar en:

- Reversibles, desaparecen cuando vuelven al estado original con el enfriamiento.

- Irreversibles, en parte recuperables con magnetización. Estas son inversamente proporcionales al valor de coercitividad intrínseca. Se deben considerar en el diseño.

- Estructurales son irreversibles e irrecuperables debido a procesos de oxidación en los bordes enriquecidos de $\mathrm{Nd}$ o excesiva temperatura que producen cambios en la estructura.

Para obtener estas pérdidas se eleva la temperatura del material de $\mathrm{T}_{1}$ (temperatura ambiente), a $\mathrm{T}_{2}$, para posteriormente volver al valor inicial, de este modo se obtiene la cantidad de flujo recuperable (ver Figura 3.42).

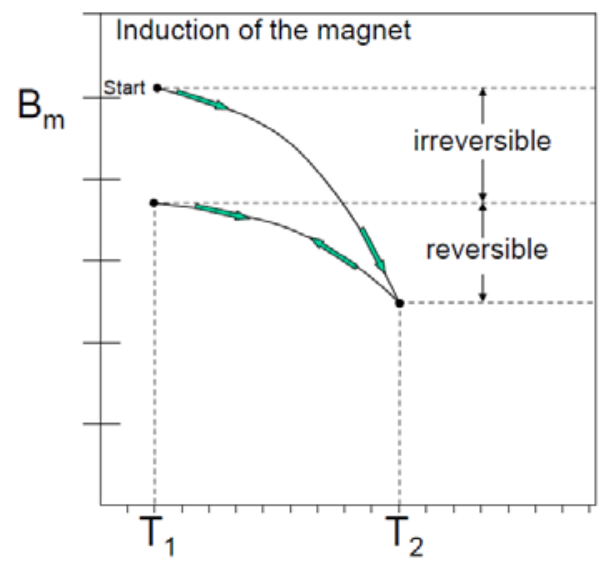

Figura 3.42. Descomposición de pérdidas en función de la temperatura.[47]

Se realizan dos tipos de prueba:

Las denominadas Short Term Irreversible Loss Test (STILT), que consiste en calendar en horno hasta la temperatura indicada y dejar enfriar durante una hora. En ese momento se mide el flujo. Una una vez que alcanza la temperatura ambiente se vuelve a calendar hasta el próximo valor y se repite el proceso a lo largo del rango de temperaturas. En la Figura 3.43 se muestran los resultados para varios tipos de imanes y se observa que las mayores pérdidas se producen en los imanes anisotrópicos (MQA). 


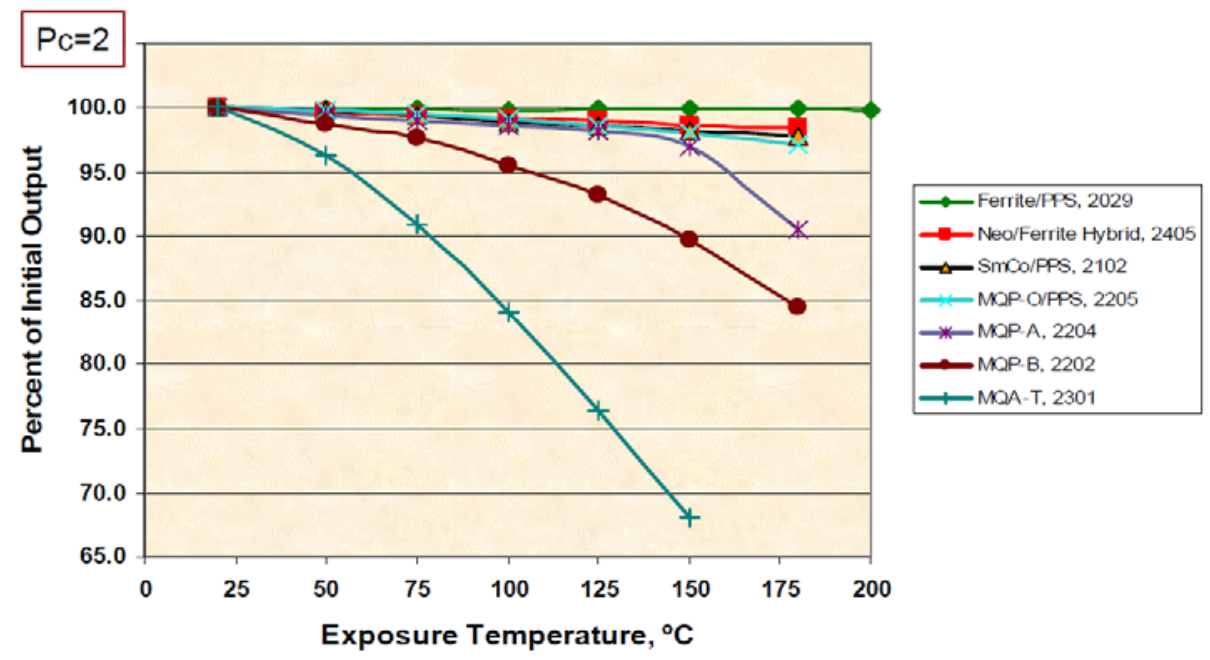

Figura 3.43. Comparativa de STILT de distintos imanes.[47]

Los materiales que superan esta primera criba se pasan a la segunda prueba: Long Term Irreversible Loss Test (LTILT). En una primera parte, hasta 168 horas, las pérdidas son recuperables. El resto pasan a pérdidas estructurales. En la Figura 3.44 se aprecia cómo son planas las correspondientes a ferrita y $\mathrm{SmCo}$ y cómo aumenta la pendiente en los $\mathrm{NdFeB}$.

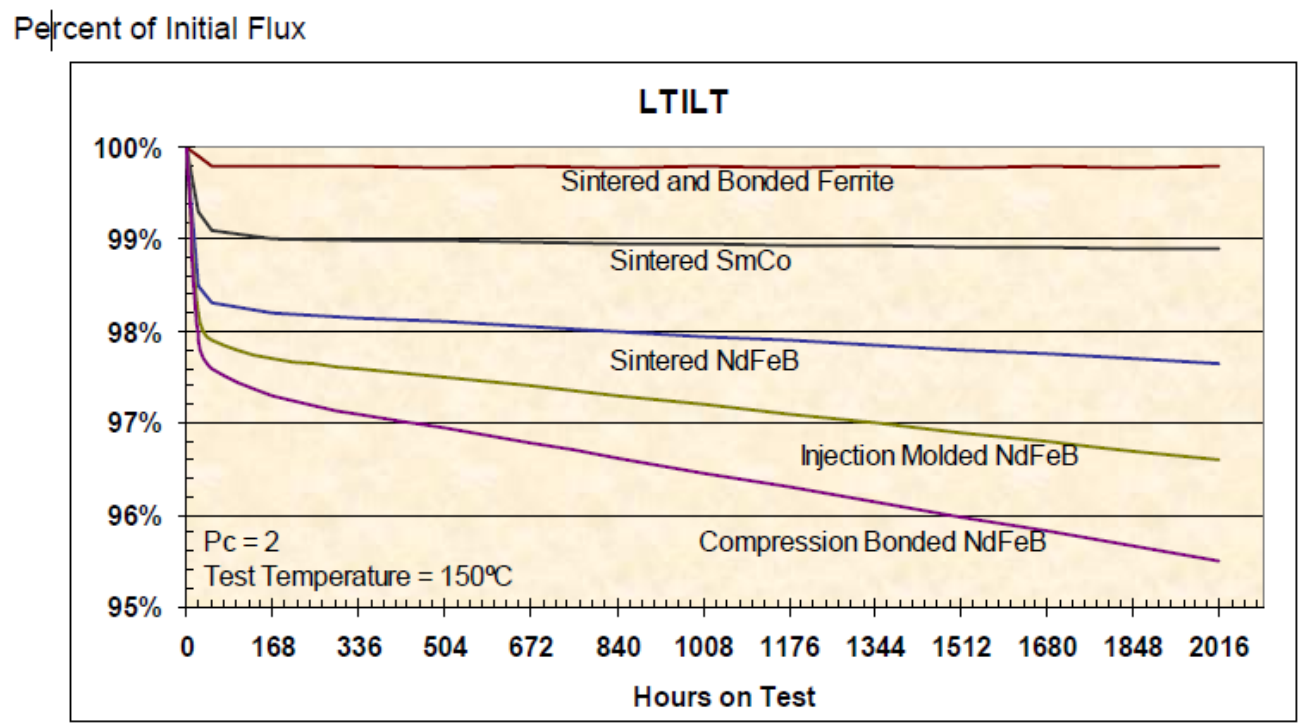

168 hours $=1$ week. Flux testing performed at room temperature.

Figura 3.44. Comparativa de pérdidas a corto plazo de distintos imanes.[47]

Para deducir, cuando las pérdidas son reversibles; desde el punto de funcionamiento de la curva de desmagnetización normal se traza una vertical hasta la curva intrínseca, el punto obtenido se une con el origen, trazando la línea de carga $P c=2$ y se observa en la curva intrínseca si corta por debajo del codo; en ese caso son irreversibles (ver Figura 3.45). 


\section{Demagnetization Due to Temperature - 1}

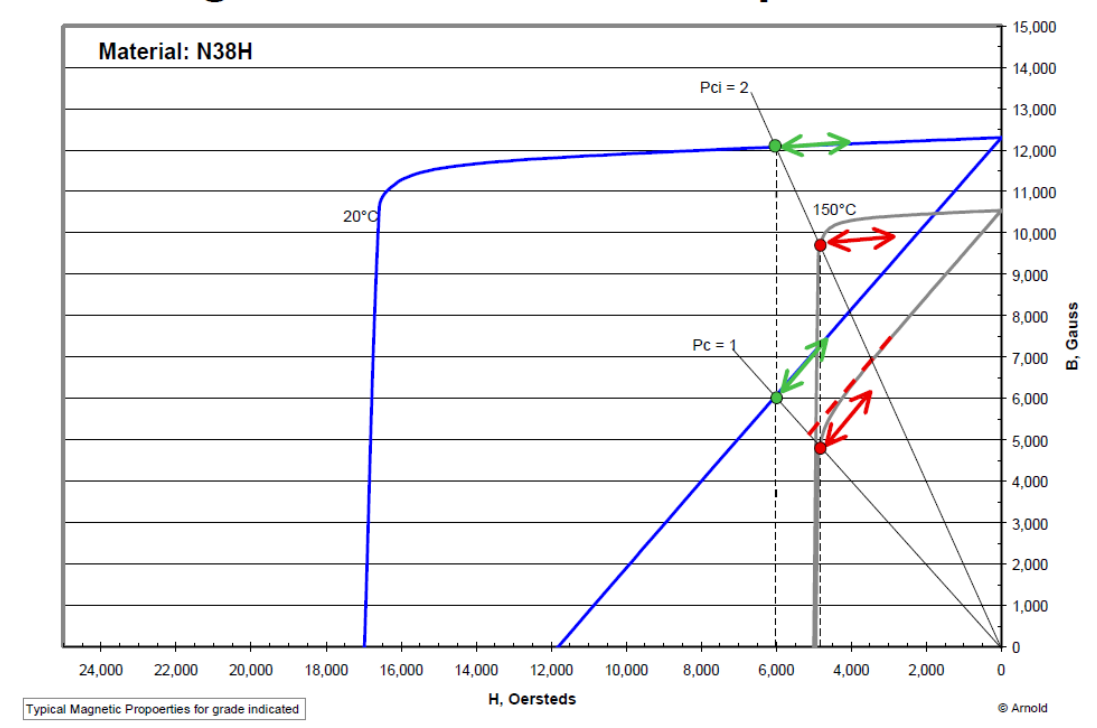

Figura 3.45. Obtención de pérdidas con distintas lineas de carga.[47]

\subsection{El mercado de tierras raras $[38,58-61]$}

Se conocen por tierras raras, también llamados metales especiales, un conjunto de 17 elementos químicos fundamentalmente pertenecientes al grupo de los lantánidos.

Su nombre no se debe a que sean escasos en la tierra sino a que su extracción es bastante dispersa y no concentrada como en la mayoría de los otros metales. Es difícil poder encontrarlos en una veta a ellos solos, siendo lo habitual que aparezcan como residuos de extracción de otras minerales, que en muchas ocasiones son minerales radioactivos como el torio y el uranio. Esto dificulta terriblemente la explotación de los mismos y de ahí que por cuestiones medioambientales, en algunos países como en la India, la producción está limitada a 2.700 Toneladas por año.

Los disparatados costos de las tierras raras no responden, por tanto a que estas sean "raras" en el sentido de escasas, sino al encarecimiento que han sufrido por cuestiones de mercado.

\subsubsection{Demanda de estos materiales. ¿Por qué son tan importantes estos materiales?}

El 20\% de estos metales se emplea en la formación de imanes magnéticos. Estos eran los datos que se manejaban a fechas de 2000. Este dato prácticamente se ha duplicado. Cando los datos corresponden al año 2008 hablamos ya del 37\% (ver Figura 3.46), pudiéndose duplicar de nuevo en 2015. Por tanto cerca del $80 \%$ de mineral se empleará en producir materiales magnéticos [62].

A la vista de estas cifras la demanda de mercado de este tipo de materiales crece a un ritmo anual entre el 4 y $6 \%$ en los primeros años, pero actualmente la cifra que se maneja está entre el $10 \%$ y el $12 \%$ refiriéndonos a los sinterizados, sin que por el momento haya afectado a los aglomerados. 


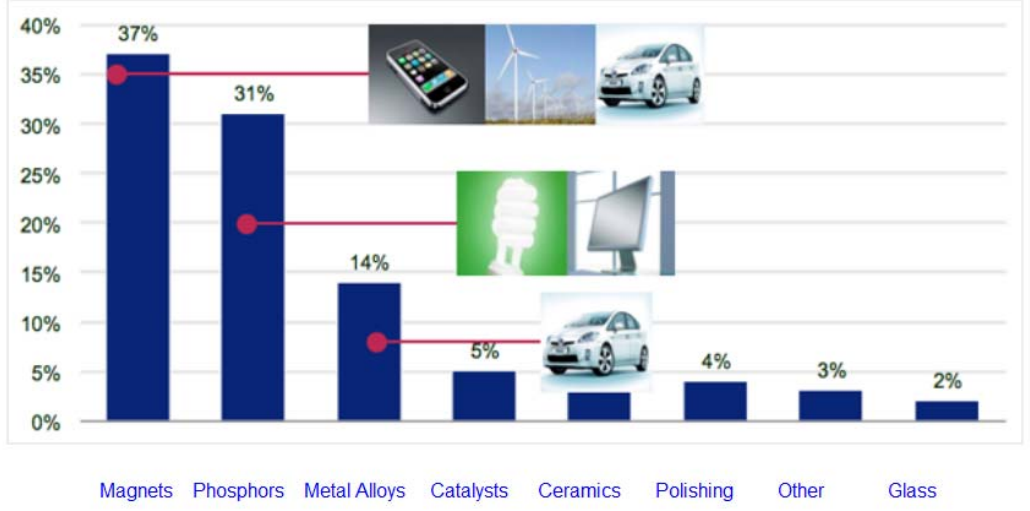

Figura 3.46. Aplicaciones de imanes de tierras raras.[63]

En el caso que nos ocupa, el motor MG2 del Prius, para proporcionar sus $55 \mathrm{~kW}$ requiere $1 \mathrm{~kg}$ de imanes permanentes, $11 \mathrm{~kg}$ de acero y $3 \mathrm{~kg}$ de cobre. El coste total del motor se estima en torno a los 660 \$, de los cuales los imanes suponen el 30\% de este coste, y con la manufactura incluida el 40\%.

Teniendo en cuenta que cada vehículo, suele llevar dos motores eléctricos, y que cada uno de ellos emplea entre 1 y $1,5 \mathrm{~kg}$ en su constitución y que el número de millones de unidades anuales (considerando solamente la marca Toyota en el 2012 ) ronda los siete millones de unidades, se puede deducir fácilmente que hablamos en torno a 15.000 toneladas de materiales de tierras raras. Si se incluye el resto de fabricantes las cantidades son asombrosas y si, siguiendo aún dentro del sector transporte, además de considerar vehículos HEV y EV se incluyen las bicicletas eléctricas, las cifras se disparan. En el caso de las bicicletas, sólo en China en el año 2012 se han vendido 20 millones y, considerando necesario para la fabricación de las mismas entre 60 y 350 gr, esto arroja unas necesidades en torno a las 9.000 toneladas.

De las otras aplicaciones de las tierras raras cabe destacar 14.200 Tns en discos duros y 16.000 Tns en energía eólica.

La producción de imanes sinterizados de $\mathrm{NdFeB}$ se ha incrementado sostenidamente de las 6.000 toneladas en 1996 a las 63.000 toneladas en 2008. La demanda de estos elementos, a medida que avanza el desarrollo tecnológico, está aumentando exponencialmente, pero no ocurre lo mismo con su producción. Este año se anuncia una producción de 46.900 Tns, mucho menor de lo requerido.

La evolución de la producción de tierras raras dependerá del precio del petróleo, pero sobre todo de las medidas medioambientales que decida cada país [64].

\subsubsection{Situación actual}

Las tierras raras son una de las claves de la estrategia económica china, que busca el control de los metales críticos. En 1992 el presidente Deng Xiaoping dijo "Oriente Medio tiene el petróleo, China las tierras raras". Solo unos años después, su sucesor, Jiang Zemin, terminó de completarla "Mejora el desarrollo y las aplicaciones de las Tierras Raras y convierte la ventaja de recursos en superioridad económica" [65]. En el año 2013, en el mercado mundial de tierras raras, China era responsable de:

- Extracción de mineral 97\%.

- Separación de los óxidos a partir del mineral y posterior refinado 97\%. 
- Separación de metales y generación de aleaciones 89\%.

- Fabricación de artículos diversos y componentes 75\%, aunque la autonomía es algo mayor, la dependencia es absoluta porque sin la materia prima no se puede fabricar nada.

La conclusión es inmediata: desde el momento en que un solo país controla completamente uno de los eslabones de la cadena y con amplia mayoría el resto, podemos hablar de un monopolio absoluto, como así se indica en un informe de finales de 2010 de la US-China Economic and Security Review Commision.

China vio la oportunidad de ganar cuota de mercado forzando la competencia de estas materias primas. Esto se vio favorecido por los bajos salarios, las leyes ambientales inexistentes, el apoyo del gobierno y las operaciones mineras baratas. Todo esto, le permitió a China producir material de RE a precios que otros países no podían igualar. El efecto de esta subvaloración era expulsar a los competidores del mercado.

Además, la expiración de la patente de la empresa Magnaquench en los años 90, provocó una reducción significativa en los precios, ya no solo del mineral sino también de los imanes terminados que se vendían por menos de $16 \$ / \mathrm{kg}$. La producción en USA cesó desde 2004 . La mayor parte de la producción de imanes RE se trasladó de los EE.UU. a Japón. Sin embargo Japón depende de la importación de las materias primas a otros países como China, Estados Unidos y Canadá (ver Figura 3.47).

Por ello, la estrategia china tiene en vilo especialmente a Japón, Estados Unidos y la Unión Europea, los grandes consumidores. Máxime desde 2010, cuando China hizo una exhibición de fuerza en un conflicto con Japón que marcaría el inicio de lo que los medios denominaron "guerra de las Tierras Raras". Tras un conflicto pesquero entre China y Japón en las islas Daiyou, cuya soberanía ambos disputan, el primero decidió restringir las exportaciones de RE a Japón. Posteriormente argumentaron que no se trataba del conflicto sino de limitar las extracciones como nueva política medioambiental.

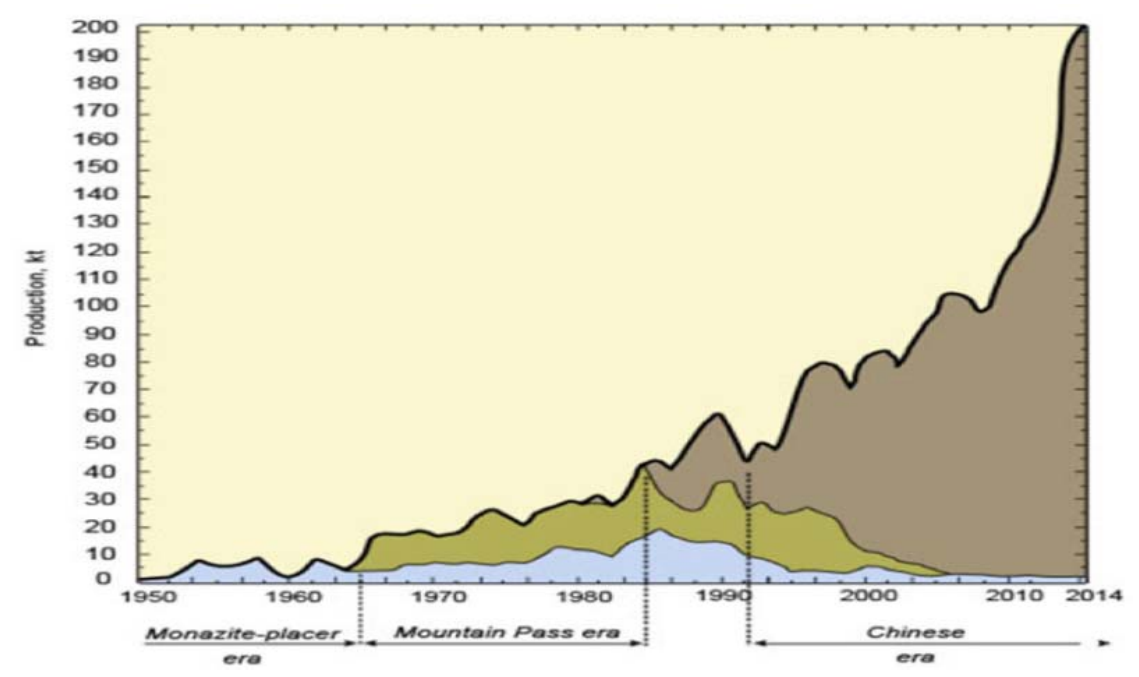

Figura 3.47. Producción mundial de óxidos de tierras raras.[47]

Por otro lado, el problema para China no es pequeño: el daño medioambiental causado en determinadas zonas es inmenso e irrecuperable, pero por el momento la hegemonía económica parece 
más importante. China ha anunciado recientemente su intención de limitar las exportaciones de materiales de RE con el fin de abastecer sus propias necesidades y para reforzar su posición en la cadena de valor como proveedores de imanes y motores. Esto ha conducido a todos a examinar el papel de los PM en las máquinas eléctricas y tratar de averiguar topologías y tecnologías que, o bien eliminan o reducen la cantidad de los imanes RE.

\subsubsection{Evolución de los precios [64]}

El mercado de los materiales magnéticos mueve 11 billones de dólares, de los cuales el 65\% corresponde a los imanes de RE. El precio de estos imanes ha aumentado de forma constante y los precios han llegado hasta los $60 \$ / \mathrm{kg}$ (ver Figura 3.48).

Es difícil hablar de precios de RE e imanes dada su elevada variabilidad. Por ejemplo el óxido de neodimio se ha disparado un 900\% desde el 2005 para volver a bajar en 2012. En 2011 el precio de imanes con una proporción en la composición del 20 y $25 \%$ de $\mathrm{Nd}$ es de $275 \$ / \mathrm{kg}$ y el de imanes con una proporción del entre el 6 y $9 \%$ de Dy es de $920 \$ / \mathrm{kg}$ [21], siendo los máximos alcanzados en el mercado de tierras raras $475 \$ / \mathrm{kg}$ para el Neodimio y $3.500 \$ / \mathrm{kg}$ para el Disprosio.

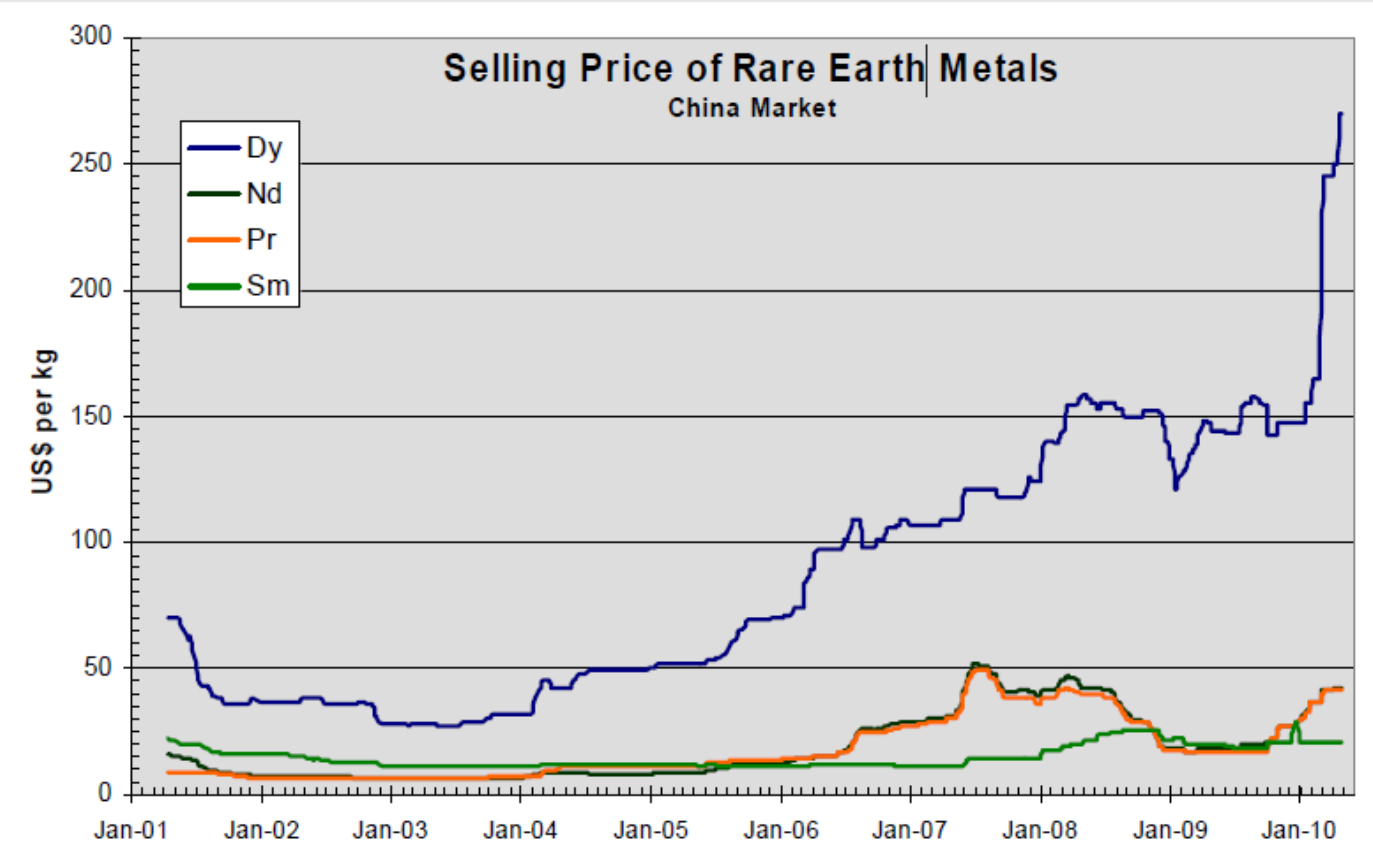

Figura 3.48. Evolución de los precios de los óxidos hasta 2010.[45]

La volatilidad de los precios de estos materiales es espectacular, desde 2012 se produce una caída de los precios por distintas razones entre las que destaca la crisis económica y el terremoto de Japón. Los datos obtenidos en [59] en 2013 se muestran en la Tabla 3-9. 


\begin{tabular}{ll}
\hline Elemento & Precio $\mathbf{( \$ / k g )}$ \\
\hline Nd & 120 \\
Sm & 80 \\
Dy & 650 \\
Co & 26 \\
Zr & 60 \\
\hline
\end{tabular}

Hasta ahora los imanes SmCo ha sido un tipo de material con un mercado muy pequeño porque el coste del mineral de samario es elevado y además los costes de fabricación un $12 \%$ más elevados. Pero si se siguen elevando las temperaturas de funcionamiento a las que han de trabajar estos materiales y el precio del Dy sigue en ascenso, los imanes SmCo pueden ser una seria alternativa dado su magnífico comportamiento ante la temperatura y frente a las pérdidas, especialmente a largo plazo.

En la Figura 3.49 , se muestra que el precio del cobalto se ha establecido por debajo de $36 \$ / \mathrm{kg}$ y se prevé que en 2015 su coste se acerque a los $25 \$ / \mathrm{kg}$, dato que refuerza la idea de retomar la fabricación de estos imanes.

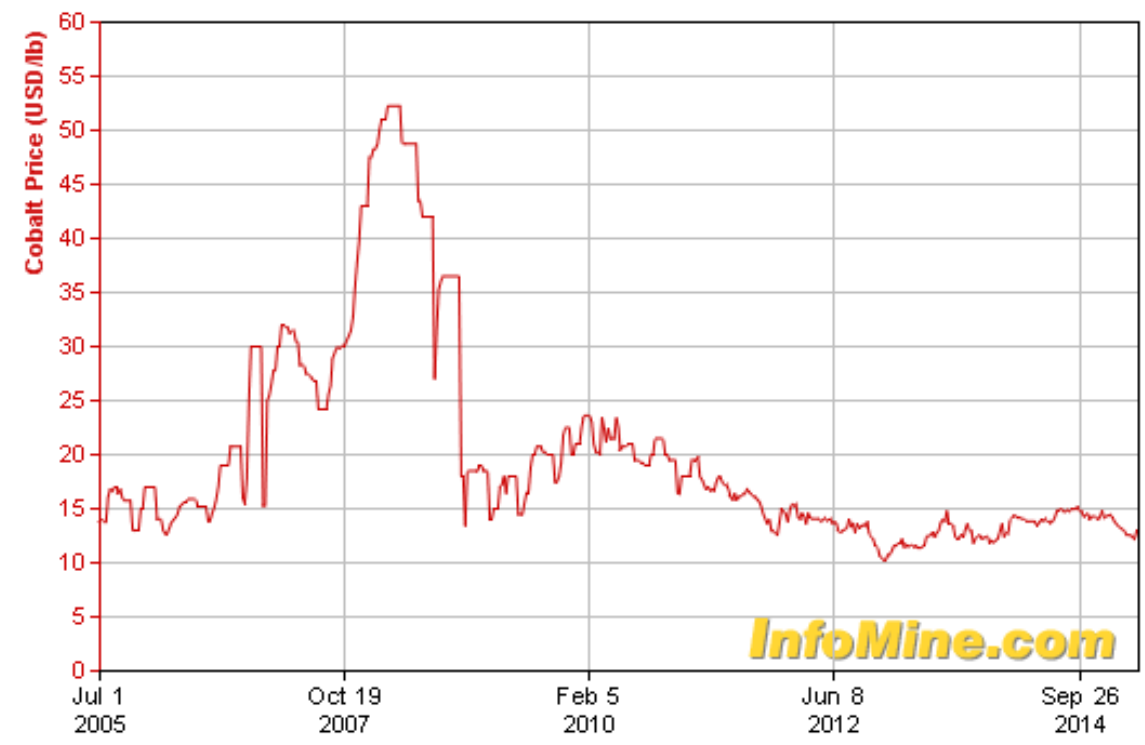

Figura 3.49. Evolución del precio del Co.[65]

Por otro lado, en la Figura 3.50 se observa como a partir de una $t^{\mathrm{a}}$ de $170{ }^{\circ} \mathrm{C}$ es más económico el uso de imanes SmCo que de los de N40SH. 


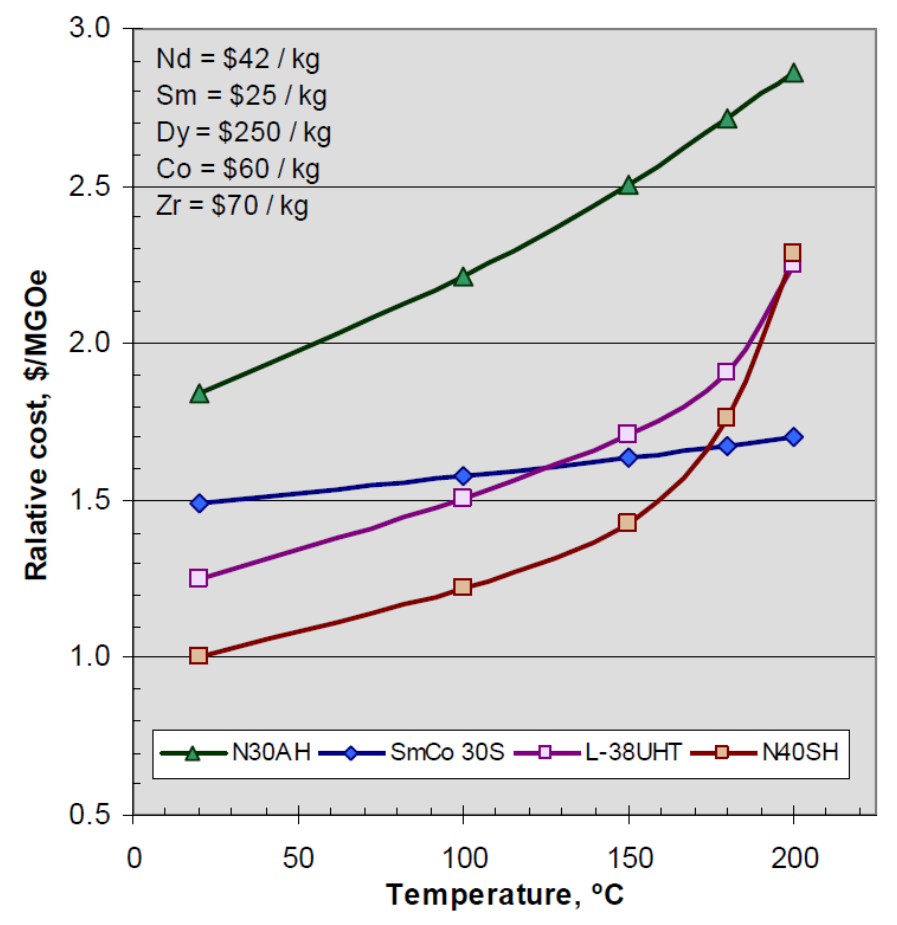

Figura 3.50. Precio de imanes en función de la $t^{\mathrm{a}}$ de trabajo.[38]

Finalmente, la Tabla 3-10Tabla 3-10. Composición de imanes de tierras raras y precios.[40] muestra la composición de los imanes y su precio final en 2013.

Tabla 3-10. Composición de imanes de tierras raras y precios.[40]

\begin{tabular}{|c|c|c|c|c|c|c|c|c|c|c|c|c|}
\hline \multirow[t]{2}{*}{ Tipo de imán } & \multirow[t]{2}{*}{ Grado } & \multicolumn{10}{|c|}{ Composición (\%) } & \multirow[t]{2}{*}{ (\$/kg) } \\
\hline & & $\mathrm{Nd}$ & Dy & $\mathrm{Co}$ & $\mathrm{Fe}$ & $\mathrm{B}$ & $\mathrm{Sm}$ & $\overline{\mathrm{Ti}}$ & $\mathrm{Y}$ & $\mathrm{Ni}$ & $\operatorname{Pr}$ & \\
\hline NdFeB & N30UH & 31 & 4,5 & 2,0 & 61,5 & 1,0 & & & & & & 21,82 \\
\hline Sinterizado & N38UH & 20,5 & 8 & 2 & 64,4 & 1,0 & & & & & 2 & ------- \\
\hline NdFeB HDDR aglom & MF25 & 23,8 & 1,6 & & 73,7 & 0,9 & & & & & & ------- \\
\hline SmCo Sinterizado & EEC 2:17-31 & & & 53,3 & 27,5 & & 11,2 & & & & & 52,86 \\
\hline Aglom NdFeB & WT-096 & 12,7 & 5,9 & 8,1 & 64 & 16 & & 1,6 & 6,4 & & & ------- \\
\hline Hiladura & MQP-14-12 & 26 & & & 71 & & & & & 2 & & ------- \\
\hline
\end{tabular}

\subsubsection{Situación futura}

Estados Unidos ya considera la dependencia, en lo que a estos elementos estratégicos se refiere, como un problema de seguridad nacional. Con el objetivo de posicionar adecuadamente el problema, el departamento de energía de Estados Unidos (DOE) ha establecido una matriz de criticidad de materiales a medio plazo (5-15 años), para ello clasifica los parámetros en dos ejes y asigna un valor del 1 al 4 a cada uno:

El eje de ordenadas tiene que ver con la importancia en el desarrollo de las energías limpias:

- Demanda de la aplicación específica

- Posibilidades de sustitución 
El eje de abscisas está relacionado con la criticidad en el suministro:

- Disponibilidad

- Demanda en tecnologías alternativas

- Factores políticos de regulación y sociales.

- Dependencia de otros mercados

- Diversidad de producción

En la Figura 3.51. Tabla de criticidad.[66]Figura 3.51 se observa que los materiales Nd y Dy se encuentran en los valores máximos de criticidad.

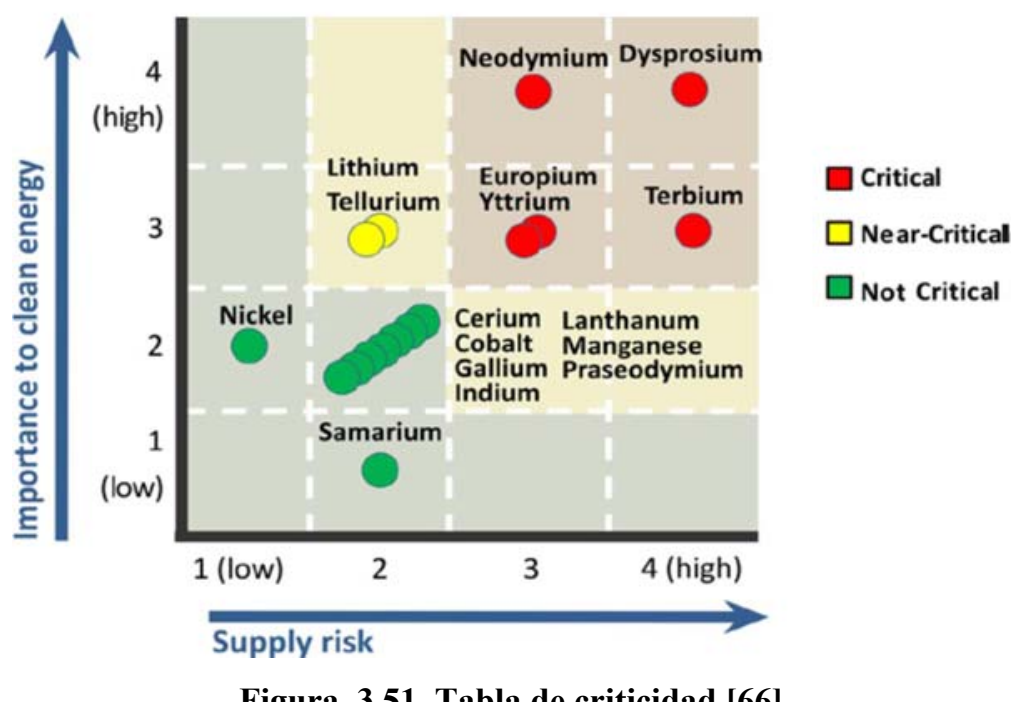

Figura 3.51. Tabla de criticidad.[66]

La situación actual del mercado es compleja, por los siguientes motivos:

- Concentración del mercado se prevé que el desarrollo de minas en otros lugares como Australia y Vietnam minimicen este problema.

- Opacidad del mercado. Como actualmente toda la cadena de procesamiento está en China las peculiaridades de su gobierno lo hacen especiales.

- Requerimiento de capital para arrancar una mina un billón de dólares.

- Conocimientos especialmente elevados en los pasos de procesamiento elevados.

- Requerimientos de regulación medioambientales complicados especialmente en las primeras fases ya que las tierras raras suelen aparecer mezclados con otros materiales de carácter radioactivo por su proximidad en la tabla periódica.

- Requerimientos de tiempo por encima de los diez años para comenzar la producción.

Con este panorama en la mente, el Departamento Americano de Defensa busca soluciones al problema, ya sea aumentando la producción y poniendo en marcha minas para su extracción (aunque la consecución de la cadena independiente de suministro podría tardar 15 años), o buscando elementos alternativos a las RE, algo que, al parecer, es mucho más difícil. Otros países como Australia, Brasil, 
Canadá o Argentina planean abrir minas o realizan prospecciones para encontrar los preciados elementos.

Un dato bastante indicativo de que la industria de la Defensa también se ha puesto a trabajar en este tema lo delata el hecho de que la multinacional aeroespacial y de defensa Boeing se haya lanzado en 2010 a la búsqueda de los mencionados minerales, firmando un acuerdo con la empresa Tierras Raras Inc. Para comenzar la explotación de minas los estados de Idaho y Montana y ayudará en las prospecciones para hallar nuevos yacimientos.

En un intento de dar un giro a la situación, en marzo de 2012 el Presidente Obama anunció que Estados Unidos se había unido con Japón y la Unión Europea para llevar adelante una resolución de la WTO contra China por sus políticas restrictivas sobre las RE.

Una de las últimas noticias más esperanzadoras y novedosas de la industria de materiales es:

"Tokio, Japón, 21 de diciembre 2011- Hitachi Metals, Ltd. ha anunciado hoy sus planes para construir una nueva planta en los Estados Unidos que va a producir imanes de neodimio diseñados para utilizar en los vehículos híbridos y eléctricos. La instalación se ubicará en Hitachi Metales Carolina del Norte, Ltd., base de fabricación imán de la compañía en los Estados Unidos. El lanzamiento de esta instalación de producción de imán de neodimio reforzará la capacidad de Hitachi Metals para satisfacer la expansión de la demanda proyectada para este tipo de imán no sólo en los Estados Unidos, sino también en el resto de América del Norte y Europa," [61].

La planta en cuestión ya lleva casi tres años de rodaje. Otros países como India Malasia y Australia cuentan ya con producción de tierras raras.

Los resultados que se deducen tras la evaluación de la situación actual indican tres caminos paralelos:

- Mantener el tipo de imanes sinterizados de neodimio, pero considerando que el índice de crecimiento para abastecer las necesidades actuales requiere, o bien otro abastecimiento alternativo a China, o bien un aumento de sus exportaciones, cumpliendo el objetivo de coste.

- Como alternativa elegir imanes de samario-cobalto y alnicos, buscando otras aleaciones o técnicas de procesamiento distintas que consiguen modificar las propiedades siendo estas comparables o superiores a los materiales existentes y con la ventaja de los costes de antemano.

- Considerar las múltiples posibilidades, especialmente por las formas, que pueden ofrecer los aglomerados con magnitudes magnéticas hoy en día muy similares a los sinterizados 



\section{Motores eléctricos en tracción eléctrica ligera}

\subsection{Selección del motor eléctrico}

El desarrollo de los motores eléctricos constituye una parte crítica en la evolución de vehículos eléctricos e híbridos, por lo tanto es necesario llevar a cabo una evaluación de las diferentes tecnologías de motores eléctricos para determinar cuáles son sus características y determinar si potencialmente son adecuados para estos vehículos. Por un lado han de ser capaces de satisfacer los objetivos especificados en cuanto a propiedades de los motores eléctricos de los HEV por el APEEM para 2020 y que se indican en la Tabla 4-1.

Tabla 4-1. Objetivos sobre motores eléctricos de la APEEM[35]

\begin{tabular}{cccc}
\hline Año & $\begin{array}{c}\text { Coste específico } \\
(\mathbf{S} / \mathbf{K W})\end{array}$ & $\begin{array}{c}\text { Potencia Específica } \\
(\mathbf{K W} / \mathbf{k g})\end{array}$ & $\begin{array}{c}\text { Densidad Específica } \\
(\mathbf{K W} / \mathbf{l})\end{array}$ \\
\hline $\mathbf{2 0 1 0}$ & 11,1 & 1,2 & 3,7 \\
$\mathbf{2 0 1 5}$ & 7 & 1,3 & 5 \\
$\mathbf{2 0 2 0}$ & 4,7 & 1,6 & 5,7 \\
\hline
\end{tabular}

Por otro lado, las características de par/potencia en función de la velocidad de los motores eléctricos y de combustión interna son las mostradas en la Figura 4.1.

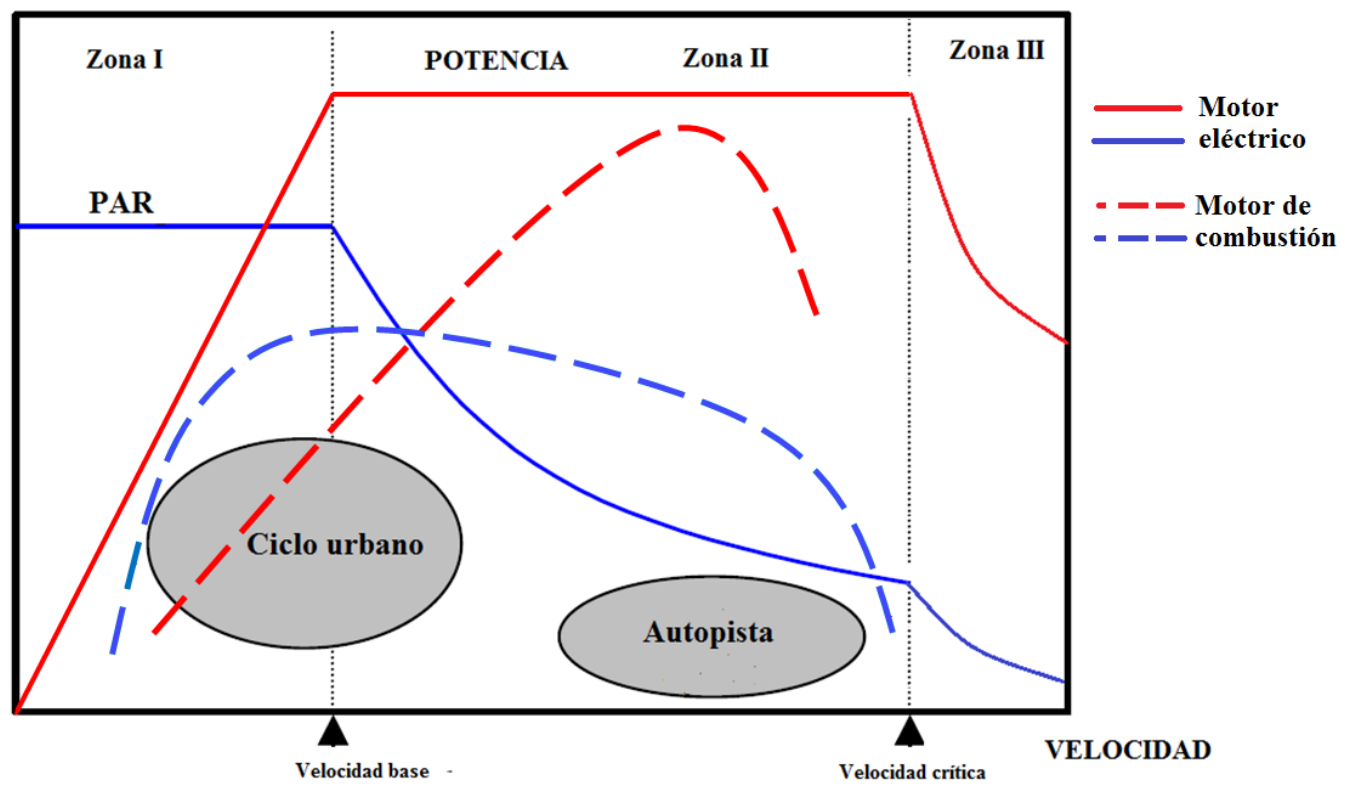

Figura 4.1. Característica par/velocidad de motores eléctricos y de combustión.[67] 
Existen tres zonas de funcionamiento en las gráficas. La primera es conocida como zona de par constante (Zona I), donde el máximo valor de éste viene determinado por la corriente del inversor, dado que el flujo es constante y en esa zona la potencia crece linealmente con la velocidad hasta el valor conocido como velocidad base.

A partir de la velocidad base está la zona de potencia constante (Zona II) que se extiende hasta la velocidad de debilitamiento de campo cuando el inversor alcanza el límite de tensión. A partir de ese punto es necesario disminuir el flujo para poder mantener la potencia constante. A partir de una velocidad crítica inevitablemente aparece la zona de reducción de potencia (Zona III).

Para cuantificar la proporción de las zonas de trabajo indicadas se define el factor de relación constante par/velocidad (CPSR) como:

$$
\mathrm{CPSR}=\frac{\omega_{\text {crítica }}}{\omega_{\text {base }}}
$$

El vehículo en ciclo urbano opera frecuentemente con baja carga y próximo a la velocidad base. En esa Zona I se buscan los rendimientos óptimos y en general, las curvas de los motores eléctricos superan en todos los aspectos a los del motor de combustión interna (ICE), aunque la potencia máxima sea la misma. A cualquier conductor le sorprende cómo desde velocidades bajas la potencia y, sobre todo, el par son considerables, aunque a velocidades superiores baja un poco la aceleración.

El adecuado diseño de estos motores, y la electrónica de control que requieren, es ahora un área muy importante de la investigación y desarrollo en todo el mundo. Los objetivos fundamentales a conseguir son:

- Elevada densidad de par, densidad de potencia, y elevado par a baja velocidad para el momento del arranque.

- Un rango de velocidad elevado en el que la potencia sea constante (CPSR de valor 3 ó 4).

- Alta eficiencia en todo el rango de funcionamiento.

- Control fiable.

- Construcción robusta a altas velocidades de giro,

- Disminución del coste.

- Disminución del ruido y bajo par de rizado.

La selección del tipo de motor eléctrico, depende en gran medida del fabricante, sin que haya claramente una tecnología domínate sobre el resto, aunque predominan los motores de inducción y los síncronos de imanes permanentes.

A continuación, en la Figura 4.2 se indican cuáles son los principales tipos de motores eléctricos, cuyas configuraciones se muestran en la Figura 4.3, y se comentan sus ventajas e inconvenientes y en la Tabla I-1 del Anexo I se muestran algunos de los vehículos híbridos existentes en la actualidad y el tipo de motor eléctrico utilizado. 


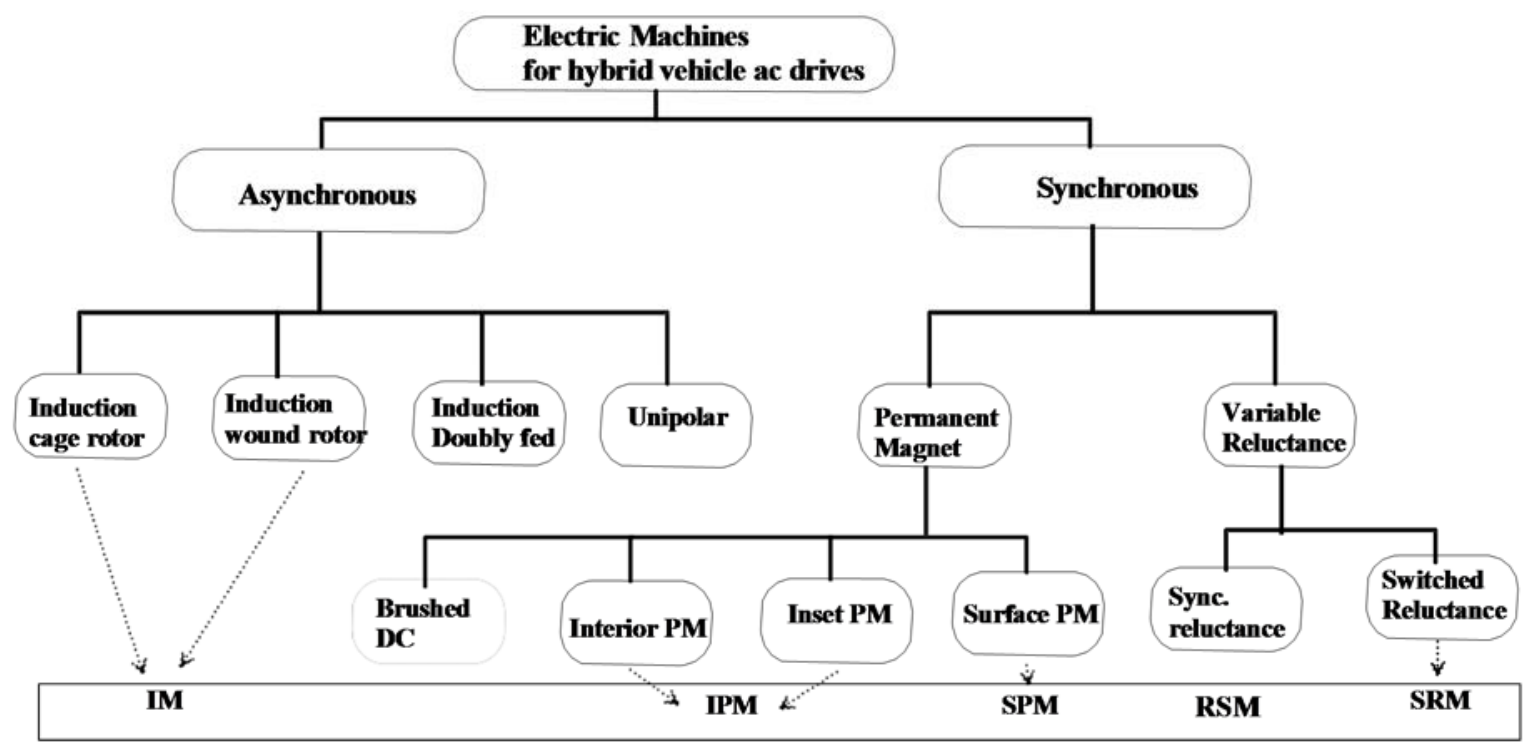

Figura 4.2. Motores eléctricos para VE/HEV.[21]

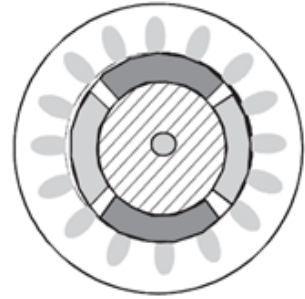

a)

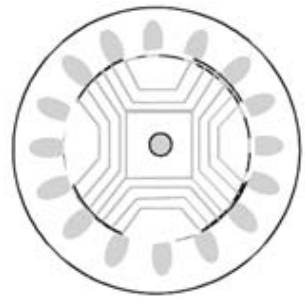

e)

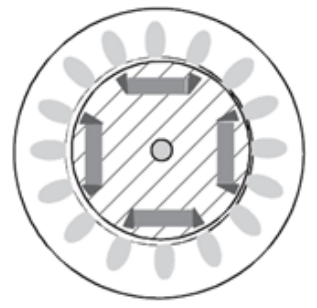

b)

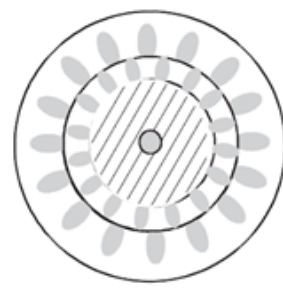

c)

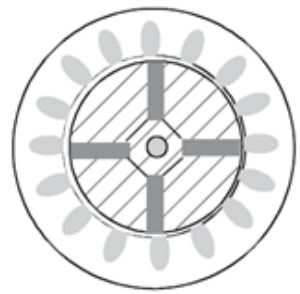

d)

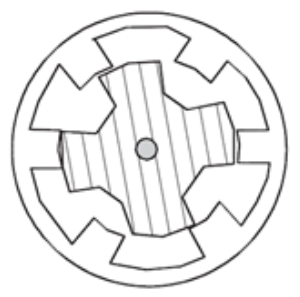

f)

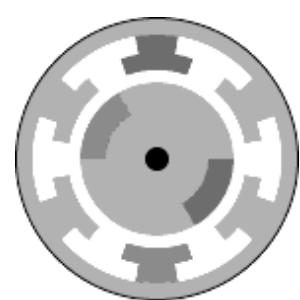

g)

Figura 4.3. Configuraciones de motores. [68]

a) Imanes en superficie (SPM)

c) Motor de inducción (IM)

e) Motor de reluctancia síncrona (RSM)

g) Motor brushless de CC (BDC) b) Motor de imanes interiores (IPM)

d) Motor de imanes radiales (IRM)

f) Motor de reluctancia variable( SRM)

La bibliografía empleada en los distintos tipos de motores que se relacionan a continuación es: $[19,29,69-71]$ 


\subsection{Motores de Inducción (IM) [72, 73]}

El motor de inducción o "Induction Motor" tiene una larga historia de funcionamiento satisfactorio en aplicaciones industriales y ha demostrado ser una máquina muy robusta, fiable, con la tecnología más probada de entre las de corriente alterna y de muy escaso mantenimiento. Existe comercialmente toda la gama de potencias tanto en motores como en inversores. Además tiene la habilidad sobradamente probada de trabajar en ambientes hostiles. Todos estos motivos han hecho que sea uno de los candidatos más importantes para los vehículos eléctricos.

A pesar de que en la clasificación de la Figura 4.2 se incluyen tanto la posibilidad de rotor bobinado como en jaula de ardilla, el empleado mayoritariamente es jaula de ardilla.

El par es el producto del flujo creado por el estátor y la corriente inducida en el rotor. En las máquinas de inducción el valor del flujo es ajustable, ya que su valor depende del coeficiente $V / f$ (tensión/frecuencia). Se han probado las máquinas doblemente alimentadas con un inversor dual para mejorar el comportamiento a bajas velocidades, a costa de bajar el parámetro de rendimiento. El par y el control de campo se pueden desacoplar con métodos de control vectorial. Tiene un amplio margen de velocidad y potencia independientemente del método de control de velocidad empleado.

Para los tamaños adecuados a esta aplicación, el motor de inducción tiene una menor eficiencia y densidad de par que los motores de imanes permanentes o de reluctancia variable, además requieren circulación de intensidad en el estátor incluso cuando la máquina funciona en vacío, por lo que el factor de potencia es muy bajo, reduciéndose aún más su valor a bajas velocidades.

Como el par de arranque se controla mediante el inversor la forma de las barras del rotor se puede modificar para estas aplicaciones en función de otros intereses como minimizar el flujo de dispersión. Para lo cual se proponen:

- barras más anchas y menos superficiales,

- eliminar la inclinación con las que se construían las barras pasando a ser paralelas al eje.

- aumentar la boca de la ranura del estátor.

Son, por tanto, máquinas de tamaño considerable que se adaptan mejor para la tracción de vehículos eléctricos pesados. Los motores IM han sido implementados en el modelo Silverado de General Motors, los de la Tesla Motors y en tracción pesada como algunos autobuses y camiones de Valeo. 


\subsection{Motores de Corriente Continua (BDC)}

Este tipo de motores han sido objeto de interés desde los primeros tiempos por la simplicidad en el desacoplamiento entre el flujo y el par. Posteriormente se descartaron por los problemas de mantenimiento de las escobillas y los avances que habían tenido los de corriente alterna para el control de la velocidad.

Actualmente las escobillas han sido sustituidas por robustos inversores que alimenta el estátor y realizan fácilmente el control del par.

Para evitar las escobillas en el rotor se sitúa un inductor con imanes permanentes, aunque éste suele ser excesivamente grande. Este nuevo diseño son los conocidos como Brushless DC (BDC).

Con la misma cantidad de imán que un motor síncrono de imanes permanentes la cantidad de par es menor. Su principal inconveniente es un elevado par de rizado por la forma trapezoidal de la fem debida a las corrientes con forma de onda cuadrada que circulan en el estátor.

Este tipo de motores son los empleados por Honda en los modelos Insight, Accord y Civic.

\subsection{Motores de Reluctancia Síncronos (RSM) [74, 75]}

Tanto los motores de reluctancia variable como los de reluctancia síncronos han captado la atención de los fabricantes de automóviles en los últimos años por la simplicidad en su estructura, no requieren ni de jaula de ardilla ni de imanes permanentes. Además es muy sencillo el control de los mismos y se eliminan alguna de sus limitaciones como la desmagnetización cuando las temperaturas son elevadas y las limitaciones en el rango de velocidades.

De la fórmula de par de los motores de imanes permanentes (4.9) que se explica más adelante se deduce que incluso si se eliminan los imanes permanentes del rotor se puede generar par con la alimentación sinusoidal en el estátor. El par se produce en estas máquinas por la tendencia del rotor a moverse a una posición donde se maximiza la inductancia del devanado del estátor excitado. Básicamente es un motor síncrono sin excitación por lo que la densidad de potencia siempre será menor que en los IPM.

El par desarrollado sigue la ecuación:

$$
T=\frac{m V^{2}}{2 \omega_{R}}\left(\frac{1}{X_{q}}-\frac{1}{X_{d}}\right) \operatorname{sen}(2 \theta)
$$

El rotor está construido normalmente de hierro magnético blando conformado para maximizar la variación de la inductancia con la posición del rotor. La saliencia del rotor, requiere valores por encima de 7 para ello se diseñan multicapas de geometría compleja con sólidas uniones para dar rigidez a unas chapas con demasiados huecos. El número de polos en el estátor y en el rotor coincide.

Permite control vectorial y presentan un buen valor de CPSR, que crece con el valor de saliencia del motor 


\subsection{Motores de Reluctancia Variable (SRM)}

El motor de reluctancia variable o "doubly salient permanent magnet" es excitado por pulsos de corriente aplicados a cada una de las fases. Los pulsos de corriente se aplican en función de la posición exacta del rotor, por lo que requiere de un sensor de posición [76].

Cuando un polo del estátor está alineado con uno del rotor la inductancia es máxima. Los devanados que utilizan son concentrados, no como los anteriores que emplean distribuido. Los polos del estátor y rotor no coinciden eligiéndose combinaciones $6 / 4$ y $8 / 6$, el primero con CPSR de 7 y el segundo de 4. El arco del polo del rotor suele ser algo mayor que el arco del polo del estátor.

Como ventajas: Simples en construcción y bajo coste. Son muy robustos y fiables, incluso a elevadas velocidades. Son capaces de mantener un funcionamiento en zona de potencia constante (amplia Zona II ) con un CPSR de 3-7. Este valor se reduce al aumentar el número de polos.

Inconvenientes: Necesitan doble número de elementos de conmutación y tienden a ser ruidosos, lo que limita su uso en vehículos. Además presentan un excesivo par de rizado y par oscilante.

La marca Jhon Deere ha empleado este tipo de motor en una máquina de obra pública. Es la única aplicación de motores de reluctancia encontrada.

\subsection{Motores Síncronos de Imanes Permanentes (IPM) [34, 77- 83]}

Dado que esta tesis se estudia el motor MG2 del Toyota Prius, que es del tipo IPM, y se desarrolla un modelo de rotor de este tipo, es necesario presentar el funcionamiento y ecuaciones de este motor, lo que se hace en este capítulo.

Actualmente para los HEV se utilizan casi universalmente motores de imán permanente interior de $\mathrm{NdFeB}$ sinterizado debido a sus propiedades superiores, especialmente la densidad de potencia. El estátor de esta máquina es bastante similar al de un motor de inducción o de un motor síncrono.

A diferencia de otras máquinas en las que se puede variar la inducción magnética mediante las intensidades de alimentación, en las de imanes permanentes este valor no es regulable por ser inherente a los imanes y constante.

\subsubsection{Motores de imanes permanentes en superficie (SPM) [84]}

Este motor presenta el inconveniente de que a altas velocidades la fuerza centrífuga hace que la sujeción de los imanes, que normalmente van pegados, sea un gran problema. Además, estos imanes no se adaptan a las formas prismáticas establecidas en la fabricación de imanes.

Las fuerzas magnetomotrices de estos motores son de forma muy sinusoidal, pero los valores de sus inductancias son bajas y por tanto no existe la posibilidad del debilitamiento de campo para su regulación. Además de eso sus inductancias directa y transversal son muy similares, lo cual como se explicará más adelante, supone un bajo par reluctante.

Tienen como característica distintiva una alta relación par/inercia. El par del eje aumenta proporcionalmente con la longitud del rotor y con el cuadrado del diámetro del rotor. 
No se conoce ninguna marca de automóviles que hayan incorporado este tipo de motor.

\subsubsection{Motores de imanes interiores (IPM)}

En contraste con los motores imanes en superficie, los de imanes interiores ofrecen ciertas ventajas, como su idoneidad para operaciones a altas velocidades, que es quizá la más obvia.

Estos motores usan habitualmente imanes prismáticos, más fáciles y baratos de fabricar que los de otras geometrías.

La disposición de los imanes puede hacerse de dos formas: embebidos en el rotor, que presentan problemas parecidos al de los SPM y otra que estén enterrados en el rotor que es la solución adoptada habitualmente. El diámetro del rotor está limitado por el número de polos del mismo.

Uno de los pocos inconvenientes respecto a los de superficie, es el aumento del flujo de dispersión especialmente en las uniones (ver Figura 4.4), por lo que se hace necesario minimizarlo y reconducirlo por los caminos adecuados; se ha probado introduciendo barreras de aire y puentes de otros materiales con la doble finalidad de sujetar el imán y aumentar la reluctancia de esos caminos.
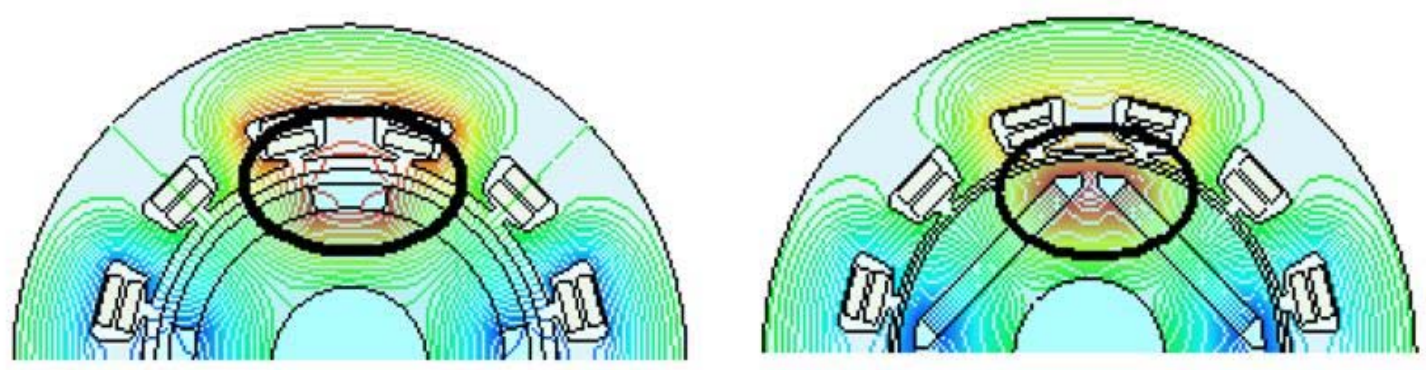

Figura 4.4. Flujos de dispersión en SPM e IPM. [85]

A cambio están más protegidos ante la desmagnetización por la reacción de inducido, para cuidar este aspecto se busca disminuir la reluctancia del camino en el eje directo de la reacción de inducido de forma que prácticamente no circule por los imanes.

Los motores de imanes permanentes presentan intrínsecamente una región estrecha de potencia constante (Zona II). Los imanes interiores añaden un componente de resistencia al par producido por el motor, que tiende a ampliar esa región respecto a las máquinas con imanes en superficie.

En general las pérdidas de Foucault en el rotor son despreciables, no se puede decir lo mismo cuando los imanes están en la superficie. Aún así, si aumenta el diámetro del rotor se practican agujeros para minimizarlas y aligerar el peso, como ocurre en el motor de los Lexus.

Las pérdidas del IPM son mayores en su conjunto especialmente a plena carga, porque los armónicos de reacción de inducido son mayores al ser el entrehierro de muy reducido tamaño.

Son el competidor más serio para los motores de inducción en aplicaciones de tracción. En realidad, muchos fabricantes de automóviles (como Toyota, Honda y Nissan) ya han utilizado estos motores en sus vehículos. Estos motores tienen varias ventajas: mayor densidad de potencia, una mayor eficiencia y la distribución más eficaz de calor en el ambiente.

Uno de los inconvenientes de este tipo de motores es la temperatura, que reduce la curva de desmagnetización de los imanes y el rendimiento por aumentar las pérdidas del cobre. Como ejemplo, un motor de $25 \mathrm{KW}$, funcionando 25 minutos a $5.000 \mathrm{rpm}$, eleva la temperatura del estátor hasta los $150^{\circ} \mathrm{C}[86]$. 


\subsubsection{Ecuaciones de los motores PMSM}

Los devanados del estátor están alimentados por un sistema trifásico equilibrado de tensiones que ha de ser transformado usando las transformaciones de Park a las referencias fijadas para el rotor. El eje directo $d$, es el que marca la dirección del flujo de imanes y está en cuadratura el eje $q$ [87].

La Figura 4.5 muestra el comportamiento de una máquina PMSM en los cuatro cuadrantes de funcionamiento con distintos valores de excitación y manteniendo el flujo constante.

La denominación empleada para los ángulos es:

$\delta=$ Angulo entre $V$ y $E$ = ángulo de potencia

$\varphi=$ Angulo entre $V$ e $I=$ factor de potencia

$\gamma=$ Angulo entre $E$ e $I=\varphi-\delta$

Cuando el ángulo de potencia $\delta$ es positivo la máquina funciona como generador y cuando es negativo funciona como motor. El ángulo $\gamma$ determina si la potencia reactiva es generada o consumida, independientemente de que la máquina sea motor o generador.

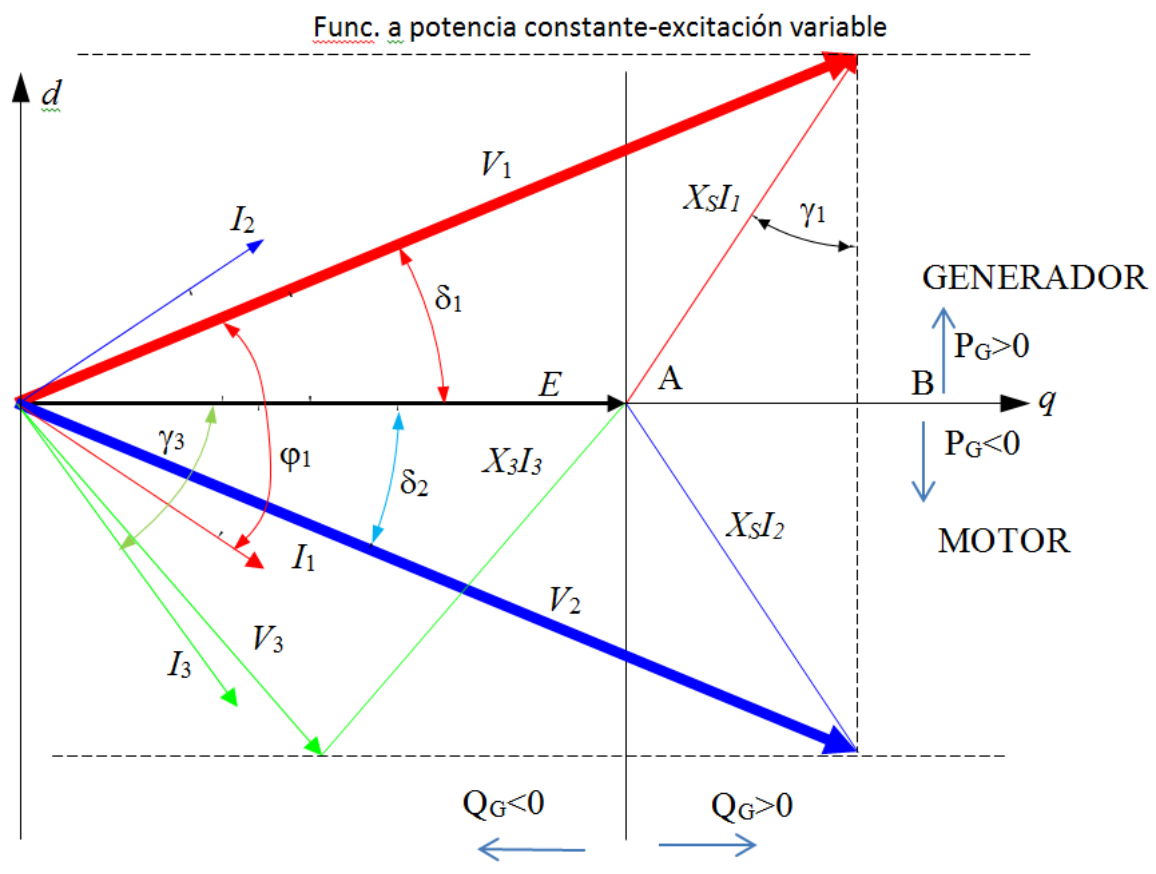

Figura 4.5. Diagrama fasorial de la máquina PMSM.

La fuerza electromotriz por fase a circuito abierto es: 


$$
E=j E_{q}=j \omega \lambda_{P M}
$$

Donde $\omega$ es la velocidad de sincronismo (velocidad eléctrica) y $\lambda_{P M}$ es el flujo común debido a la componente fundamental en el eje $d$ producido por el imán permanente.

De los diagramas fasoriales de Figura 4.5 pueden deducirse:

$$
\begin{aligned}
& V_{d}=-X_{q} I_{q}+R I_{d} \\
& V_{q}=E_{q}+X_{d} I_{d}+R I_{q}
\end{aligned}
$$

En un gran motor la resistencia de los devanados, $R$, es despreciable y se obtiene:

$$
\begin{gathered}
I_{d}=\frac{V_{q}-E_{q}}{X_{d}} \\
I_{q}=-\frac{V_{d}}{X_{q}}
\end{gathered}
$$

La potencia compleja por fase y polo en el motor es:

$$
\begin{aligned}
& \vec{S}=\overrightarrow{V I}=\left(V_{d}+j V_{q}\right)\left(I_{d}-j I_{q}\right)= \\
& =V_{d} I_{d}+V_{q} I_{q}+j\left(V_{q} I_{d}+V_{d} I_{q}\right)=P+j Q
\end{aligned}
$$

Sustituimos las expresiones para obtener la potencia activa. Asumiendo que no hay pérdidas, el par de salida total para las tres fases con $p$ pares de polos será:

$$
T=\frac{3 p}{\omega} P=\frac{3 p}{\omega}\left[\frac{V_{t} E_{q}}{X_{d}} \operatorname{sen} \delta+\frac{\left(X_{d}-X_{q}\right) V_{t}^{2}}{2 X_{d} X_{q}} \operatorname{sen}(2 \delta)\right]
$$

Donde

$$
V_{t}=\sqrt{V_{d}^{2}+V_{q}^{2}}
$$

El primer término de la ecuación (4.9) es el par magnético (o síncrono) y el segundo término es el par reluctante, que es proporcional a la diferencia entre las inductancias del estátor $L_{d}$ y $L_{q}$. En un motor SPM, $L_{d}$ es casi igual que $L_{q}$ y por tanto el par reluctante se anula. En los motores IPM el valor de $L_{d}$ es menor que el de $L_{q}$ debido a que el flujo magnético a lo largo del eje $d$ tiene que cruzar a 
través de los huecos de los imanes además del entrehierro en el rotor, mientras que el flujo magnético en el eje $q$ sólo cruza el entrehierro.

De las dos componentes del par el síncrono es la componente fundamental y el segundo armónico lo constituye el par reluctante.

La Figura 4.6 muestra que el IPM puede alcanzar mayores pares que un motor PM de imanes en superficie, por la diferencia que añade el par reluctante, en color verde.

Si están alineados el flujo y la intensidad del estátor la atracción entre ellos es radial y no se genera par electromagnético, el par máximo se produce a $90^{\circ}$ considerando sólo el magnético, como añadimos el reluctante, se produce con ángulos superiores a los $90^{\circ}$.

En el caso de que el valor de la reactancia en el eje $q$ es mayor que en el eje $d$, el par total empieza adquiriendo valores negativos.

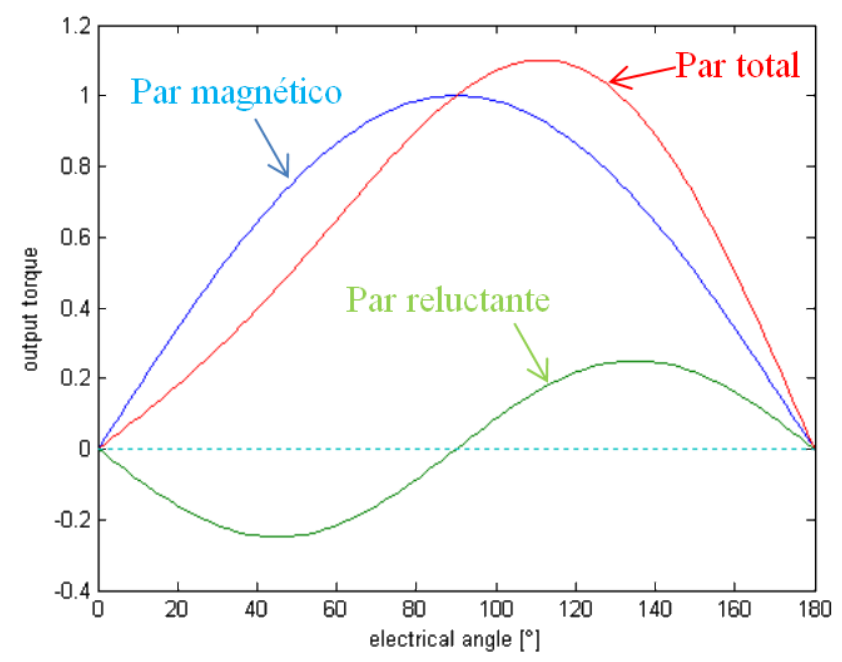

Figura 4.6. Pares característicos de un motor IPM.

Si tomamos un valor normal de corriente de inducido, como puede ser por ejemplo $150 \mathrm{~A}$, los valores habituales de los pares son $176 \mathrm{Nm}$ y120 Nm con una relación entre ellos de 1,47. En la Figura 4.7 puede observarse, por un lado, la proporción indicada de par reluctante y magnético sobre el total, y por otro lado el incremento del par total entre las versiones de Prius 2000 y 2004. La tendencia de todos los fabricantes conduce al predominio del par reluctante sobre el total para evitar la dependencia de los imanes. Todos los estudios indican que se alcanzan el óptimo con un diseño en doble capa.

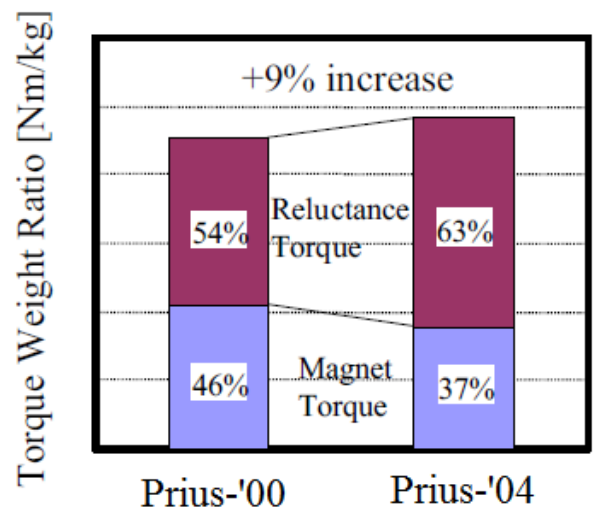

Figura 4.7. Evolución de la composición del par total.[30] 
La ecuación (4.9) puede escribirse con otras expresiones como la (4.12) en la que se aprecia de nuevo como el primer término de la misma depende exclusivamente del flujo magnético de los imanes y el segundo término de la geometría del motor.

$$
\begin{aligned}
& T=\frac{3 p}{\omega}\left[\lambda_{P M} I_{q}+\left(L_{d}-L_{q}\right) I_{d} I_{q}\right]=T_{\text {iman }}+T_{\text {reluct }} \\
& T=\frac{P_{\text {sal }}}{\omega}=I_{q} E_{\text {iman }} / \omega+I_{d} I_{q}\left(L_{q}-L_{d}\right)
\end{aligned}
$$

A la relación $\frac{L_{d}}{L_{q}}=\xi$ se le denomina saliencia. Es un valor que generalmente no es mayor de $3[88]$ y del cual depende directamente el par de reluctancia.

Sería de gran interés poder descomponer en el análisis los dos pares y de este modo ver cómo varía el par reluctante con formas de imanes curvos y ver si compensa la disminución del par de flujo cuando el material aglomerado empleado para dar la forma elegida es de menor energía magnética.

Para maximizar el par habrá que:

- Hacer que el flujo del par magnético no aumente excesivamente a altas velocidades mientras el par reluctante es usado de forma efectiva.

- Dado que $I_{d}$ tiene valor negativo por tanto para mejorar el par reluctante se busca maximizar $L_{q}$ y minimizar $L_{d}$. La geometría debe facilitar el flujo magnético del eje $q$ y el del eje $d$, menos fácilmente.

\subsubsection{Factor de potencia}

Uno de los peores inconvenientes de los IPM es su bajo factor de potencia, incluso cuando trabajan a su máxima potencia.

Algunos ensayos[71] indican que el factor de potencia de potencia máximo de los motores IPM puede ser tan bajo como 0,45. La razón es tan sencilla como que en funcionamiento normal, que corresponde al estado con subíndice 1 del diagrama fasorial de la Figura 4.5, el ángulo de factor de potencia $(\varphi)$, es grande, haciendo que el factor de potencia, $\cos (\varphi)$, sea bajo.

\subsubsection{Modos de funcionamiento [72, 89]}

En la Zona I de la Figura 4.1, cuando la velocidad es baja, se obtiene el par nominal con el valor de intensidad y flujo nominales. La tensión y la potencia van creciendo con la velocidad y cuando la tensión alcanza la máxima de salida del inversor alcanzamos la velocidad base y termina la zona de funcionamiento a par constante, también conocido como MPTA.

Para un valor determinado de corriente del estátor, el par alcanza el máximo, cuando están en fase la intensidad y fem, a partir de la ecuación anterior, en la que ya habíamos despreciado las pérdidas, 
podemos ver que en este caso la tensión solo depende de fem y de la reactancia en el eje $q$ (ver Figura 4.8).

$$
\begin{aligned}
& V^{2}=E_{0}^{2}+\left(I_{q} X_{q}\right)^{2}=(k \omega \varphi)^{2}+\left(I \omega L_{q}\right)^{2} \\
& \frac{V}{\omega}=\sqrt{(k \varphi)^{2}+\left(I L_{q}\right)^{2}}
\end{aligned}
$$

De modo similar al control en las máquinas de inducción hemos de mantener la relación tensión frecuencia.
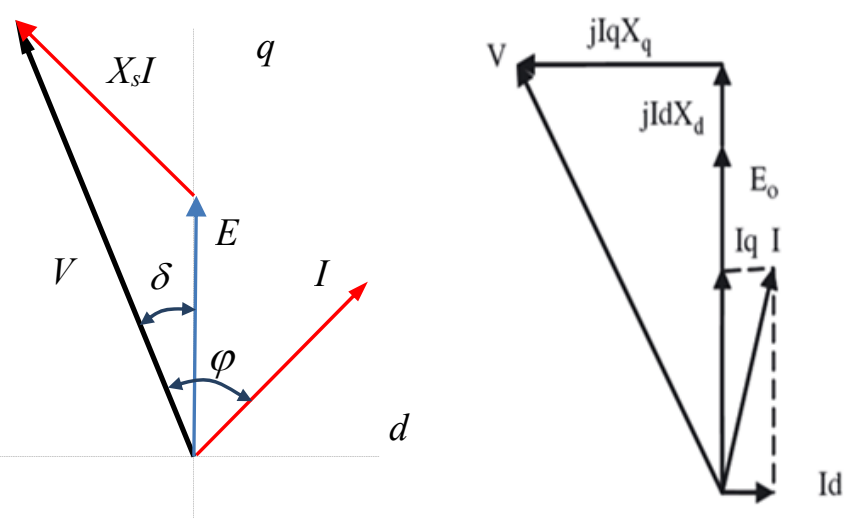

Figura 4.8. Corriente magnetizante en el eje $d$.

A partir de la velocidad base aparece la zona de funcionamiento a potencia constante (Zona II). Para un $\delta$ ángulo de potencia dado, el primer término de (4.13) es constante si $V$ es constante, y ambos $X_{d}$ y $E_{o}$ son proporcionales a la frecuencia $\omega$ como marca el primer término de la ecuación (4.9). El par, por tanto, es inversamente proporcional a la frecuencia en esta zona II.

Para poder seguir aumentando la velocidad, sin que aumente la tensión, es necesario debilitar el campo. En las máquinas con flujo creado por devanados esto es fácil de conseguir variando su intensidad, pero en las IPM se requiere una reacción de inducido que inyecte corriente en el eje directo, contraria al flujo creado por los imanes.

Expresándolo de otro modo, cuando la tensión del estátor alcanza su máximo, la ecuación (4.13) ya no se puede mantener. A medida que aumenta $\omega, V$ se hace constante, y hay que suministrar, una corriente en la dirección del eje $d$ de sentido contrario a la anterior. La relación de la tensión y la frecuencia se puede expresar ahora como:

$$
\begin{aligned}
& V^{2}=\left(E_{0}-I_{d} \cdot X_{d}\right)^{2}+\left(I_{q} \cdot X_{q}\right)^{2}=\left(k \omega \varphi-I_{d} \omega L_{d}\right)^{2}+\left(I_{q} \omega L_{q}\right)^{2} \\
& \frac{V}{\omega}=\sqrt{\left(k \varphi-I_{d} \cdot X_{d}\right)^{2}+\left(I_{q} \cdot X_{q}\right)^{2}}
\end{aligned}
$$

Este es el funcionamiento con debilitamiento de campo debido a que la corriente del eje $d$ genera un flujo magnético en la dirección opuesta al campo PM. Cuando la máquina funciona así es necesario 
tener en cuenta limitaciones tales como el valor de corriente del inversor, la corriente de eje $q$ debería ser disminuida de su valor nominal para mantener el valor la corriente total del inversor (ver Figura 4.9). Las pérdidas adicionales a velocidades más altas pueden hacer que sea necesario reducir aún más el par total.

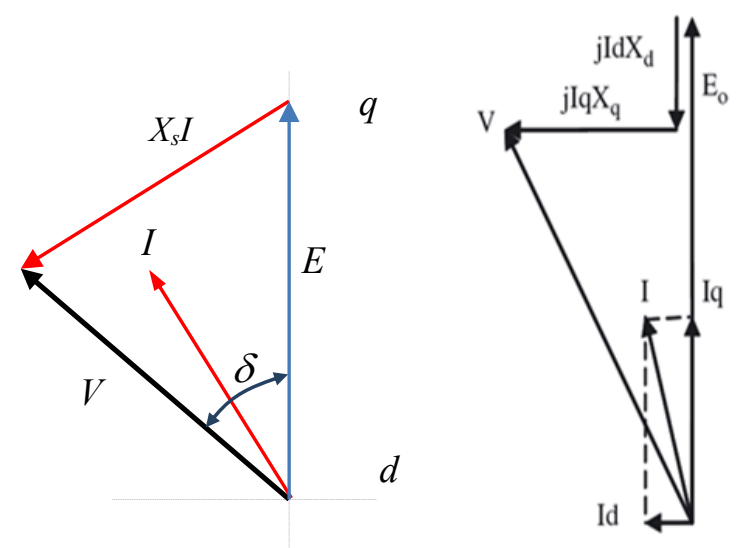

Figura 4.9. Corriente desmagnetizante en el eje $d$.

Es necesario para todo lo dicho anteriormente que haya una diferencia importante entre las reactancias en los ejes $d$ y $q$. Una de las desventajas que aportan los imanes superficiales es que se iguala la reactancia en el eje $d$ y en el perpendicular, anulándose ese término del par y no permitiendo este modo. En cambio, para los motores IPM, el eje $q$ tiene menos reluctancia debido a la existencia de hierro dulce en su camino, y el eje $d$, que tiene imanes, presenta mayor reactancia. Por lo tanto, $X_{q}$ es mucho mayor que $X_{d}$ y la maquina opera adecuadamente con debilitamiento de campo.

\subsubsection{Par oscilante $[90,91]$}

Uno de los inconvenientes de estas máquinas como ya se ha mencionado es el par de rizado (ripple) [90]. Éste se debe a tres componentes: par oscilante, par de reluctancia y la distorsión de la forma de onda de la densidad de flujo magnético en el entrehierro.

El par oscilante o "cogging torque" responde a la ecuación (4.15) que se muestra gráficamente en la Figura 4.10. Este par se debe a la interacción del flujo magnético de los imanes y la geometría de los dientes del estátor lo que produce una reluctancia variable que depende de la posición del rotor.

Se manifiesta por la tendencia del rotor de alinearse a una serie de posiciones y se produce incluso cuando no hay intensidad en los devanados. Es un par periódico con el movimiento del rotor y con signo negativo, oponiéndose a los otros pares.

$$
T_{c}=-\frac{1}{2} \frac{\oslash^{2} d R_{m}}{d \delta}
$$

Donde:

$\varnothing=$ flujo en el entrehierro 


$$
\frac{d R_{m}}{d \delta}=\text { variación de la reactancia respecto del ángulo }
$$

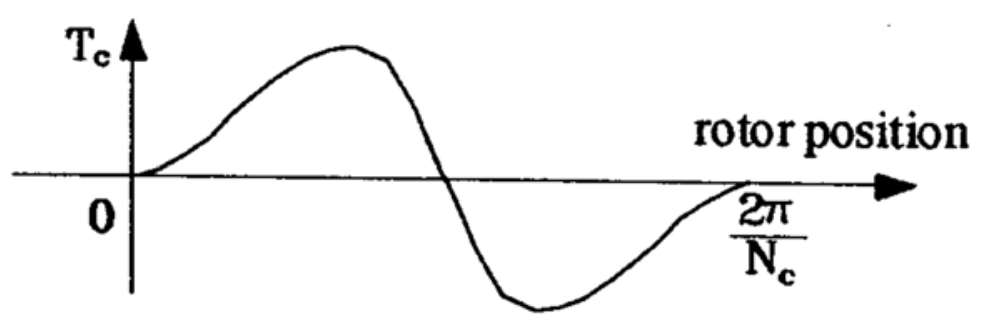

Figura 4.10. Forma típica del par oscilante.[19]

Es un fenómeno no deseado porque, además del rizado en el par, produce ruido y vibración mecánica. La reducción del par oscilante no garantiza la disminución del rizado total.

Se han probado varios métodos para reducirlo:

- Sesgando bien las ranuras del estátor o los polos, ambos métodos resultan excesivamente caros en los procesos de fabricación.

- Número fraccional de ranuras.

- Modificación de la forma y dimensiones de la ranura del estátor.

- Muescas en la superficie del diente y en las chapas del rotor.

- Cambios en la dirección de magnetización de los imanes.

- Posibilidades asimétricas en la disposición de los elementos.

\subsection{Resumen comparativo de tipos de motores $[79,92]$}

Se presenta a continuación una comparativa para su aplicación a HEV de los tipos de motor comentados en los apartados anteriores.

\subsubsection{Comparativa de par específico}

En la Figura 4.11 se reflejan los valores medios del par específico de los motores anteriores, donde puede apreciarse que los que incorporan imanes permanentes superan el valor de $80 \mathrm{Nm} / \mathrm{kg}$. 


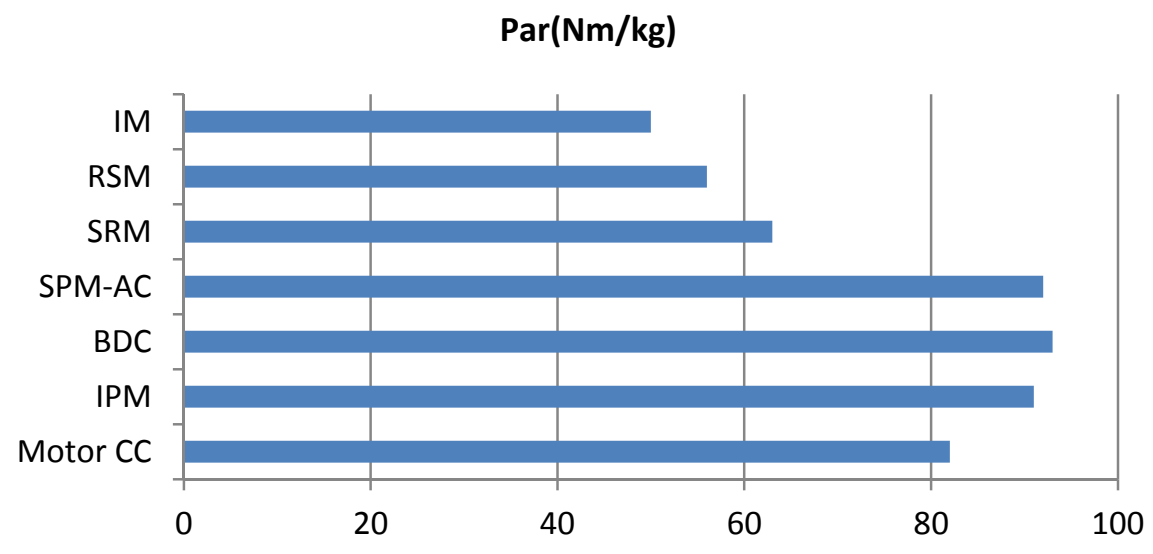

Figura 4.11. Par específico para distintos tipos de motores.[79]

Además, como se muestra en la Figura 4.12, los IPM presentan zonas amplias de par y potencia constante, por tanto con buenos valores de CPSR (de 3-4 veces la velocidad base), lo cual no puede decirse de los motores RSM.

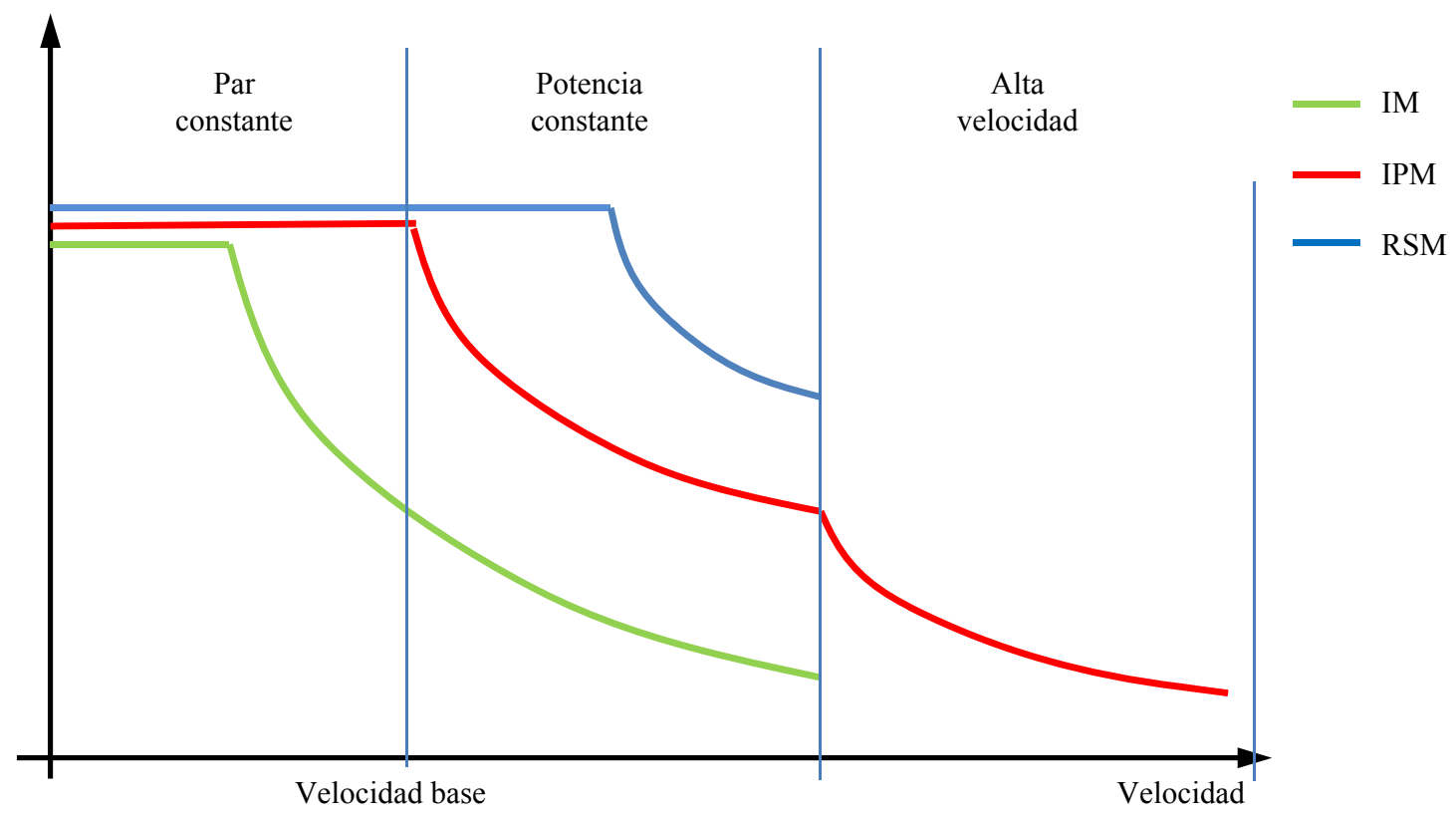

Figura 4.12. Curvas de par por tipo de motor.[93]

\subsubsection{Comparativa de rendimiento}

Los datos de eficiencia mostrados en la Tabla 4-2 son genéricos ya que no contemplan los ciclos de conducción de los vehículos, por lo que pueden variar al menos en un 3\%, pero sirven para tener una idea general de los mismos. Los motores sin devanados eliminan las perdidas por efecto Joule y presentan, como era de esperar, rendimientos superiores.

Tabla 4-2. Comparativa de eficiencia de tipos de motores eléctricos

\begin{tabular}{cc}
\hline \multicolumn{2}{c}{ Eficiencia del motor (\%) } \\
\hline PMSM & 97 \\
SRM & 94 \\
\hline
\end{tabular}




\begin{tabular}{cc}
\hline IM & 90 \\
BDC & 80 \\
\hline
\end{tabular}

En el estudio realizado por Malcolm Burwell [94] se superponen los puntos más habituales de operación sobre la curva de rendimiento del motor (ver Figura 4.13). Se puede observar que cuando el motor eléctrico opera en ciclo urbano (lo más habitual), sitúa gran parte de sus puntos de rendimiento por encima del $90 \%$ y en el momento que aumenta la velocidad se sitúa en mejores posiciones del mapa. Si lo comparamos con el mapa de inducción, partimos de valores más bajos de rendimiento representados con tonos menos rojos hablamos de un 5\% menos y además la zona de mayor rendimiento se sitúa más alejada de la zona de trabajo, ambos factores hacen que la diferencia sea importante.

\section{IPM}
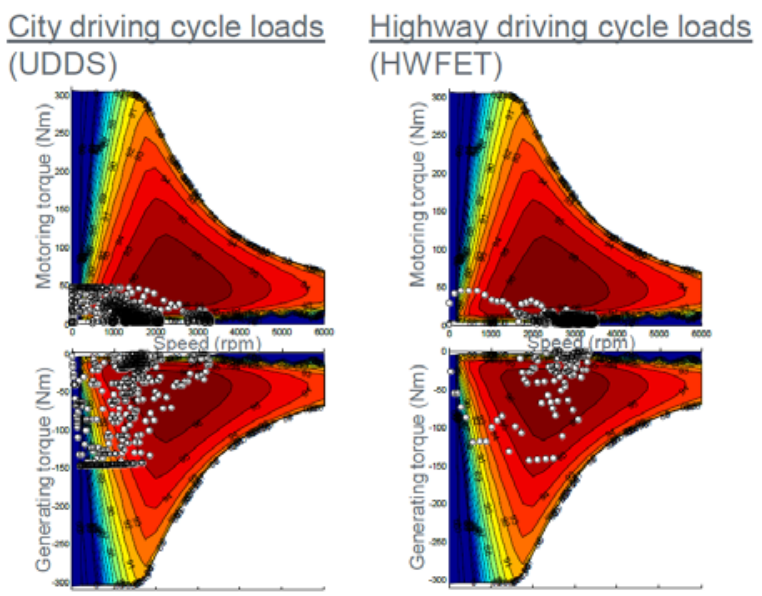

Aggressive driving cycle loads
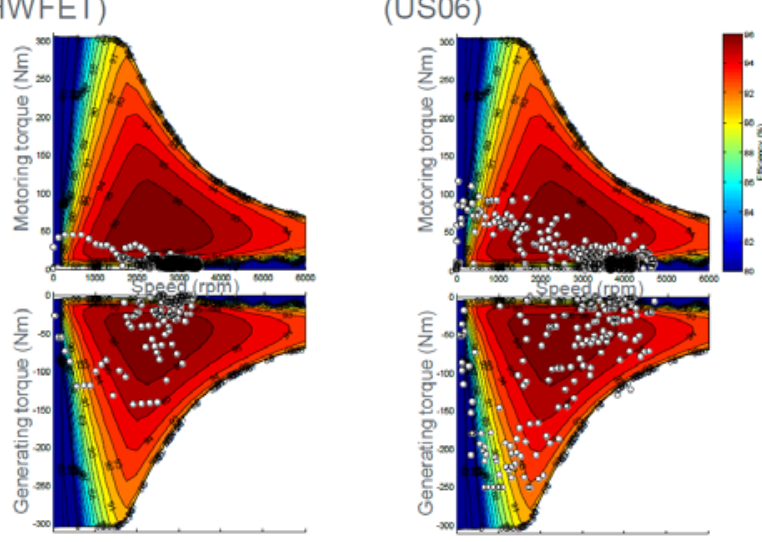

IM
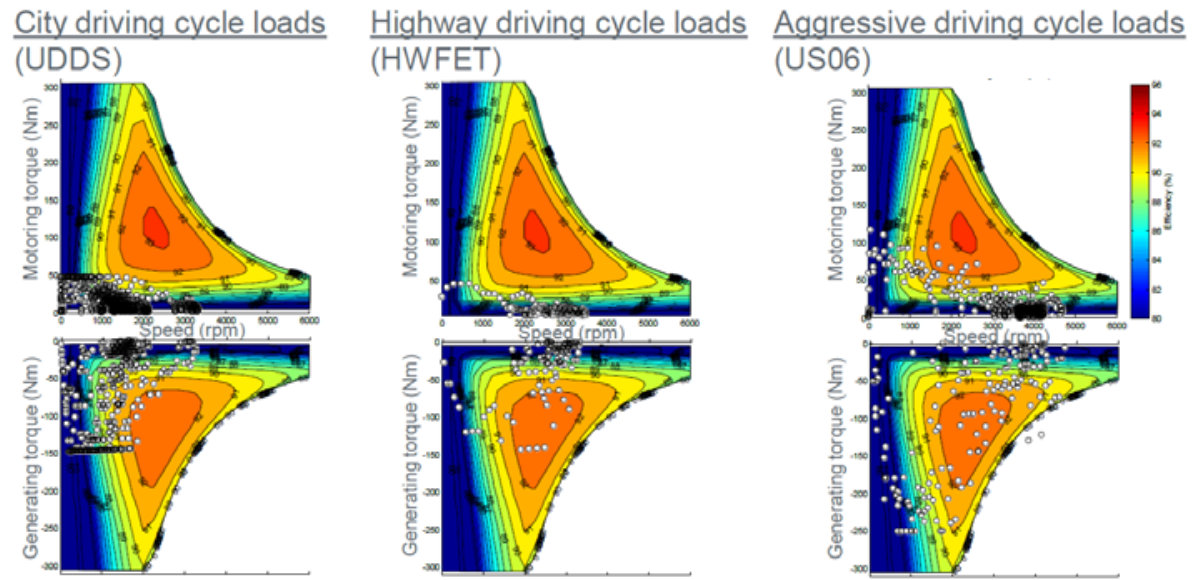

Figura 4.13. Eficiencia de motores IPM (encima) e IM en distintos puntos de funcionamiento.[94]

Otra comparativa de la eficiencia se muestra en la Figura 4.14. Las curvas de rendimiento en función de la potencia presentan el mismo orden y magnitudes que los presentados en la Tabla 4-2. 


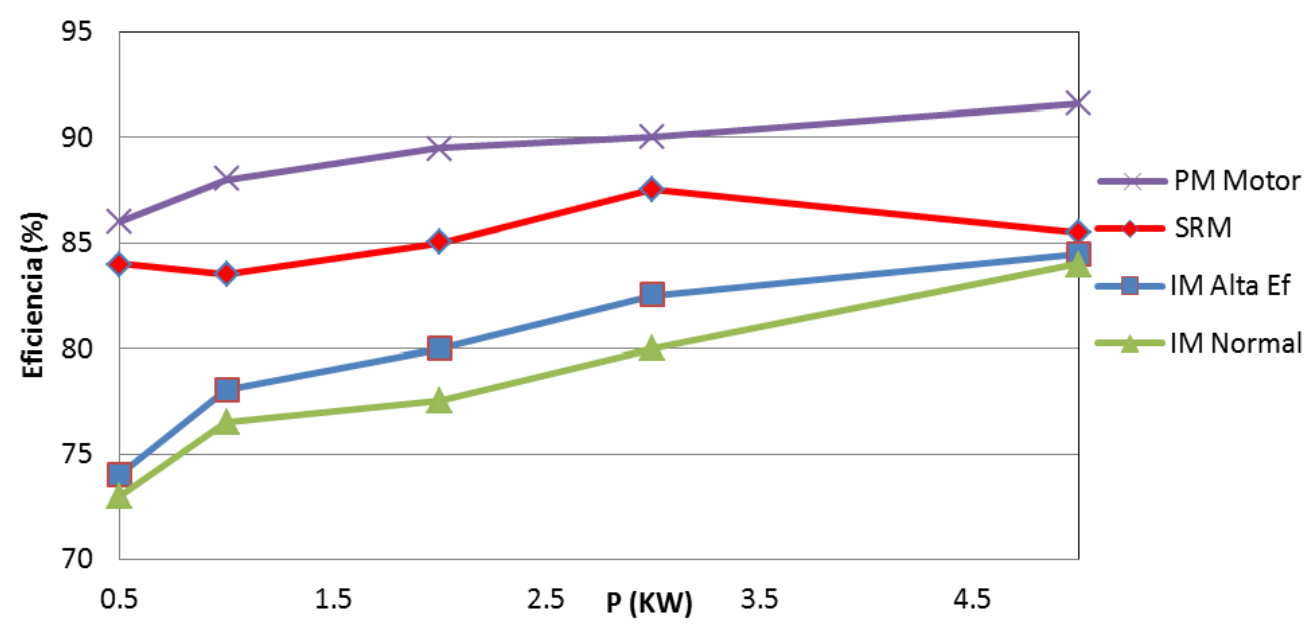

Figura 4.14. Comparativa entre motores de inducción, IPM y SRM. [69]

\subsubsection{Comparativa de costes/peso y tamaño}

En la Tabla 4-3, se presenta la última comparativa con datos prácticos. Los costes de los motores de inducción no sufren variación importante, mientras que los de imanes permanentes dependen del precio los imanes (bastante volátiles) a los que se dedicará un apartado especial en el capítulo 3.

En relación al peso el cobre de los devanados hace que se duplique el peso de los motores asíncronos y el volumen sea un $70 \%$ menor para el IPM (Figura 4.15).

Tabla 4-3. Comparativa de coste y peso por tipo de motor [93]

\begin{tabular}{lrr}
\hline Tipo & $\begin{array}{r}\text { Coste } \\
(\mathbf{\$} / \mathbf{k g})\end{array}$ & $\begin{array}{r}\text { Peso } \\
(\% \text { sobre }\end{array}$ \\
\hline PMSM)
\end{tabular}

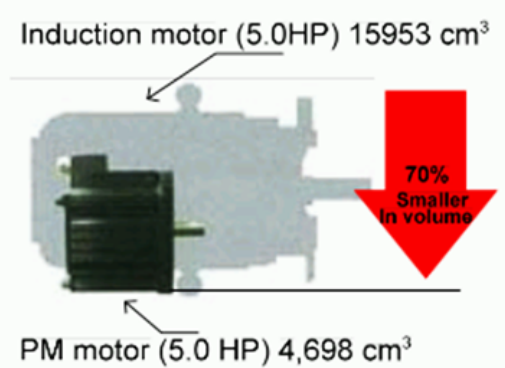

Size comparison of PM and IM (YE motor)

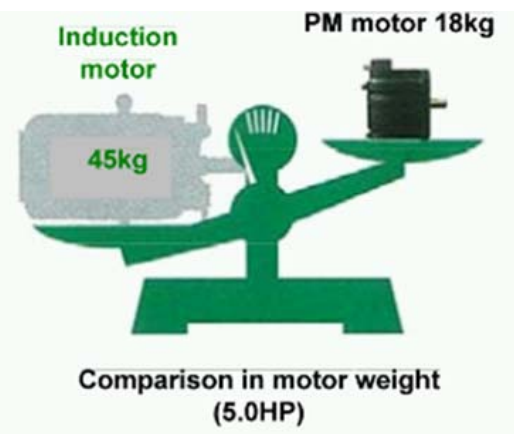

(5.OHP)

Figura 4.15. Ventajas de los motores PM respecto a los de inducción.[95]

La elección del motor no sólo tiene importancia por sí misma sino que además tiene influencia en los elementos con los que se relaciona como la batería y el inversor. Actualmente la batalla más importante se presenta entre dos tecnologías, IM e IPM siendo los factores que inclinan la balanza a uno u otro lado claros: mejor rendimiento de los IPM y mejor precio los IM. 
Otro claro factor que determina la elección de un tipo u otro es la potencia. Las aplicaciones en vehículos pesados industriales, en aplicaciones militares, camiones y autobuses, todos ellos de gran tamaño y elevada potencia, las dominan los IM, quedando el mercado de vehículos ligeros y de menor potencia para los IPM.

Existe otro factor relacionado con los gustos de los fabricantes: los coches de diseño americano implementan preferentemente IM y los japoneses se inclinan por los IPM. En la tabla del Anexo I se puede comprobar este hecho.

Hasta hoy los demás tipos se consideraban intentos exóticos, pero los precios de mercado tanto de tierras raras como del cobre, y los avances de los inversores hace que, a fecha de hoy, las otras tecnologías vuelvan a ser una fuerte apuesta para los fabricantes.

Como resumen de los distintos aspectos comentados en este apartado se presentan las siguientes tablas comparativas. En la Tabla 4-4 se indican las ventajas e inconvenientes de los tipos de motor eléctrico cuando se aplican a los vehículos eléctricos.

Tabla 4-4. Ventajas e inconvenientes de motores utilizados en vehículos eléctricos.

\begin{tabular}{|c|c|c|}
\hline Tipo de motor & Ventajas & Inconvenientes \\
\hline $\begin{array}{l}\text { Motor de CC } \\
\text { (BDC) }\end{array}$ & $\begin{array}{c}\text { Fácil de controlar } \\
\text { Curva par-velocidad deseable }\end{array}$ & $\begin{array}{l}\text { Necesidad de mantenimiento. } \\
\text { Baja eficiencia y fiabilidad } \\
\text { Bajo rango de velocidades }\end{array}$ \\
\hline $\begin{array}{l}\text { Motor de inducción } \\
\text { (IM) }\end{array}$ & $\begin{array}{l}\text { Alto rango de velocidades } \\
\quad \text { Alta fiabilidad } \\
\text { Bajo coste } \\
\text { Robusto en entorno hostil }\end{array}$ & $\begin{array}{c}\text { Baja densidad de potencia y gran tamaño } \\
\text { Baja eficiencia } \\
\text { Problemas térmicos a altas velocidades }\end{array}$ \\
\hline $\begin{array}{l}\text { Motor Síncrono } \\
\text { de imanes permanentes } \\
\text { (PMSM) }\end{array}$ & $\begin{array}{l}\text { Alta densidad de potencia } \\
\text { y pequeño tamaño } \\
\text { Alta eficiencia }\end{array}$ & $\begin{array}{l}\text { Rango de velocidades limitado } \\
\text { Alto coste } \\
\text { Altas pérdidas en el núcleo del estátor a altas velocidades }\end{array}$ \\
\hline $\begin{array}{l}\text { Motor de reluctancia variable } \\
\text { (SRM) }\end{array}$ & $\begin{array}{l}\text { Curva par-velocidad deseable } \\
\text { Alta fiabilidad } \\
\text { Bajo coste } \\
\text { Robusto en entorno hostil }\end{array}$ & $\begin{array}{l}\text { Alto par de rizado y ruido } \\
\text { Baja densidad de potencia } \\
\text { Baja eficiencia }\end{array}$ \\
\hline
\end{tabular}

Finalmente por expresarlo de un modo más cuantitativo, en [93] se eligen seis factores asignándoles una puntuación de 1 a 5 como valor máximo en su categoría. El motor con mayor puntuación es el de inducción con 26 puntos, seguido por el de imanes permanentes con 25 puntos.

Tabla 4-5. Valoración de tipos de motores eléctricos para HEV. [93]

\begin{tabular}{lccccc}
\hline \multicolumn{1}{c}{ Característica } & BDC & IM & SPM & IPM & SRM \\
\hline Densidad de potencia & 2,5 & 3 & 4,5 & 5 & 3,5 \\
Eficiencia & 2,5 & 3 & 5 & 5 & 3,5 \\
Debilitamiento de campo & 5 & 5 & 3 & 4 & 3 \\
Fiabilidad & 3 & 5 & 3 & 4 & 5 \\
Desarrollo tecnológico & 5 & 5 & 3 & 4 & 4 \\
Coste & 4 & 5 & 4 & 3 & 4 \\
Total & 22 & 26 & 22,5 & 25 & 23 \\
\hline
\end{tabular}

Además de los tipos indicados, actualmente se están manejando otras posibilidades referidas a cambios estructurales, como situar los imanes en un rotor exterior y los devanados en el estátor interior (Figura 4.16). Esta es la solución adoptada por Audi en su modelo Q7 e-tron y desarrollada por UQM como evolución de su modelo anterior, presentado en el capítulo de simulación: 


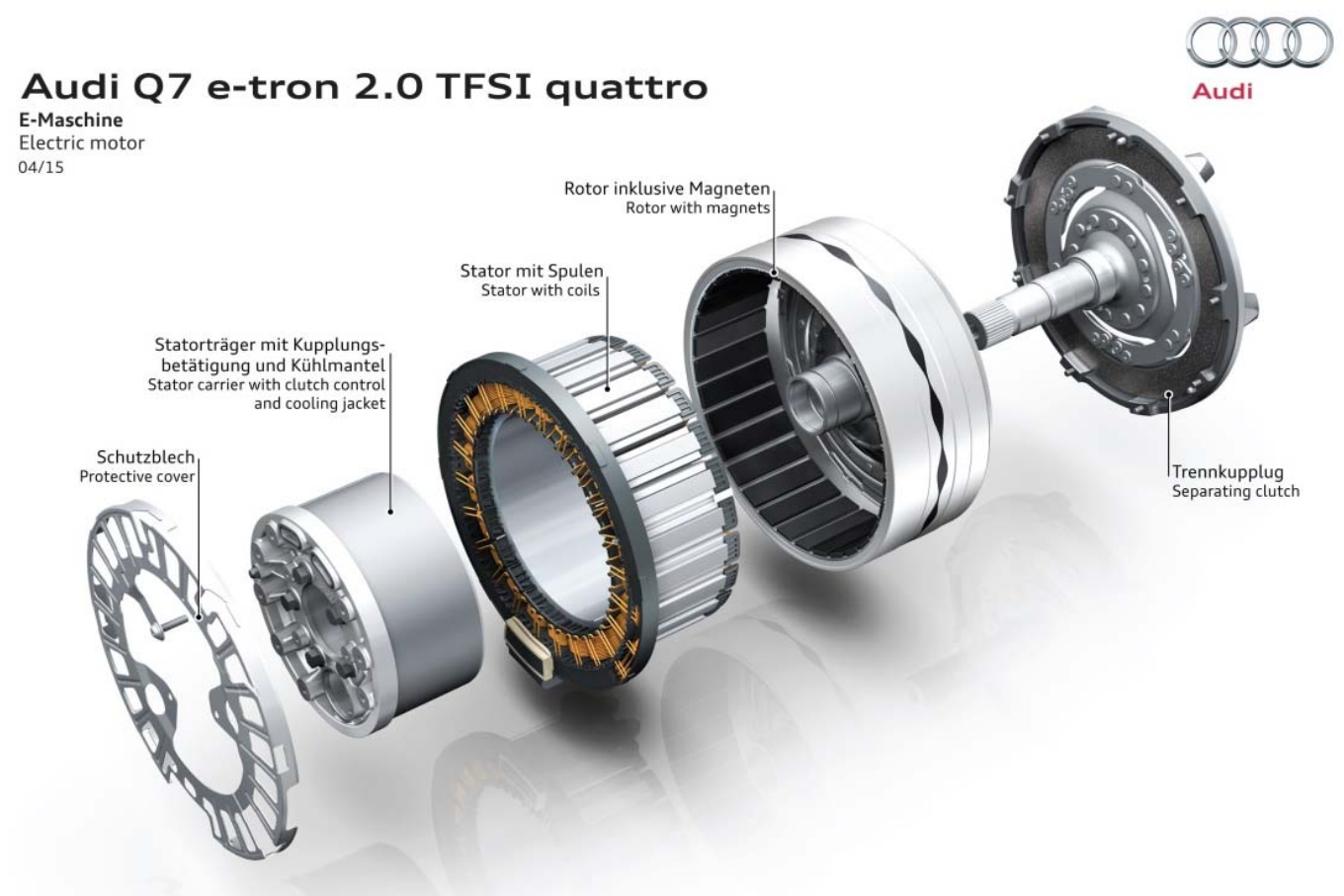

Figura 4.16. Motor eléctrico Audi Q7 e-tron.[96]

Otra posible modificación es colocar gran cantidad de imanes radiales empleando para los mismos ferritas sinterizadas y el uso de motores de flujo axial, siendo de momento prototipos que no se han implementado por ningún fabricante. 



\section{Análisis de modelos mediante elementos finitos}

\subsection{Introducción a la simulación por elementos finitos [97-99]}

El análisis mediante elementos finitos ("Finite Elements Analysis") o FEA es una herramienta matemática que proporciona soluciones numéricas aproximadas para la solución de ecuaciones diferenciales que se aplican sobre cuerpos para caracterizar su comportamiento físico. Para ello el cuerpo se divide en pequeños subdominios denominados elementos finitos definidos por vértices o nodos que forman mallas. En los nodos se plantean ecuaciones que relacionan un conjunto de variables incógnitas denominadas grados de libertad donde se pueden establecer ecuaciones linealizadas entre los distintos elementos adyacentes que facilitan el cálculo.

La aplicación de FEA en el estudio de las máquinas eléctricas es una herramienta muy útil ya que permite predecir el comportamiento estático o dinámico y optimizar su geometría sin tener que construir la máquina físicamente. En nuestro trabajo utilizamos el software Maxwell de ANSYS(C) para la definición y análisis de los modelos desarrollados.

Los tipos de análisis que normalmente se pueden realizar mediante esta herramienta de elementos finitos son:

- Análisis de campos electrostáticos: Calcula el campo eléctrico estático que existe en una estructura dada una distribución de tensiones de CC y cargas estáticas. Una matriz de capacitancia, fuerza, par de torsión, y la concatenación de flujo también se pueden calcular.

- Análisis de campos magnetostáticos: Calcula el campo magnético estático que existe en una estructura dada una distribución de corrientes CC y los imanes permanentes. El campo magnético se puede calcular en ambas estructuras con materiales no lineales y lineales. También se pueden calcular la matriz de inductancia, la fuerza, par de torsión, y la concatenación a partir de la energía almacenada en el campo magnético

- Análisis de conducción en Corriente Alterna: Calcula, dada una distribución de tensiones alternas, la densidad de corriente y las tensiones de distribución de CA en un material que tiene propiedades tanto conductoras como dieléctricas. También se pueden calcular la matriz de admitancias y el flujo de corriente a partir de los campos calculados.

- Análisis de conducción en Corriente Continua: Calcula las corrientes continuas que fluyen en un dieléctrico con pérdidas dada una distribución de tensiones continuas. Una matriz de conductancia y el flujo de corriente también se pueden calcular a partir de la solución de campo eléctrico. 
- Análisis de corrientes de Foucault (Eddy currents): Calcula el campo magnético oscilante que existe en una estructura dada una distribución de corrientes alternas. También calcula densidades de corriente, teniendo en cuenta todos los efectos de las corrientes de Foucault (incluidos los debidos al efecto piel). También se pueden calcular la matriz de impedancias, fuerza, par de torsión, pérdidas en el hierro y el flujo de corriente a partir de las soluciones anteriores.

- Análisis magnético transitorio: Calcula los campos magnéticos transitorios (en el dominio del tiempo) debidos a imanes permanentes, conductores y bobinados alimentados por tensión y/o fuentes de corriente con variación arbitraria en función del tiempo, la posición y la velocidad. También se puede acoplar con circuitos externos. Los efectos de movimiento rotacional o de traslación pueden ser incluidos en la simulación

El análisis de una máquina eléctrica mediante elementos finitos consta de los siguientes procesos:

1.- Definir la geometría de los elementos de la máquina, bien importándola de programas de $\mathrm{CAD}$, bien diseñándola desde el propio software. Normalmente se hace de forma paramétrica para poder estudiar el efecto del cambio de una variable como, por ejemplo, el espesor o longitud de los imanes.

En nuestro caso, si bien podemos modelar el motor en 3D, la forma cilíndrica del motor hace mucho más rápido y sencillo el cálculo en $2 \mathrm{D}$ aprovechando su simetría axial. Así, dado que el motor dispone de 8 polos, con analizar un octavo del motor ( $45^{\circ}$ de sección) será suficiente (ver Figura 5.1).

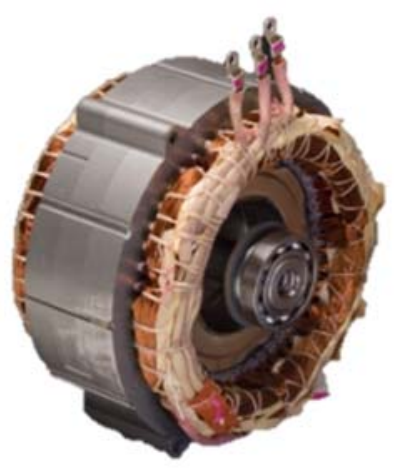

a)

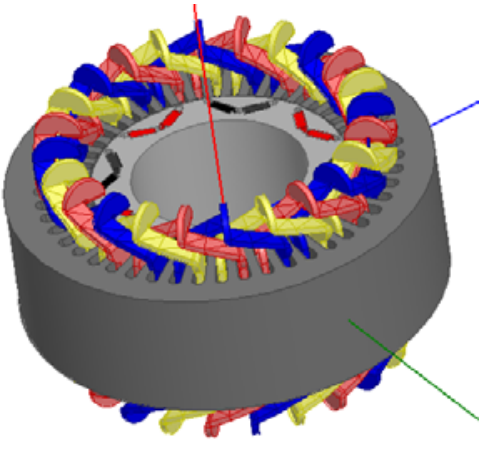

b)

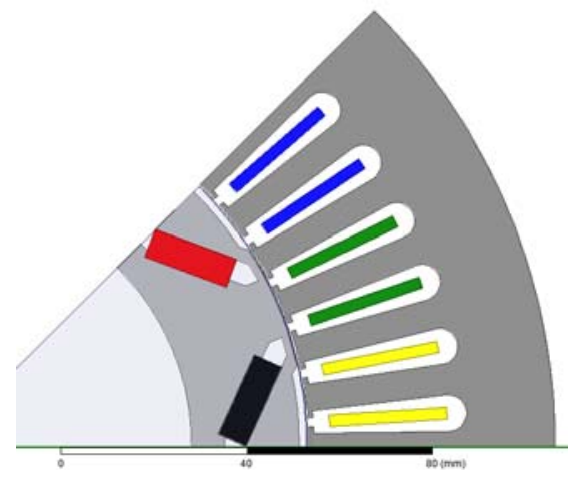

c)

Figura 5.1. Motor MG2 del Toyota Prius 2004: a) real y su modelado b) completo en 3D y c) en 2D con simetría de un polo.

2.- Asignar materiales y sus propiedades a los distintos elementos. Dependiendo del tipo de análisis que se vaya a hacer (mecánico, magnético, eléctrico,..) serán necesarias unas propiedades físicas u otras. En el caso de los imanes se debe establecer la forma y la isotropía y dirección de su magnetización.

En los modelos desarrollados se utilizan 3 tipos de materiales con características magnéticas distintas:

- El acero magnético de las chapas del rotor y estátor. En este caso, como se indica en el apartado 2.3.1, el acero utilizado en la mayoría de motores es el denominado M19-29G, que es el equivalente 
al mencionado en el capítulo 2.3.1 y cuya curva de magnetización es no lineal y se muestra en la Figura 5.2.

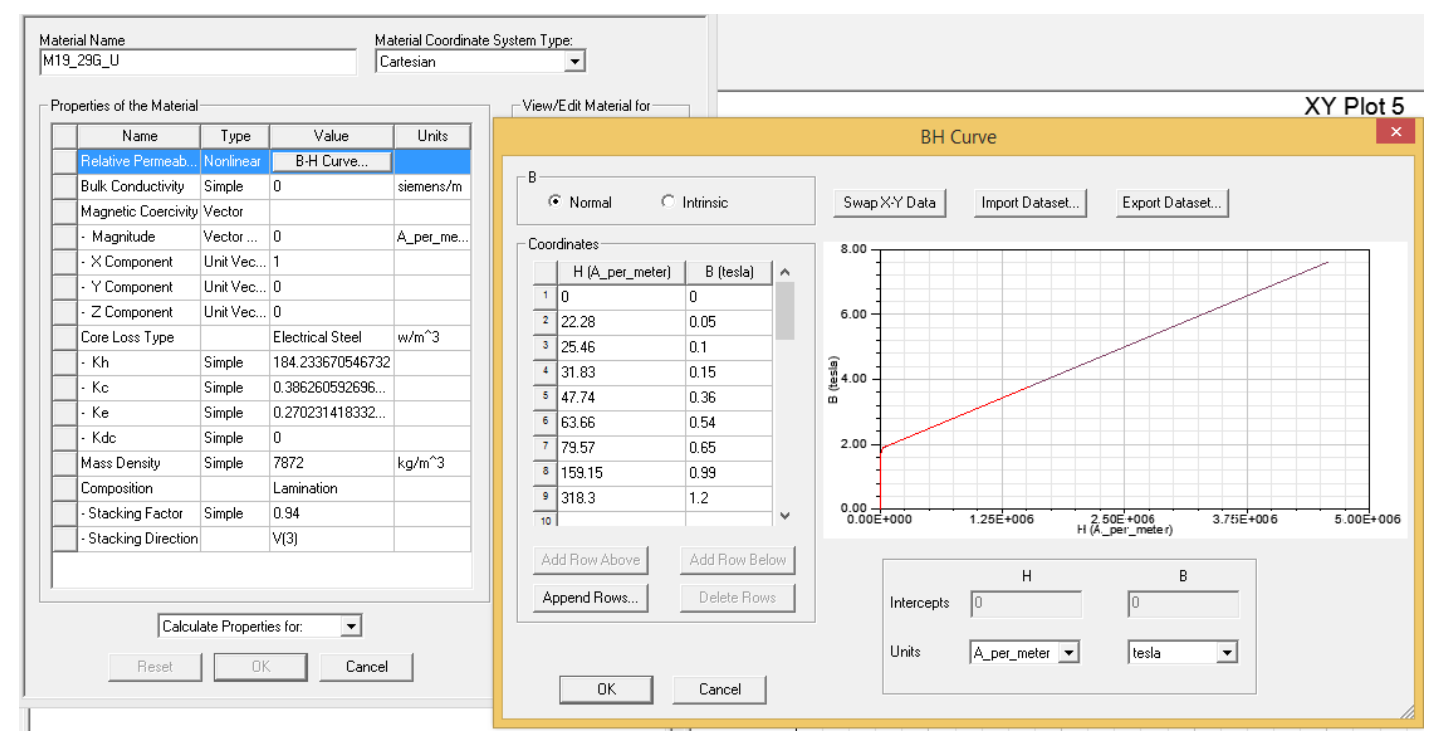

Figura 5.2. Curva de magnetización no lineal del acero M19-29G. [98]

- El cobre de los bobinados del estátor. Dado que no es un material magnético sólo se indica su resistividad eléctrica. En ellos se va a indicar la intensidad de excitación.

- El material magnético de los imanes. Todo software de análisis de elementos finitos tiene un bloque de definición de materiales magnéticos y sus curvas características de desmagnetización. En este caso se dispone de un apartado específico para definición de materiales de imanes permanentes.

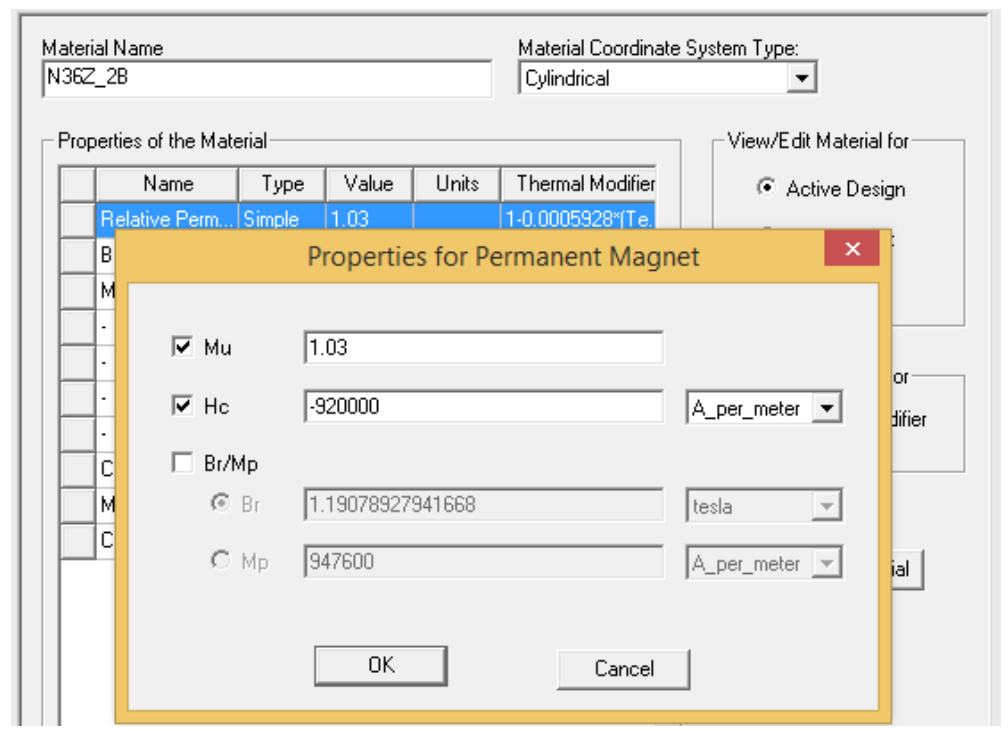

Figura 5.3. Definición de material para imanes permanentes. [98]

También hay que indicar la dirección de magnetización de los imanes, lo que se realiza con sistemas de coordenadas relativos asociados a los imanes para que al girar el rotor la magnetización sea correcta. 


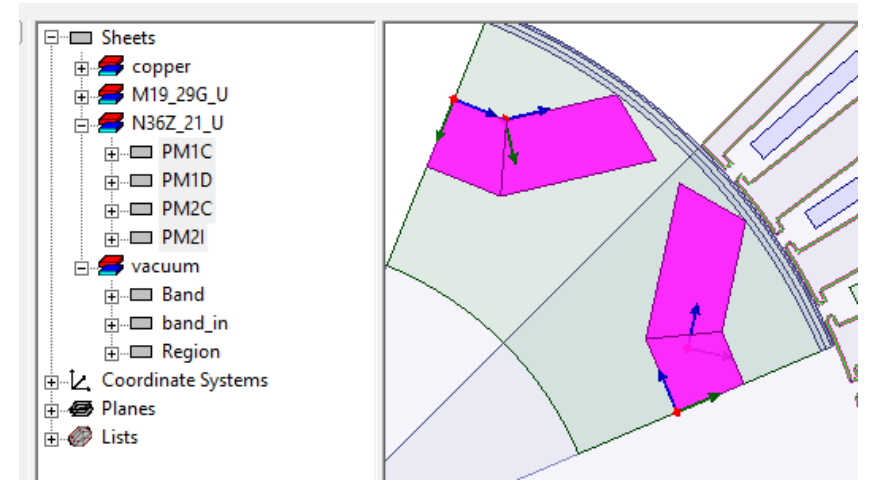

Figura 5.4. Sistemas de coordenadas relativos en los imanes.

3.- Definición de las excitaciones eléctricas. Pueden ser tensiones o intensidades y, dependiendo del tipo de análisis, pueden ser de corriente continua o de corriente alterna. Se indican mediante vectores con módulo y dirección en análisis magnetostáticos o con funciones matemáticas en los análisis de régimen transitorio, que en nuestro caso se trata de corrientes trifásicas sinusoidales equilibradas que se definen mediante sus ecuaciones sinusoidales y se aplican en cada bobina como se muestra en la Figura 5.5.

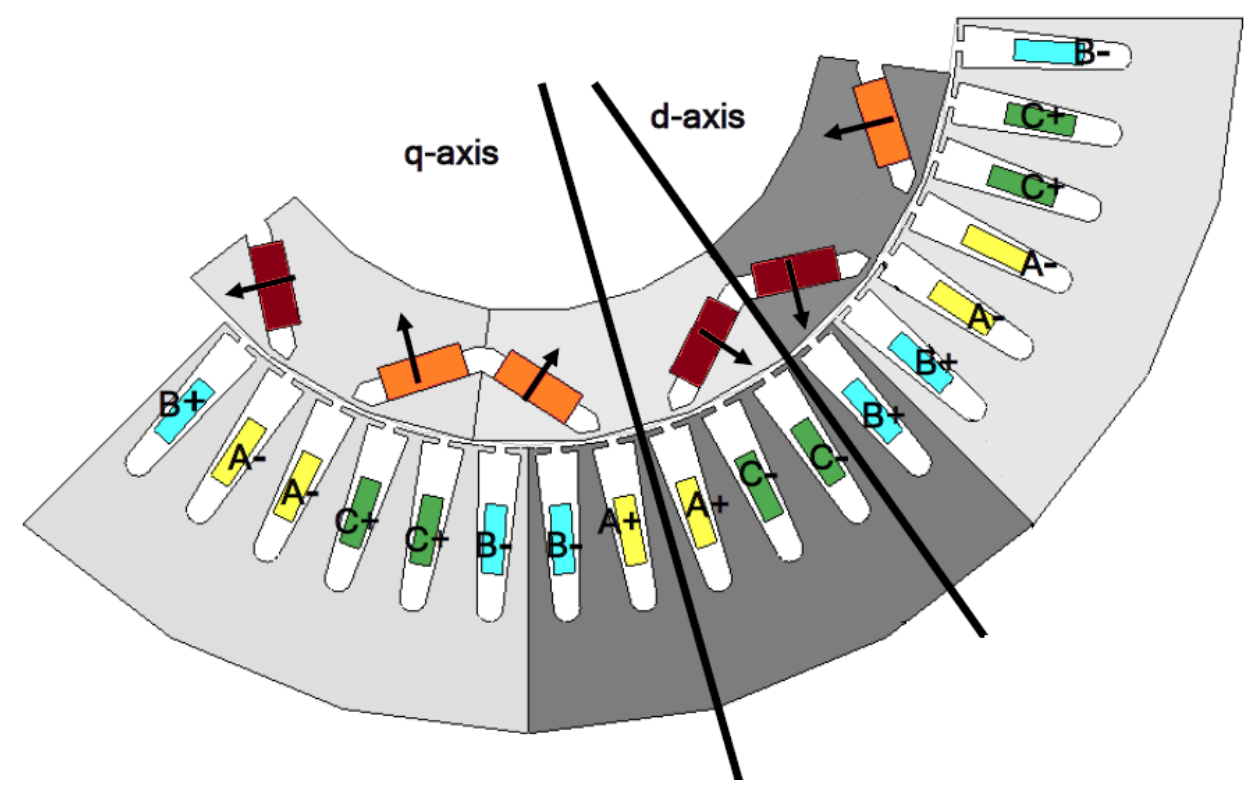

Figura 5.5. Excitación trifásica en las bobinas. Ejes d y q y magnetización de los imanes. [98]

4.- Definición de las condiciones de entorno. Representan las condiciones del espacio donde se introduce el modelo, como líneas de flujo nulo (línea roja) y las simetrías de flujo y geometría (líneas amarillas) que se definen en la geometría del motor y delimitan el sector de círculo mostrado en la Figura 5.6 


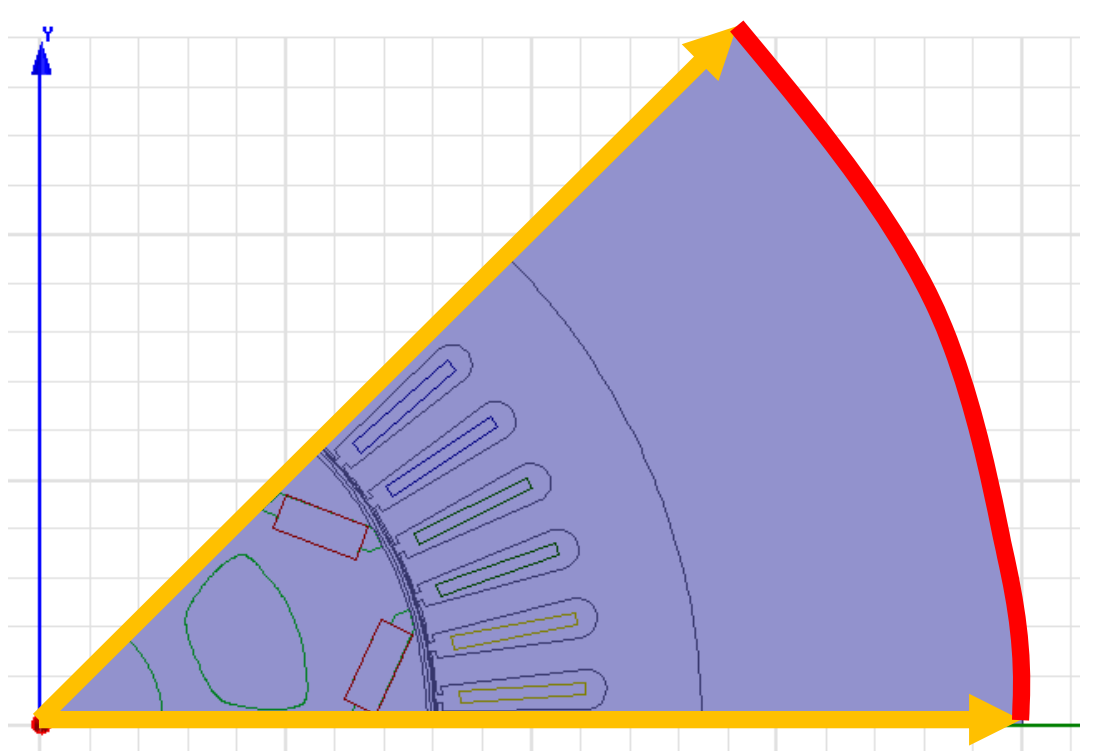

Figura 5.6. Definición de las condiciones de contorno.

5.- Establecimiento de las condiciones del análisis. Se define el tipo de análisis de los mencionados anteriormente y sus parámetros. Por ejemplo, si es un análisis magnetostático transitorio, cuál es el periodo de tiempo a simular y con qué incremento de tiempo, cuál es la velocidad de giro, inercia del rotor, elementos sobre los que aparece el par, etc...

6.- Definición de las operaciones de mallado de los elementos finitos. Se indica cómo se calculan los elementos finitos en los que se divide un elemento. Por ejemplo si son tetraedros o paralelogramos, tamaño máximo, refinamientos en zonas determinadas como franjas estrechas, entrehierro, zonas de concentración de flujo, etc..

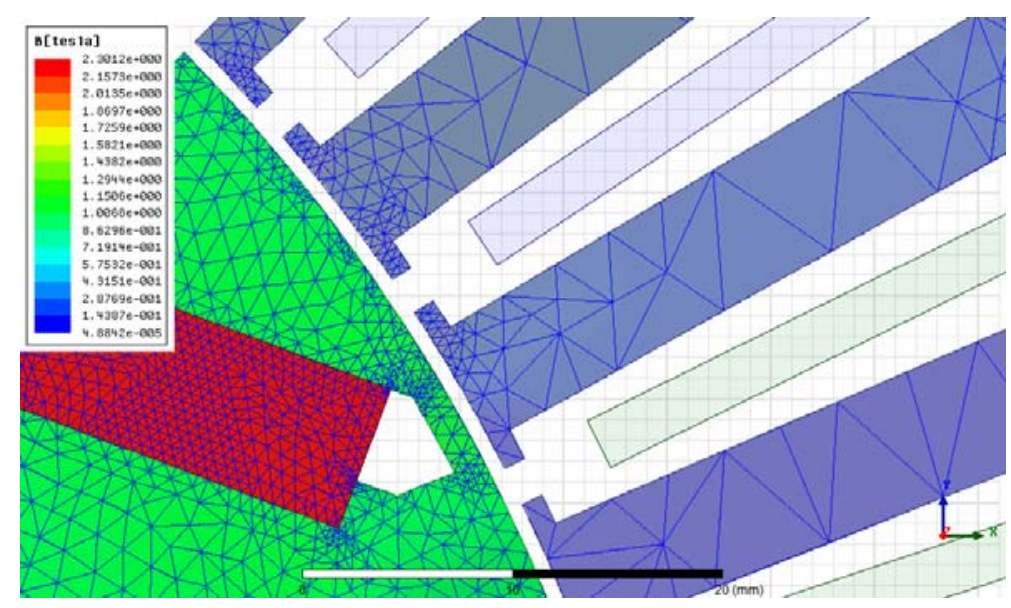

Figura 5.7. Diferentes niveles de mallado de elementos finitos.

7.- Cálculo de los campos básicos por parte del software de análisis. Sin entrar en profundidades matemáticas, existen dos tipos de análisis: a) integración de las ecuaciones de Euler y b) método de la energía, siendo este último el que más se utiliza. Los campos básicos son el vector 
de potencial magnético $A$, Campo magnético $H$, densidad de flujo magnético $B$ y densidad de corriente eléctrica $J$.

8.- Cálculo, representación y análisis de resultados, mediante distintos tipos de gráficas, curvas y tablas. A partir de los campos básicos como la densidad de flujo, se calculan las fuerzas y pares en los elementos. Estos resultados pueden mostrarse bien sobre el propio motor, o como gráficas de 2 o 3 ejes y en forma de líneas, vectores o gradientes de color.

En nuestro caso podemos obtener, entre otras magnitudes propias de la geometría del motor (ver Figura 5.8):

1.- Los campos básicos citados $H, B$ y vectores $A$ y $J$ :

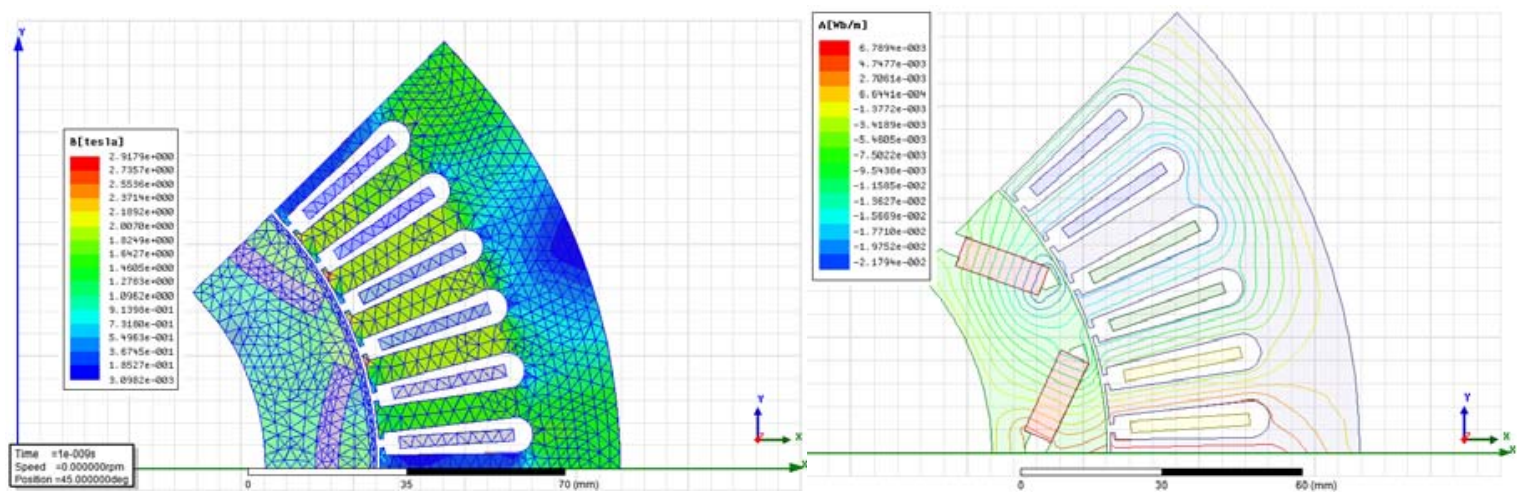

Figura 5.8. Flujo magnético $B$, líneas de flujo $A$ y elementos finitos en un motor PMSM.

2.- Como magnitudes en función del tiempo o de post proceso se pueden representar gráficamente magnitudes temporales y cálculos matemáticos (ver Figura 5.9) como la fem, que en nuestro caso no se utiliza, pues resulta ser una información intermedia que es especialmente útil para obtener el circuito equivalente de la máquina.
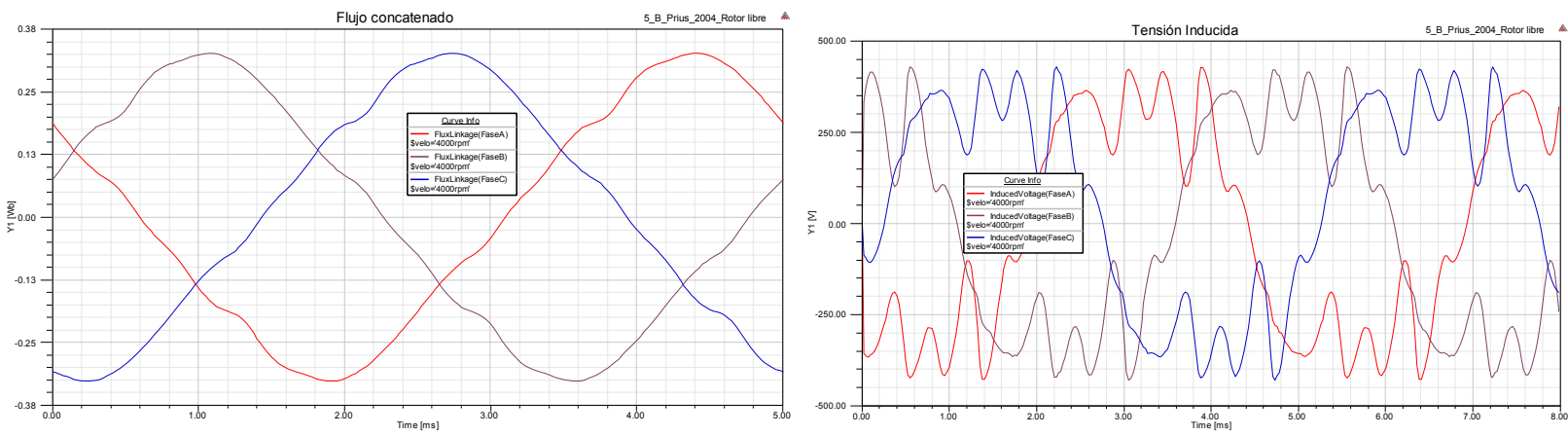

Figura 5.9. Flujo concatenado y fem en los bobinados

3.- El par motor en función del tiempo y la velocidad, cuyo valor medio será el efectivo del motor a unas determinadas revoluciones. En esta forma de onda puede estudiarse el rizado del par dinámico. El par oscilante o par "sin corriente", sin circulación de intensidad por el estátor, y es el causante de ruido y vibraciones en el motor (Figura 5.10). 

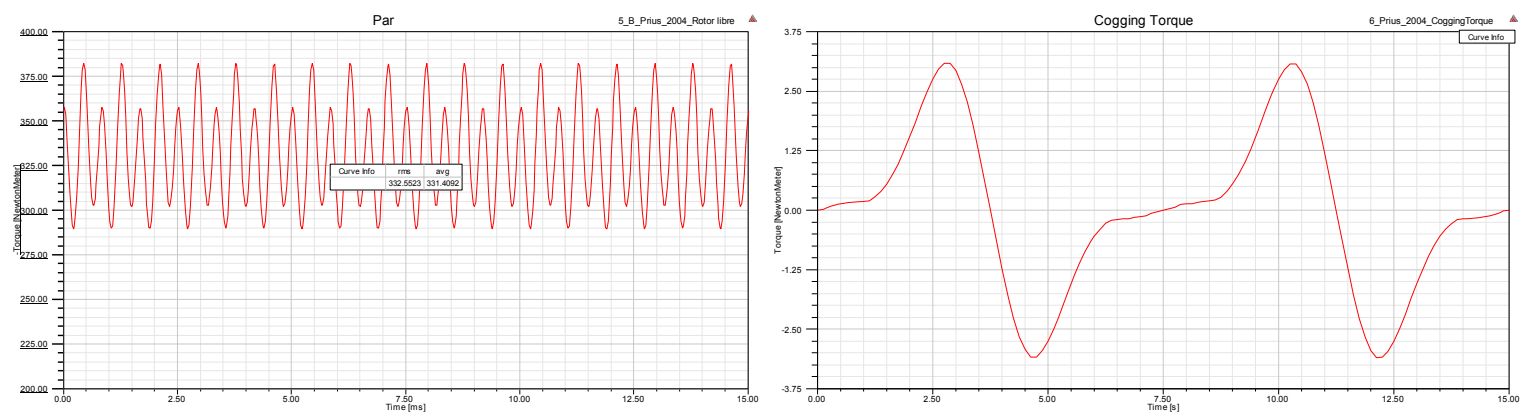

Figura 5.10. Curva de par motriz/tiempo y de par oscilante

\subsection{Modelos y análisis realizados}

En este apartado se exponen los 7 modelos de motor PMSM desarrollados para su estudio mediante FEA y se indican en la Tabla 5-1. Tres de los modelos corresponden a los motores comentados anteriormente en las versiones desarrolladas por Toyota para el Prius, que denominaremos 2000, 2004 y 2010 revisados en el apartado 2.3, y cuya geometría es conocida y se incluye en el Anexo II. En estos modelos se ha intentado reflejar fielmente la geometría real, pero se han debido realizar ciertas simplificaciones que no afectan apreciablemente a los resultados, como un rebaje en el rotor que se menciona en anexo III. Para su modelización se ha utilizado un módulo propio del software que permite diseñar motores IPM.

Los otros modelos corresponden a: un prototipo adaptado, que se encuentra en [100], y otras 3 propuestas propias. En este grupo de modelos no se dispone de datos dimensionales de los imanes y se parametrizará manualmente la geometría de los imanes.

Tabla 5-1. Modelos desarrollados

\begin{tabular}{lccl}
\hline Modelo & Imanes/polo & Capas & Disposición \\
\hline Prius 2004 & 2 & 1 & En V \\
Prius 2000 & 1 & 1 & Plano \\
Prius 2010 & 2 & 1 & En V \\
UQM & 3 & 1 & En arco \\
Curvo & 1 & 1 & En arco \\
Doble Plano & 2 & 2 & En V \\
Doble curvo & 2 & 2 & Concéntricos \\
\hline
\end{tabular}

Estos prototipos has sido seleccionados y desarrollados tras revisar numerosos trabajos sobre los motores IPM y los efectos que producen en el par las características geométricas de sus imanes, especialmente la componente de par reluctante.

Para el estudio y comparación de los modelos entre sí se ha establecido una serie de premisas y parámetros comunes que puedan permitir una comparativa objetiva. Estos parámetros son en su mayoría los correspondientes al diseño del modelo Prius 2004, que se toma como modelo de referencia:

- El estátor del Prius del 2004, que se ha mantenido casi invariable en las tres versiones del Prius. Es trifásico y dispone de 48 ranuras. Se ha descrito en el apartado 2.3.1 y su sección puede verse en la Figura 2.11. 
- La longitud del conjunto estátor/rotor.

- En el rotor los valores que puedan ser comunes: el $n^{0}$ de polos, los diámetros exterior e interior, el entrehierro y la distancia del extremo de los imanes al entrehierro.

Tabla 5-2. Datos comunes del rotor en los modelos

\begin{tabular}{rr}
\hline Parámetro & Valor \\
\hline re_rotor $(\mathrm{mm})$ & $\mathbf{8 0 , 2}$ \\
entrehierro $(\mathrm{mm})$ & $\mathbf{1 , 4 8}$ \\
r_bridge $(\mathrm{mm})$ & $\mathbf{7 8 , 7 2}$ \\
longitud $^{l}(\mathrm{~mm})$ & $\mathbf{8 3 , 8 2}$ \\
polos & $\mathbf{8}$ \\
entrehierro $(\mathrm{mm})$ & $\mathbf{0 , 7}$ \\
\hline
\end{tabular}

- La intensidad nominal de excitación por fase, $250 \mathrm{~A}$.

- El material magnético de los imanes permanentes es inicialmente FeNdB sinterizado del tipo $\mathrm{N} 36$, con $H_{c}=902 \mathrm{kA} / \mathrm{m}$.

- El material magnético del rotor y el estátor, como se ha indicado en la introducción, es del tipo M19-29G equivalente al utilizado por Toyota.

- La temperatura base para los análisis es de $20^{\circ} \mathrm{C}$ que es el de referencia para las tablas de los fabricantes.

Con las premisas anteriores en un primer paso se determinará, para los 4 modelos propuestos, los parámetros geométricos que maximizan el par máximo de la curva de corriente continua explicada a continuación. Se ha escogido esta magnitud, en vez de otra como el valor medio del par, el par reluctante o el síncrono, por entender que este valor es el que representa un mejor aprovechamiento del motor y es referente, como en el caso de ORNL, para ver cuál es el máximo par posible, el ángulo de trabajo en el que se produce y el reparto de los pares síncrono y reluctante, entre otros valores.

Una vez optimizadas las geometrías variables de los modelos propuestos, se va a determinar en cada uno de ellos el área de imanes necesario para producir el par máximo de referencia de $353 \mathrm{Nm}$ del Prius 2004. De forma análoga se puede comparar el par producido con la misma cantidad de imán de cada prototipo.

Asimismo se estudiará el par oscilante de los modelos así como el rizado de su par dinámico y del flujo de dispersión.

Posteriormente, como se ha indicado como objetivo de esta tesis, se comprobará la aplicación del modelo propuesto de imanes curvos con imanes $\mathrm{NeFdB}$ aglomerados, que si bien presentan peores características magnéticas que los sinterizados, permiten construir geometrías más complejas que estos últimos y se analizará el efecto de la temperatura en el par motor.

\subsubsection{Curva de par Magnetostática de Corriente Continua}

Las curvas magnetostáticas, también denominadas de corriente continua o de "rotor bloqueado", se obtienen con una excitación de corriente continua en los tres bobinados trifásicos con una excitación correspondiente a un instante determinado, por lo que si en una de las fases se tiene un valor máximo, en las otras dos fases se tendrán valores cuya magnitud es la mitad y su sentido el contrario a la de fase referenciada [34] (Ver Figura 5.11).

\footnotetext{
${ }^{1}$ Excepto para el modelo del Prius 2010, que es de $50 \mathrm{~mm}$ como en su diseño original.
} 
El par en este caso depende de la intensidad de excitación y de la posición del rotor respecto al estátor y al campo magnético creado en él, mediante su ángulo de par o rotor $(\delta)$. Como se comentó en el capítulo sobre motores síncronos y se muestra en la Figura 5.12, esta curva es la combinación de los pares síncrono y reluctante del motor, siendo este último fuertemente dependiente de la geometría de los imanes.

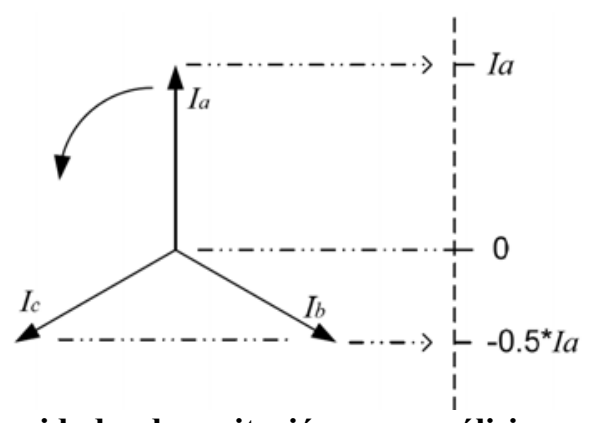

Figura 5.11. Intensidades de excitación para análisis magnetostático [34].

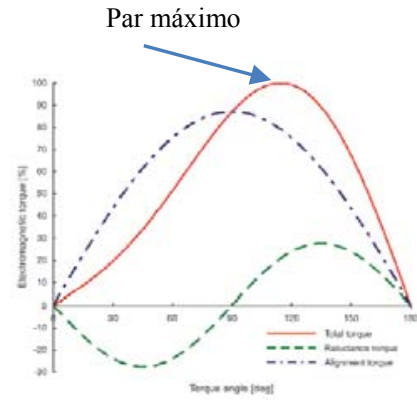

a)

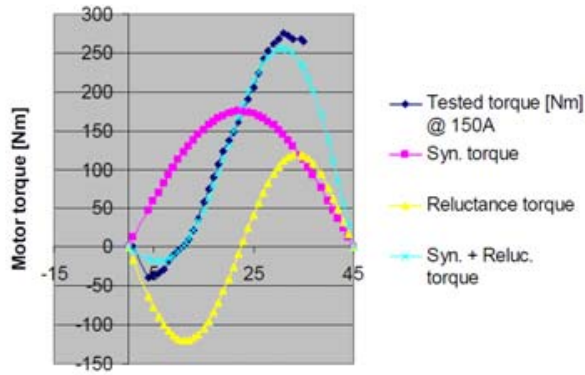

b)

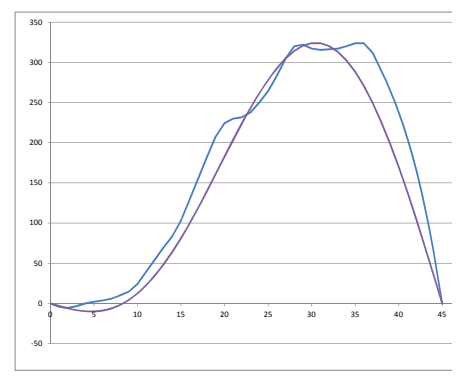

c)

Figura 5.12. Pares síncrono y reluctante de un motor IPM a) teóricos b) reales[34] c) del modelo Prius 2000

\subsubsection{Optimización de la geometría del rotor}

Como se ha indicado anteriormente, una vez parametrizada la geometría del rotor se optimizará el par máximo de la curva magnetostática de los 4 modelos propuestos. Debe tenerse en cuenta que la variación de la geometría de los imanes y el rotor implica recalcular los mallados de elementos finitos y los campos básicos y por lo tanto el tiempo de cálculo es considerable.

Para la optimización el software utilizado dispone de un módulo propio, donde se definen las variables y sus límites, la función objetivo y el tipo de optimización a aplicar: cuasi-newtoniana, algoritmos genéticos, etc...(Figura 5.13), siendo la programación Quasi-newtoniana la más efectiva en general. La función objetivo ha sido, como se ha indicado, el valor máximo de la curva de par magnetostático.

Si bien de la definición de la curva magnetostática podría deducirse que el ángulo $\delta$ podría ser constante, se comprueba que no es así, sino que se suele encontrar en una franja de unos $8^{\circ}$ mecánicos, por lo que hay que considerarla como una variable más en la optimización. 


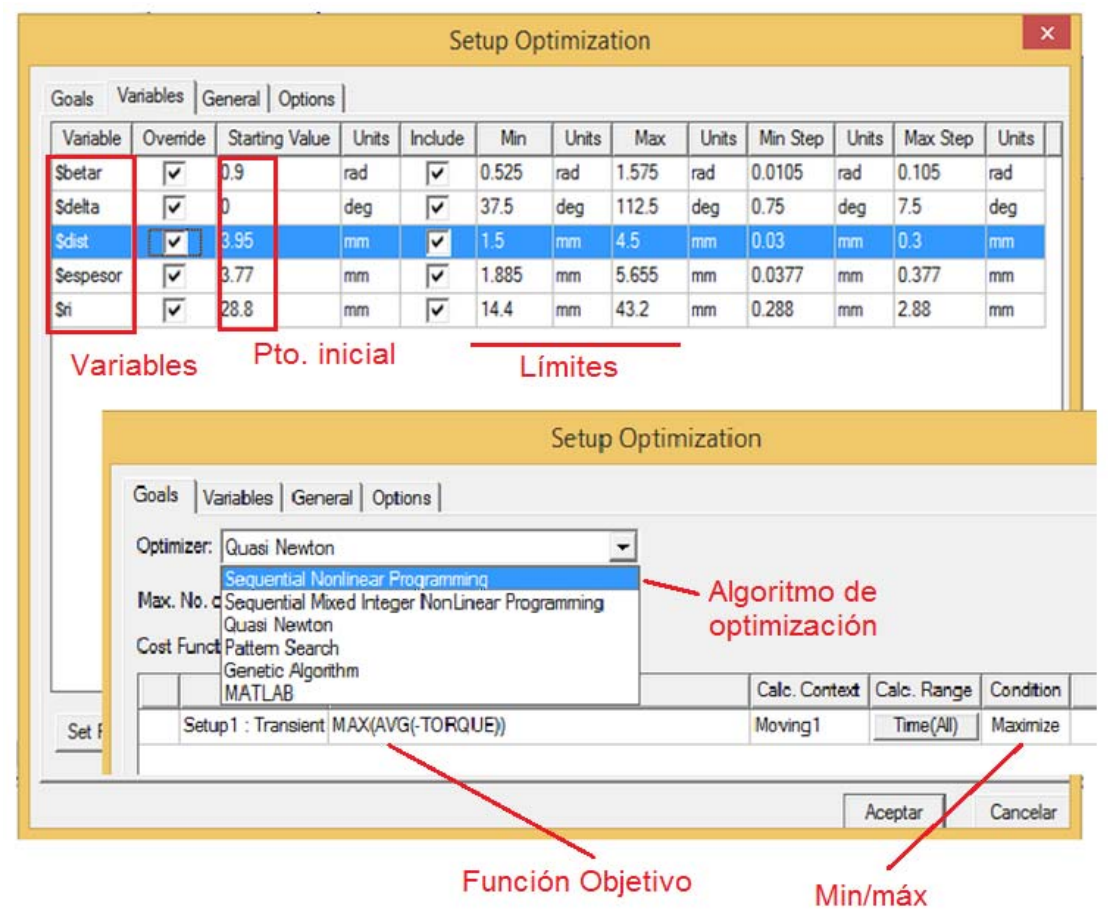

Figura 5.13. Inclusión de variables con sus límites en el proceso de optimización y definición de función objetivo para modelo de imán curvo.

En todos los modelos analizados se puede apreciar que, por un lado, la forma de la curva de par magnetostático, y por otro lado su valor máximo, dependen de cada geometría a través de sus parámetros, como la longitud de los imanes o su espesor, que determinan uno o varios puntos de par máximo denominados Óptimos locales. Como ejemplo la Figura 5.14 representa en 3D y en 2D una zona del par magnetostático de un rotor con imán curvo en función de dos parámetros: \$delta, que este es el ángulo mecánico de posición del rotor respecto al estátor, y \$betar, que es el ángulo en grados abarcado por el imán respecto de su centro de curvatura. Puede apreciarse claramente una zona de óptimo global en rojo y varios óptimos locales cercanos, que complican el proceso de optimización, y más teniendo en cuenta que los modelos de rotor pueden tener hasta 6 parámetros distintos para definir su geometría.

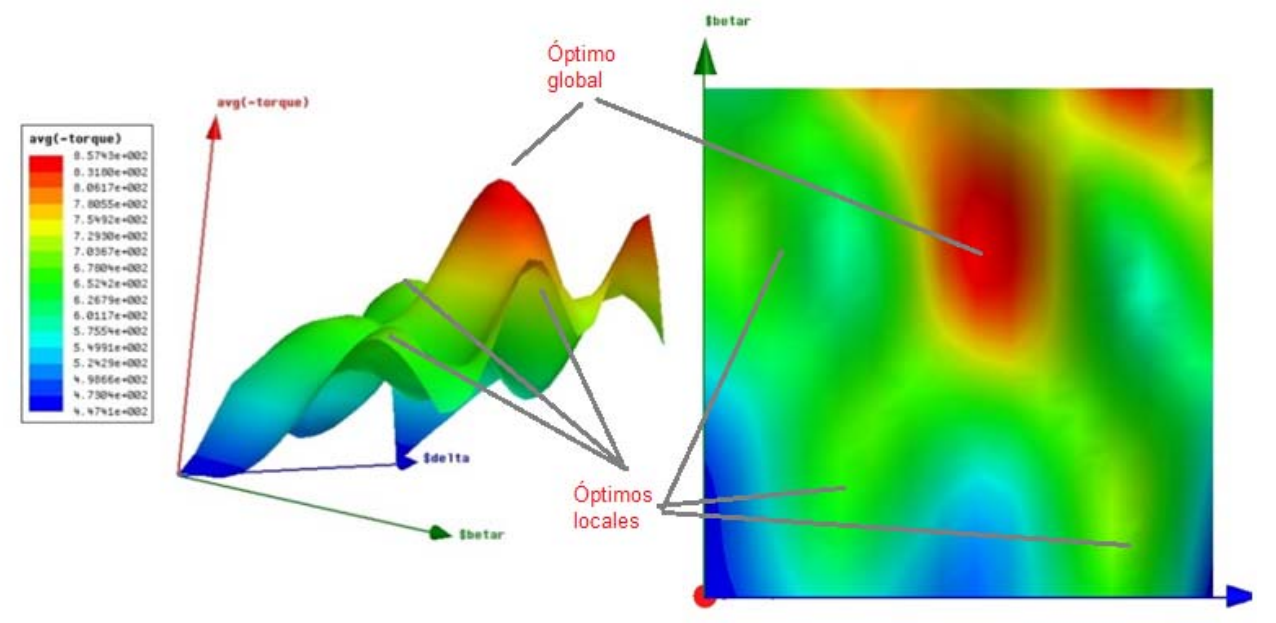

Figura 5.14. Óptimos global y locales en curvas del par magnetostático en función de 2 parámetros geométricos en 3D y en $2 D$. 
Se ha observado que ciertos parámetros de diseño tienen más influencia que otros en la variación del valor de par máximo. Por ejemplo, el espesor de los imanes o su separación presentan "mesetas" muy planas cerca del punto óptimo donde la sensibilidad es baja, mientras otras como el ángulo de curvatura de los imanes curvos o su radio presentan gradientes más pronunciados.

\subsubsection{Toyota Prius 2004}

Aunque es la segunda versión del MG2, se comienza con este modelo por ser el que se toma como referencia para las comparativas con los otros modelos y ser el motor del que más datos técnicos publicados y simulaciones se dispone[20, 22, 98, 101-104]. Este motor presenta 2 imanes por polo en $\mathrm{V}$ a $135^{\circ}$ como muestra la Figura 5.15. La geometría utilizada se presenta en la Tabla 5-3 y en la Figura 5.16 se representan las curvas de par magnetostático para distintas intensidades.
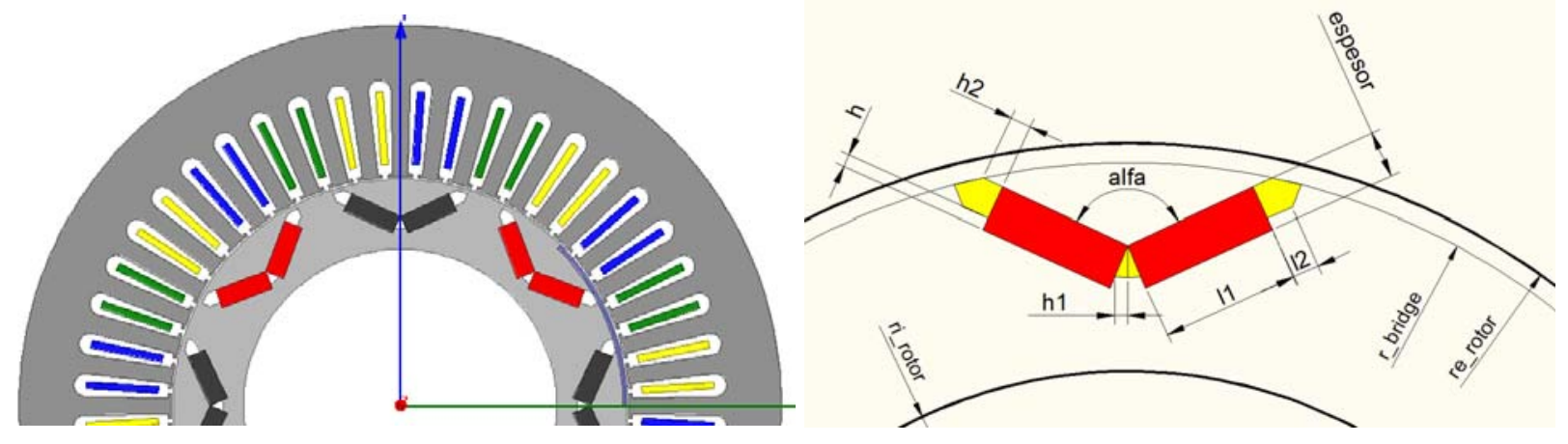

Figura 5.15. Sección y parametrización del modelo Prius 2004.

Tabla 5-3. Parámetros del modelo del Prius 2004

\begin{tabular}{rr}
\hline Parámetro & Valor \\
\hline alfa $\left({ }^{\circ}\right)$ & $\mathbf{1 3 5}$ \\
$l l(\mathrm{~mm})$ & $\mathbf{1 8 , 9}$ \\
$l 2(\mathrm{~mm})$ & $\mathbf{3 , 8 2}$ \\
espesor $(\mathrm{mm})$ & $\mathbf{6 , 4 8}$ \\
$h(\mathrm{~mm})$ & $\mathbf{1 , 7 8}$ \\
$h 1(\mathrm{~mm})$ & $\mathbf{1 , 6 7}$ \\
$h 2(\mathrm{~mm})$ & $\mathbf{2 , 9 6}$ \\
Área/polo $\left(\mathrm{mm}^{2}\right)$ & $\mathbf{2 4 4}$ \\
Par máx $\left(\mathrm{Nm}^{2}\right)$ & $\mathbf{3 5 3}$ \\
$\mathrm{Nm} / \mathrm{mm}^{2}$ & $\mathbf{1 , 4 4}$ \\
\hline
\end{tabular}

Una vez implementado el diseño del modelo en el software de FEA, se procede a verificar su validez contrastando los resultados obtenidos con los de otras simulaciones y con los valores reales registrados por el ORNL en sus laboratorios. Una descripción completa de esta contrastación con otro modelo teórico FEA y con datos reales puede encontrase en el anexo III de esta tesis. Se determina que los resultados obtenidos para el modelo son correctos. Puede observarse que la curva ocupa $45^{\circ}$ mecánicos correspondientes a un polo del motor. El hecho de que la curva comience en $30^{\circ}$ se debe a la posición inicial del rotor del modelo y sus ejes $d$ y $q$ respecto de la fase de valor eficaz máximo. Dado que los otros modelos se han diseñado en la misma posición, este ángulo de $30^{\circ}$ será común a todos ellos. También puede observarse en la figura que para cada intensidad las curvas cambian de forma y que el ángulo donde se produce el par máximo es distinto desplazándose hacia la derecha según aumenta la intensidad, como se indica en [62]. 
Prius 2004

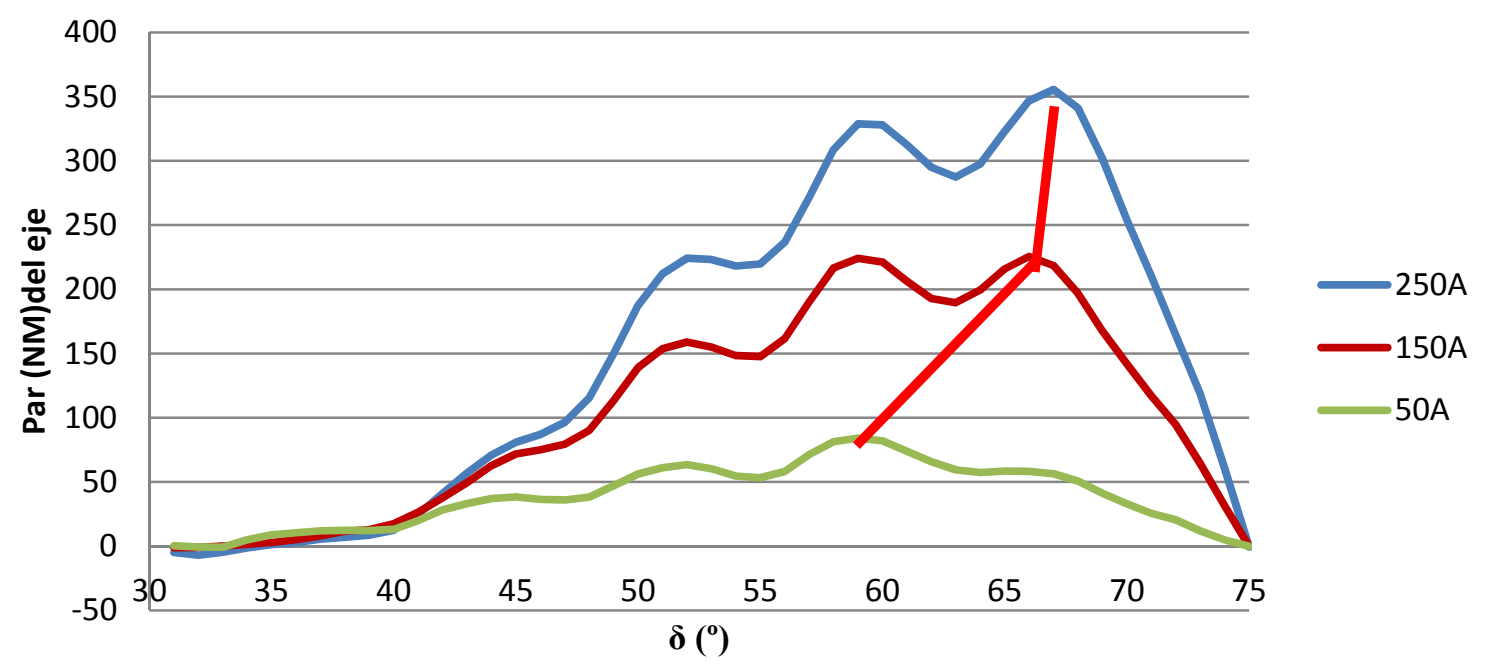

Figura 5.16. Curvas de par a rotor bloqueado del modelo Prius 2004 con distintas intensidades de excitación.

\subsubsection{Toyota Prius 2000}

Este modelo corresponde a la primera versión del MG2 del Prius, puesta en Europa en el año 2000. Se caracteriza por su simpleza, ya que los imanes utilizados son rectangulares y se disponen en una única capa (ver Figura 5.17). En la Tabla 5-4 se muestran los parámetros utilizados en el modelo y el par máximo obtenido.
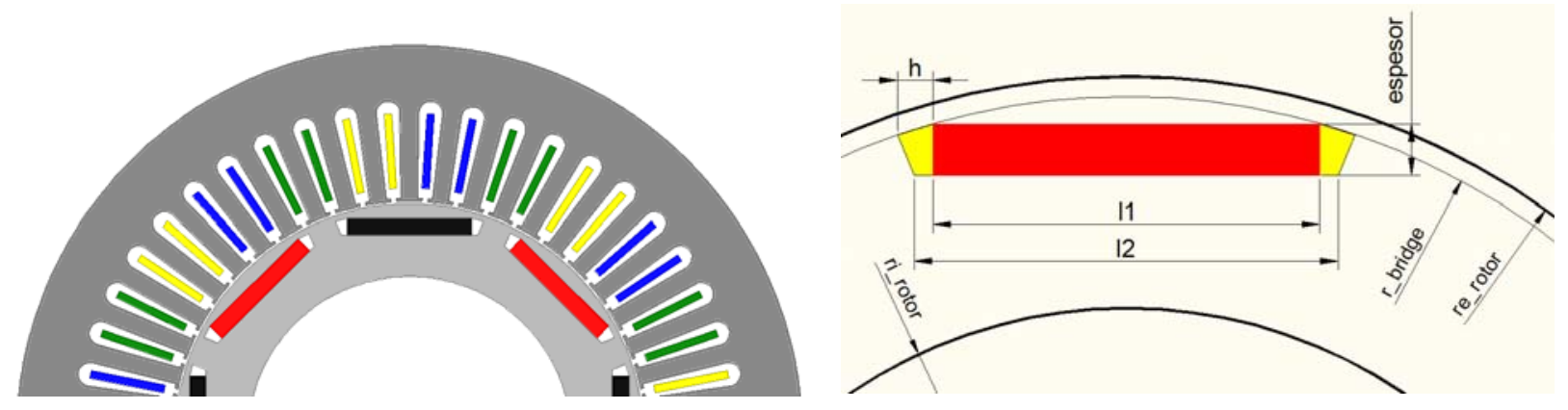

Figura 5.17. Sección y parametrización del modelo Prius 2000.

Tabla 5-4. Parámetros del modelo del Prius 2000

\begin{tabular}{rr}
\hline Parámetro & Valor \\
\hline$l 1(\mathrm{~mm})$ & $\mathbf{3 8 , 4 8}$ \\
$l 2(\mathrm{~mm})$ & $\mathbf{4 6 , 7 6}$ \\
espesor $(\mathrm{mm})$ & $\mathbf{5 , 3 1}$ \\
$h(\mathrm{~mm})$ & $\mathbf{4 , 1 8}$ \\
Área/polo $\left(\mathrm{mm}^{2}\right)$ & $\mathbf{2 0 4 , 3}$ \\
Par máx $(\mathrm{Nm})$ & $\mathbf{3 2 5}$ \\
$\mathrm{Nm} / \mathrm{mm}^{2}$ & $\mathbf{1 , 5 9}$ \\
\hline
\end{tabular}

En la Figura 5.18 se muestran las curvas magnetostáticas para 3 intensidades. Se aprecia una zona de valores máximos más plana que en el modelo del 2004. 
Prius 2000

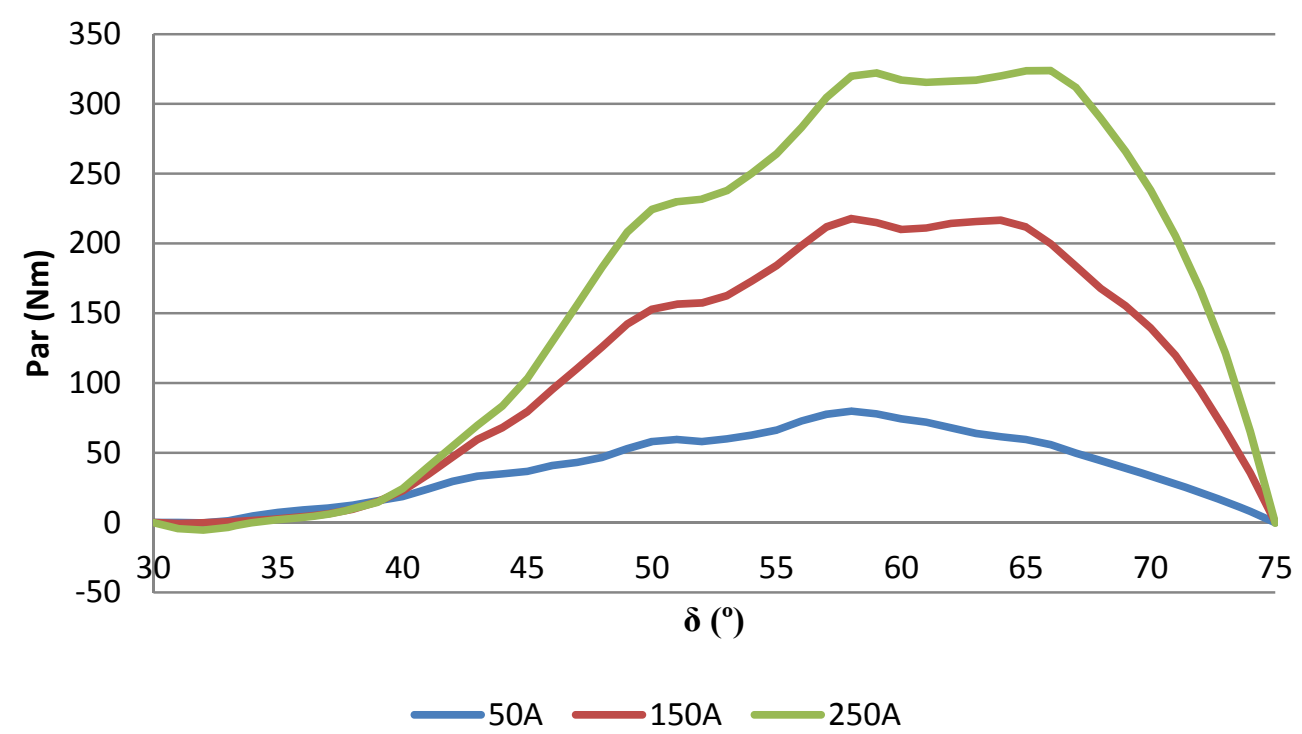

Figura 5.18. Curvas de par a rotor bloqueado del Prius 2000

\subsubsection{Toyota Prius 2010}

En esta versión del motor se mantiene la disposición en $\mathrm{V}$ de los imanes, pero por cuestiones mecánicas Toyota opta por una mayor velocidad de funcionamiento $(13.200 \mathrm{rpm}$ frente a $6.000 \mathrm{rpm}$ de sus predecesores) lo que conlleva que suministre un par menor y que su rigidez mecánica se vea aumentada modificando los siguientes aspectos (ver Figura 5.19):

- Disminuyendo el diámetro interior del rotor, aligerándolo mediante huecos y disponiendo nervios radiales.

- Añadiendo un nuevo puente entre los imanes (rib) y aumentado ligeramente el puente exterior.

- Reduciendo su longitud de 84 a $50 \mathrm{~mm}$.
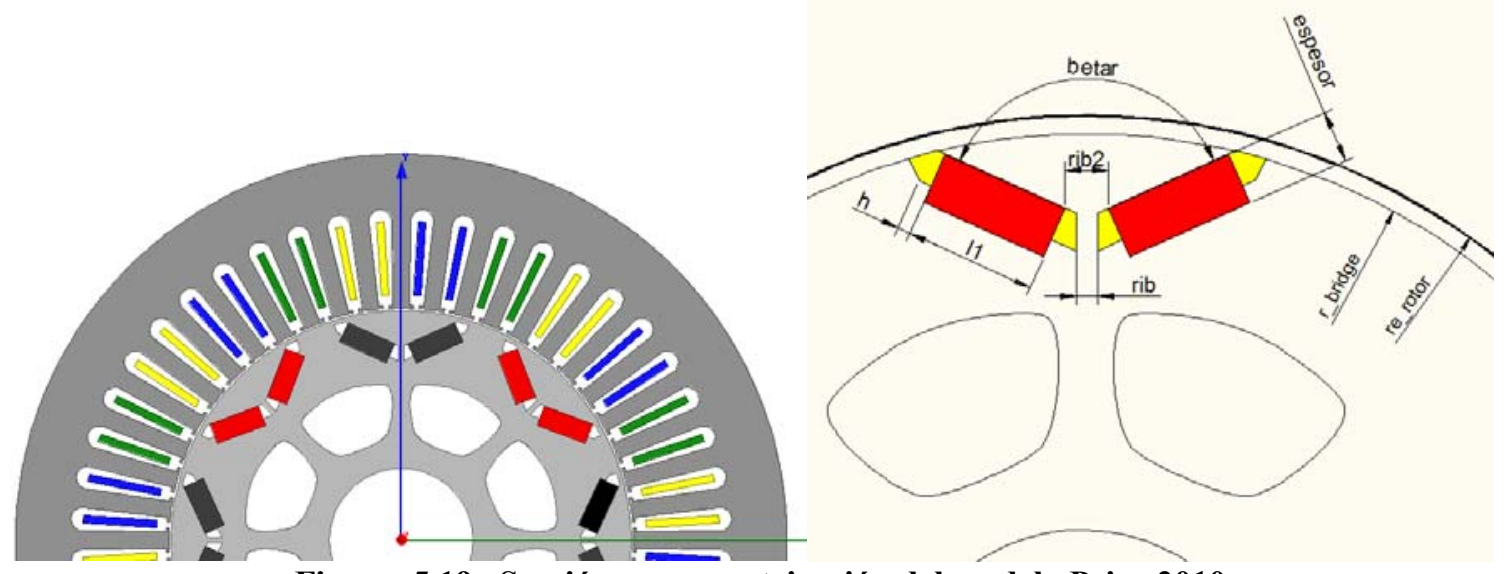

Figura 5.19. Sección y parametrización del modelo Prius 2010. 
En la Tabla 5-5 se indican los parámetros constructivos más significativos del motor.

Tabla 5-5. Parámetros del modelo del Prius 2010

\begin{tabular}{rr}
\hline Parámetro & Valor \\
\hline betar $\left({ }^{\circ}\right)$ & $\mathbf{1 3 1}$ \\
$l l(\mathrm{~mm})$ & $\mathbf{1 7 , 8 8}$ \\
espesor $(\mathrm{mm})$ & $\mathbf{7 , 1 6}$ \\
$h(\mathrm{~mm})$ & $\mathbf{1 , 7 8}$ \\
$h 1(\mathrm{~mm})$ & $\mathbf{1 , 6 7}$ \\
$h 2(\mathrm{~mm})$ & $\mathbf{2 , 9 6}$ \\
rib $(\mathrm{mm})$ & $\mathbf{1 , 7 6}$ \\
Área/polo $\left(\mathrm{mm}^{2}\right)$ & $\mathbf{2 5 6 , 0}$ \\
Par máx $\left(\mathrm{Nm}^{2}\right)$ & $\mathbf{2 0 7}$ \\
$\mathrm{Nm} / \mathrm{mm}^{2}$ & $\mathbf{0 , 8 1}$ \\
\hline
\end{tabular}

De esta forma el motor tiene un área de imanes de $256 \mathrm{~mm}^{2}$ y $207 \mathrm{Nm}$ de par nominal para su longitud de $50 \mathrm{~mm}$. La simulación se ha realizado con este valor de longitud para comprobar su efecto en el motor real. Dado que el par es proporcional a la longitud del motor, si éste tuviese la misma longitud que el 2004 el par sería muy similar (347 Nm) al del 2004.

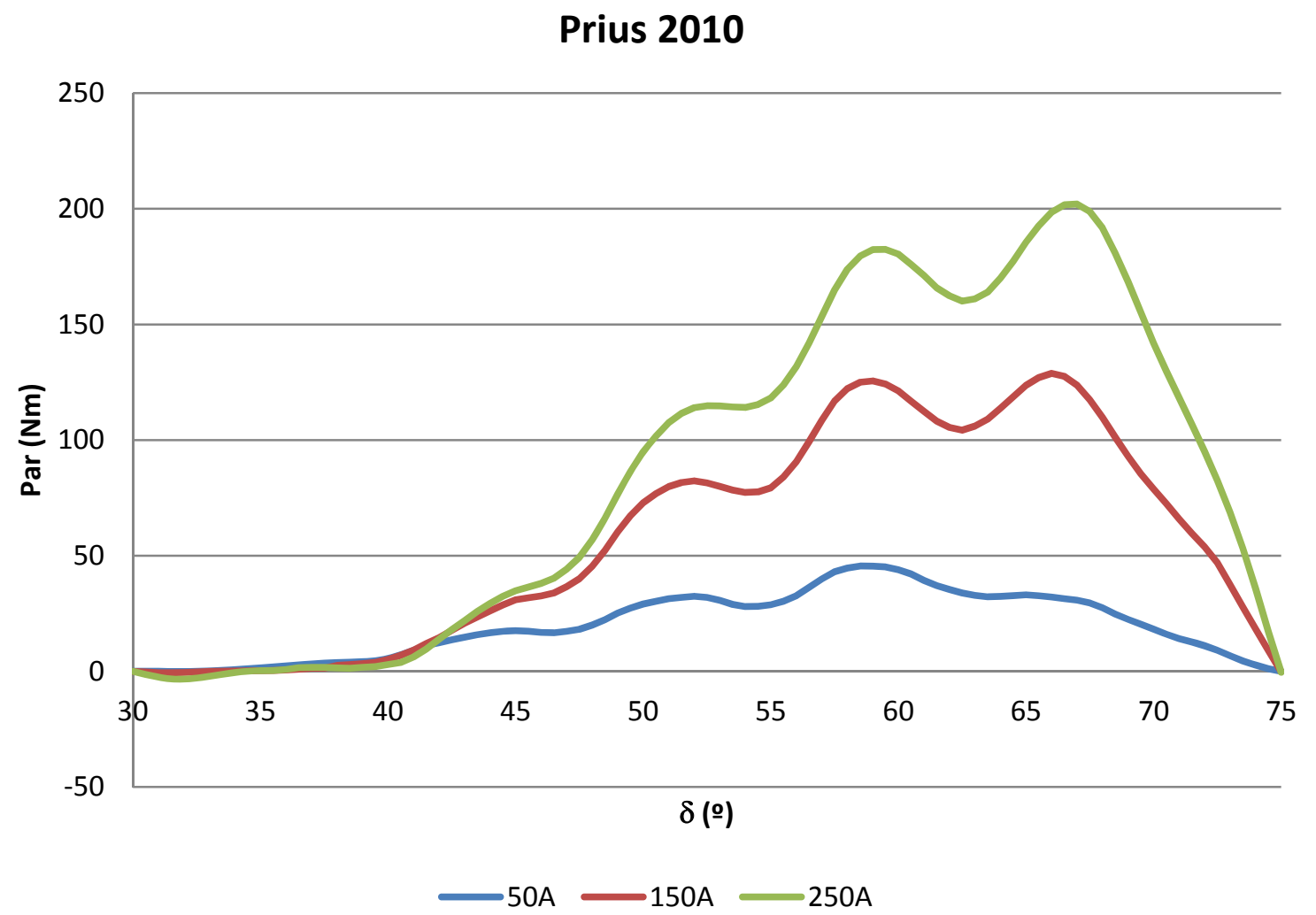

Figura 5.20. Curvas de para a rotor bloqueado del Prius 2010 para distintas intensidades. 


\subsubsection{Modelo DOE-UQM}

Este modelo se incluye en el estudio por ser la clara apuesta del Departamento de Energía de los EEUU en el mundo de los vehículos eléctricos [100] a través del fabricante de motores eléctricos UQM. Si bien el número de polos y de ranuras del motor original es distinto, lo interesante es la forma y disposición de los imanes. Cada polo está compuesto por 3 imanes trapezoidales iguales conformando un arco de círculo con segmentos rectos como muestra la Figura 5.21.

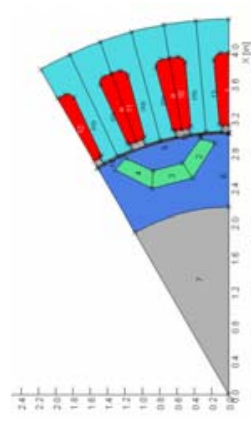

a)

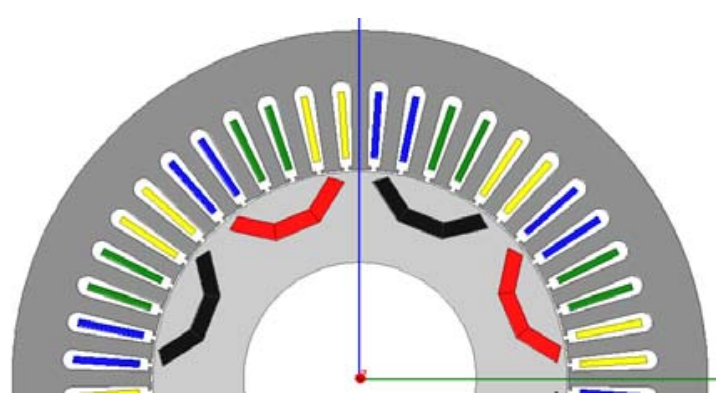

b)

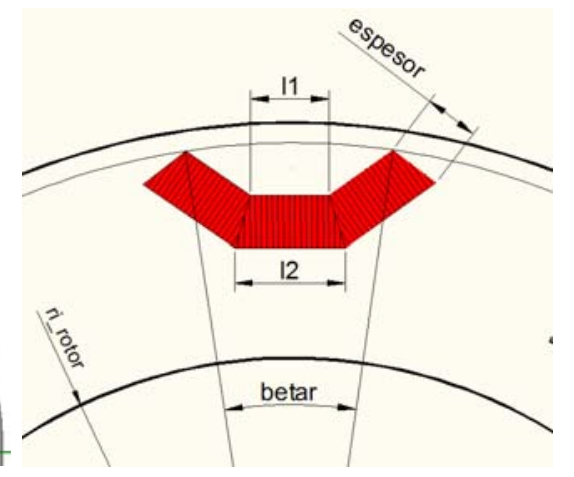

c)

Figura 5.21. a) Sección del modelo del DOE-UQM [100], b) sección del modelo adaptado y c) parametrización del modelo.

A diferencia de los 3 modelos anteriores en los que los parámetros utilizados eran los utilizados en la realidad, en los 4 modelos propuestos se muestran los valores obtenidos en la optimización, en este caso en la Tabla 5-6.

Tabla 5-6. Parámetros del modelo del modelo UQM

\begin{tabular}{rr}
\hline Parámetro & Valor \\
\hline betar $\left(^{\circ}\right)$ & $\mathbf{1 7 , 3}$ \\
$l 1(\mathrm{~mm})$ & $\mathbf{1 4 , 8 0}$ \\
$l 2(\mathrm{~mm})$ & $\mathbf{2 0 , 0 5}$ \\
espesor $(\mathrm{mm})$ & $\mathbf{9 , 6}$ \\
Área/polo $\left(\mathrm{mm}^{2}\right)$ & $\mathbf{4 9 4 , 5}$ \\
Par máx $\left(\mathrm{Nm}^{2}\right)$ & $\mathbf{4 3 0}$ \\
$\mathrm{Nm} / \mathrm{mm}^{2}$ & $\mathbf{0 , 8 5}$ \\
\hline
\end{tabular}

Las curva de par de rotor bloqueado para distintas intensidades es la mostrada en la es la mostrada la Figura 5.22 con un par máximo de $430 \mathrm{Nm}$ para $250 \mathrm{~A}$. 


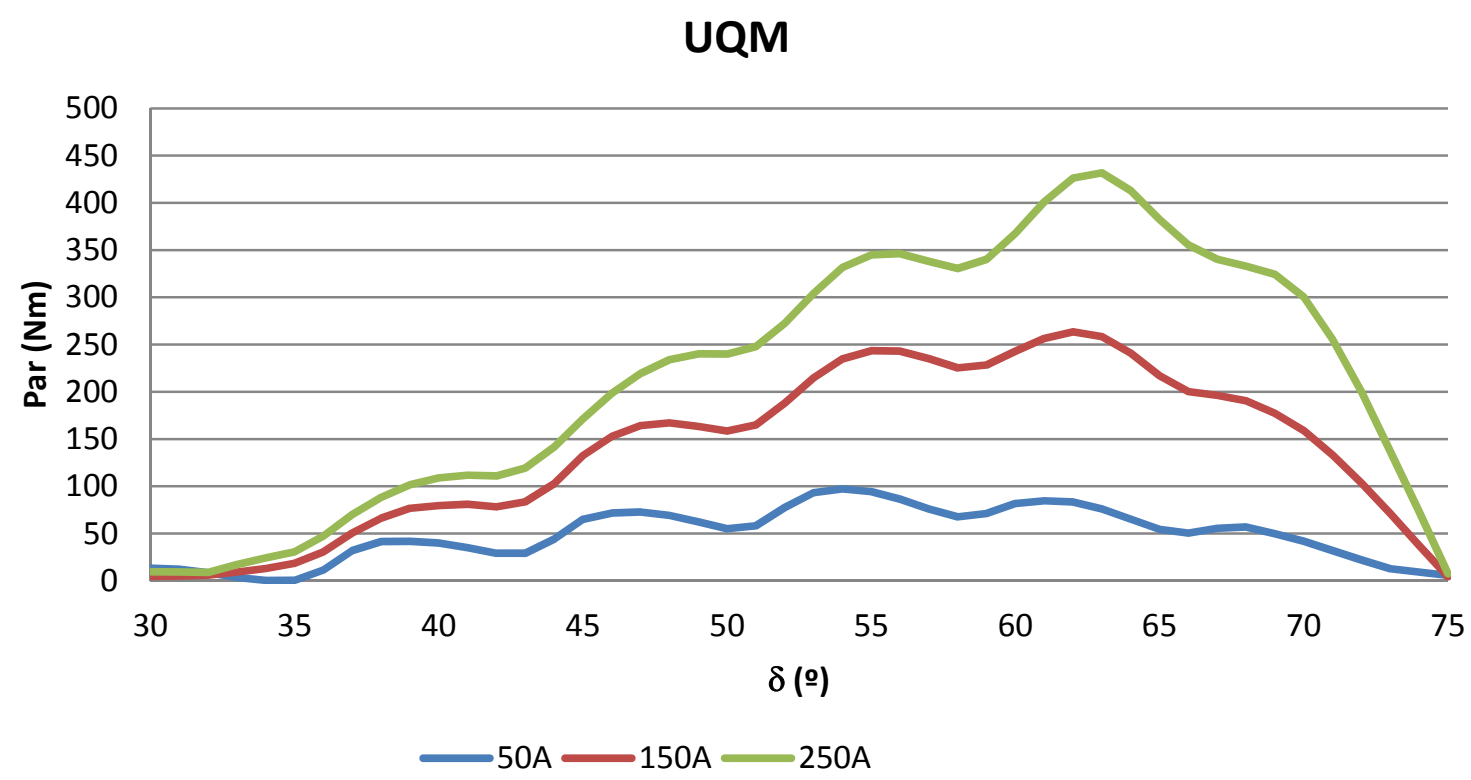

Figura 5.22. Curva de par del modelo DOE-UQM para distintas intensidades.

\subsubsection{Modelos de doble capa planos}

Tomando como punto de partida los modelos 2000 y 2004 e investigando los nuevos tipos de rotor que se están desarrollando en otros trabajos, se determina que, para aumentar la potencia específica de los motores, se disponen los imanes en múltiples capas, especialmente 2 ó 3 capas de imanes planos. Para estudiar estas geometrías se han implementado los modelos mostrados en la Figura 5.23.

De las simulaciones realizadas con ambos modelos se deduce que el modelo con los 4 imanes dispuestos en $\mathrm{V}$ proporciona un mayor par que el de 2 imanes paralelos, por lo que se descarta este último.

Podría considerarse la disposición de los imanes en tres o más capas, pero de la bibliografía consultada, se determina que el uso de más de 2 capas no proporciona gran ventaja en términos de par por unidad de superficie de imán, especialmente en motores de más de 2 polos, y además complica la fabricación y debilita la rigidez mecánica del rotor, por lo que únicamente se considerarán 2 capas de imanes.
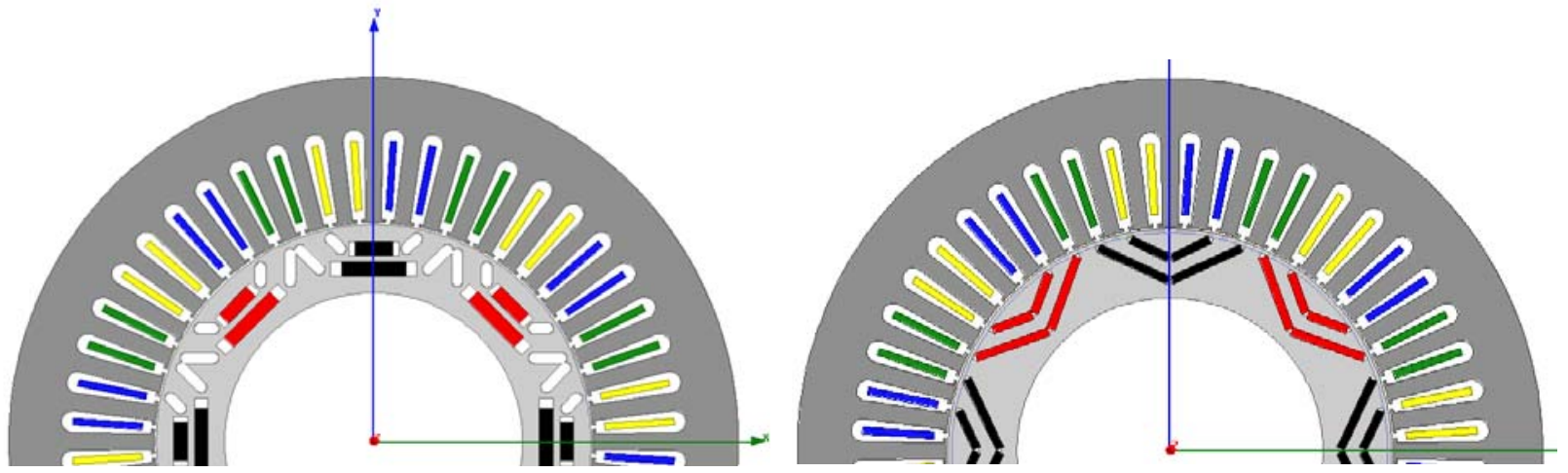

Figura 5.23. Secciones de 2 modelos de imanes en doble capa planos. 


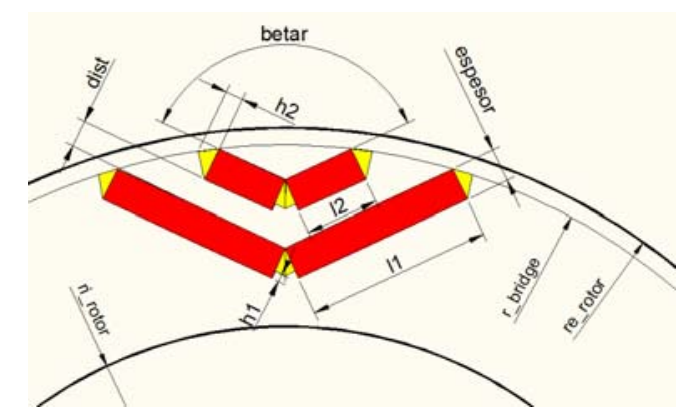

Figura 5.24. Parametrización de modelo de doble capa plano en V.

Tabla 5-7. Parámetros del modelo del modelo doble capa en V

\begin{tabular}{rr}
\hline Parámetro & Valor \\
\hline betar $\left({ }^{\circ}\right)$ & $\mathbf{1 3 3}$ \\
$l l(\mathrm{~mm})$ & $\mathbf{1 5 , 8 5}$ \\
$l 2(\mathrm{~mm})$ & $\mathbf{2 7 , 8 2}$ \\
espesor $(\mathrm{mm})$ & $\mathbf{6 , 4 8}$ \\
dist $(\mathrm{mm})$ & $\mathbf{3 , 5 5}$ \\
$h 1(\mathrm{~mm})$ & $\mathbf{1 , 2 1}$ \\
$h 2(\mathrm{~mm})$ & $\mathbf{1 , 1 5}$ \\
Área/polo $\left(\mathrm{mm}^{2}\right)$ & $\mathbf{3 1 4 , 3 6}$ \\
Par máx $\left(\mathrm{Nm}^{2}\right)$ & $\mathbf{6 3 1}$ \\
$\mathrm{Nm} / \mathrm{mm}^{2}$ & $\mathbf{2 , 0 1}$ \\
\hline
\end{tabular}

\section{Doble Capa en V}

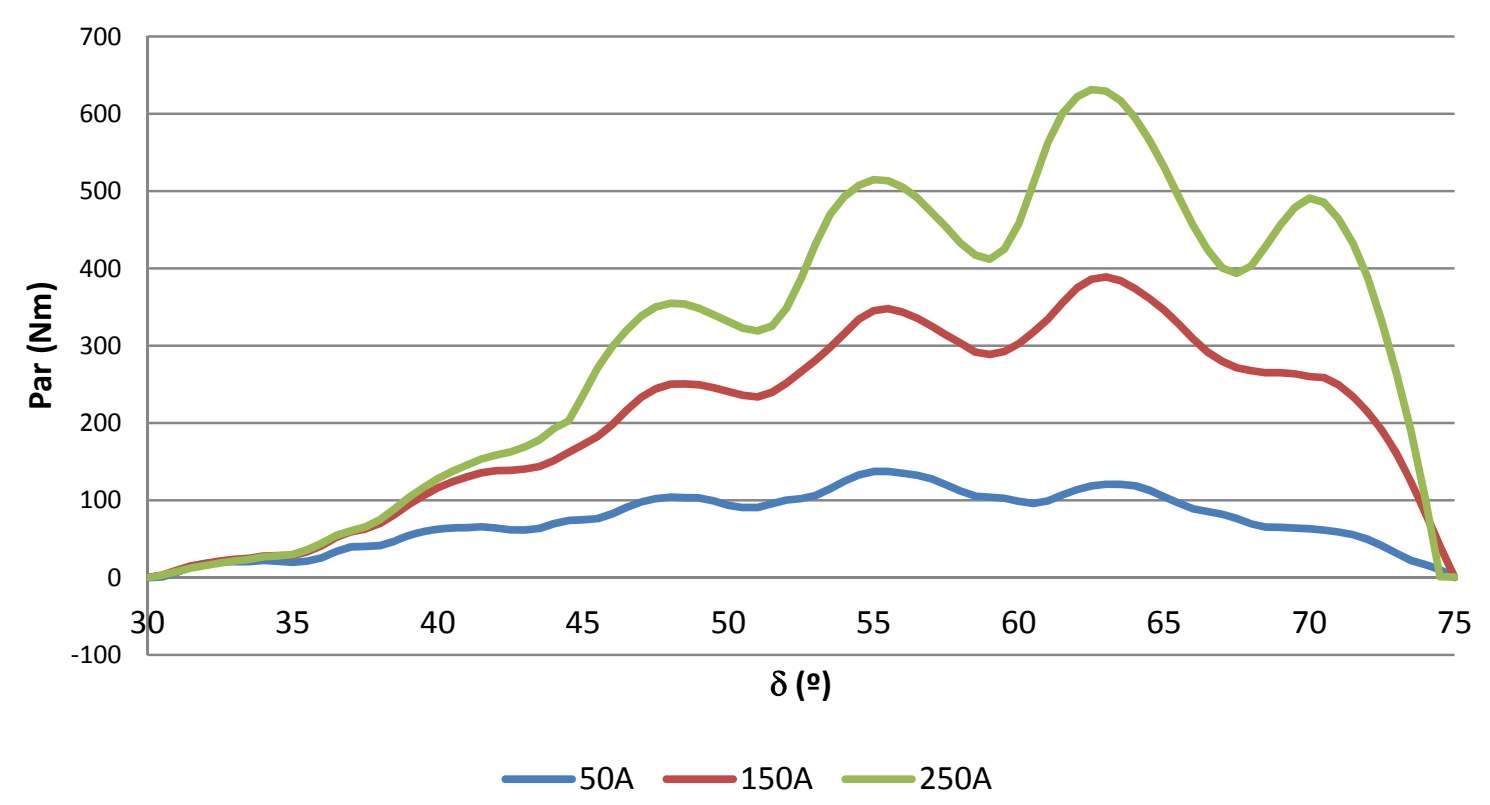

Figura 5.25. Curvas de par del modelo Doble Capa en V para varias intensidades. 


\subsubsection{Modelos de Imanes curvos}

Con la intención de sustituir los imanes dispuestos en V del modelo Prius 2004, inicialmente se considera un único imán en forma de arco circular, con la curvatura en sentido favorable al flujo magnético del estátor. En una primera aproximación se ha parametrizado en dos versiones distintas. Una de ellas con el hueco del extremo de los imanes similar al del Prius 2004 con las variables mostradas en la Figura 5.26. La otra versión, mostrada en la Figura 5.27, es sin hueco en los extremos de los imanes, y los extremos en dirección no radial, abarcando de esta forma mayor cantidad de flujo del campo magnético.
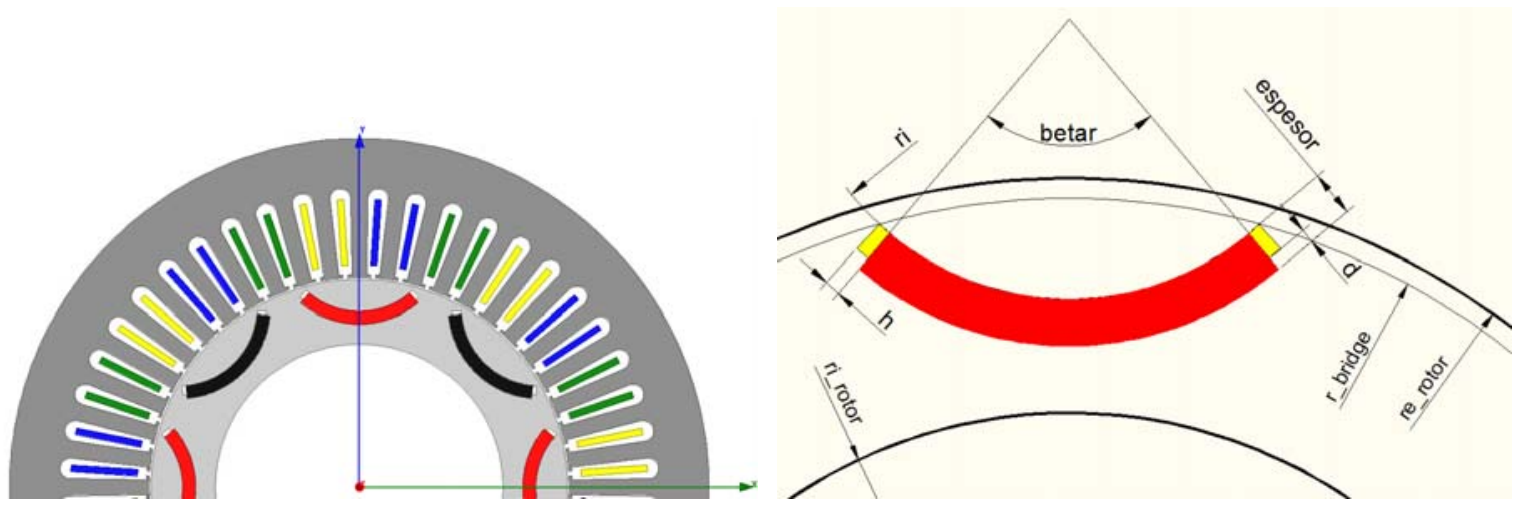

Figura 5.26. Sección del modelo de imán curvo Tipo 1.
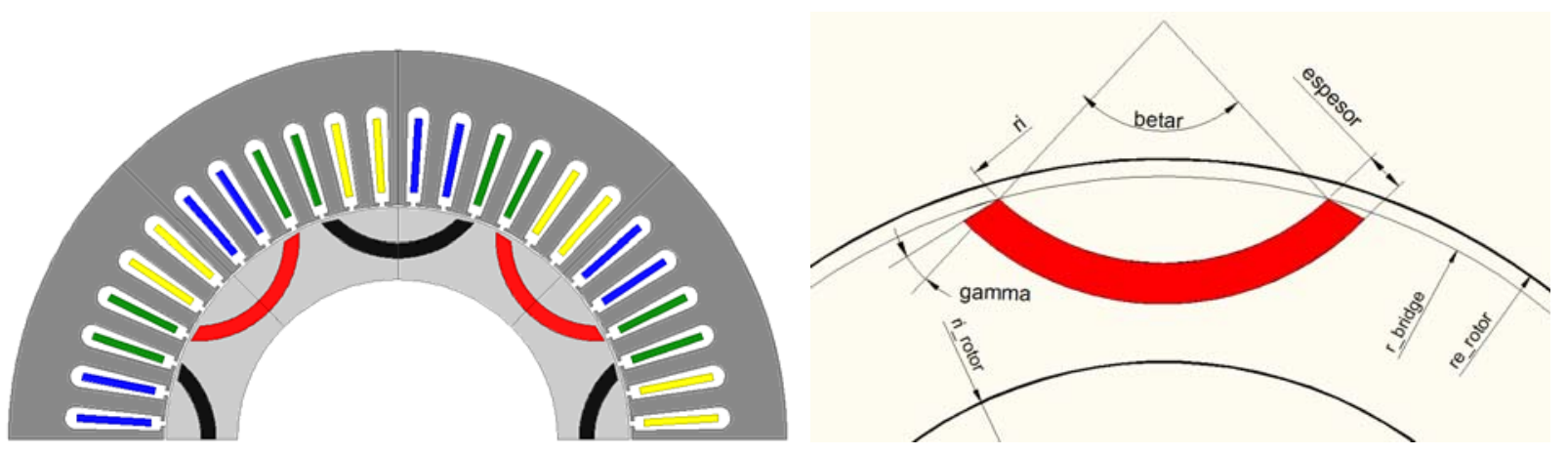

Figura 5.27. Sección del modelo de imán curvo Tipo 2.

Dado que el imán del modelo tipo2 cubre una mayor superficie, el par máximo proporcionado es mayor descartamos el tipo 1.

Para observar el efecto de la geometría sobre las curvas de par magnetostático se muestra la Figura 5.28. Donde se puede aprecia, en este caso, el fuerte efecto que tiene en la forma del par el radio de curvatura de los imanes ( $\$ r i)$ en el rango del ángulo $\delta$ de $50^{\circ}$ a $70^{\circ}$. Puede apreciarse que, además de cambiar el valor del par máximo, también cambia la forma de la curva y el ángulo $\delta$ en el que se produce el máximo. Otros parámetros como el ángulo abarcado o el espesor de los imanes muestran un efecto bastante menor en la variación dichas curvas. 

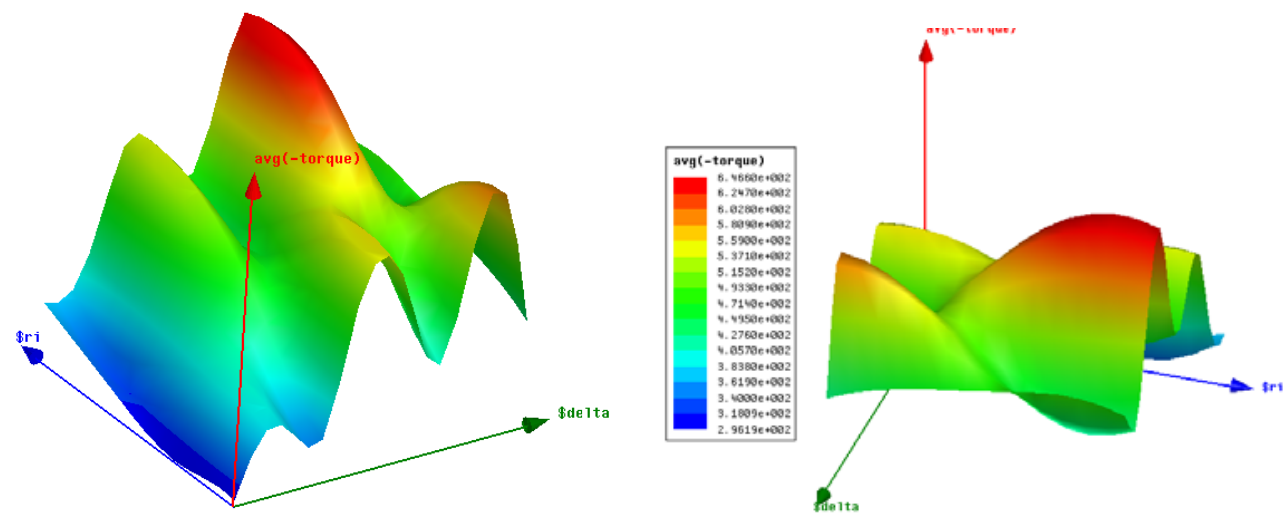

Figura 5.28. Variación del par magnetostático en función del radio de curvatura \$ri de los imanes.

Posteriormente se considera la clara evolución a disponer dos capas de imanes concéntricos y del mismo espesor separados una distancia y manteniendo en cada capa el puente, dando lugar al modelo de doble capa de imanes planos mostrado en la Figura 5.29.

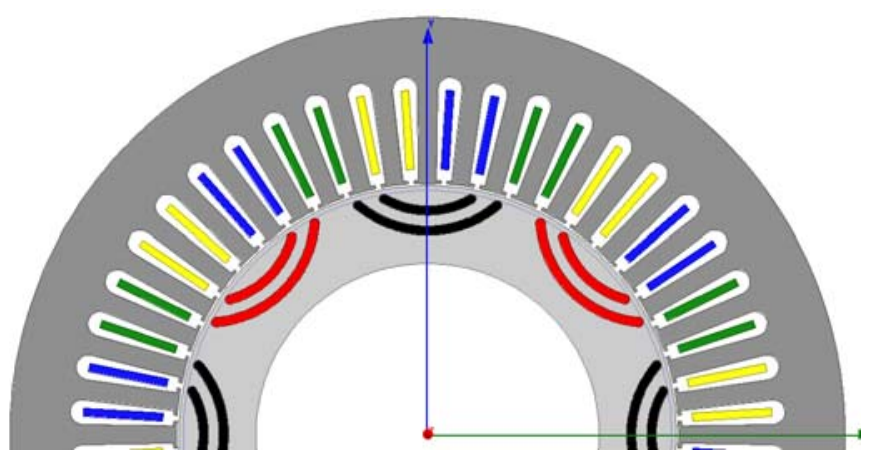

Figura 5.29. Modelo básico de doble capa de imanes curvos.

\subsubsection{Forma de los extremos del imán curvo}

Dado que en el caso de los imanes NdFeB aglomerados el imán puede conformarse con una mayor posibilidad de geometrías se va a estudiar el efecto de la forma del extremo. Para ello se van a considerar las 3 opciones mostradas en la Figura 5.30. En primer lugar en a) se consideran extremos rectos, con los bordes en dirección radial al centro de curvatura del imán, después en b) la punta de los imanes se hace recta, pero casi paralela al diámetro exterior del rotor y el extremo agudo redondeado por cuestiones mecánicas y en c) por último se considera semicircular. La condición para fijar el ángulo abarcado por el imán de la capa inferior sigue siendo mantener el mismo puente que el de la capa superior.

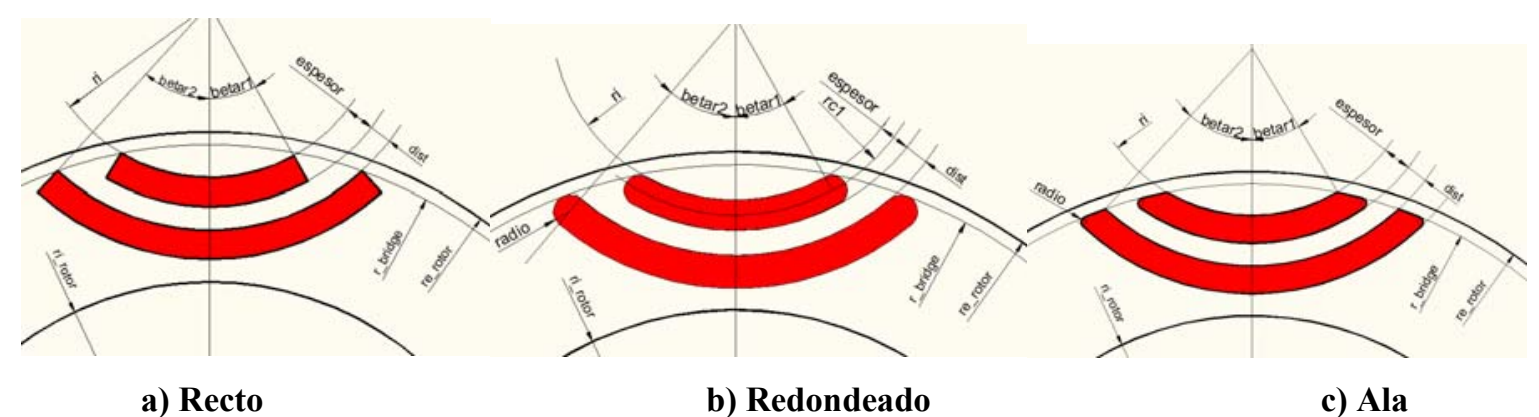

Figura 5.30. Formas de los extremos de los imanes curvos del modelo. 
Tras la optimización de cada modelo se obtienen los resultados de la Tabla 5-8 y las curvas de par de la Figura 5.31. El modelo recto es el que menor par proporciona ya que, para el mismo radio de curvatura, separación y espesor de imanes tiene menor superficie. Puede apreciarse el gran efecto que la forma de los extremos tiene en la forma de la curva del par y en su valor máximo.

Tabla 5-8. Parámetros de los modelos de doble capa curvos

\begin{tabular}{rccc}
\hline Parámetro & Recto & Redondeado & Ala \\
\hline ri $(\mathrm{mm})$ & $\mathbf{2 7 , 4 5}$ & $\mathbf{2 8 , 4 5}$ & $\mathbf{2 7 , 2}$ \\
espesor $(\mathrm{mm})$ & $\mathbf{4 , 2 3}$ & $\mathbf{4 , 4 5}$ & $\mathbf{4 , 2 5}$ \\
dist $(\mathrm{mm})$ & $\mathbf{4 , 4 2}$ & $\mathbf{4 , 4 5}$ & $\mathbf{3 , 1 5}$ \\
betarl $\left({ }^{\circ}\right)$ & $\mathbf{3 4 , 9 5}$ & $\mathbf{3 0 , 3 3}$ & $\mathbf{3 0 , 0 8}$ \\
radio $(\mathrm{mm})$ & --- & --- & $\mathbf{0 , 7 7}$ \\
Área/polo $\left(\mathrm{mm}^{2}\right)$ & $\mathbf{2 8 5 , 2 8}$ & $\mathbf{4 1 4 , 9}$ & $\mathbf{3 5 3 , 2}$ \\
Par máx $\left(\mathrm{Nm}^{2}\right)$ & $\mathbf{4 9 4}$ & $\mathbf{6 4 8}$ & $\mathbf{8 5 8 , 5}$ \\
\hline $\mathrm{Nm} / \mathrm{mm}^{2}$ & $\mathbf{1 , 9 6}$ & $\mathbf{1 , 5 6}$ & $\mathbf{2 , 4 3}$ \\
\hline
\end{tabular}

\section{Doble capa curvo}

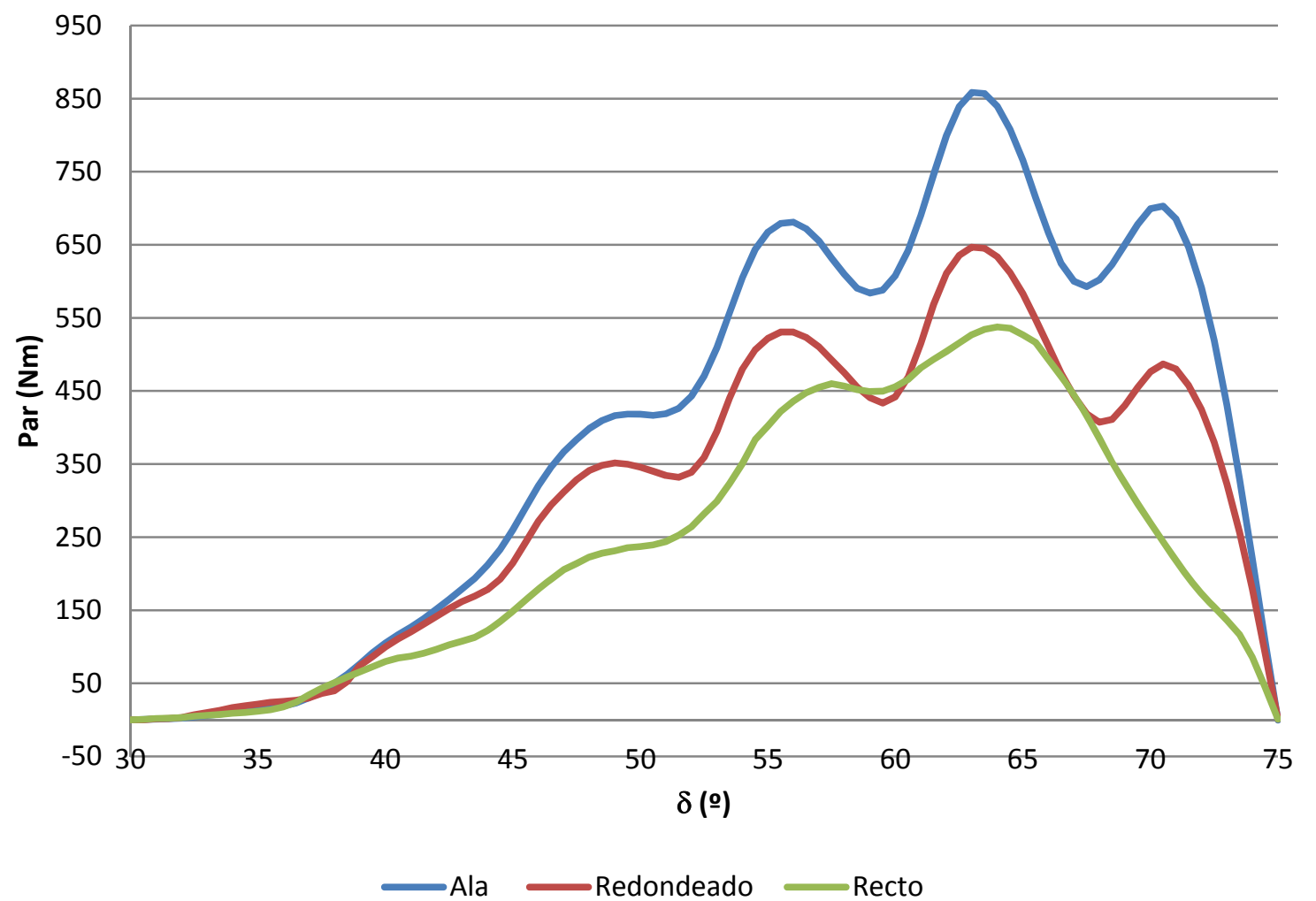

Figura 5.31. Curvas de par variando la forma de los extremos.

Con estas consideraciones se opta por descartar los modelos de extremos rectos y redondeados y tomar como base el de ala para su optimización. 


\subsubsection{Dirección de la magnetización de los imanes}

Por otro lado, y dado que la geometría del es un arco de círculo, la dirección de su magnetización puede disponerse, como muestra la Figura 5.32, de forma uniforme a lo largo de un eje cartesiano de forma similar al de los imanes de los modelos anteriores (a la que se denomina diametral o lineal), $o$ de forma radial en un sistema de coordenadas cilíndrico centrado en el arco de círculo del imán.

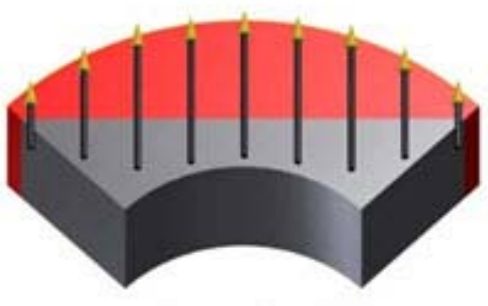

a)

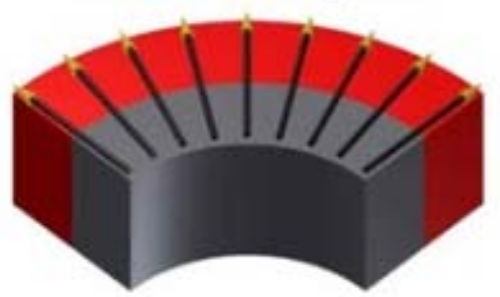

b)

Figura 5.32. Dirección de magnetización de imanes curvos: a) lineal y b) radial saliente del material.

En ambos casos además la magnetización puede ser entrante o saliente al centro del arco. Para aplicar el tipo de magnetización radial en la simulación es necesario definir dos tipos de material, uno con sentido entrante y otro con sentido saliente. Los valores óptimos de las geometrías difieren ligeramente como muestra la Tabla 5-9, siendo los imanes del modelo de magnetización radial más estrechos y separados. Las curvas de par resultantes de aplicar ambos tipo de magnetización se muestran en las figuras siguientes. En la Figura 5.33 puede observarse las líneas de flujo en los imanes y como el vector de potencial magnético $A$ toma valores ligeramente más elevados con la magnetización radial que resulta en una mayor densidad de par por unidad de superficie de los imanes.

Tabla 5-9. Parámetros óptimos según la dirección de magnetización

\begin{tabular}{lrr}
\hline & Lineal & Radial \\
\hline Sri $(\mathrm{mm})$ & 27,2 & 28,8 \\
Sespesor (mm) & 4,25 & 3,77 \\
Sdist (mm) & 3,15 & 3,95 \\
\$betar (rad) & 1,05 & 1,05 \\
Área/polo & 353,2 & 350,7 \\
Mmax (Nm) & 858,5 & 889,9 \\
$\mathbf{N m} / \mathbf{m m}_{2}$ & 2,43 & 2,54 \\
\hline
\end{tabular}



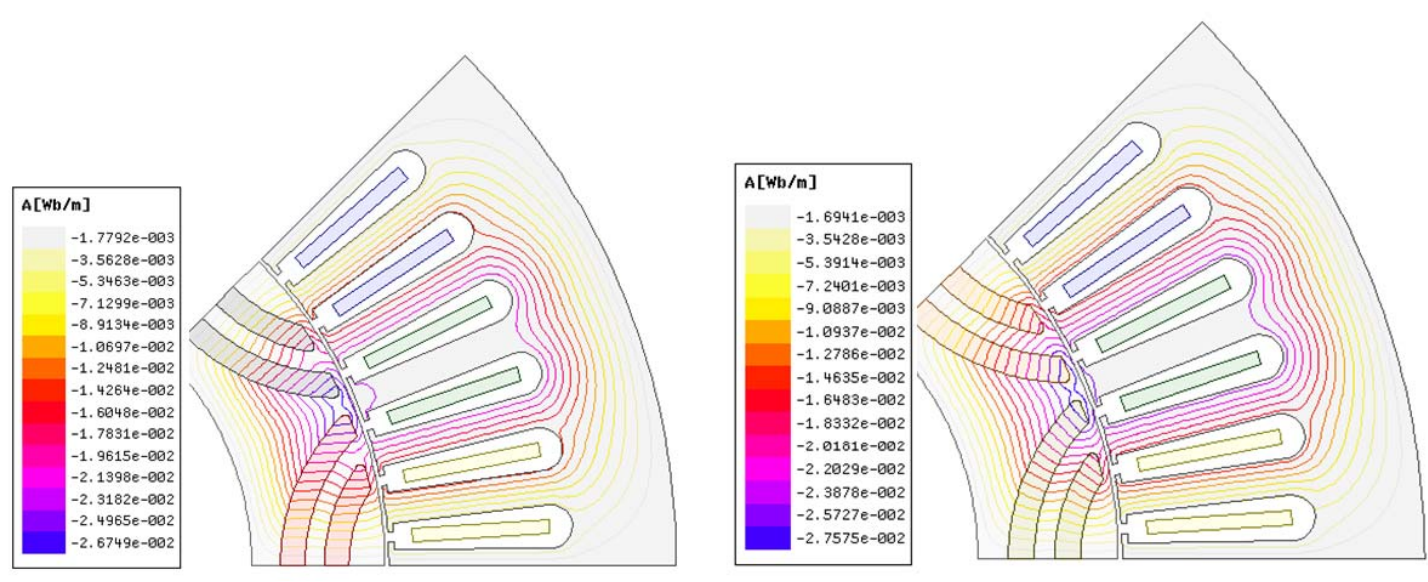

Figura 5.33. Líneas de flujo según la magnetización lineal y radial.

Asimismo, en la Figura 5.34 se muestran las formas de las curvas de par para distintas intensidades y la dirección de magnetización y en la Figura 5.35 una tabla comparativa de dichos valores máximos, donde puede observarse que la diferencia es mayor cuanto menor es la intensidad duplicándose entre la de 50 A respecto de la de $250 \mathrm{~A}$.

\section{Doble curvo/ala}

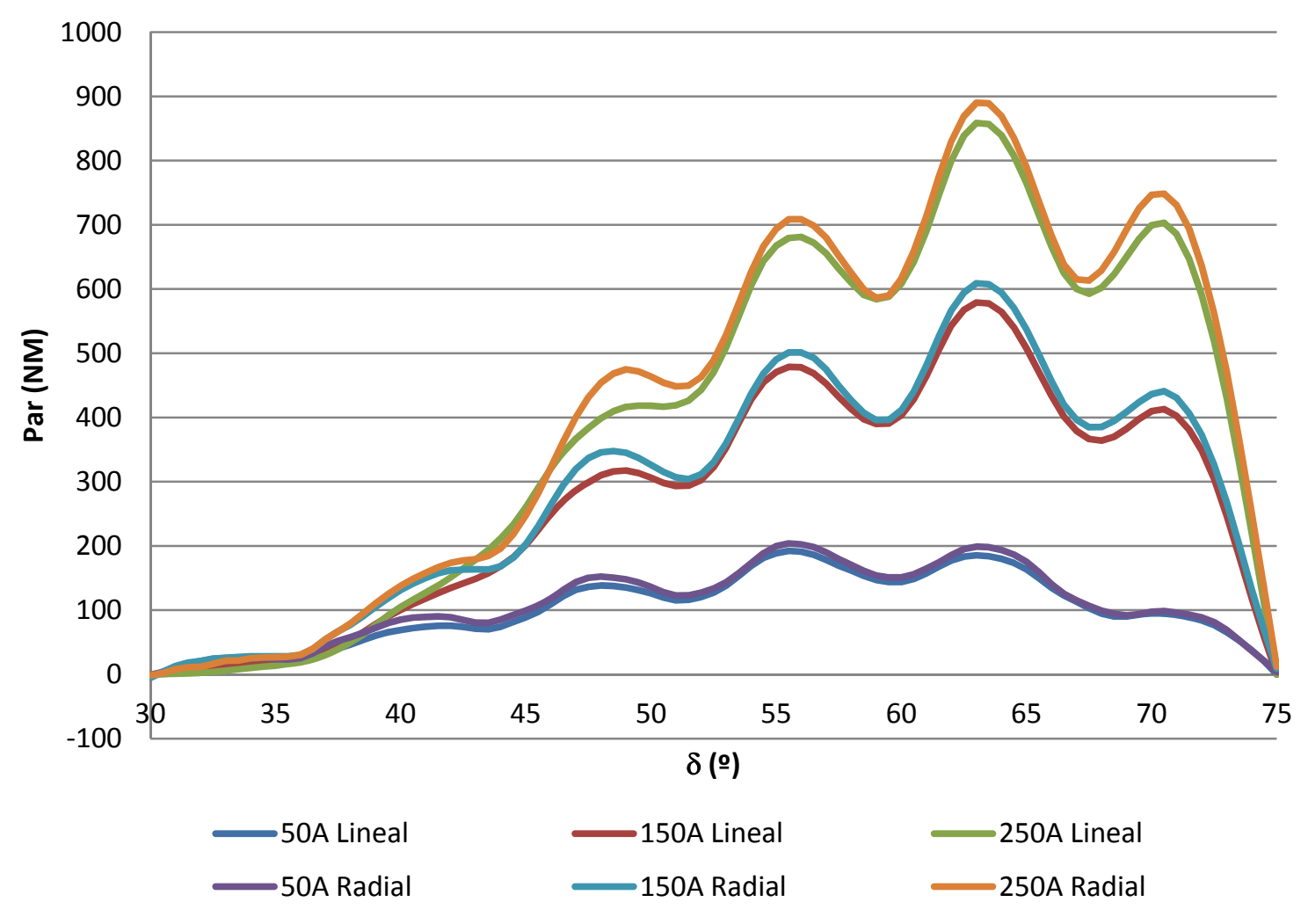

Figura 5.34. Curvas de para a rotor bloqueado de imanes curvos. Magnetización lineal y radial. 


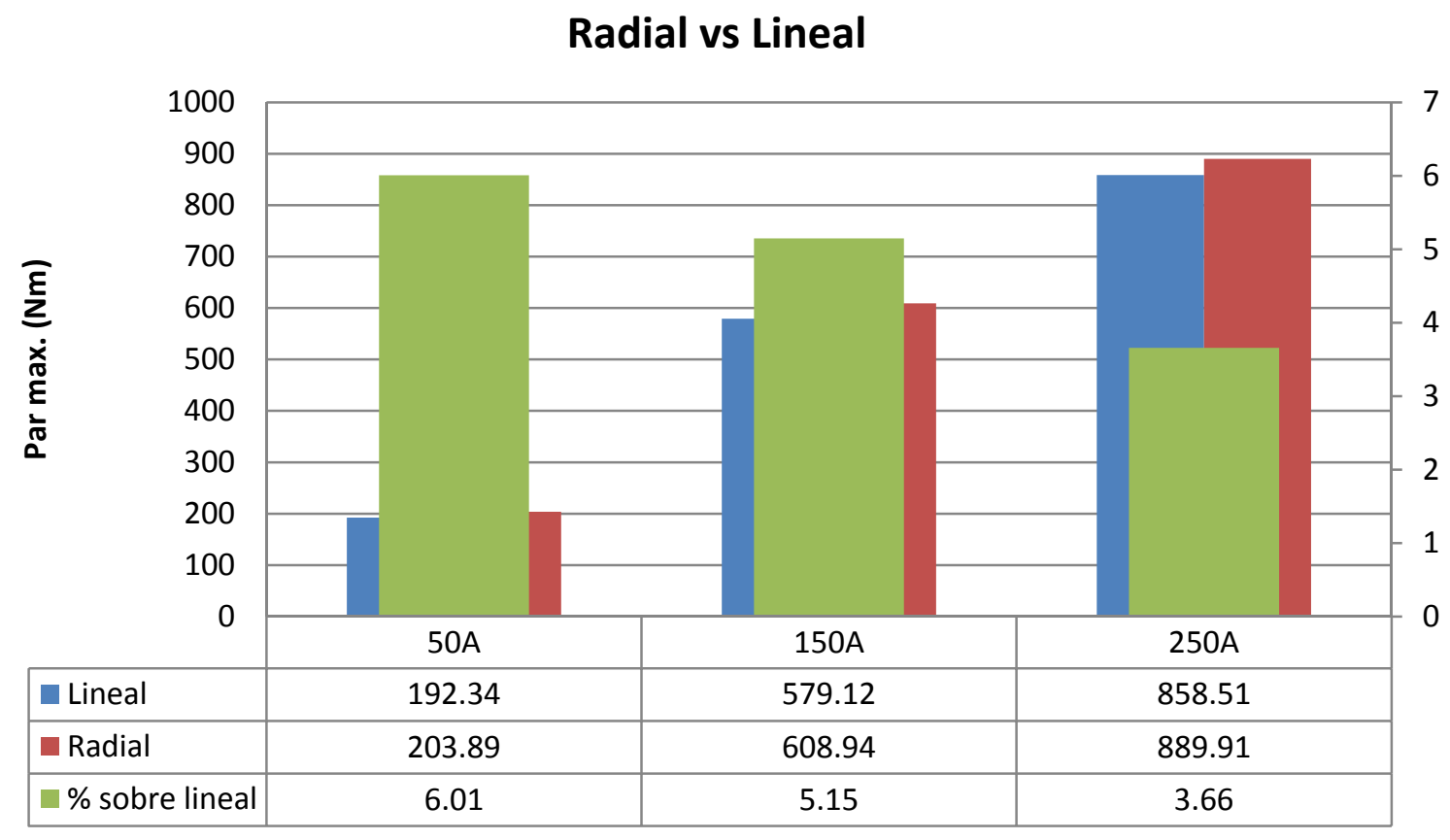

Figura 5.35. Comparativa del par máximo en función de la intensidad y dirección de magnetización.

Con los análisis y resultados obtenidos, finalmente se toma como modelo de rotor propuesto el imán de doble capa de imanes curvo, con magnetización radial y extremos en ala.

\subsection{Análisis realizados}

\subsubsection{Comparativas}

Una primera comparativa de los modelos comentados se muestra en la Figura 5.36, donde la gráfica muestra las curvas de par magnetostático de los mismos. En el caso de los 3 modelos del Prius estos datos son sin optimizar la geometría del rotor, es decir, con las dimensiones de los modelos reales y en los otros casos se muestran los valores optimizados. 


\section{Curvas de par por modelo}

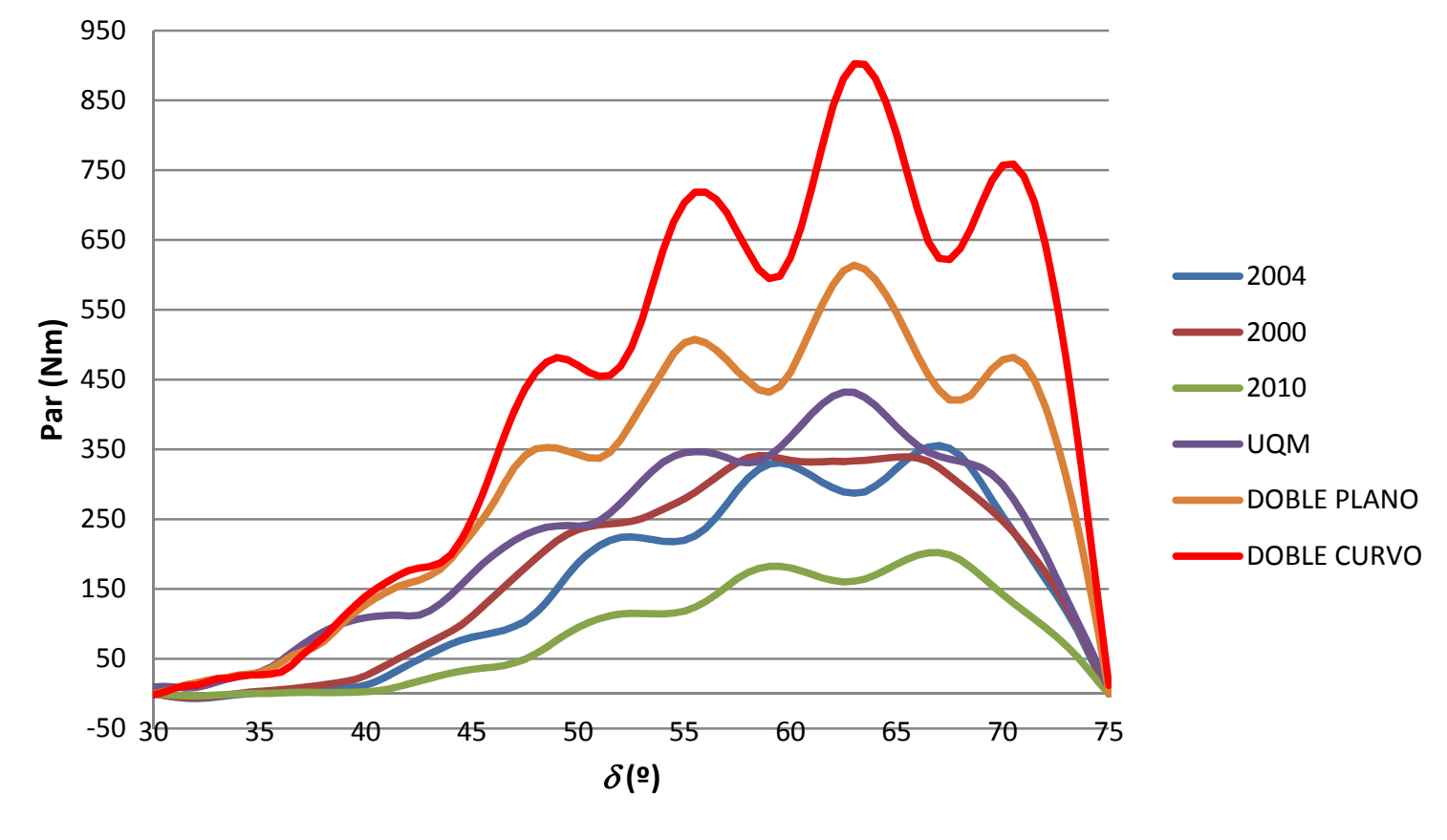

Figura 5.36. Curvas de par magnetostático de los modelos analizados.

La conclusión más evidente al observar la figura es que los máximos valores del par los alcanzan los modelos de doble capa en general, y más en concreto el modelo doble curvo. Es una consecuencia lógica al ser los que más área de imán tienen.

En dichos modelos de doble capa se aprecian 4 puntos de valores máximos o picos repetidos periódicamente cada 7,5 ${ }^{\circ}$. Este ángulo corresponde al espacio angular de los 360/48 dientes del estátor. La amplitud de estos picos depende fuertemente del ángulo betar2 (ver Figura 5.30) comprendido por el imán de la capa inferior. Se ha comprobado que cuanto menor sea este ángulo, más plana será la curva en esa zona y menores los picos, pero la pérdida de par máximo es muy importante, como muestra la Figura 5.37. 


\section{Doble curvo en ala}

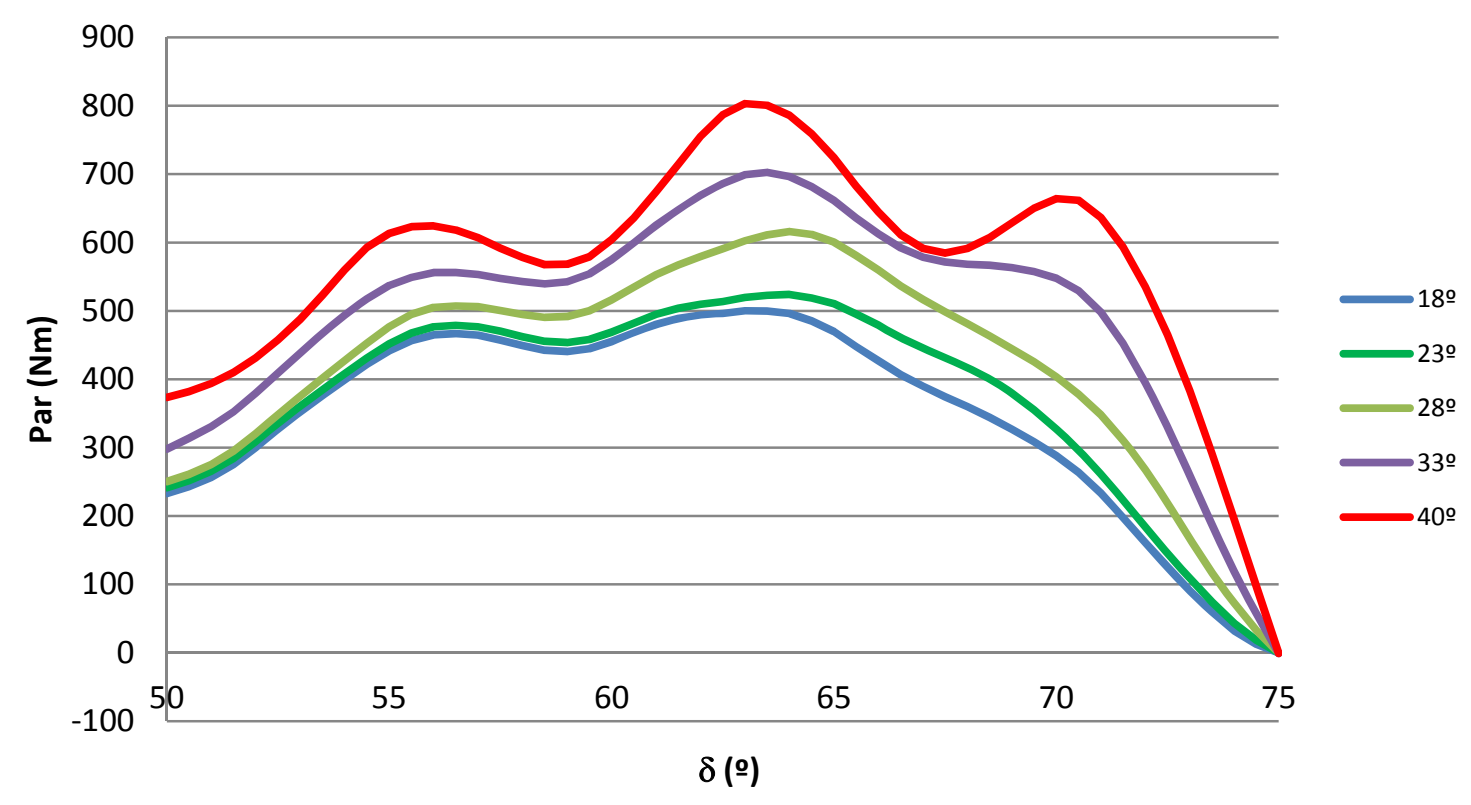

Figura 5.37. Curvas de par al variar el ángulo del imán inferior betar2.

En la Figura 5.38 se presenta otra gráfica con el par máximo de cada modelo y el producido por unidad de área de imanes, si bien en este caso para comparar en igualdad de condiciones, la longitud del modelo del Prius 2010 es la de $83 \mathrm{~mm}$, no la original de 50mm, lo que se indica con Prius 2010* en su modelo.

Por otro lado el valor máximo global en todos los casos se produce cuando $\delta$ toma valores cercanos a $63^{\circ}$. Cada $45^{\circ}$ mecánicos corresponden a $180^{\circ}$ eléctricos, con lo que el máximo total se produce cerca de los $130^{\circ}$ eléctricos. En la Figura 5.12.a puede comprobarse que corresponde a un valor cercano al teórico obtenido por la suma del par síncrono y el reluctante. 


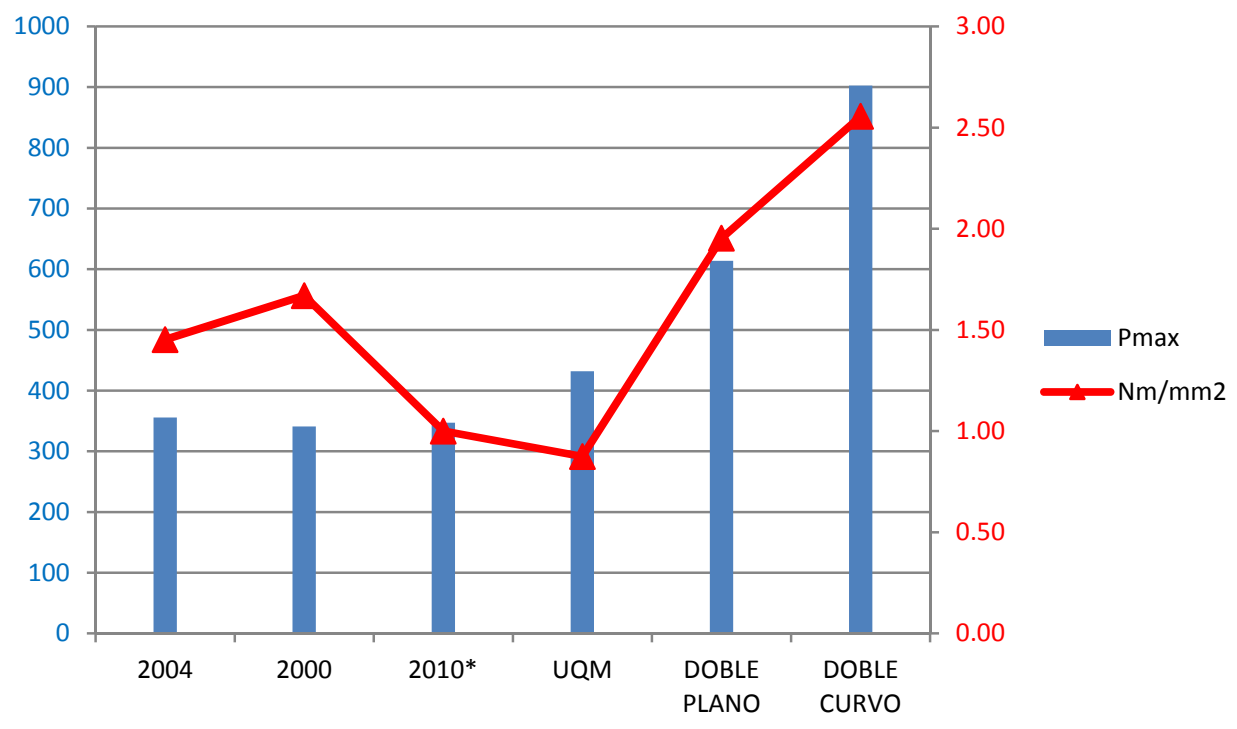

Figura 5.38. Valores de par máximo y par/área en las curvas magnetostáticas

En un segundo análisis se procede a determinar la sección de imanes necesaria en cada modelo de rotor para alcanzar el par máximo obtenido en el Prius 2004 con una intensidad de $250 \mathrm{~A}$, valor que se determinó en $353 \mathrm{Nm}$. Para ello se reduce la superficie de los imanes reduciendo el espesor de los mismos.

Si se compara el área necesaria en cada caso respecto de la base del Prius 2004 se obtiene la Tabla 5-10, donde se indican las áreas de imán requerido, su proporción respecto a la del Prius 2004 y, como medida representativa, el par por unidad de superficie de cada modelo.

Tabla 5-10. Comparación de áreas

\begin{tabular}{lrrrrrr}
\hline & Prius & Prius & Prius & & Doble & Doble \\
& $\mathbf{2 0 0 4}$ & $\mathbf{2 0 0 0}$ & $\mathbf{2 0 1 0 *}$ & UQM & \multicolumn{1}{c}{ V } & Curvo \\
\hline Área $\left(\mathbf{m m}^{\mathbf{2}}\right)$ /polo & 244,0 & 372,0 & 248,22 & 249,7 & 110,5 & 88,8 \\
\% sobre 2004 & 100 & 152,5 & 101,1 & 102,3 & 45,3 & 35,9 \\
$\mathbf{N m} / \mathbf{m m}^{2}$ & 1,45 & 0,95 & 1,42 & 1,41 & 3,19 & 4,03 \\
\hline
\end{tabular}

Como era de esperar el modelo de Prius 2000, con polos planos y un par inicialmente menor, es el que más material requiere, un 52\% más que el del 2004 con los polos en V. Todos los modelos propuestos superan o igualan el comportamiento de los modelo de referencia. Los modelos de doble capa proporcionan mayor par por unidad de superficie por aumentar su par reluctante, siendo el doble curvo en ala, con un espesor de imanes de $1,3 \mathrm{~mm}$, el que menos cantidad de material requiere (un 40\% del área del 2004).

El par por unidad de superficie del modelo UQM es similar, el del modelo Doble V es ligeramente superior, pero el de doble capa curvo es casi dos veces y media superior.

Como estudio similar, en la Tabla 5-11 se obtiene la comparativa del par máximo obtenido para una misma área de imanes $\left(244 \mathrm{~mm}^{2}\right)$ de los modelos. Puede observarse que el modelo doble curvo es el que mayor par proporciona, duplicando el de referencia. 
Tabla 5-11. Comparación de Pares para el mismo área de imanes

\begin{tabular}{lrrrrr}
\hline & $\begin{array}{r}\text { Prius } \\
\text { 2004 }\end{array}$ & $\begin{array}{r}\text { Prius } \\
\text { 2000 }\end{array}$ & UQM & $\begin{array}{r}\text { Doble } \\
\text { V }\end{array}$ & $\begin{array}{r}\text { Doble } \\
\text { Curvo }\end{array}$ \\
\hline Par (Nm) & 353 & 342 & 357 & 603 & 717 \\
$\mathbf{N m} / \mathbf{m m}^{2}$ & 1,44 & 1,40 & 1,46 & 2,47 & 2,94 \\
\% sobre 2004 & 100 & 96,9 & 101 & 170 & 203 \\
\hline
\end{tabular}

De los resultados anteriores se observa que la densidad de par $\left(\mathrm{Nm} / \mathrm{mm}^{2}\right)$ es mayor cuando se utiliza menos área de imanes. En la Figura 5.39 se muestra esta situación en el caso del modelo doble curvo y cómo cuando el área disminuye, la densidad aumenta y cuando el par es máximo, con unos $\left(400 \mathrm{~mm}^{2}\right)$, la densidad de potencia es aproximadamente la mitad que cuando el área es de $150 \mathrm{~mm}^{2}$. Dado que el objetivo de esta Tesis es la aplicación de imanes aglomerados, con menor producto de energía, se va a dar prioridad al par máximo sobre la densidad de par.

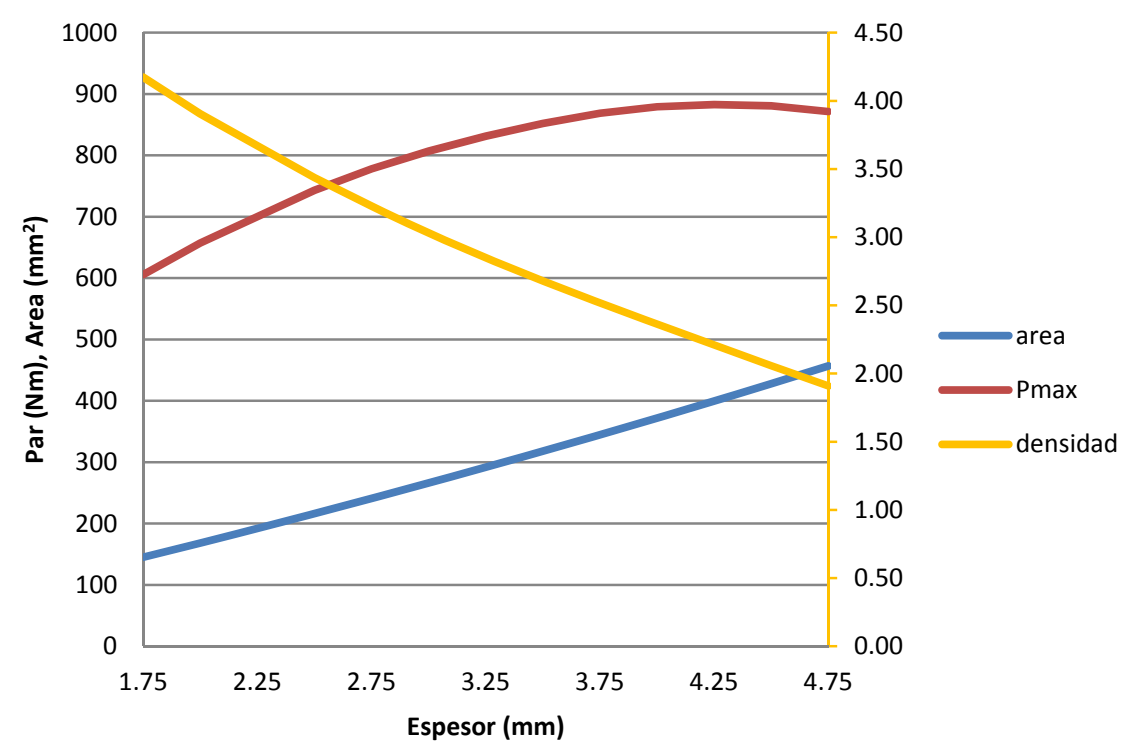

Figura 5.39. Par y densidad de potencia en función del espesor de los imanes.

\subsubsection{Estudio del par oscilante}

Si bien el estudio del par oscilante no es una parte importante de la tesis se ha realizado la comparativa de los modelos presentados para aportar una idea de su magnitud y su relación con la geometría de los imanes.

Como se ha indicado anteriormente, el par oscilante o "cogging torque" es el que se produce en el rotor por el efecto que se produce al pasar los bordes de los imanes cerca de los dientes del estátor cuando éste gira. Este par depende fuertemente de la geometría de ambas partes rotor y estátor) y se utilizan distintas modificaciones para reducirlo.

Aunque este par no puede calcularse directamente mediante FEA puede obtenerse de dos formas: la primera es a partir de una serie de soluciones estáticas con distintas posiciones del rotor y la segunda es obtenerla en una única simulación dinámica, eliminando las excitaciones de intensidad, de tal forma que no aparezcan efectos dinámicos inducidos, por ejemplo, a $1^{\circ}$ por segundo $[98,104]$. En la 
Figura 5.40 puede observarse la forma de las curvas del par oscilante obtenidas de esta forma para los modelos estudiados y en la Figura 5.41 los valores máximo y eficaz de dichas curvas de par oscilante.

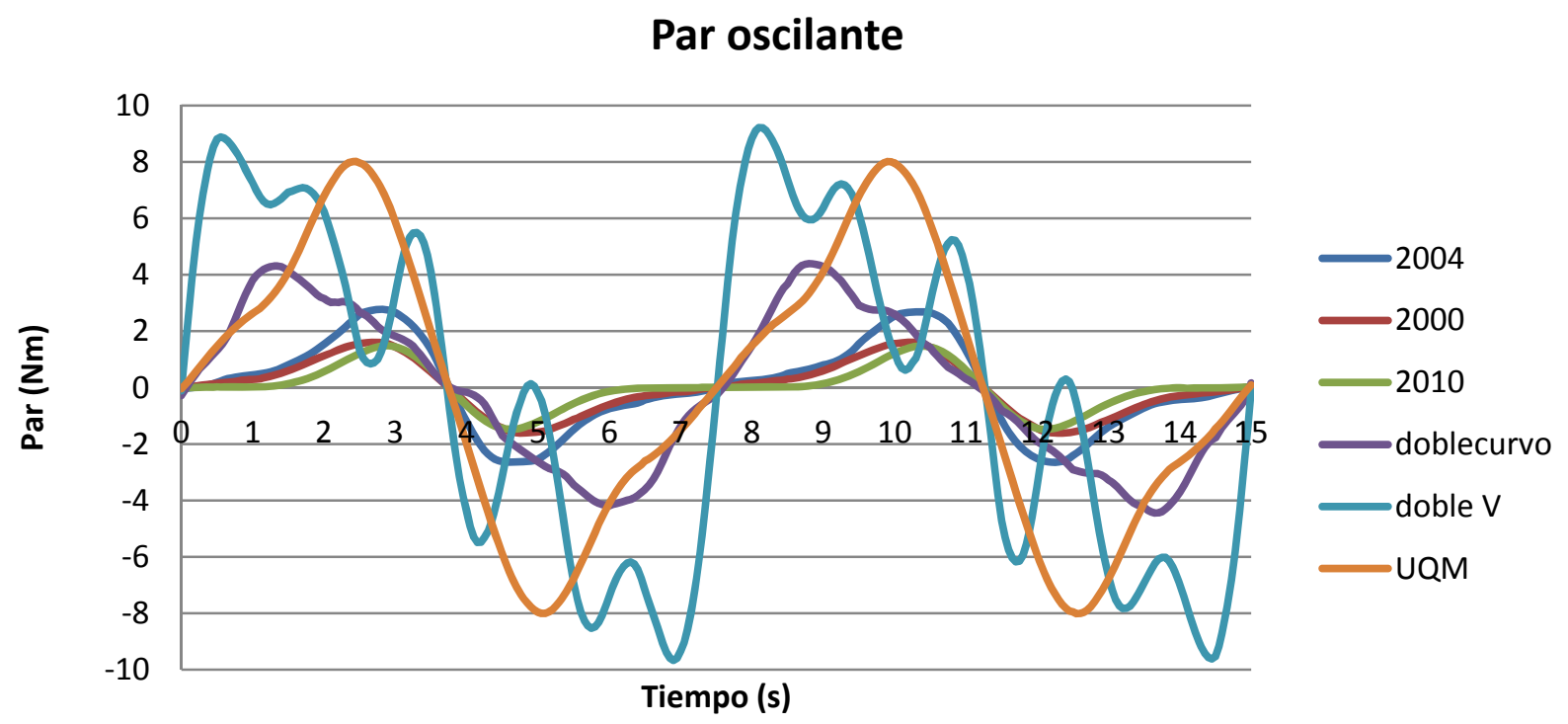

Figura 5.40. Curvas de par oscilante para distintos modelos

Dado que los dientes del estátor están separados 7,5 ${ }^{\circ}$ será este tiempo el periodo del par oscilante a una velocidad de $1^{\circ}$ por segundo, el periodo será $7,5 \mathrm{~s}$.

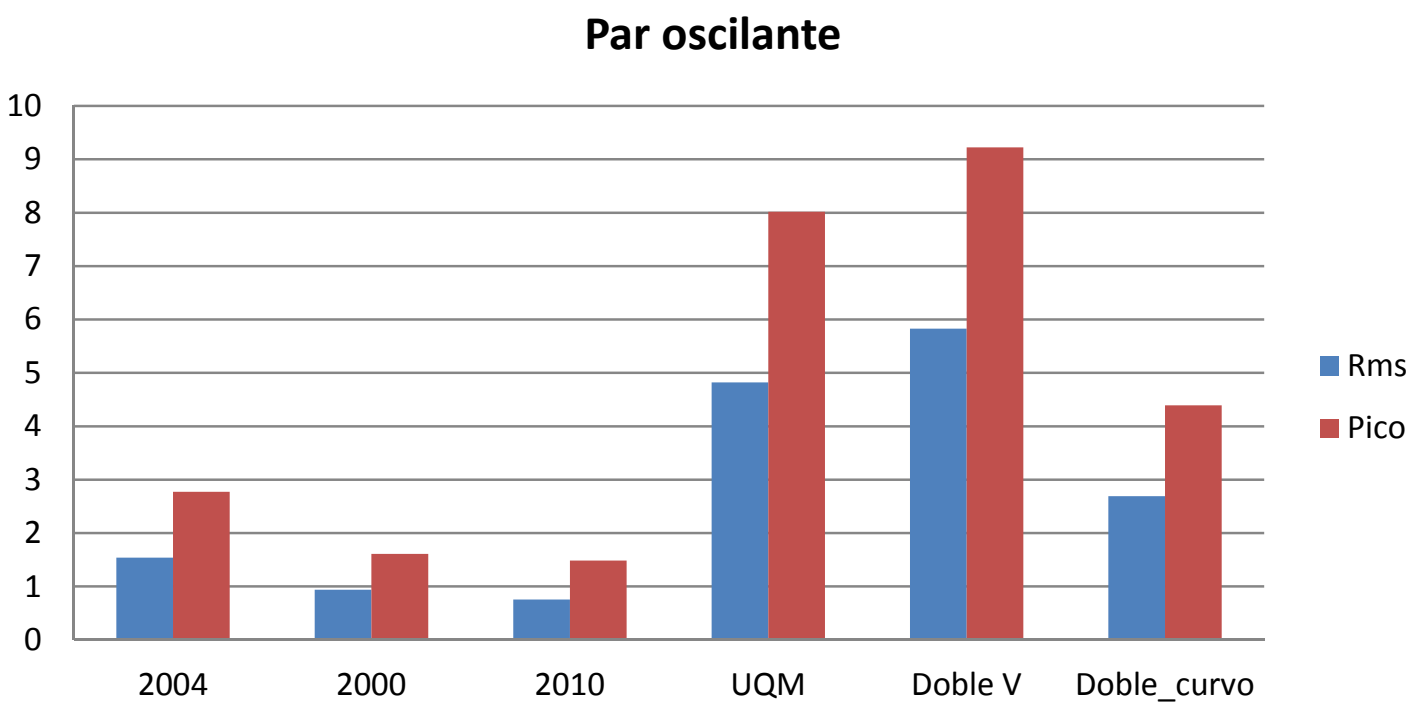

Figura 5.41. Valor eficaz (Rms) y de pico del par oscilante de los modelos.

Puede observarse que los imanes rectos e inclinados, en su versiones 2004, UQM y doble V, presentan los valores más elevados de par, ya que los extremos de los imanes ejercen una mayor atracción sobre los extremos de los dientes del estátor y dado que en el de doble capa en $\mathrm{V}$ coinciden prácticamente los 2 imanes con dos huecos de dientes (ver Figura 5.42), el valor que toma es el más elevado, mientras que el modelo doble curvo esa coincidencia extremo rotor/hueco diente es ligeramente menor. 


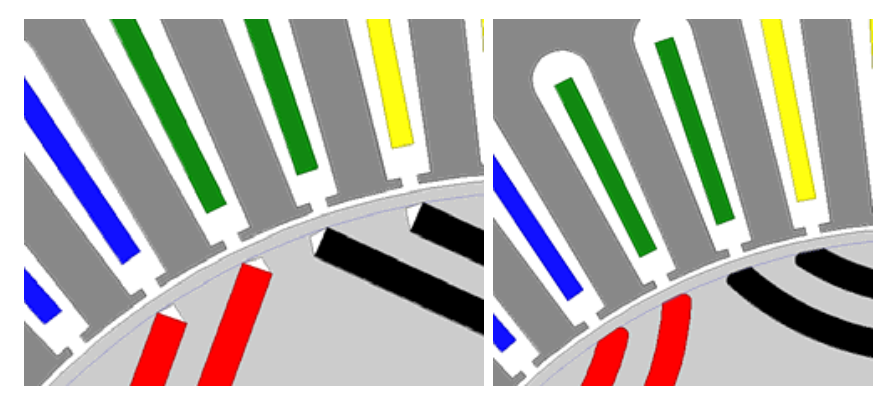

Figura 5.42. Modelos optimizados de doble capa en V y doble curvo.

Evidentemente una solución para disminuir el par oscilante sería hacer que el número de ranuras del estátor y del rotor sean números primos entre sí o que los extremos de los imanes no coincidan simultáneamente con las ranuras cambiando la separación entre capas, por ejemplo.

\subsubsection{Estudio del rizado del par dinámico}

Si bien las curvas de par magnetostático nos proporcionan una idea del par máximo del motor y nos permiten calcular los parámetros de su circuito equivalente, las curvas de par dinámico representan la forma real del par a unas determinadas revoluciones de giro. Estas formas de onda presentan un rizado que, como se ha indicado en el capítulo 4.6.6, es la combinación del par oscilante, del par de reluctancia y de la distorsión de la forma de onda de la densidad de flujo magnético en el entrehierro y sus componentes armónicas. Aunque la aplicación al modelo de imanes aglomerados se explica en el capítulo siguiente, en la Figura 5.43 se muestran los valores comparativos del modelo en ala propuesto con imanes sinterizados y aglomerados respecto del modelo del Prius 2004.

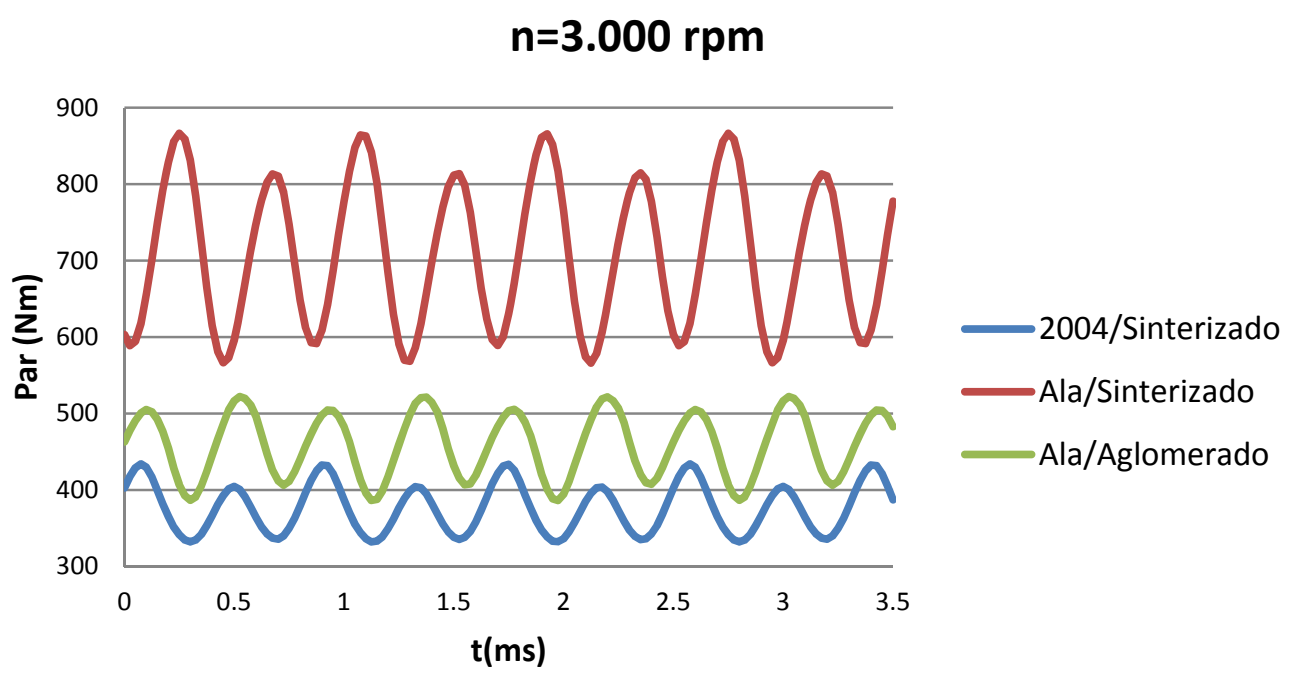

Figura 5.43. Curvas de par dinámico para 3.000 rpm. Prius 2004 y doble curvo en ala.

Se puede cuantificar el rizado mediante la siguiente ecuación:

$$
\text { ripple }=\frac{r m s_{A C}}{a v g}
$$


Donde:

rmSAC es el valor eficaz de la componente de corriente alterna de la curva

avg es el valor medio de la onda

De los valores obtenidos, que se muestran en la Tabla 5-12, se observa que el modelo en ala propuesta tiene un rizado que en ambos casos supera al modelo 2004, si bien al usar imanes aglomerados, esta diferencia es bastante menor.

Tabla 5-12. Valores de rizado para el modelo 2004 y doble curvo en ala

\begin{tabular}{rr|rr|}
\hline Modelo & $\mathbf{2 0 0 4}$ & \multicolumn{2}{|c|}{ Ala } \\
\hline Material & $\mathbf{N 3 6}$ & $\mathbf{N 3 6}$ & $\mathbf{N 1 0 B H}$ \\
Rms & 375,3 & 717,4 & 454,2 \\
rmsaC & 31,22 & 94,13 & 43,13 \\
ripple & $\mathbf{8 , 3}$ & $\mathbf{1 3 , 3}$ & $\mathbf{9 , 5}$ \\
\hline
\end{tabular}

\subsubsection{Imanes aglomerados moldeados por compresión}

Hasta ahora las simulaciones se han hecho con material sinterizado N36 para todos los modelos. Como se ha indicado al principio, como objetivo principal de esta tesis se pretende obtener un modelo de rotor con una geometría que aproveche las nuevas características de fabricación de los imanes aglomerados, especialmente de los moldeados por compresión. Si con los imanes sinterizados las geometrías se limitan a líneas rectas principalmente y los imanes deben construirse, magnetizarse, mecanizarse y tratarse superficialmente antes de su montaje, con los imanes aglomerados puede "rellenarse" cualquier hueco que se construya en el rotor y magnetizarlos. Evidentemente tienen el inconveniente de que su producto de energía es menor que el de los imanes sinterizados.

Se trata entonces de conseguir un rotor cuya geometría haga factible el uso de estos imanes aglomerados obteniendo un par razonablemente alto para poder sustituir los imanes sinterizados.

Dado que el modelo de doble capa curvo optimizado es el que mayor par por unidad de superficie proporciona parece ser el propicio para esta aplicación. Basta entonces con cambiar el material magnético de los imanes para analizar su efecto.

En catálogos comerciales de imanes $\mathrm{NdFeB}$ aglomerados por compresión encontramos para un imán de clase estándar valores de $B_{r}$ y $H_{c}$ del rango de los mostrados en la Tabla 5-13. Estos imanes están elaborados con polvo Magnequench isotrópico MQP-14-12, que no todavía no presenta los últimos avances en estos materiales.

Tabla 5-13. Características de imanes NdFeB aglomerados por compresión

\begin{tabular}{|c|c|c|c|c|c|c|c|c|}
\hline \multirow[b]{2}{*}{ Fabricante } & \multirow{2}{*}{$\begin{array}{l}\text { Denominación } \\
\text { comercial }\end{array}$} & \multicolumn{2}{|c|}{$H_{C}$} & \multicolumn{2}{|c|}{$\boldsymbol{B}_{r}$} & \multirow{2}{*}{$\begin{array}{c}\alpha \\
\% /{ }^{\circ} \mathrm{C}\end{array}$} & \multirow{2}{*}{$\begin{array}{c}\boldsymbol{\beta} \\
\% /{ }^{\circ} \mathrm{C}\end{array}$} & \multirow{2}{*}{$\begin{array}{c}\boldsymbol{\rho} \\
\mathrm{g} / \mathrm{dm}^{3}\end{array}$} \\
\hline & & $\mathrm{kA} / \mathrm{m}$ & $\mathrm{kOe}$ & $\mathrm{mT}$ & $\mathrm{G}$ & & & \\
\hline Bomatec [105] & BMNP-10H MQ & 410 & 5,16 & 670 & 6.700 & $-0,1$ & -0.34 & 6.000 \\
\hline Dexter magnetics [106] & NeoForm & 438 & 5,5 & 785 & 7.850 & $-0,12$ & --- & 6.000 \\
\hline Magnetic Materials \& Components [107] & N10-BH & 448 & 5,6 & 690 & 6.900 & $-0,10$ & $-0,4$ & 6.100 \\
\hline Eneflux Magnetics[108] & EAM-B 10 & 414 & 5,2 & 690 & 6.900 & $-0,10$ & $-0,4$ & 6.000 \\
\hline
\end{tabular}


Puede apreciarse que son valores similares entre fabricantes, por lo que para el resultado final de aplicar este material a nuestro modelo la diferencia no va a ser importante.

Aplicando uno de ellos, por ejemplo el N10-BH se obtienen las curvas de la Figura 5.44, donde el par máximo ronda los $600 \mathrm{Nm}$.

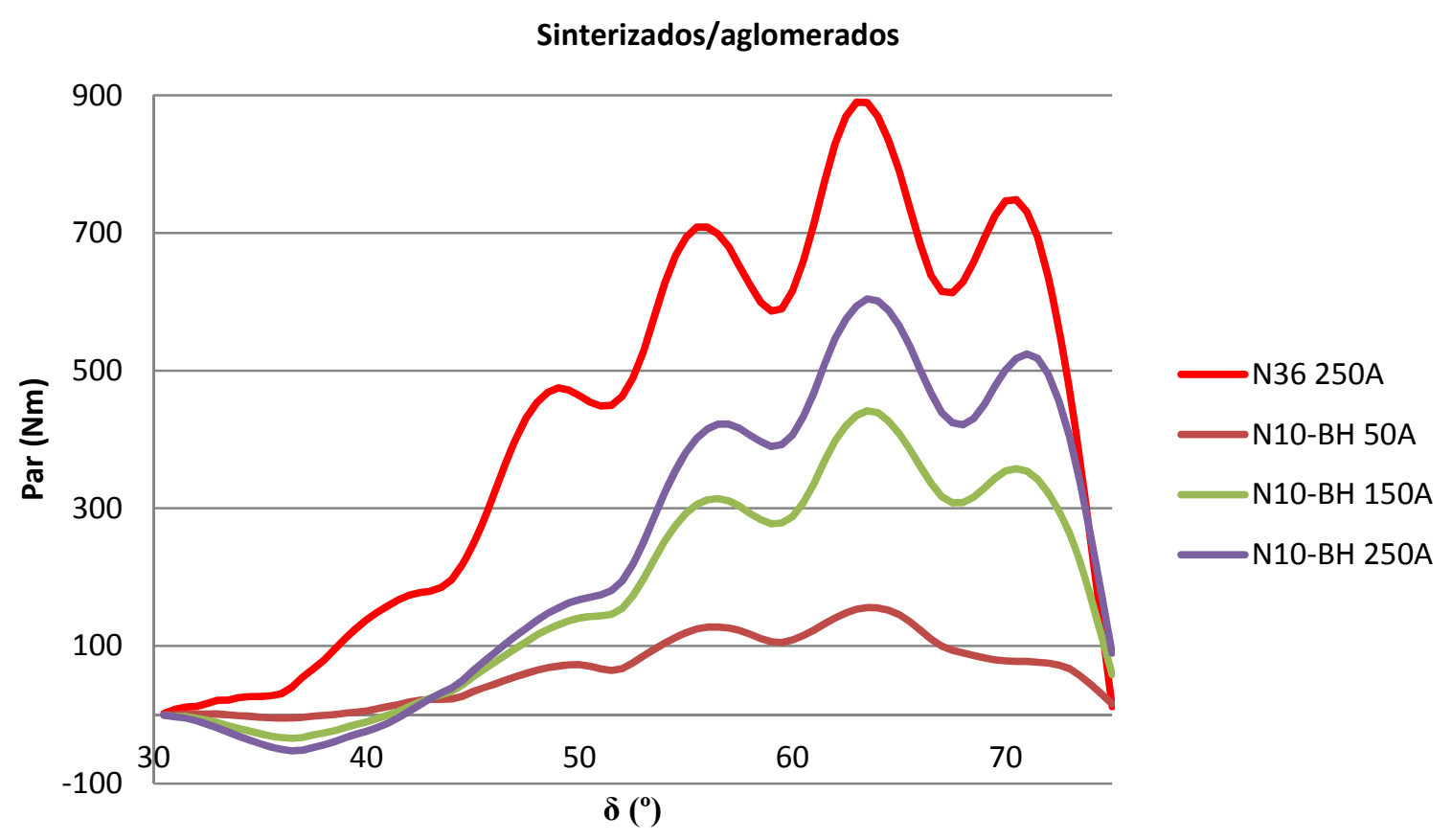

Figura 5.44. Curvas de par magnetostático para el modelo con sinterizados (N36) y aglomerados (NB-10H).

Dado que estos imanes tienen una densidad del orden del $18 \%$ inferior $\left(6,1 \mathrm{~g} / \mathrm{cm}^{3}\right.$ frente a los 7,4 $\mathrm{g} / \mathrm{cm}^{3}$ de los sinterizados), los esfuerzos en el puente debidos a la fuerza centrífuga, son también menores, por lo que el puente podría ser reducido y proporcionar más par. Como ejemplo, una reducción del puente actual de $1,48 \mathrm{~mm}$ a $1 \mathrm{~mm}$ supone un aumento de un $5 \%$ en al valor de par máximo.

Otra de las ventajas derivadas de la menor fuerza magnética de este tipo de materiales frente a los sinterizados es el menor par oscilante, que se reduce hasta un valor eficaz de $240 \mathrm{mN}$ de valor eficaz (Figura 5.45). 


\section{Par oscilante}

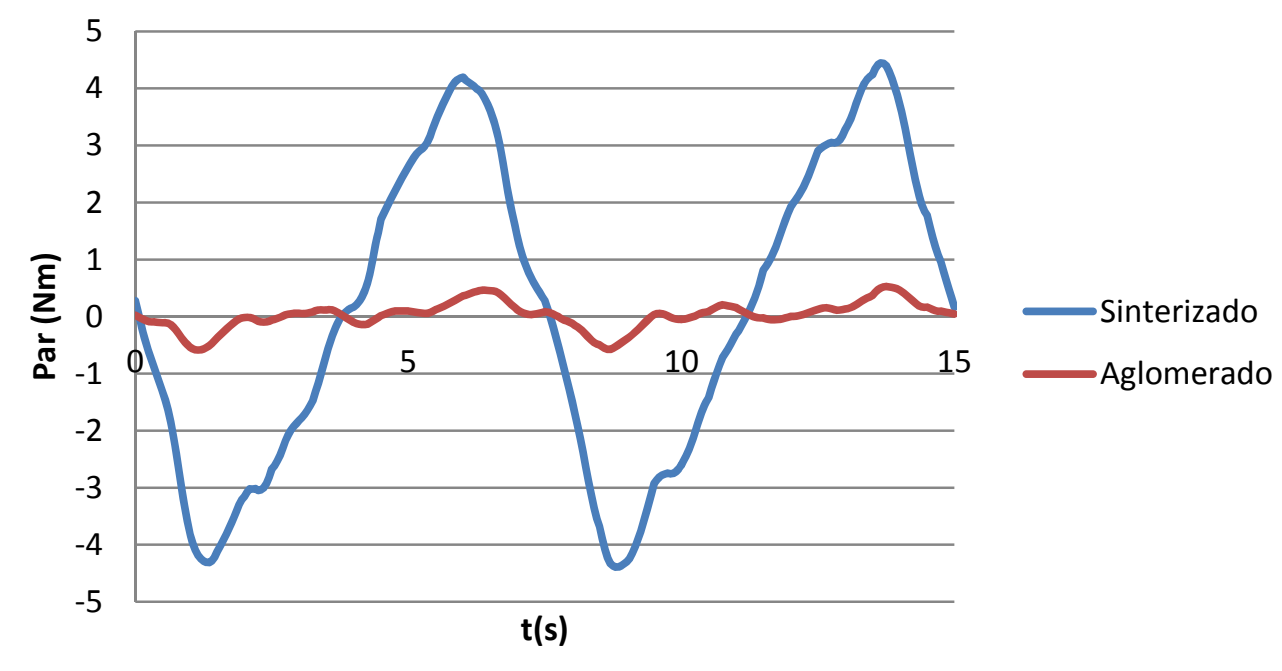

Figura 5.45. Par oscilante del modelo de imanes curvos en ala con material sinterizado (N36) y aglomerado (N-10-BH).

\subsubsection{Análisis ampliados}

\subsubsection{Efecto de la temperatura}

Como se ha indicado en el apartado de materiales magnéticos, los imanes permanentes tienen importantes límites térmicos que pueden hacer que pierdan parte de su magnetismo o incluso desmagnetizarlos totalmente. Las curvas de desmagnetización dependen de la temperatura y cuanto mayor sea ésta, menor par producirán los imanes del rotor. Hay que pensar que el motor del Prius alcanza temperaturas de funcionamiento de entre 120 y $130{ }^{\circ} \mathrm{C}$, lo que hace que el par efectivo real sea menor que el obtenido en las curvas a temperatura ambiente.

El software FEA de análisis magnético tiene un apartado especial para la definición de las propiedades magnéticas de los imanes permanentes, que incluye el efecto de la temperatura mediante los factores $\alpha$ y $\beta$ indicados en el capítulo 3.3.1.4 que afectan la permeabilidad y coercitividad, respectivamente (ver Figura 5.46). Estos factores los suministran los fabricantes en sus catálogos y hojas de características. 


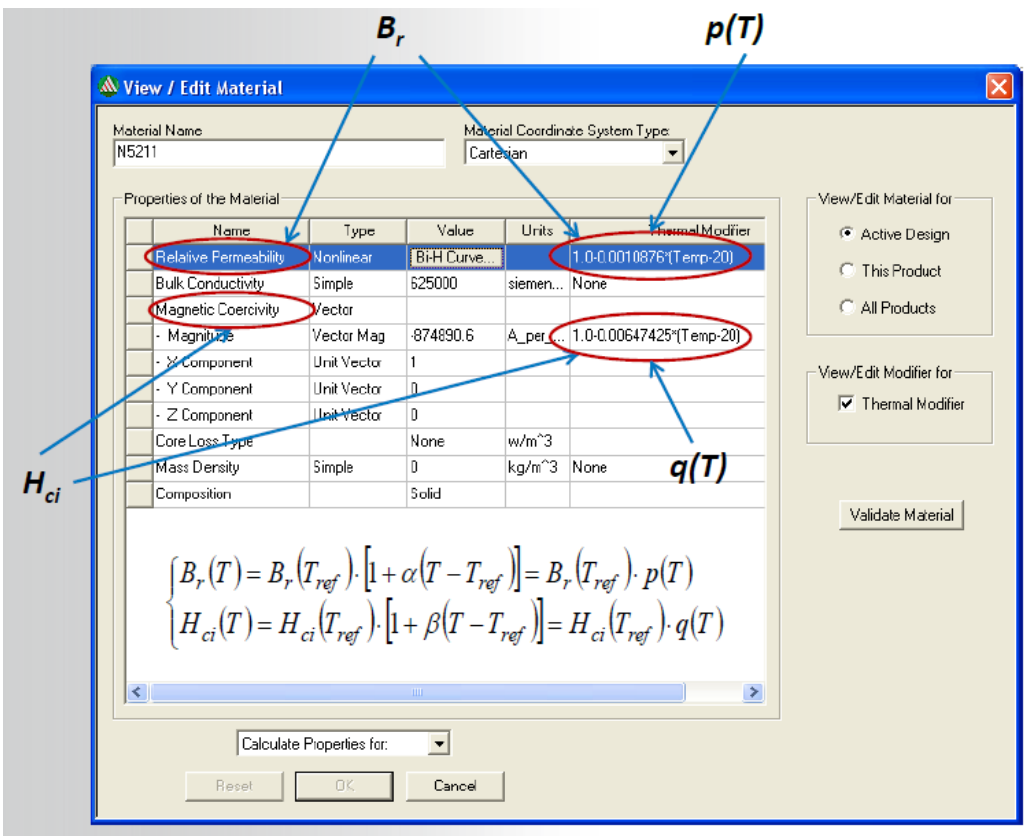

Figura 5.46. Efecto de la temperatura en desmagnetización de imanes permanentes. [109].

Los resultados de aplicar estos coeficientes y variar la temperatura en la curva de par magnetostático del modelo se muestras en la Figura 5.47. Como era de esperar, al aumentar la temperatura de los imanes el par disminuye, haciéndose negativo en alguna zona donde era positivo. Los puntos de principio y final de curva se mantienen.

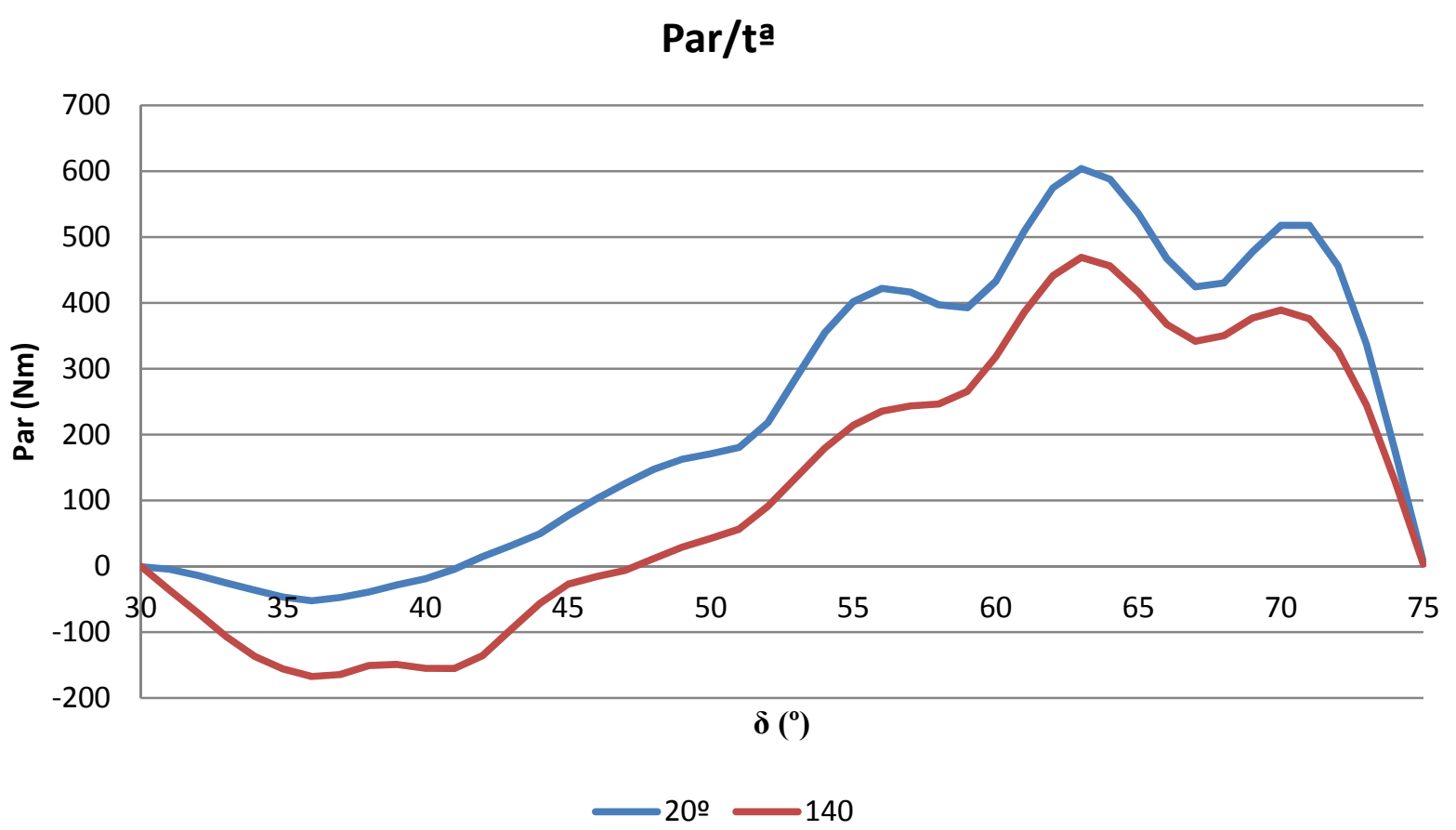

Figura 5.47. Curvas de par magnetostático. Material N10-B-H para $20^{\circ} \mathrm{C}$ y $140{ }^{\circ} \mathrm{C}$. 


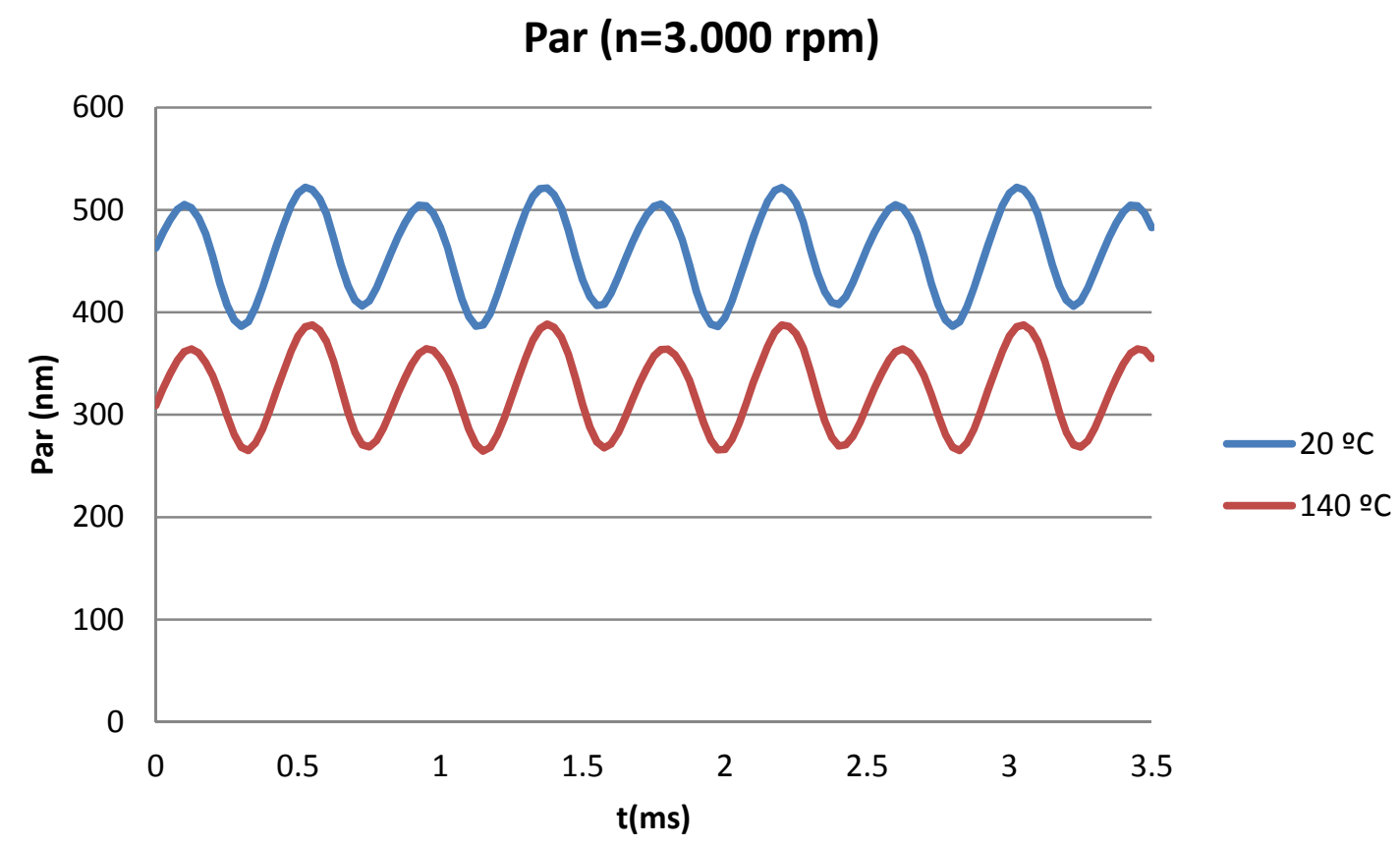

Figura 5.48. Curvas de par dinámico a $3.000 \mathrm{rpm}$. Material N10-B-H para $20^{\circ} \mathrm{C}$ y $140{ }^{\circ} \mathrm{C}$.

En el caso de la curva de par dinámico, cuyos resultados se muestran en la Figura 5.48, dado que los coeficientes $\alpha$ y $\beta$ típicos de aglomerados son 0,1 y $0,4 \%$, en una variación de $120{ }^{\circ} \mathrm{C}$ la disminución de $B$ y $H$ suponen un $12 \%$ y un $58 \%$ respectivamente, lo que arroja una disminución del par considerable, del $30 \%$.

\subsubsection{Descomposición de la curva de par $[110,111]$}

Como se ha indicado en el apartado 4.6.3 y se muestra en la Figura 5.12, el par magnetostático puede descomponerse en el par magnetizante o síncrono y en el par reluctante. Este último puede ser obtenido por análisis FEA eliminando los imanes del modelo y repitiendo el análisis magnetostático. Una vez obtenido este par, puede restarse a la curva de para total para obtener el par magnetizante.

En la Figura 5.49 se muestran los resultados obtenidos par los modelos Prius 2000 y doble capa de imanes curvos con una intensidad de 250 A. En ella puede observarse que:

1.- Tanto las curvas de par reluctante como las de par magnetizante tienen forma fundamentalmente sinusoidal, si bien claramente presentan componentes armónicas de orden 5 y 12 en la reluctante y en la síncrono respectivamente. Estos armónicos se deben a las componentes propias del flujo, que a su vez dependen de la relación entre el número de ranuras y de polos (48 ranuras/ 4 pares polos =12). En cambio, los armónicos del par reluctante provienen de la diferencia de los valores de las inductancias, siendo $L_{q}$ la que debido a la saturación magnética está dominada por el $5^{\circ}$ armónico.

2.- Las curvas de par reluctante, como corresponde a la ecuación (4.9), tienen frecuencia doble que la de par magnetizante y comienzan tomando valor negativo. Estas curvas a su vez dependen del nivel de saturación (de la intensidad) por tanto, a media carga la distorsión es mayor que a plena carga. 

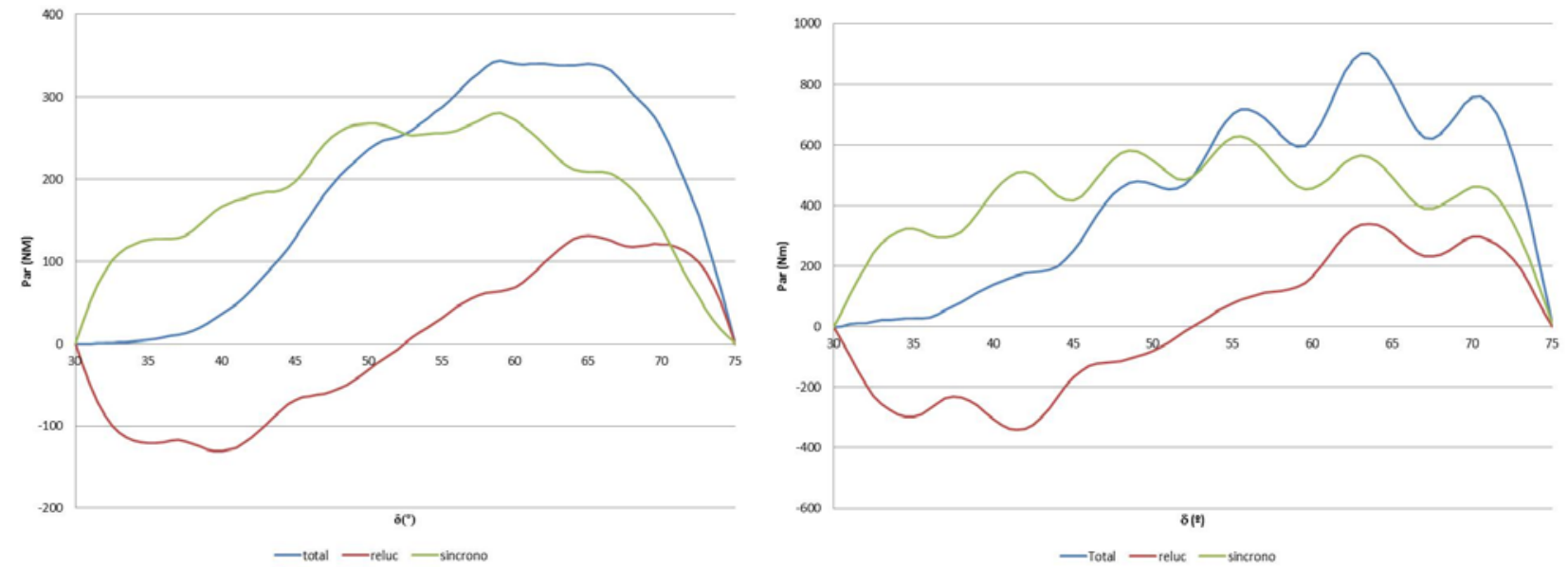

Figura 5.49. Curvas de para para el modelo Prius 2000 (izda) y doble capa curvo (dcha).

Parece evidente entonces que a medida que el rotor tiene una mayor componente de par reluctante, la ecuación del par debería contemplar las componentes armónicas

\subsubsection{Pérdidas en el hierro}

Se ha procedido a comparar las pérdidas en el hierro del modelo de referencia con el modelo propuesto, y se muestra en la Figura 5.50. En la misma se indica que las pérdidas calculadas a 3.000 rpm para el Prius 2004 son de $0,73 \mathrm{~kW}$ y para nuestro modelo son de $1 \mathrm{~kW}$. Este hecho se debe fundamentalmente al cambio estructural y el aumento de reluctancia en el rotor del modelo propuesto. Como se indica en capítulo de trabajos futuros, este hecho puede mejorarse con el uso de otros materiales magnéticos de mejor calidad y con un menor espesor de chapa.

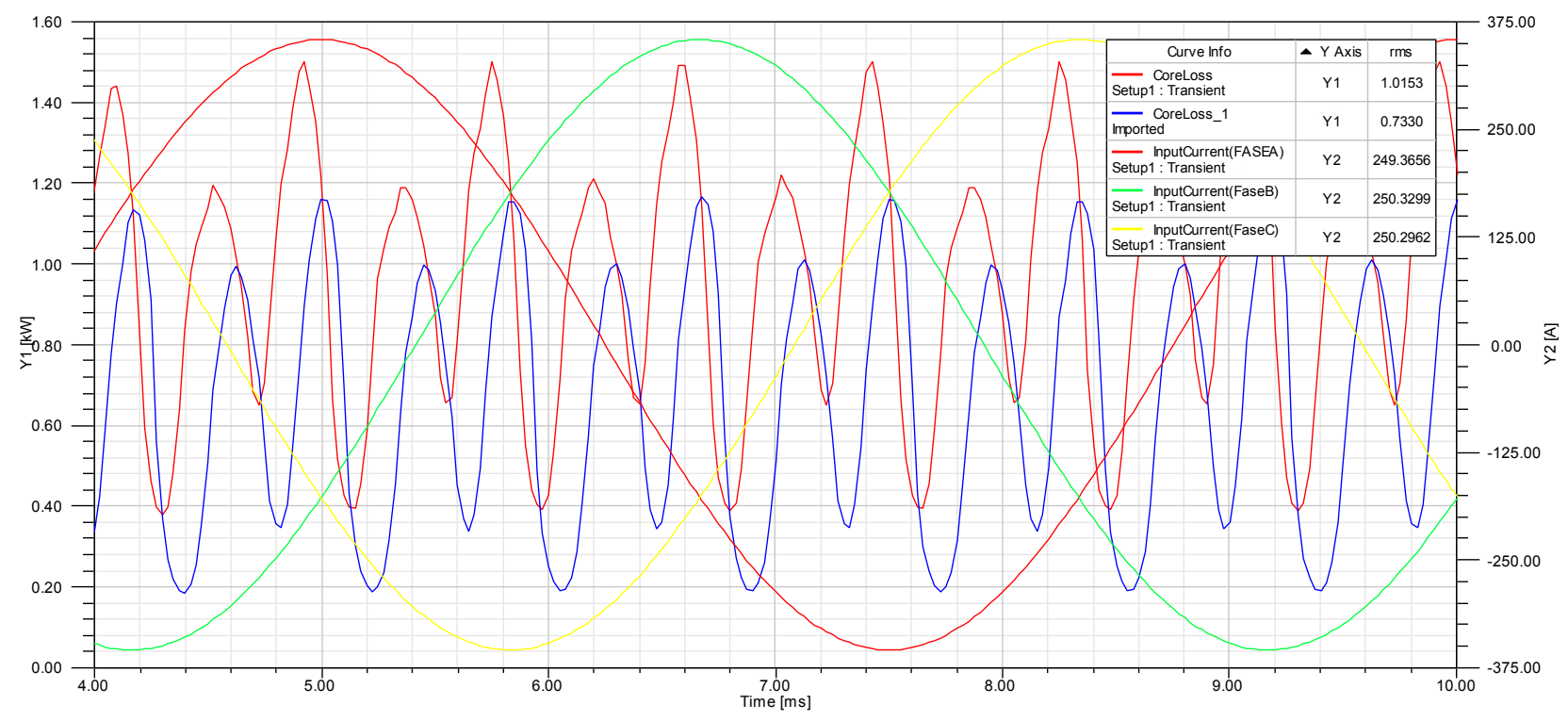

Figura 5.50. Intensidades y pérdidas en el hierro del modelo 2004 (azul) y ala con N10-BH (rojo) para $\mathrm{n}=3.000 \mathrm{rpm}$. 


\subsection{Resumen final del modelo propuesto y sus valores específicos}

Como resumen final de la comparativa de modelos desarrollados, se indican los valores del rotor propuesto, utilizando materiales NdFeB aglomerados. En la Tabla 5-14 se indican los parámetros de diseño de los imanes finales y en la Tabla 5-15 los datos del motor completo para $20^{\circ}$ y $250 \mathrm{~A}$.

Tabla 5-14. Parámetros de modelado

\begin{tabular}{|c|c|c|}
\hline Variable & Parámetro & valor \\
\hline Espesor imanes (mm) & \$espesor & 3,77 \\
\hline Separación entre imanes (mm) & $\$ d i s t$ & 3,95 \\
\hline Angulo abarcado $\left({ }^{\circ}\right)$ & Sbetar & 60,16 \\
\hline Radio de curvatura imanes (mm) & $\$ r i$ & 28,8 \\
\hline Puente (mm) & \$bridge & 1,48 \\
\hline Radio de empalme (mm) & $\$$ radio & 0,7 \\
\hline Ángulo del ala superior $\left({ }^{\circ}\right)$ & $\$ g a m m a$ & 8 \\
\hline Ángulo del ala inferior $\left({ }^{\circ}\right)$ & $\$ g a m m a 2$ & 2,5 \\
\hline
\end{tabular}

Tabla 5-15. Datos del motor a $20^{\circ} \mathrm{C}, 250 \mathrm{~A}$.

\begin{tabular}{l|r|r|}
\hline & Modelo propuesto & 2004 \\
\hline Área de los imanes (mm2/polo) & 353,04 & 244,9 \\
\cline { 2 - 3 } Peso imanes (kg) & 1,42 & 1,23 \\
\cline { 2 - 3 } Peso rotor (kg) & 4,95 & 5,38 \\
\cline { 2 - 3 } Peso estátor (kg) & 16,47 & 16,47 \\
\cline { 2 - 3 } Peso cobre (kg) & 4,93 & 4,93 \\
\hline Peso mat. activo & 27,77 & 28,01 \\
\hline Peso carcasa + eje & 16,99 & 16,99 \\
\hline Peso total & 44,76 & 45,00 \\
\hline Par máximo (Nm) & 600 & 400 \\
\hline Potencia (KW)* & 75 & 50 \\
\hline Potencia específica (kW/kg) & $\mathbf{1 , 6 7}$ & 1,11 \\
\cline { 2 - 3 } Densidad específica (KW/l) & $\mathbf{4 , 8 7}$ & 3,25 \\
\cline { 2 - 3 } & & \\
\cline { 2 - 3 } &
\end{tabular}

Si bien no se cumplen los objetivos APEEM para el 2020en cuanto a densidad específica, los valores son superiores a los del modelo de referencia.

Nota: Para el cálculo de la potencia se debe determinar cuál es punto donde se pasa a trabajar de par constante a trabajar a potencia constante, que depende de la capacidad del inversor y que en la bibliografía se establece entre 1.200 y $1.600 \mathrm{rpm}$. Tomando el valor más bajo de $1.200 \mathrm{rpm}$ :

$$
P=M \omega=600 \mathrm{Nm} \cdot 1200 \frac{\mathrm{rev}}{\mathrm{min}} \cdot 2 \pi \frac{\mathrm{rad}}{\mathrm{rev}} \cdot \frac{\mathrm{min}}{60 \mathrm{~s}}=75 \mathrm{KW}
$$




\section{Resumen, conclusiones y desarrollos y trabajos futuros}

\subsection{Resumen y conclusiones}

En el capítulo 2 se indica que el modelo de coche HEV se ha impuesto en el sector de la automoción sobre los EV, y prácticamente todos los fabricantes están desarrollando su propio modelo, aunque ninguna de las propuestas se aparta mucho de la importante innovación que supuso el Toyota Prius, ni tampoco de su motor eléctrico MG2 que se describe en profundidad.

En el capítulo 3 se estudian los materiales utilizados en la fabricación de los imanes de los PMSM. Los materiales magnéticos de tierras raras constituyen la esencia del motor. Para el estudio de estos materiales existe poca documentación, apenas algunos datos de los fabricantes de polvo magnético y algunas presentaciones de ensayos realizados por AMES Laboratory. La mayor aportación de esta tesis en este tema ha sido esclarecer los métodos de fabricación y tendencias en investigación para minorar su dependencia de elementos críticos y aumentar el producto de energía. Los imanes aglomerados alcanzan actualmente valores similares a los sinterizados permitiendo formas de construcción complejas y sin mecanizado. Nuevas alternativas de materiales Alnico, SmCo o los $\mathrm{NdFeB}$ aglomerados están abiertas al desarrollo y se investigan por los fabricantes de polvo magnético.

Por último se quiere reflejar la complicada situación político-económica que presenta la minería de tierras raras.

En el capítulo 4 se estudian y comparan los distintos tipos de motores eléctricos aplicables a los HEV destacando que las opciones más utilizadas son los IPM y los IM.

El tipo de motor que mejor cumple todas las expectativas es el IPM, siempre y cuando se pueda garantizar la estabilidad en el precio. Las mejoras de este motor vienen derivadas del aumento del par reluctante y su relación sobre el par total.

La situación obligará a seguir probando todas las posibilidades en diseños de motores eléctricos que cumplan las expectativas, siendo las principales apuestas los motores de reluctancia variable, propuesto por el ORNL y algúnos modelos de flujo axial.

En el capítulo 5 se introduce el uso de FEA como herramienta para diseño de máquinas eléctricas, se modelan los tres motores del Toyota Prius y tomando como base el estátor del Prius 2004 se modelan y optimizan los otros rotores a base de modificar la geometría de los imanes, como el propuesto por el fabricante UQM, el de doble capas plano y el de doble capa con imanes curvos. Se analizan las curvas de par magnetostático de todos los modelos empleando el mismo material y se 
desarrolla y propone un modelo de rotor adecuado para el uso de materiales NdFeB aglomerados. El modelo finalmente propuesto es de doble capa de imanes curvos con magnetización radial. Este modelo proporciona un par máximo cercano a los $603 \mathrm{Nm}$ con una intensidad eficaz de $250 \mathrm{~A}$ y un bajo par oscilante en comparación con el modelo propuesto por UQM.

\subsection{Aportaciones}

Se considera que la Tesis realizada presenta las siguientes aportaciones principales:

- Recopilar la bibliografía necesaria, con la que se ha podido desgranar el mítico motor MG2 en todos los aspectos tanto a nivel de geometría, funcionamiento y composición.

- Determinación de las tecnologías más actuales en obtención de polvos magnéticos para imanes de tierras raras, destacando la nueva posibilidad de los imanes $\mathrm{NdFeB}$ aglomerados como alternativa viable a los sinterizados. Los valores de energía obtenidos mediante proceso HDDR son competitivos, el principal problema que presentan es la disminución de la coercitividad con la temperatura, pero se ha comprobado en la simulación que apenas es determinante este efecto en el par del motor.

- Sugerir que otras posibilidades como los imanes de Sm-Co en breve puedan considerarse una opción alternativa provocado por las oscilaciones del mercado y sus buenas características magnéticas.

- Tener una perspectiva sobre los pros y los contras que presentan los diversos motores eléctricos en aplicaciones de movilidad eléctrica.

- Considerar la aplicación de los procesos de fabricación por compresión de imanes aglomerados a la fabricación de imanes interiores para motores IPM. Cabe destacar que de esta forma puede montarse el rotor del motor dejando los huecos de los imanes y en la propia fábrica del motor rellenar los huecos y moldear y magnetizar los imanes in situ, lo que evita procesos de transporte y manipulación de imanes, su mecanizado y los problemas de tolerancias que puedan aparecer.

- Con el conocimiento de los parámetros que determinan el par ha permitido obtener una geometría de un rotor optimizado de IPM con imanes de material aglomerado que proporcione una potencia comparable a la del motor MG2 estudiado, para evitar el uso de imanes sinterizados, abriendo las posibilidades a todos los BPM que se vayan incorporando al mercado.

- Análisis comparativo y contrastado del comportamiento de los distintos modelos sobre la potencia específica, el par máximo y el par oscilante mediante FEA. 


\subsection{Desarrollos y trabajos futuros}

Una tesis no debe ser una puerta que se cierra y da por finalizado un trabajo de investigación, sino todo lo contrario, debe abrir nuevas líneas de trabajo que no han sido iniciadas o que pueden ampliarse.

Las posibilidades de profundizar en el diseño y mejora de un motor son muchas, tanto en el campo de los materiales magnéticos de tierras raras como en el de diseño de motores IPM.

Algunos de los futuros trabajos consideran los datos de partida y otros los medios de análisis requeridos. A continuación se indican los desarrollos que se consideran más importantes.

\subsubsection{El modelo del rotor}

El modelo de doble capa de imanes curvos presentado es un diseño básico en el que como objetivo principal se ha buscado obtener el mayor par máximo posible. Este diseño puede refinarse con algunos detalles para que, aunque se sacrifique algo del par máximo, se estudien y mejoren sus pérdidas y otros aspectos prácticos. Como se ha indicado en el capítulo de simulación, los imanes aglomerados tienen una densidad un $20 \%$ de media menor a los sinterizados. Al ser más ligeros permiten un mayor régimen de giro del motor y en el diseño puede disminuirse el espesor del puente, limitado por los esfuerzos mecánicos, aumentando de esta forma el par obtenido.

Las posibles modificaciones del modelo que se destacan son:

- La inclusión de barreras del flujo de dispersión mediante la inclusión en los extremos de huecos de material no magnético.

- La posibilidad de que los espesores de los imanes sean distintos.

- Hacer menor el ángulo cubierto por los imanes de la $2^{\mathrm{a}}$ capa para aplanar la zona de par máximo y mayor su radio de curvatura.

- La inclusión de otros huecos no magnéticos para conducir el flujo magnético.

- El aumento del $\mathrm{n}^{\mathrm{o}}$ de polos favorecido por el uso de imanes aglomerados.

El trabajo ha tomado como base la optimización del par máximo de la curva de par magnetostática, pero puede deducirse, y así se comprueba en el capítulo de comparativa de modelos, que la relación Par/área de imanes es mayor cuanto menor es el área de imanes. Esto es debido a que aumenta la proporción de par reluctante depende de la forma de los imanes y aumenta al disminuir la cantidad de imán utilizado. Podría establecerse como función objetivo dicha "densidad relativa" y obtener un modelo más pequeño de motor, pero más eficiente en dicha relación par/área de imanes.

\subsubsection{El estátor $[80]$}

Como punto de partida es necesario reconsiderar el estátor de la máquina, que no ha sufrido ninguna modificación, tanto en materiales como en diseño. 
Se propone estudiar el uso de otros tipos de aceros magnéticos comparándolos con el empleado en el motor base (M19 JFE 35 JNE 250 (C) "non oriented grain electrical steel") frente a otros también convencionales como puede ser el M-6 de grano orientado GOES u otros de los denominados de alta densidad de flujo como Permendur(C SIC-2 de MSM, y Rotelloy® 3.

Sería necesario investigar otros compuestos de epoxi y aceros con silicona de grano orientado GOSS con cristalizaciones especiales como base de material magnético y cuáles son las áreas más apropiadas para su uso que además faciliten la eliminación de calor.

El espesor de las chapas ha de ser un factor variable, no una constante de $0,35 \mathrm{~mm}$.

\section{NOES GOES GOSS}

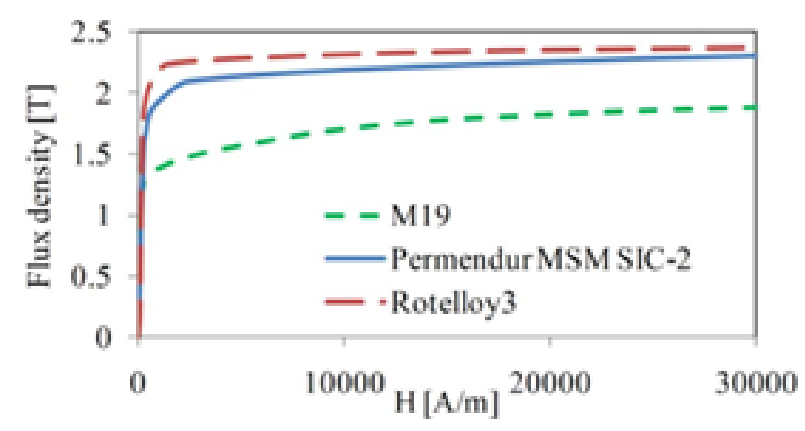

Figura 6.1. Aceros magnéticos para estátor y rotor. [80]

\subsubsection{Circuito eléctrico equivalente[21]}

Para contrastar los resultados obtenidos por FEA, sería de mucha utilidad incorporar el circuito eléctrico equivalente del magnético, desglosado en el eje $d$ y $q$ [19].Existen algunos modelos, sería interesante obtener los de cada modelo propuesto considerando además la forma de las chapas del estátor.

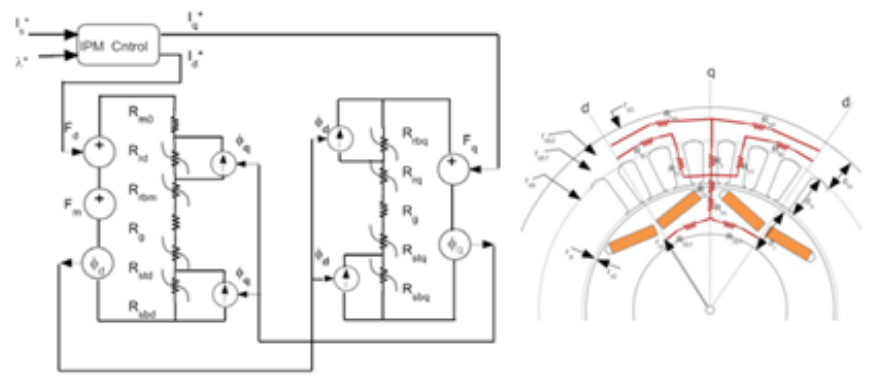

Figura 6.2. Circuito equivalente de un motor derivado de su análisis FEA.

\subsubsection{Obtención del rendimiento}

Una de las más interesantes líneas de trabajo futuro es obtener un mapa de rendimientos más pormenorizado. El estudio se debería de centrar en las chapas de estátor ya que las pérdidas magnéticas del rotor son menores y las del cobre no admiten apenas variaciones. 
Además es interesante obtener estos datos en distintos regímenes de funcionamiento. Una simple prueba a 1.500 y $6.000 \mathrm{rpm}$ debería hacer evidente la mejora con el cambio de chapa.

El análisis debería incluir la descomposición en todas sus componentes, para identificar las actuaciones más interesantes.

Una vez que están tabulados los datos de rendimiento, el siguiente paso sería obtener un análisis térmico.

\subsubsection{Obtención de las inductancias $L_{d}$ y $L_{q}$}

A partir de análisis magnetostáticos se pueden obtener los datos de las reactancias en el eje directo y transversal. Esto permite descomponer el par en sus dos componentes y analizar de qué forma varía el par reluctante con la curvatura de los imanes.

Se tiene información de la no linealidad de las inductancias en los ejes $q \mathrm{y} d$, con una simulación dinámica se pueden obtener datos más precisos que permitiría explicar algún punto de la curva que no responde con exactitud a la suma de los dos pares, obteniendo así una tercera componente del par

Para este análisis es necesario incluir los datos del rotor, pudiendo incorporar algún otro modelo con un interés concreto en este campo como el que contempla la figura.

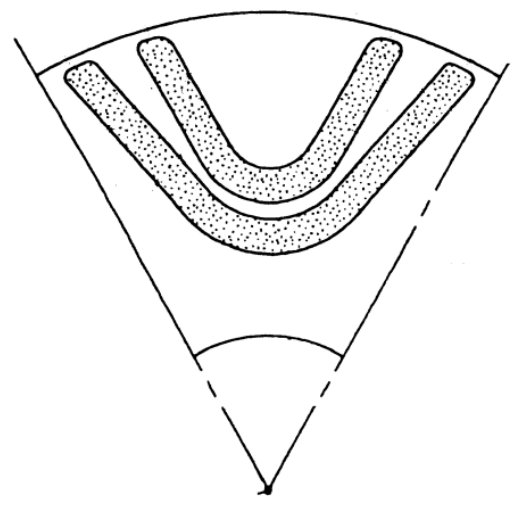

Figura 6.3. Rotor con doble capa de imanes en U.

\subsubsection{Flujo de dispersión}

Los datos del flujo de dispersión que se tienen delos polos, son del $28 \%$ obtenidos del MEC y un $26 \%$ el programa de elementos finitos ambos son valores muy elevados y es conveniente reducirlos modificando la ruta del flujo magnético a base de huecos en el rotor u otras barreras.

\subsubsection{Rizado del par}

Un problema que presentan los PMSM, como se ha mencionado en el capítulo 5.3.3, y puede verse en la Figura 5.43 es el rizado del par mecánico. Para disminuir este efecto nocivo se utilizan actualmente varias opciones: 
a) La inclinación o skewing de las ranuras del estátor o de los imanes del rotor como muestra la Figura 6.1, lo que supone una gran complejidad constructiva del estátor al ser todas las chapas distintas [112].

b) Utilizar distintas geometrías de devanados fraccionales en el estátor, lo que implica que $q=$ $\frac{n^{\circ} \text { ranuras }}{n^{\circ} \text { polos } n^{\circ} \text { fases }}$ es menor que la unidad [113].

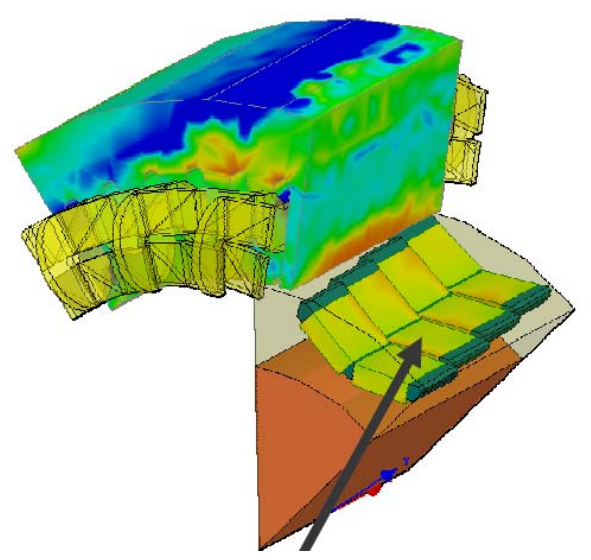

Figura 6.1. Inclinación de los imanes del rotor del MG2.[87].

c) Con la geometría de los chapas obtener los armónicos que intervienen en el campo magnético [114]

\subsubsection{Desarrollo de técnicas de técnicas CPSR (Constant Power Speed Ratio).}

Para ello se busca obtener un control del flujo magnético en tiempo real, lo que se lleva a cabo de distintas formas como: debilitamiento de campo, control vectorial del flujo, variando el número de espiras de las bobinas, variando el entrehierro. Mediante FEA podría cuál de estas posibilidades es la mejor.

a) En este campo, que parece ser el más importante actualmente, uno de los caminos es implementar la doble excitación del motor, es decir, disponer unos bobinados adicionales en el rotor de la máquina [115] [116]. Estos bobinados auxiliares crean una variación del campo magnético dependiente de su intensidad.

b) Partiendo de los valores obtenidos para las inductancias $L_{d}$ y $L_{q}$ determinar cuál es el mejor dato para el IPM respecto de la posición del vector de intensidad para mantener la potencia por encima de la velocidad crítica.

\subsubsection{Generales}

Además de las líneas de trabajo anteriores se pueden considerar las siguientes.

No existe una normativa internacional que fije los parámetros que determinan el comportamiento del motor ni los procedimientos de obtención de los mismos para determinar de forma objetiva las potencias, pares y rendimientos de los HEV. Sin esa base es difícil parametrizar la vida del motor después de haber rodado un determinado número de kilómetros. Pero sería interesante determinar la 
variación del rendimiento y el comportamiento de los imanes, teniendo en cuenta el régimen de funcionamiento del motor y la variación a lo largo del tiempo del punto de funcionamiento del imán.

Aunque se ha querido profundizar en las modificaciones que presenta el diseño del motor de los nuevos vehículos de Marcas como Mitsubishi, Audi no es posible tener información de las nuevas tecnologías implantadas por los fabricantes aunque las tendencias hablan de motores más revolucionados (cerca de $20.000 \mathrm{rpm}$ ) y por ello más largos y de menor diámetro [28].

Los imanes serán:

- Bien aglomerados libres de disprosio con valores de energía por encima de los 50 MGOe con disposición en arco de círculo como en nuestro modelo y con mayor número de polos.

- O bien se colocará más cantidad de imán con menor producto de energía en disposición radial.

El análisis aquí realizado fija como objetivo la potencia específica que alcanza el motor y se obtienen los óptimos de las dimensiones de los imanes y por tanto el volumen necesario de cada uno de los materiales, lo cual permitiría a continuación calcular el coste de cada modelo. Este último paso de precios no se ha realizado porque estos mercados son muy fluctuantes y no se creyó pertinente entrar en ese aspecto. 



\section{Bibliografía y referencias}

[1] Abe, S. Direction and trend of technical development of hybrid vehicles. in Control Conference (CCC), 2011 30th Chinese. 2011.

[2] G.C., C., Worldwide Prius Cumulative Sales Top 2M Mark; Toyota Reportedly Plans Two New Prius Variants for the US By End of 2012, in Green Car Congress. 2010.

[3] Company, T.M. Worldwide Sales of Toyota Hybrids Top 7 Million Units. 2014; Available from: http://newsroom.toyota.co.jp/en/detail/4069183.

[4] Congress, G.C. Toyota broadly outlines next-generation Prius; developing wireless inductive charging for the plug-in model; bullish on hydrogen. 2013; Available from: http:/www.greencarcongress.com/2013/08/20130828-ogiso.html.

[5] Burress, T.A., Benchmarking of Competitive Technologies. 2012 U.S. DOE Hydrogen and Fuel Cells Program and Vehicle Technologies Program Annual Merit Review and Peer Evaluation Meeting Washington, D.C. Oak Ridge National Laboratory,Project ID: APE006, May 15, 2012.

[6] ToyotaTraining, Tecnical Training Series. Toyota Prius. 2008.

[7] Toyota. Toyota Global Technology File. 2013; Available from: http://www.toyotaglobal.com/innovation/environmental_technology/technology_file/plug-in_hybrid.html.

[8] Voelcker, J., Top 10 tech cars. Spectrum, IEEE, 2009. 46(4): p. 42-49.

[9] Voelcker, J., Top 10 tech cars. Spectrum, IEEE, 2004. 41(3): p. 28-35.

[10] Hsu, J.S.A., C.W.; Coomer, C.L.; Wiles, R.H.; Burress, T.A.; Campbell, S.L.; Lowe, K.T.; Michelhaugh, R.T., Report on Toyota/Prius Motor Torque Capability, Torque Property, NoLoad Back EMF, and Mechanical Losses, Revised May 2007. 2007.

[11] McKeever, J.W., Radial-Gap Permanent Magnet Motor and Drive Research FY 2004. 2005. p. Medium: ED.

[12] Rogers, S.A., ed. Advanced Power Electronics and Electric Motors Annual Progress Report Advanced Power Electronics and Electric Motors Annual Progress Report 2011. 368.

[13] Rogers, S.A., ed. Advanced Power Electronics and Electric Motors Annual Progress Report Advanced Power Electronics and Electric Motors Annual Progress Report 2012. 364.

[14] Van Haute, S.H., St; K. Hameyer, R. Belmans, Design and Control of a Permanent Magnet Synchronous Motor Drive for a Hybrid Electric Vehicle. 2009: p. 6.

[15] Staunton, R.H., PM Motor Parametric Design Analyses for a Hybrid Electric Vehicle Traction Drive Application. 2004. p. Medium: ED.

[16] Chen, K., et al. A common model validation in the case of the Toyota Prius II. in Vehicle Power and Propulsion Conference (VPPC), 2010 IEEE. 2010. 
[17] Hsu, J.S., Report on Toyota/Prius Motor Torque-Capability, Torque-Property, No-Load Back EMF, and Mechanical Losses. 2004. p. Medium: ED.

[18] Meier, F., Permanent-magnet Synchronous Machines with Non-overlapping Concentrated Windings for Low-Speed Direct-drive Applications. 2008: School of Electrical Engineering, Electrical Machines and Power Electronics.

[19] Zhu, Z.Q. and D. Howe, Influence of design parameters on cogging torque in permanent magnet machines. Energy Conversion, IEEE Transactions on, 2000. 15(4): p. 407-412.

[20] Hsu, J.S., Report on Toyota/Prius Motor Design and Manufacturing Assessment. 2004. p. Medium: ED.

[21] Olszewski, M., FY2011 Oak Ridge National Laboratory Annual Progress Report for the Power Electronics and Electric Machinery Program. 2011. p. Medium: ED.

[22] Burress, T.A., et al., Evaluation of the 2010 Toyota Prius Hybrid Synergy Drive System. 2011. p. Medium: ED.

[23] Aslan, B., et al., Influence of Rotor Structure and Number of Phases on Torque and Flux Weakening Characteristics of V-shape Interior PM Electrical Machine. 2012.

[24] Dorrell, D.G., M. Hsieh, and A.M. Knight, Alternative Rotor Designs for High Performance Brushless Permanent Magnet Machines for Hybrid Electric Vehicles. Magnetics, IEEE Transactions on, 2012. 48(2): p. 835-838.

[25] Kamiya, M., Rotor of Rotating Electric Machine, Rotating Electric Machine and Vehicle Drive Apparatus. 2006, Google Patents.

[26] Tani, Y., S. Morimoto, and M. Sanada. Influence of number of poles, magnet arrangement, and current density on characteristics of inner and outer rotor PMSMs. in Power Electronics and Drive Systems (PEDS), 2011 IEEE Ninth International Conference on. 2011. IEEE.

[27] Kamiya, M., Rotor of Rotating Electric Machine, Rotating Machine And Vehicle Aparatus US Patents, 2008: p. 13.

[28] Honkura, Y., The development of Dy free MAGFINE and its applications to Motors. 한 국 자기 학 회 학 술 연구발표회 논 문 개요 집, 2013: p. 95-95.

[29] Barcaro, M., N. Bianchi, and F. Magnussen. PM motors for hybrid electric vehicles. in Universities Power Engineering Conference, 2008. UPEC 2008. 43rd International. 2008.

[30] Kamiya, M., Development of Traction Drive Motors for the Toyota Hybrid System. IEEJ Transactions on Industry Applications, 2006. 126(4): p. 473-479.

[31] Matsui, N. Progresses for a Last Decade and Perspectives in Applications Specific Electric Motors and Drives in Japan. in Power Conversion Conference - Nagoya, 2007. PCC '07. 2007.

[32] Bertotti, G., General properties of power losses in soft ferromagnetic materials. Magnetics, IEEE Transactions on, 1988. 24(1): p. 621-630.

[33] Nagorny, A.D., Narajan; Jansen, Ralph; Kenny, Barbara, Design aspects of a High Speed Permanent Magnet Synchronous Motor/Generator for Flywheel Applications. NASA, 2005: p. 7.

[34] Ayers, C.W., et al., Evaluation of 2004 Toyota Prius Hybrid Electic Drive System Interim Report - Revised. 2007. p. Medium: ED; Size: 599 Kb. 
[35] USA, D.o.E.o., Advanced Power Electronics and Electric Machines (APEEM) R\&D Program. DOE Hydrogen Program and Vehicle Technologies AMR, 2005.

[36] McCallum, R.W., Replacing critical rare earth materials in high energy density magnets. Bulletin of the American Physical Society, 2012.57.

[37] Constantinides, S., A Manufacturing and Performance Comparison Between Bonded and Sintered Permanent Magnets, F.P. Report, Editor. 2007: Advanced Power Electronics and Electric Motors

[38] Constantinides, S. The demand for rare earth materials in permanent magnets. in 51st Annual Conference of Metallurgists. 2012.

[39] Muñoz, R.L., Generalidades sobre imanes permanentesy su caracterización. Octubre 2008. p. 47.

[40] Gutfleisch, O., et al., Magnetic materials and devices for the 21st century: stronger, lighter, and more energy efficient. Advanced Materials, 2011. 23(7): p. 821-842.

[41] Anderson, I.A., Permanent Magnet Development for Automotive Traction Motors, in 2014 DOE Hydrogen and Fuel Cells Program and Vehicle Technologies, A. Laboratories, Editor. 2014.

[42] Kramer, M., Constantinides, Anderson, New Understanding of Alnico Magnets Helps Design Improvements to Boost Properties for Drive Motors. Advanced Power Electronics and Electric Motors., 2013. FY 2012 Progress Report: p. 33.

[43] alnico-info.com, Temperature Effects on Alnico magnets. 2015.

[44] Anderson, I.A., Accomplishments in Rare Earth Anisotropic (R2Fe14B-type) Magnet Research, in FY 2011 Progress Report, A.P.E.a.E. Motors, Editor. 2012.

[45] Fessler, R., Final Report on Assessment of Motor Technologies for Traction Drives of Hybrid and Electric Vehicles. Oak Ridge National laboratory, 2011: p. 27.

[46] Jinfang Liu, P.D., Sm-Co Magnets \& Applications, E.E. Coroporation, Editor. 2013, Electron Energy Coroporation.

[47] Constantinides, S., Understanding and Using Reversible Temperature Coefficients, in MAGNETICS 2010, A. Magnetics, Editor. 2010. p. 28.

[48] Magnets, N., Neorem Magnets Webpage. 2012.

[49] Sugimoto, S., Current status and recent topics of rare-earth permanent magnets. Journal of Physics D: Applied Physics, 2011. 44(6): p. 064001.

[50] Campbell, P., System Cost Analysis for an Interior Permanent Magnet Motor. Ames laboratory, 2008.

[51] Kato, Y., Thermal stability of sintered and bonded rare-earth magnets. Journal of applied physics, 1999. 85(8): p. 4868-4870.

[52] Anderson, I.A., Magnetic Material for PM Motors, D.H.P.a.V.T.A.M. Review, Editor. 2009. p. 18.

[53] Sokolowski, P.K., Processing and protection of rare earth permanent magnet particulate for bonded magnet applications. 2007: ProQuest.

[54] Anderson, I.A., Development of improved Podwer for Bonded Permanent Magnets. FreedomCAR and Vehicle Technologies Annual Progress Report for the Advanced Power Electronics Technology Area 2006: p. 249-262. 
[55] Brown DN.; Ma BM.; Campbell, P. The comparison of anisotropic (and isotropic) powders for polymer bonded Rare-Earth permanent magnets ". in Proc. of 17th Int. Workshop on RE Magnets and their Applications. 2002.

[56] Molycorp. Standard Grades of Magnetic Powders. 2015; Available from: http://www.molycorp.com/about-us/our-facilities/molycorp-magnequench/magneticpowders/standard-grades/.

[57] Aichi-Steel.co.jp. The development of Dy free MAGFINE and its applications to Motors. 2015.

[58] Kramer, M.J., et al., Prospects for Non-Rare Earth Permanent Magnets for Traction Motors and Generators. JOM, 2012. 64(7): p. 752-763.

[59] www.mining.com. Your Source for Global Minig News. 2015.

[60] Sirvent Zaragoza, G., El Mercado de Tierras Raras: Un Mercado Estratégico I.E.d.E. Estratégicos, Editor. 2012: www.ieee.es. p. 15.

[61] Benecki, W.T., Hitachi Metals, Ltd. - The Magnet Industry Newsmaker, Www.mining.com, Editor. 2013, Magnetics Magazine: www.magneticsmagazine.com. p. 5.

[62] Tang Z., L.W., Simulation Based Performance Characterization of an electric Drive Train System I. Engineering, Editor. 2008, ANSOFT.

[63] Top_Target_Materials. Rare Earth Applications. 2015; Available from: http://www.toptargets.com/rare-earth-applications.

[64] China, M.o.L.a.R.o.t.P.R.o. Mineral Resources Law 2015; Available from: http://www.mlr.gov.cn/mlrenglish/laws/.

[65] Infomine, Cobalt Prices. 2015: infomine.com.

[66] Chu, S., Critical Materials Strategy, ed. U.S.D.o. Energy. 2011: DIANE Publishing.

[67] Lee, S.T., Development and Analysis of Interior Permanent Magnet Synchronous Motor With Field Excitation Structure. University of Tennessee, 2009.

[68] Ramu, K., Permanent Magnet Synchronous and Brushless DC Motor Drives. 2009: CRC Press/Taylor \& Francis.

[69] Hendershot, J.R., Electric traction machine choices for hybrid \& electric vehicles. 2014: p. 71.

[70] Zhu, Z.Q. and D. Howe, Electrical Machines and Drives for Electric, Hybrid, and Fuel Cell Vehicles. Proceedings of the IEEE, 2007. 95(4): p. 746-765.

[71] Puramen, J., Induction motor versus permanent magnet synchronous motor in motion control applications: a comparative study. 2006: p. 147.

[72] Chizh, A., Permanent Magnet Synchronous Machine for Parallel Hybrid Vehicle. Lappeenranta University of Technology, 2011: p. 68.

[73] TeslaMotors, Go Electric. 2010.

[74] Hsu, J.S., et al. Effect of Side Permanent Magnets for Reluctance Interior Permanent Magnet Machines. in Power Electronics Specialists Conference, 2007. PESC 2007. IEEE. 2007.

[75] Otaduy-ORNL, P. and W. Johnson-UTK, The Role of Reluctance in PM Motors. 2005.

[76] Mi C., M.A.M., David Wenzhong Gao, Hybrid Electric Vehicles: Principles and Applications with Practical Perspectives. 2011: p. 468. 
[77] Burress, T.A., Vector Control and Experimental Evaluation of Permanent Magnet Synchronous Motors for HEVs. 2006.

[78] Chin, Y.-k., A permanent magnet synchronous motor for an electric vehicle-design analysis. 2004.

[79] Dajaku, G.D.G., Design of Permanent Magnet Machines for Hybrid Vehicles. ANSYS Conference \& 25th CADFEM User's Meeting, 2007: p. 11.

[80] Dorrell, D.G., A.M. Knight, and M. Popescu, Performance Improvement in HighPerformance Brushless Rare-Earth Magnet Motors for Hybrid Vehicles by Use of High FluxDensity Steel. Magnetics, IEEE Transactions on, 2011. 47(10): p. 3016-3019.

[81] Dorrell, D.G., et al. Comparison of permanent magnet drive motor with a cage induction motor design for a hybrid electric vehicle. in Power Electronics Conference (IPEC), 2010 International. 2010.

[82] Miller, J.M., Electric Drive System Technologies. Propulsion Systems for Hybrid Vehicles. 2004: Institution of Engineering and Technology.

[83] Wallmark, O., Control of permanent-magnet synchronous machines in automotive applications. 2006: Chalmers University of Technology.

[84] Janusz Bialik, J.Z., Magnetic Forces Calculation in Two-Speed Large Power Salient Pole, Synchronous Motor. Prace Naukowe Instytutu Maszyn, 2008(Politechniki Wroclawskiej Elektrycznych): p. 8.

[85] Zhao, J., et al., Research on the Torque and Back EMF Performance of a High Speed PMSM Used for Flywheel Energy Storage. Energies, 2015. 8(4): p. 2867-2888.

[86] Lim, D.H., et al., Performance Evaluation of an In-Wheel Motor Cooling System in an Electric Vehicle/Hybrid Electric Vehicle. Energies, 2014. 7(2): p. 961-971.

[87] Stanton S., T.Z., Design of Interior Permanent Magnet Machines for Hybrid Electric Vehicles. Ansoft Corporation, 2008: p. 12.

[88] Jones, D., A New Buried magnet Brushless PM Motor for a traction Application Proceedings of The Power Conversion Conference, 1997. 2: p. 3.

[89] Zordan, M., et al., Field-weakening in high-performance PMSM drives. COMPEL: Int J for Computation and Maths. in Electrical and Electronic Eng., 2002. 21(2): p. 338-354.

[90] Güemes, J.A., et al., Torque Analysis in Permanent-Magnet Synchronous Motors: A Comparative Study. Energy Conversion, IEEE Transactions on, 2011. 26(1): p. 55-63.

[91] Hsiao, C.-Y., S.-N. Yeh, and J.-C. Hwang, A novel cogging torque simulation method for permanent-magnet synchronous machines. Energies, 2011. 4(12): p. 2166-2179.

[92] Zeraoulia, M., M.E.H. Benbouzid, and D. Diallo, Electric Motor Drive Selection Issues for HEV Propulsion Systems: A Comparative Study. Vehicular Technology, IEEE Transactions on, 2006. 55(6): p. 1756-1764.

[93] Hashemnia, N. and B. Asaei. Comparative study of using different electric motors in the electric vehicles. in Electrical Machines, 2008. ICEM 2008. 18th International Conference on. 2008. IEEE.

[94] Burwell, M.G.J.P., Mircea Performance/cost comparison of induction-motor \& permanentmagnet-motor in a hybrid electric car 2013, International Copper Association. p. 27.

[95] Gieras, J.F., Permanent magnet motor technology: design and applications. 2002: CRC press. 
[96] designmoteur.com, Ingolstadt piloted driving to Shanghai at CES: Audi Q7 e-tron 2.0 TFSI quattro \& Audi R8 e-tron. 2015.

[97] Bremner, R.D., Rapid optimization of interior permanent magnet (IPM) machines using the response surface method and dimensionless parameters. 2010.

[98] ANSYS, Maxwell V15 2D. User's Guide, ed. A. Inc. 2010.

[99] Petkovska, L., Steady State Performance Evaluation of a Permanent Magnet Synchronous Motor Based on FEA. 2005.

[100] Ley Josh, L.J., FreedomCAR Advanced Traction Drive Motor Development Phase I. UQM Technologies. Oak ridge National Laboratories, 2006: p. 84.

[101] Ayers, C.W., Evaluation of 2004 Toyota Prius Hybrid Electric Drive System Interim Report. 2004. p. Medium: ED.

[102] Nasiri, H., et al. A MATLAB Simulink model for Toyota Prius 2004 based on DOE reports. in Power Electronics and Applications (EPE 2011), Proceedings of the 2011-14th European Conference on. 2011.

[103] Kaczmarek, R., Simulating the Toyota Prius electric motor, C.T. Services, Editor. 2012. p. 23.

[104] Ilea, D. Simulating the Toyota Prius electric motor using Opera-3d. 2015.

[105] Bomatech, Compressed plastic-bonded magnets: for high precision. 2015.

[106] Magnetics, D., Charts/graphs reference typical magnet performance. Further reading about Bonded Neodymium - NeoForm ${ }^{\circledR} .2015$.

[107] Components, M.M., Compression Bonded Magnets. 2015.

[108] Magnetics, E.A., Magnetic and physical properties. Compression Bonded Neodymium, E. Armtek, Editor. 2015.

[109] Lin E., H.X., Understanding Temperature-Dependent Demagnetization. ANSYS ADVANTAGE, 2012. 6(3).

[110] Ionel, D.M., et al., Assessment of torque components in brushless permanent-magnet machines through numerical analysis of the electromagnetic field. Industry Applications, IEEE Transactions on, 2005. 41(5): p. 1149-1158.

[111] Jang, K., Effect of IPMSM dq Axis Parameters According to Magnetic Saturation and Armature Reaction. Journal of Electrical Engineering \& Technology, 2015. 10(2): p. 539-544.

[112] Guemes, J.A., et al. Analysis of torque in permanent magnet synchronous motors with fractional slot windings. in Electrical Machines, 2008. ICEM 2008. 18th International Conference on. 2008.

[113] Salminen, P., Fractional Slot Permanent Magnet Synchronous Motors for Low Speed Applications. Acta Universitatis Lappeenrantaensis, 2004. Lappeenranta University of Technology.

[114] Doolittle, R.G., Noise Reduction Control Strategy of a Permanent Magnet Synchronous Machine For Vehicle Applications. Texas A\&M Uviersity Libraries, 2008: p. 105.

[115] Fodorean, D., et al., A Double Excited Synchronous Machine for Direct Drive Application\&\#x2014; Design and Prototype Tests. Energy Conversion, IEEE Transactions on, 2007. 22(3): p. 656-665. 
[116] Olszewski, M., FY 2005 Oak Ridge National Laboratory Annual Progress Report for the Power Electronics and Electric Machinery Program. 2005. p. Medium: ED. 

ANEXO I. Vehículos híbridos actuales 
Se presentan en la siguiente tabla algunos de los modelos de vehículos híbridos fabricados en el momento de realización de la tesis, junto con el tipo de motor eléctrico utilizado. Debe tenerse en cuenta que no se dispone de todos los datos de potencia/par.

Leyenda:

IPM: Motor síncrono de imanes permanentes interiores

MI: Motor de Inducción

BDC: Motor de corriente continua sin escobillas.

Tabla I-1. Relación de vehículos híbridos comercializados.

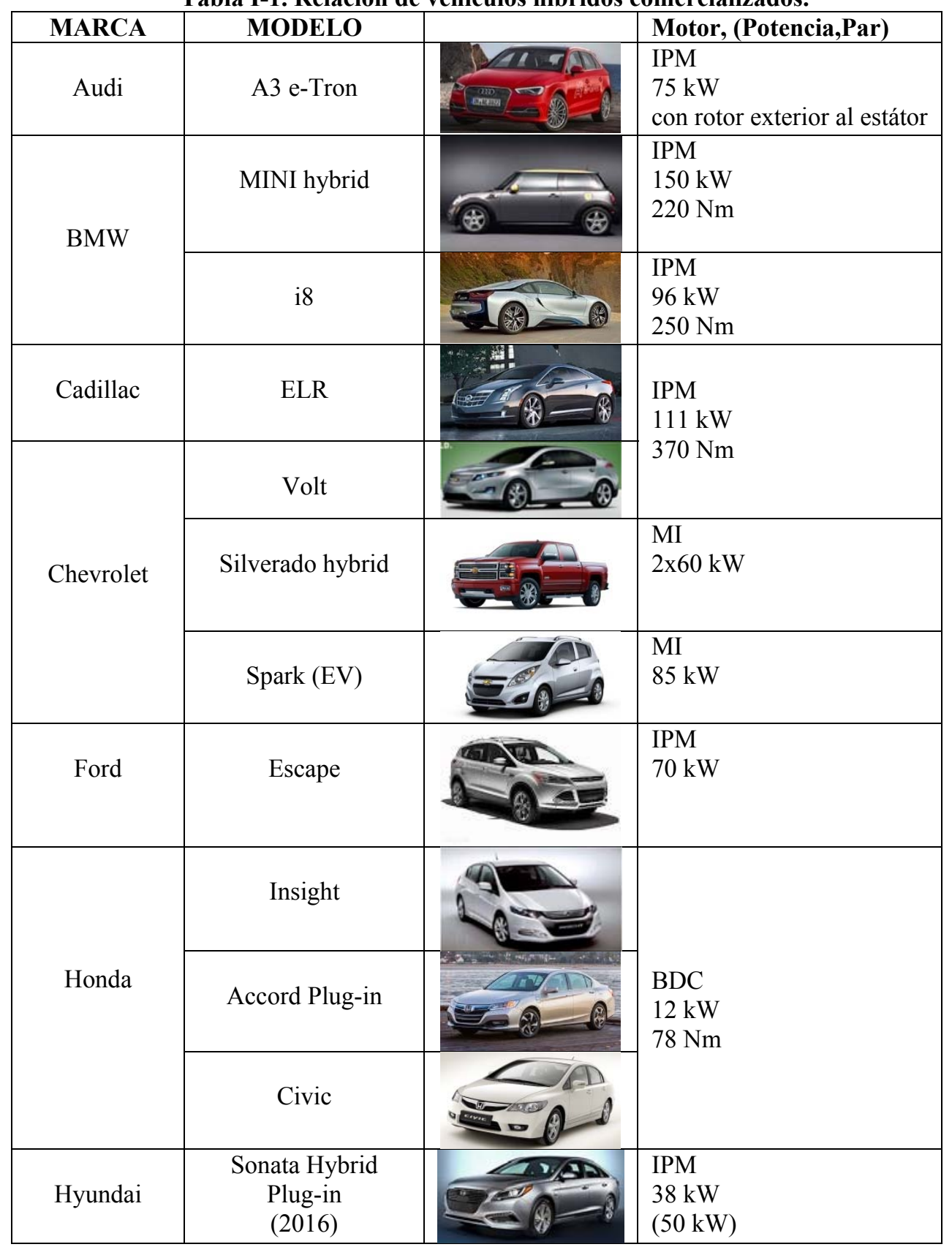




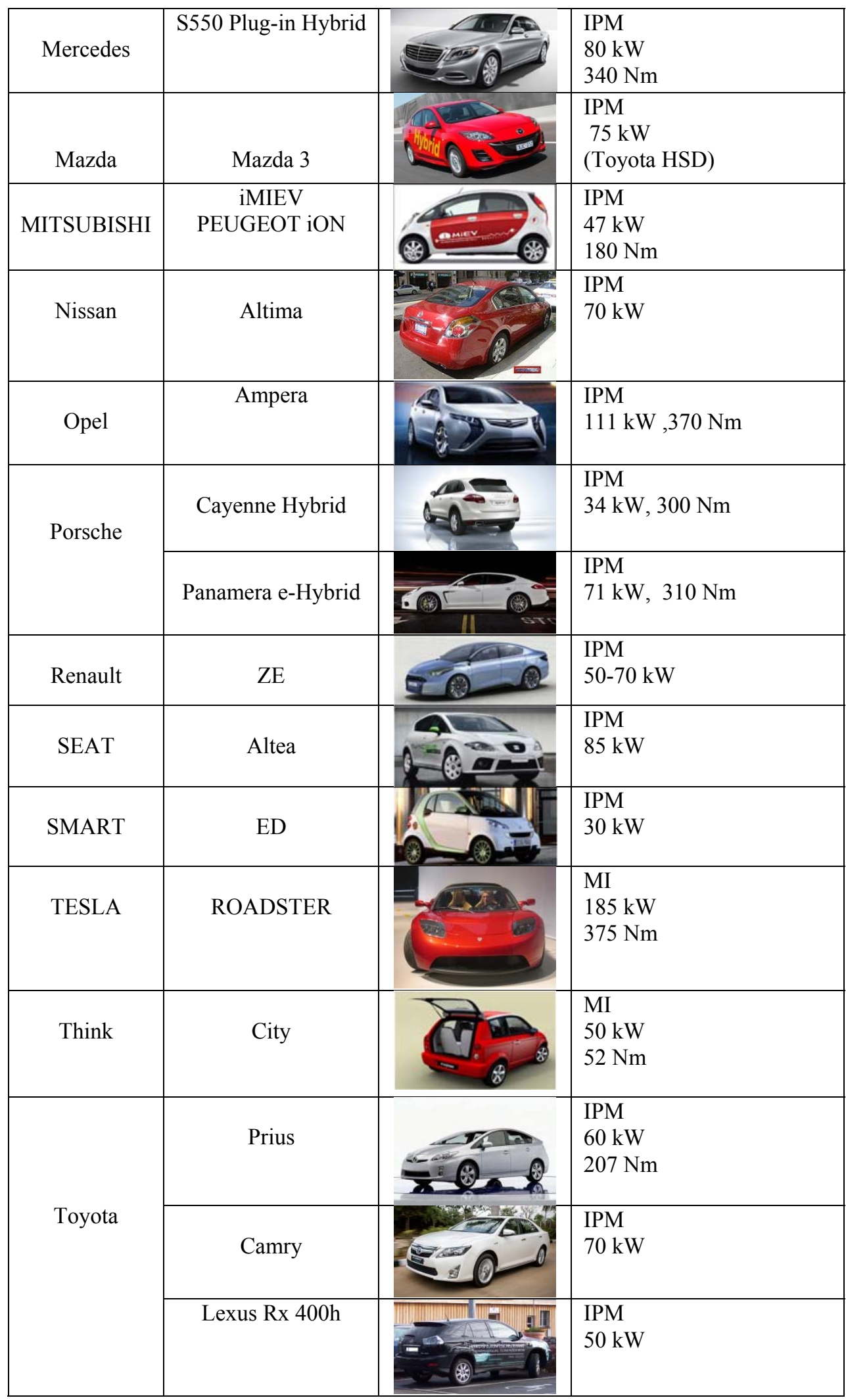




\section{ANEXO II. Datos del MG2 del Toyota Prius}


Se incluyen en este anexo los datos disponibles sobre las tres versiones de los motores MG2 de Prius citados en este documento. Asimismo se incluye una gráfica con la comparativa de las curvas par-velocidad de estos motores.

Tabla II-1. Datos y características de los motores MG2 de Toyota Prius

\begin{tabular}{|c|c|c|c|}
\hline Características & Toyota Prius 2000 & Toyota Prius 2004 & Toyota Prius 2010 \\
\hline$N^{o}$ de Fases & 3 & 3 & 3 \\
\hline Polos del Rotor & 8 & 8 & 8 \\
\hline Ranuras Estátor/Polo & 6 & 6 & 6 \\
\hline Ranuras Estátor & 48 & 48 & 48 \\
\hline Material Imanes & \multicolumn{3}{|c|}{$\mathrm{Nd}_{2} \mathrm{Fe}_{14} \mathrm{~B}$} \\
\hline$B_{r}$ & $1,24 \mathrm{~T}$ & $1,24 \mathrm{~T}$ & $1,22 \mathrm{~T}$ \\
\hline$H_{c}$ & $9,2 \cdot 10^{5} \mathrm{Am}^{-1}$ & $9,2 \cdot 10^{5} \mathrm{~A} / \mathrm{m}$ & $11,4 \cdot 10^{5} \mathrm{~A} / \mathrm{m}$ \\
\hline Disposición de Imanes & Interior - Plano & Interior - En V & Interior - En V \\
\hline $\mathrm{N}^{\mathrm{o}}$ de Puentes & 2 & 2 & 3 \\
\hline Espesor laminado & $-/ 0,33 \mathrm{~mm}$ & $-/ 0,33 \mathrm{~mm}$ & $-/ 0,305 \mathrm{~mm}$ \\
\hline Tensión de Excitación & $200-288 \mathrm{~V}$ & $250-500 \mathrm{~V}$ & $200-600 V$ \\
\hline Bobinados por Fase & \multicolumn{3}{|c|}{8} \\
\hline $\mathrm{N}^{\mathrm{o}}$ Arrollamientos/Bobinado & 9 & 9 & 11 \\
\hline Sección cobre/Arrollamiento & 13 hilos $/ 0,65 \mathrm{~mm}^{2}$ & 13 hilos/ $0,65 \mathrm{~mm}^{2}$ & 12 hilos/ $0,52 \mathrm{~mm}^{2}$ \\
\hline Capas Bobinas/Ranura & \multicolumn{3}{|c|}{1} \\
\hline \multicolumn{4}{|c|}{ Características de construcción } \\
\hline Diámetro Exterior del Estátor & $269,2 \mathrm{~mm}$ & $269,24 \mathrm{~mm}$ & $264 \mathrm{~mm}$ \\
\hline Diámetro Interior del Estátor & $160 \mathrm{~mm}$ & $161,9 \mathrm{~mm}$ & $161,9 \mathrm{~mm}$ \\
\hline Longitud de Ranura Est. & $35,31 \mathrm{~mm}$ & $33,5 \mathrm{~mm}$ & $30,9 \mathrm{~mm}$ \\
\hline Anchura Ranura Est. & 4-7 mm & $5-8 \mathrm{~mm}$ & $5-8 \mathrm{~mm}$ \\
\hline Longitud motor (profundidad) & $88,57 \mathrm{~mm}$ & $83,82 \mathrm{~mm}$ & $49,3 \mathrm{~mm}$ \\
\hline Espesor Imán(es) & $5,31 \mathrm{~mm}$ & $6,5 \mathrm{~mm}$ & $7,16 \mathrm{~mm}$ \\
\hline Anchura Imán(es) & $38,48 \mathrm{~mm} / 2$, parte & $18,9 \mathrm{~mm} \times 2$ & $17,88 \mathrm{~mm} \times 2$ \\
\hline Área Imán/polo & $248,9 \mathrm{~mm}^{2}$ & $244,94 \mathrm{~mm}^{2}$ & $256,04 \mathrm{~mm}^{2}$ \\
\hline Diámetro interior Rotor & $100,92 \mathrm{~mm}$ & $110,64 \mathrm{~mm}$ & $50,1 \mathrm{~mm}$ \\
\hline Diámetro Exterior Rotor & $160,4 \mathrm{~mm}$ & $160,38 \mathrm{~mm}$ & $160,4 \mathrm{~mm}$ \\
\hline Anchura Del Entrehierro & $0,9 \mathrm{~mm}$ & $0,78 \mathrm{~mm}$ & $0,73 \mathrm{~mm}$ \\
\hline Espesor del Puente & $1,45 \mathrm{~mm}$ & $1,5 \mathrm{~mm}$ & $1,6 \mathrm{~mm}$ \\
\hline \multicolumn{4}{|c|}{ Características de Operación } \\
\hline Potencia Eléctrica & $33 \mathrm{~kW}$ & $50 \mathrm{~kW}$ & $60 \mathrm{~kW}$ \\
\hline Máx RPM & $6000 \mathrm{rpm}$ & $6000 \mathrm{rpm}$ & 13500rpm \\
\hline Par Máximo & $350 \mathrm{Nm}$ & $400 \mathrm{Nm}$ & $207 \mathrm{Nm}$ \\
\hline Peso kg & $41 \mathrm{~kg}$ & $45 \mathrm{~kg}$ & $36,7 \mathrm{~kg}$ \\
\hline Peso Imanes & $1,07 \mathrm{~kg}$ & $1,23 \mathrm{~kg}$ & $0,768 \mathrm{~kg}$ \\
\hline Factor potencia/peso & $0,81 \mathrm{~kW} / \mathrm{kg}$ & $1,11 \mathrm{~kW} / \mathrm{kg}$ & $1,6 \mathrm{~kW} / \mathrm{kg}$ \\
\hline
\end{tabular}




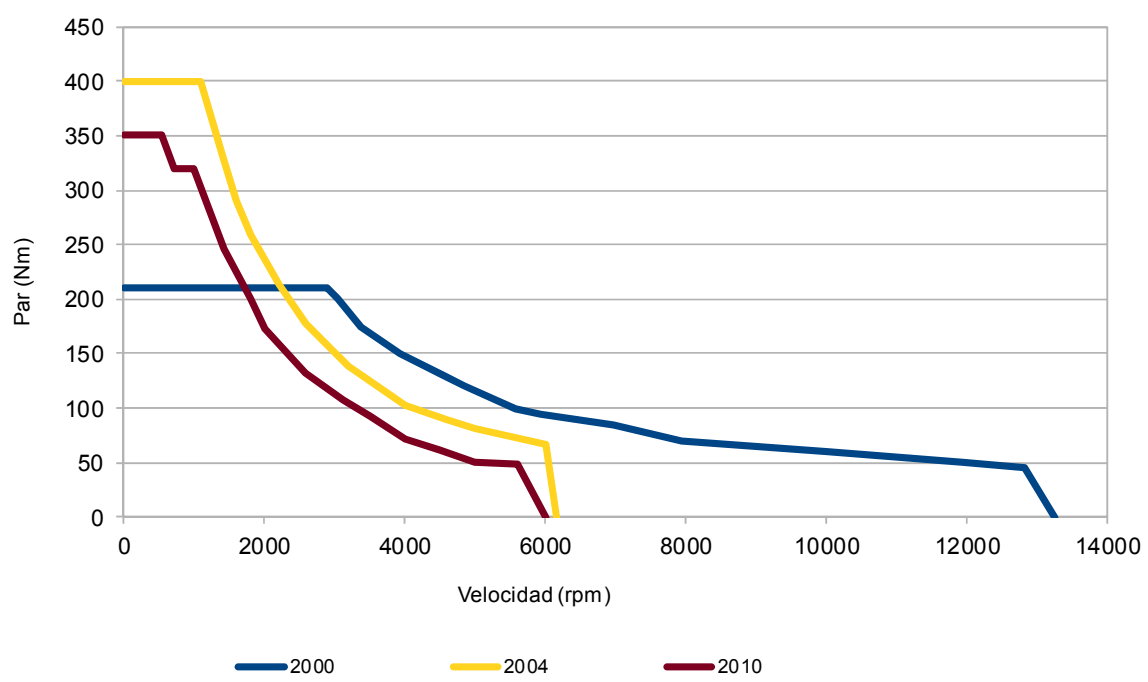

Figura II. 1. Curvas par-velocidad de las versiones del MG2

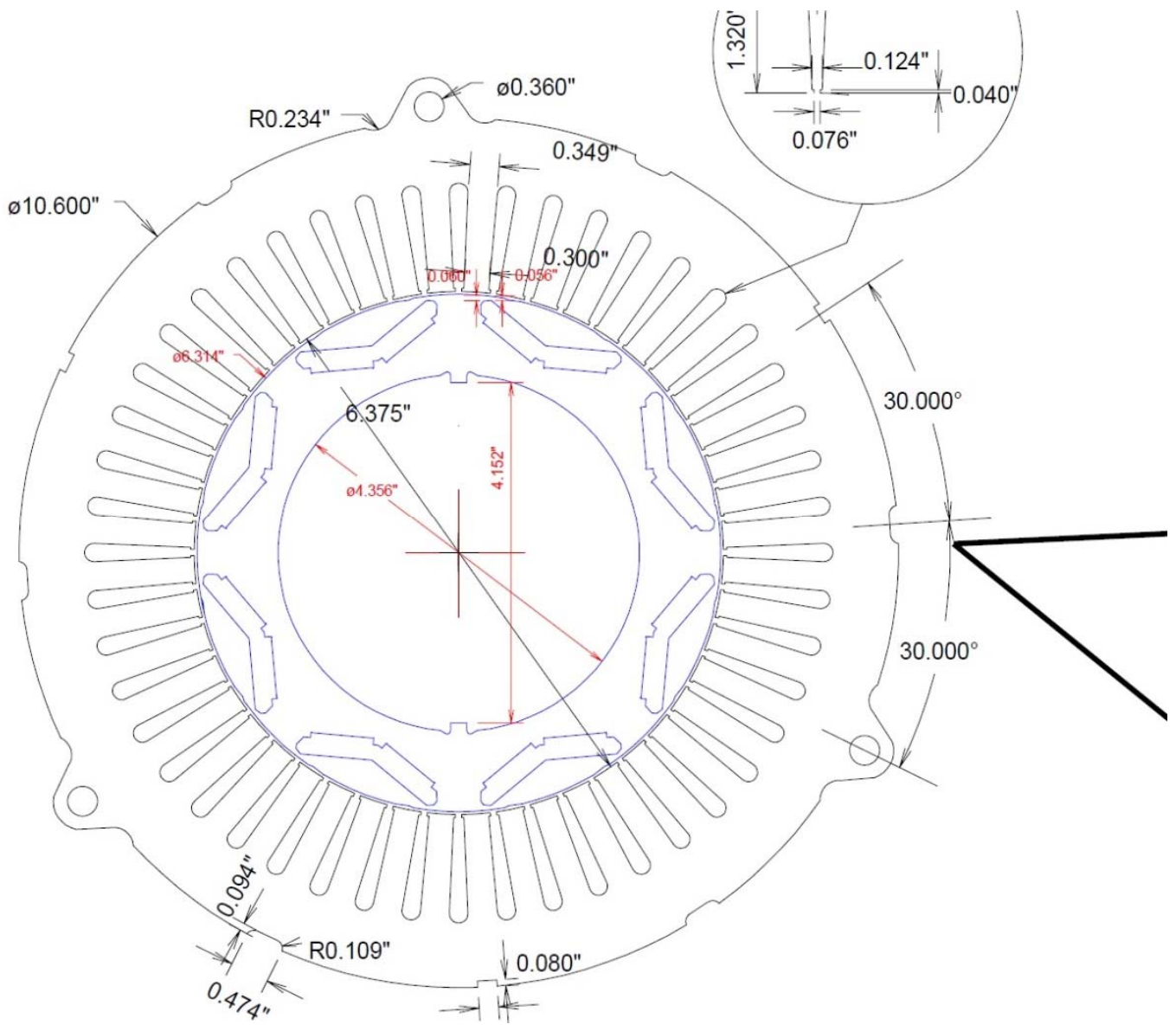

Figura II.2. Dimensiones del MG2 del Prius 2004.

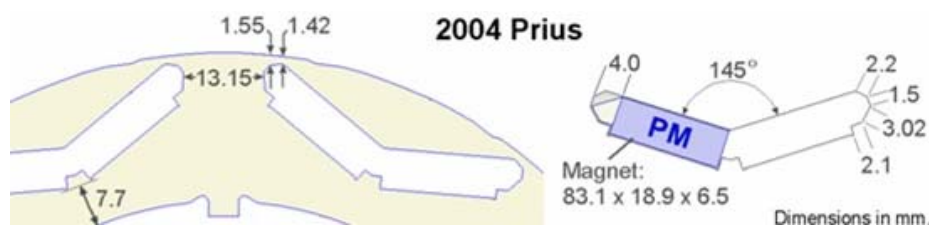

Figura II.3. Dimensiones de los imanes y huecos del Prius 2004. 


\section{ANEXO III. Contrastación de resultados de FEA del MG2 del Toyota Prius 2004}


En este anexo se muestra la comparativa de los resultados obtenidos por nuestro modelo del Toyota Prius 2004 con los de otras fuentes consultadas para comprobar el correcto funcionamiento del modelo. Se realiza con el motor del Prius 2004 por ser el más estudiado y del que más información se dispone.

En las gráficas que se presentan a continuación se observará que el ángulo de rotor de referencia para las curvas es distinto para los modelos. Simplemente se debe a la posición inicial de rotor en cada uno de ellos y a la polaridad de magnetización de los imanes. Lo que debe tenerse en cuenta en que un polo ocupa $45^{\circ}$ de giro del rotor.

\section{III.1 Curvas de par magnetostático}

Se dispone de las curvas obtenidas mediante simulación por el software OPERA [103, 104] para varias intensidades de excitación (Figura III.1) y de las obtenidas por ORNL en su estudio sobre el Prius 2004 (Figura III.4). Las obtenidas en nuestro modelo se muestran en la Figura III.2 y en la Figura III.3.

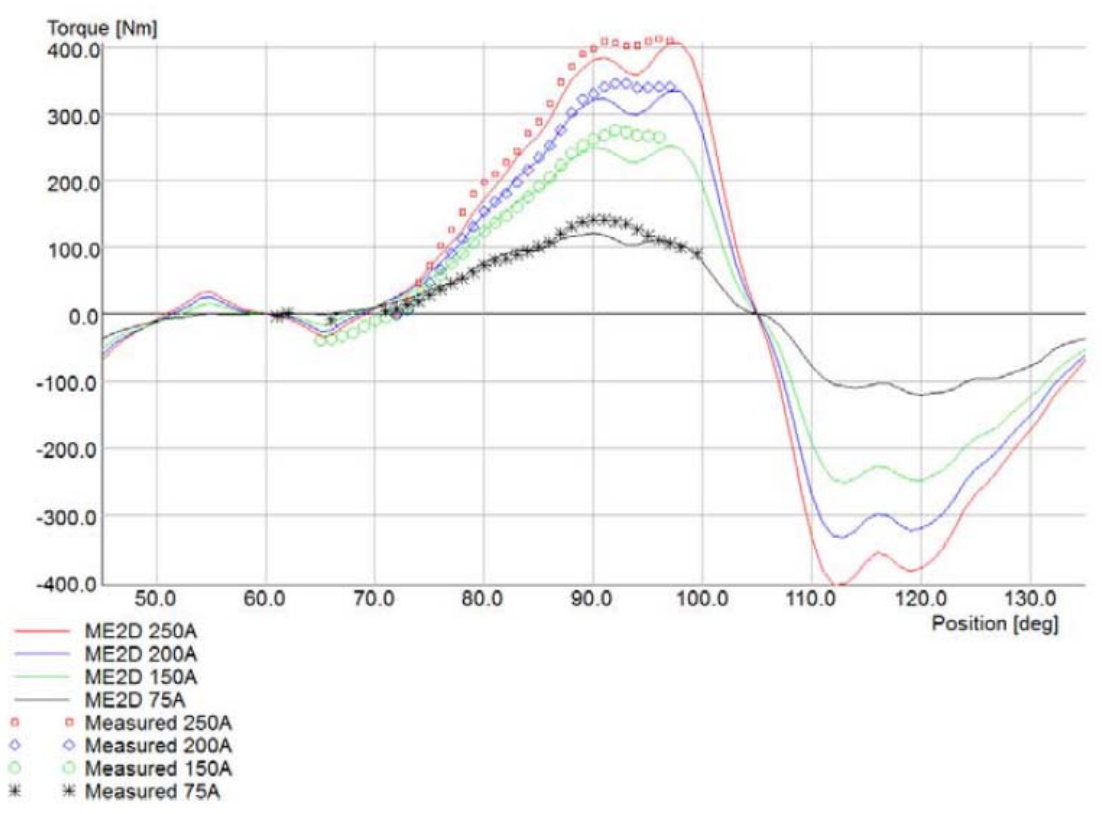

Figura III.1 Curvas de par magnetostático de OPERA [103, 104] 


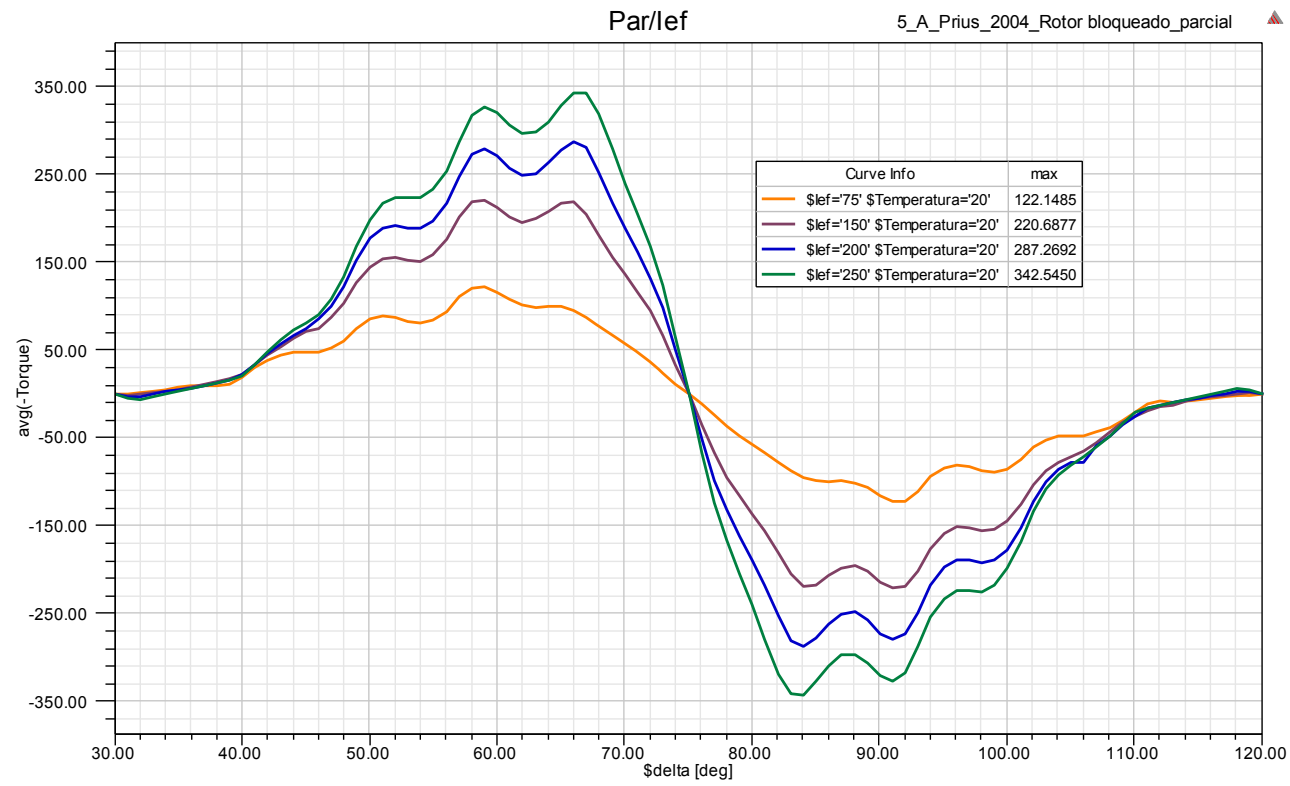

Figura III.2. Curvas de par magnetostático de nuestro modelo

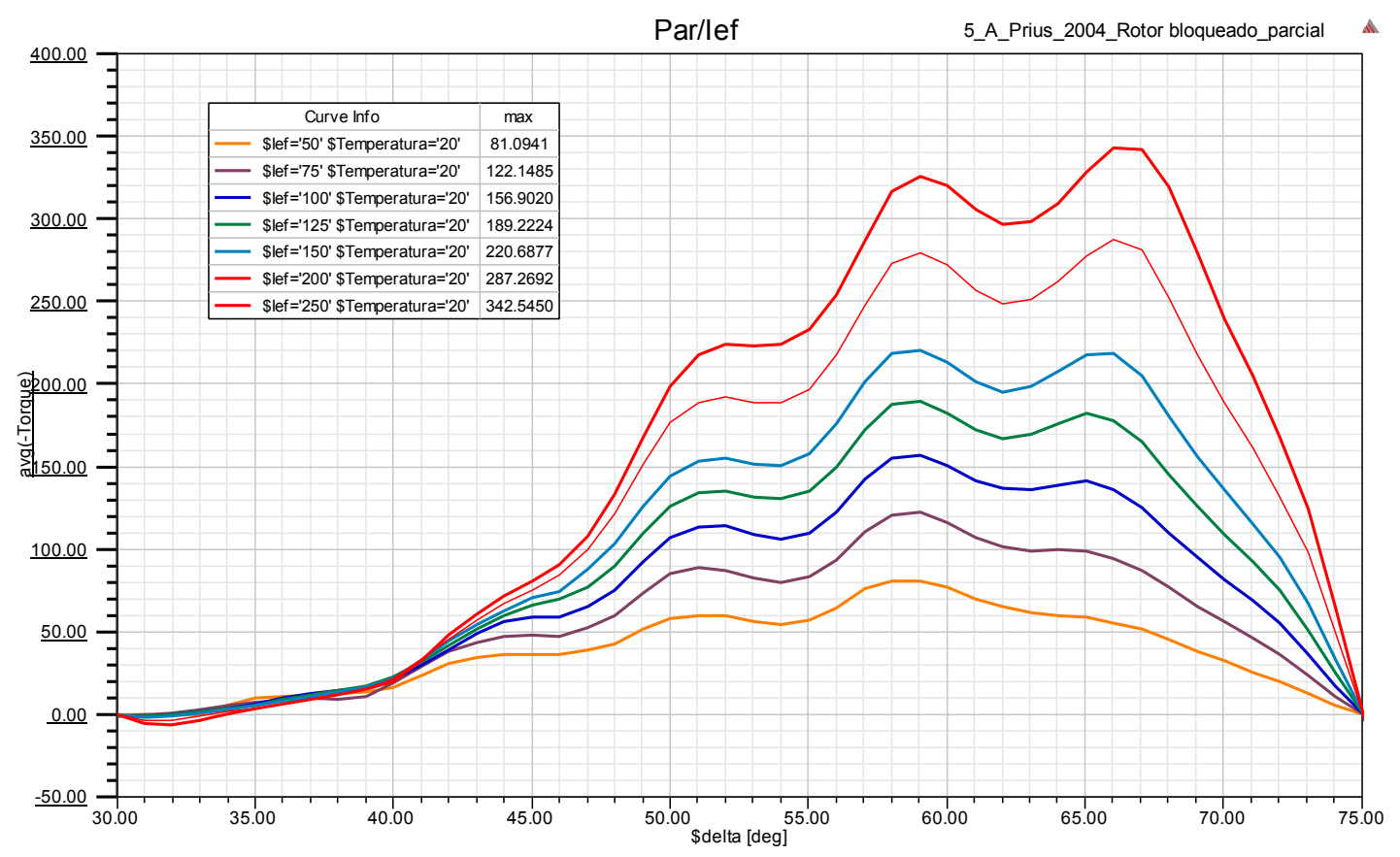

Figura III.3. Curvas de par magnetostático de nuestro modelo

Una primera diferencia apreciable se produce en los 10 primeros grados de giro del rotor, donde el par medido por ORNL es bastante superior al obtenido por el modelo. También se aprecia una diferencia importante en la zona de par máximo (entre $58^{\circ}$ y $68^{\circ}$ de nuestro modelo). 


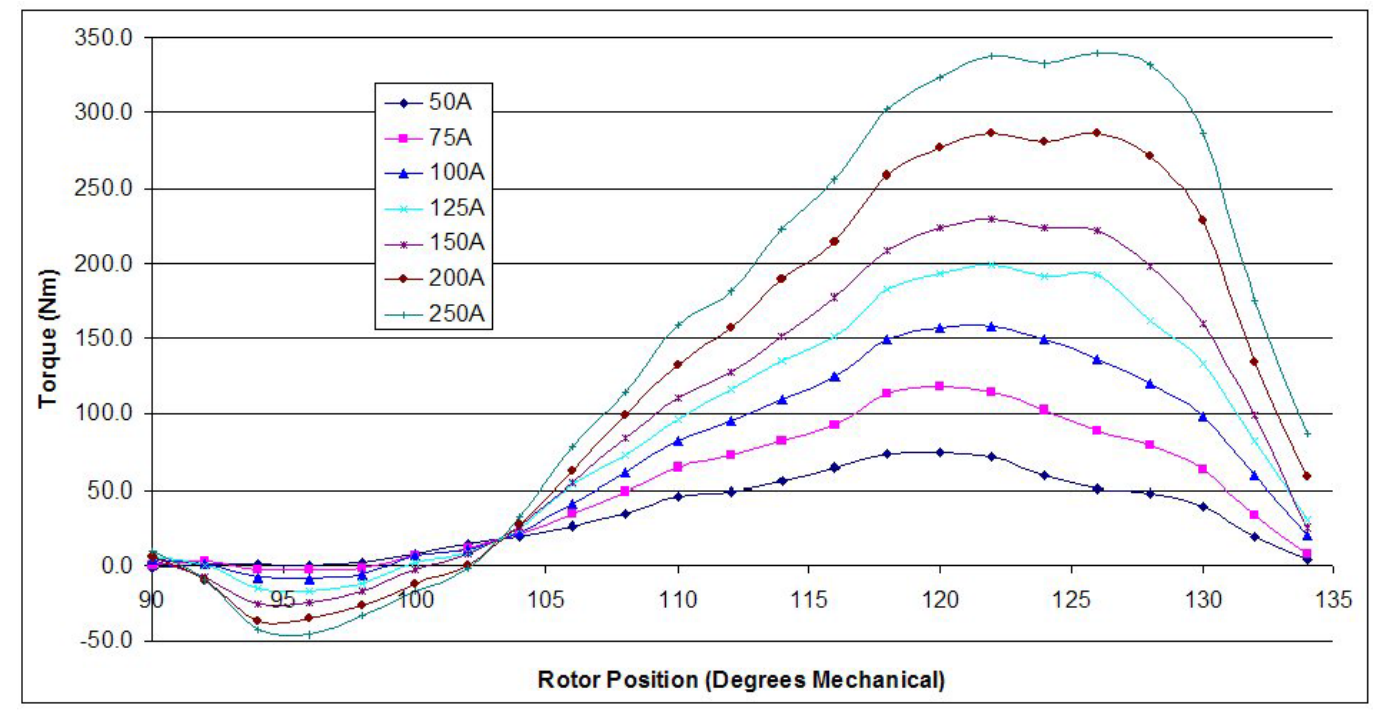

Figura III.4. Curvas magnetostáticas del ORNL [116]

Esto se debe a que en nuestro modelo y en el de OPERA el exterior del rotor es puramente cilíndrico, mientras que en el motor real existe un pequeño rebaje del diámetro de aproximadamente $1 \mathrm{~mm}$ en la zona abarcada por la $\mathrm{v}$ que forman los imanes, como se aprecia en la Figura III.5.

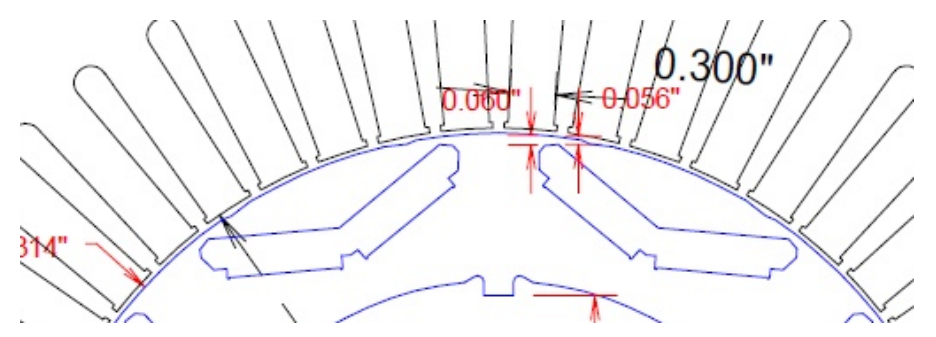

Figura III.5. Detalle del rotor del Prius 2004

Una vez modelado este rebaje en nuestro modelo, la nueva curva de par obtenida para un rebaje de $0,5 \mathrm{~mm}$ y de $1,4 \mathrm{~mm}$ son las mostradas en la Figura III.6, que ya son más similares a las reales. 


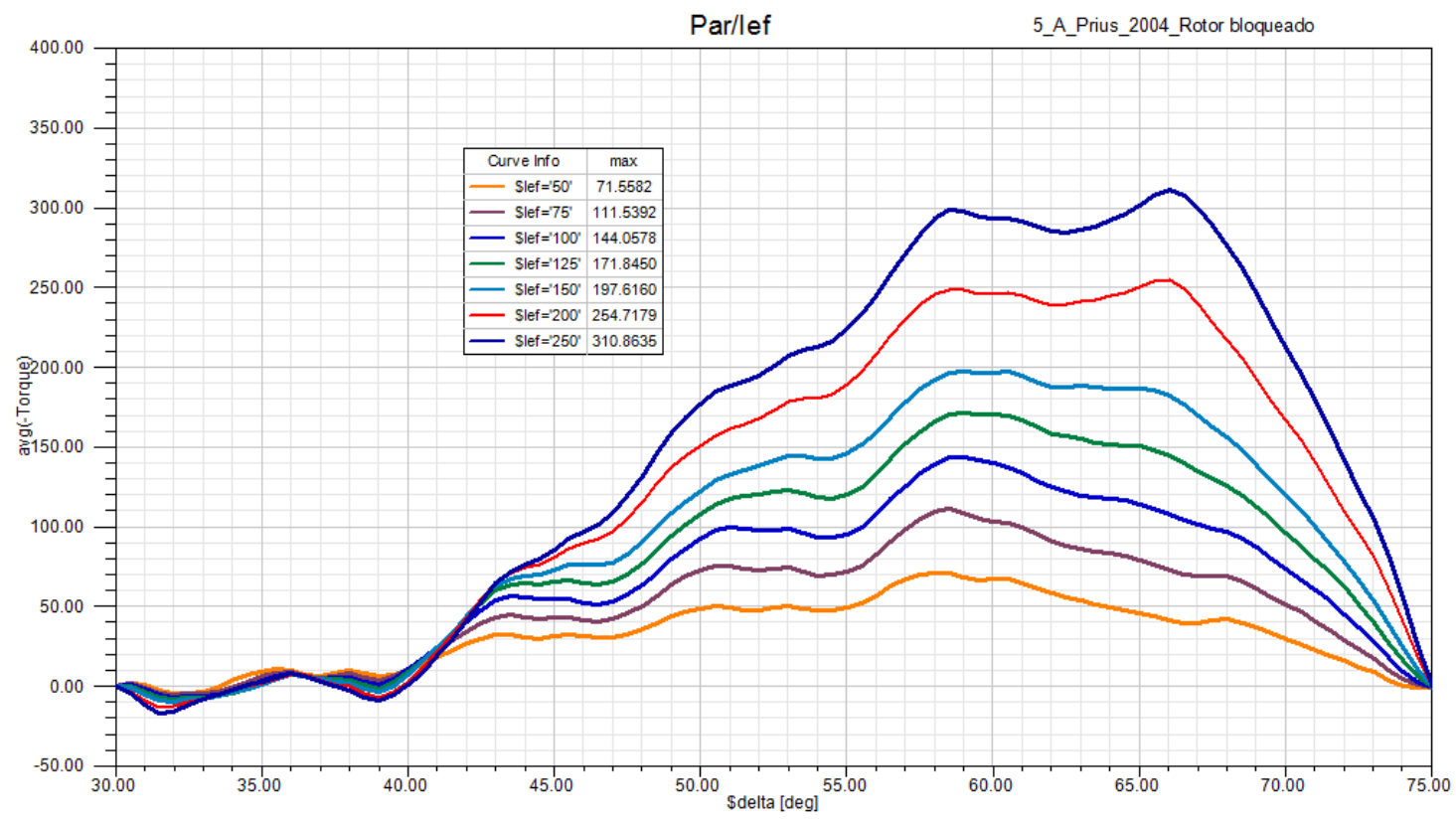

Figura III.6. Curvas de par con rebaje de rotor

\section{III.2. Valor de pico del par magnetostático}

Los valores de referencia se toman de $[10,20,116]$, y son los mostrados en la Figura III.7

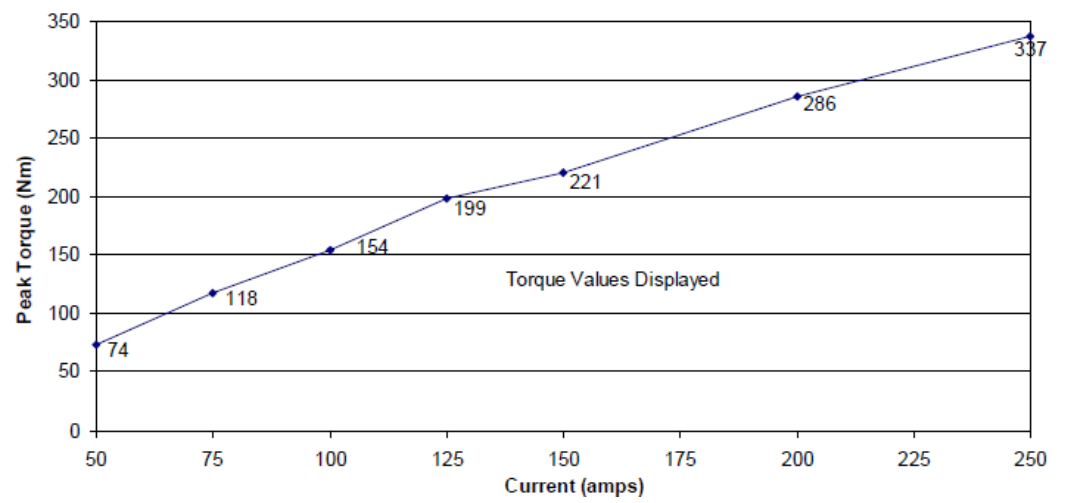

Figura III.7. Valor de pico del par en función de la intensidad. [116]

Los resultados obtenidos con nuestro modelo se comparan en la Figura III.8, donde también se muestra el error porcentual. Se observa que son los valores del modelo son aceptables y que el error, a excepción de la serie correspondiente a 50 A de excitación, no alcanza el 4\%. 


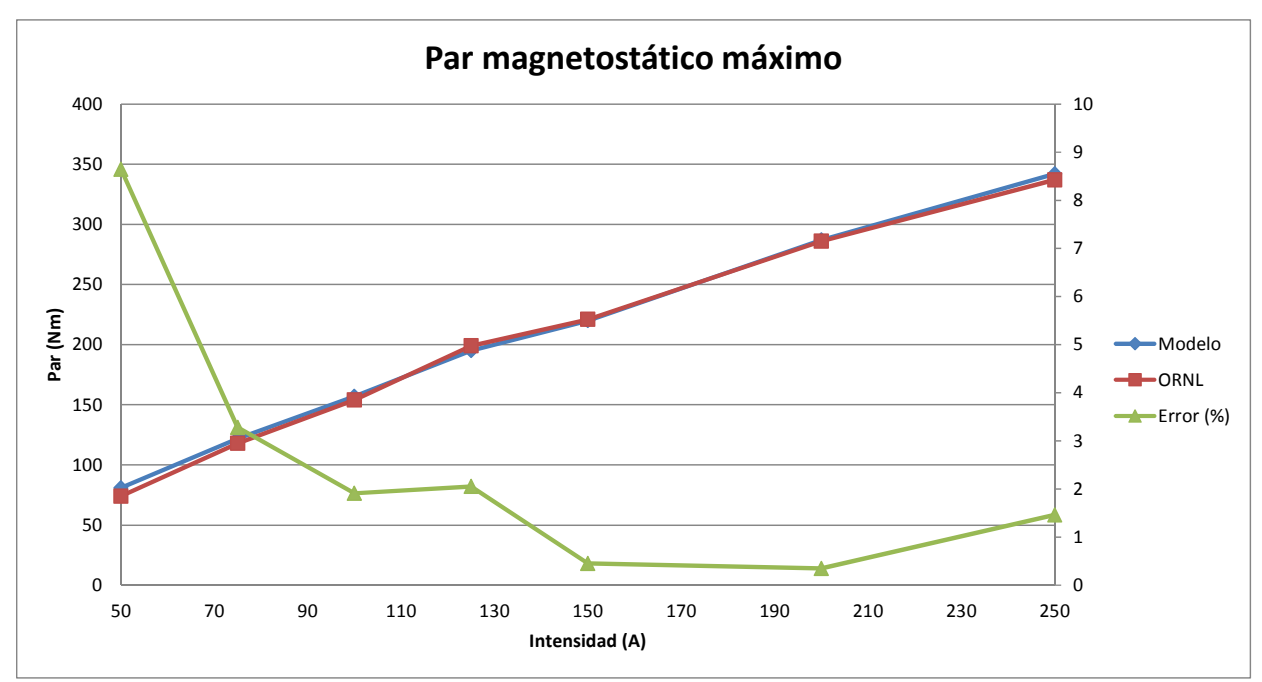

Figura III.8. Valor de pico del par en función de la intensidad. ORNL[116] y modelo

\section{III.3. Valor de la fem inducida/velocidad}

Se muestran en la Tabla III-1 y en la Figura III.9 los valores eficaces y de pico de la fem obtenidas experimentalmente por el ORNL y calculadas en el modelo. El error máximo se produce a $500 \mathrm{rpm}$ y es cercano al 10\%. En el resto de los casos no supera el $8 \%$.

Tabla III-1. Valores de fem medidos por el ORNL [116]

\begin{tabular}{rccccc}
\hline $\begin{array}{c}\text { Axle } \\
\text { Speed, } \\
\text { rpm }\end{array}$ & $\begin{array}{c}\text { Motor-Shaft } \\
\text { Speed, rpm }\end{array}$ & $\begin{array}{c}\text { Axle } \\
\text { Torque, } \\
\text { Nm }\end{array}$ & $\begin{array}{c}\text { Electrical } \\
\text { Frequency, Hz }\end{array}$ & $\begin{array}{c}\text { Scaled Back- } \\
\text { emf (Vrms) }\end{array}$ & $\begin{array}{c}\text { Scaled Back- } \\
\text { emf (Vpeak) }\end{array}$ \\
\hline 122 & 502 & 8.0 & 33.8 & 42.0 & 75 \\
243 & 1000 & 8.4 & 66.5 & 85.7 & 150 \\
365 & 1502 & 9.3 & 99.8 & 132.3 & 225 \\
486 & 1999 & 10.2 & 134.4 & 181.6 & 300 \\
608 & 2501 & 10.8 & 168.1 & 221.8 & 350 \\
729 & 2999 & 11.3 & 200.2 & 269.3 & 425 \\
851 & 3501 & 12.0 & 233.9 & 315.7 & 500 \\
972 & 3999 & 12.6 & 265.4 & 354.6 & 575 \\
1094 & 4501 & 13.1 & 295.7 & 405.5 & 625 \\
1215 & 4999 & 13.6 & 333.0 & 440.4 & 700 \\
1337 & 5500 & 14.6 & 366.3 & 503.4 & 775 \\
1458 & 5998 & 15.6 & 401.3 & 539.8 & 850 \\
\hline
\end{tabular}




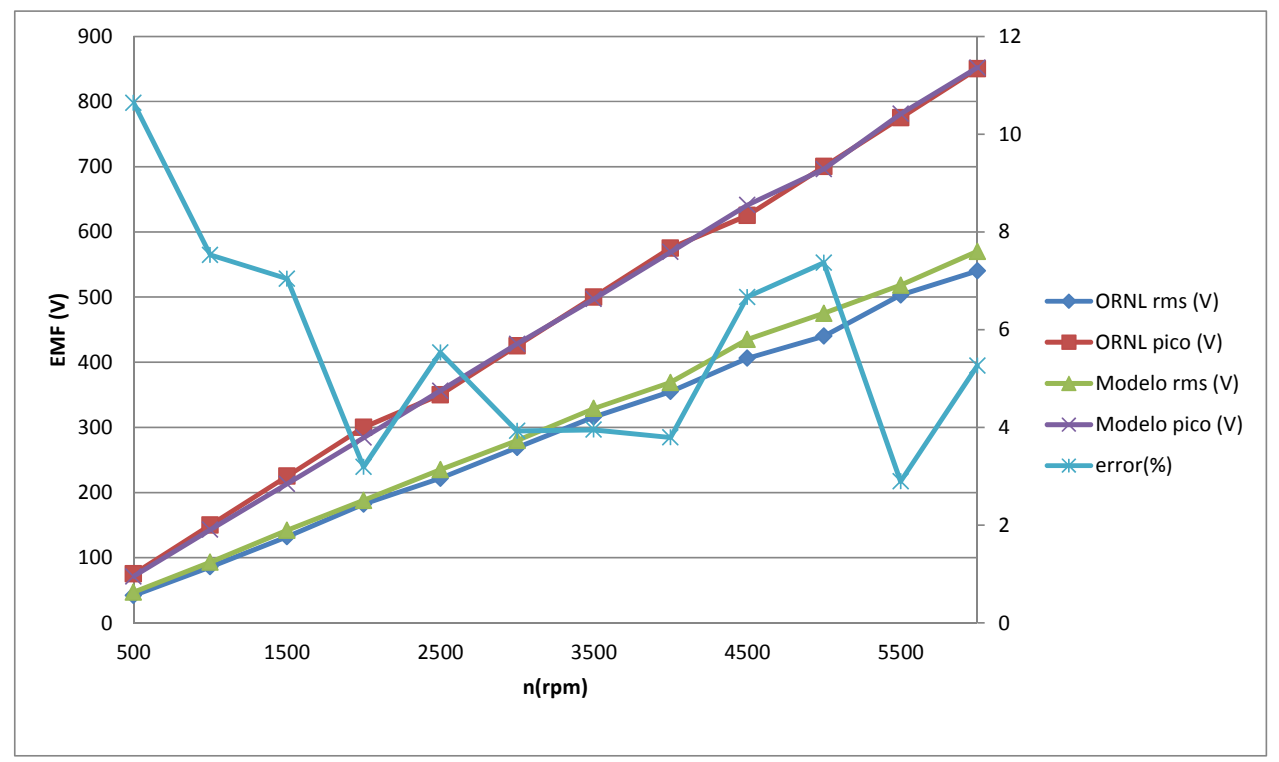

Figura III.9. Comparativa de $f e m$ a distintas revoluciones: ORNL[116] y del modelo

\section{III.4. Curvas de par oscilante}

Las curvas reales no han sido obtenidas por parte del ORNL, por lo que se utilizan las del software OPERA. Como muestra la Figura III.10 la forma de la onda es bastante concordante, si bien los valores calculados en nuestro modelo son superiores que los obtenidos por OPERA. Este hecho se debe al bajo valor del par oscilante y la extrema sensibilidad de los parámetros utilizados en la simulación referentes a mallado y cálculo mediante estudio magnetostático o dinámico a baja velocidad.

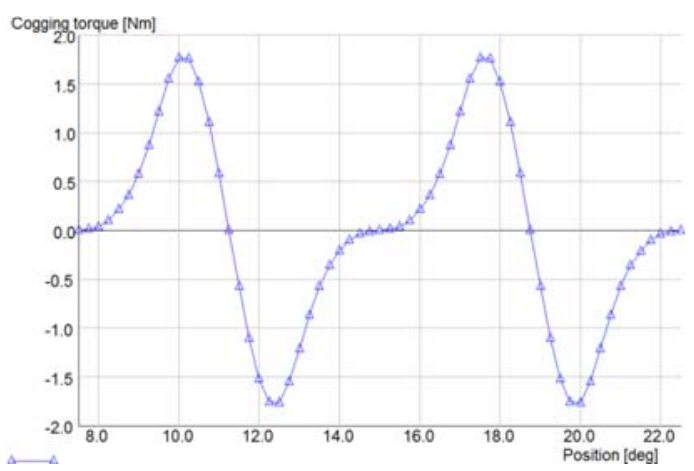

a)

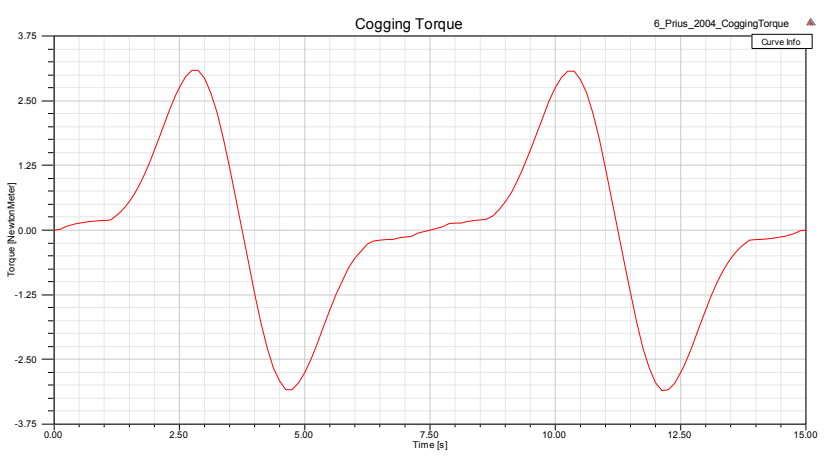

b)

Figura III.10. Curvas de par oscilante a) OPERA[103] y b) Modelo. 


\section{III.5. Curvas de par dinámico}

Se comparan los resultados obtenidos por OPERA en $[103,104]$ con los de nuestro modelo para la curva dinámica de 250 A eficaces y $3000 \mathrm{rpm}$, resultando ser bastante coincidentes.
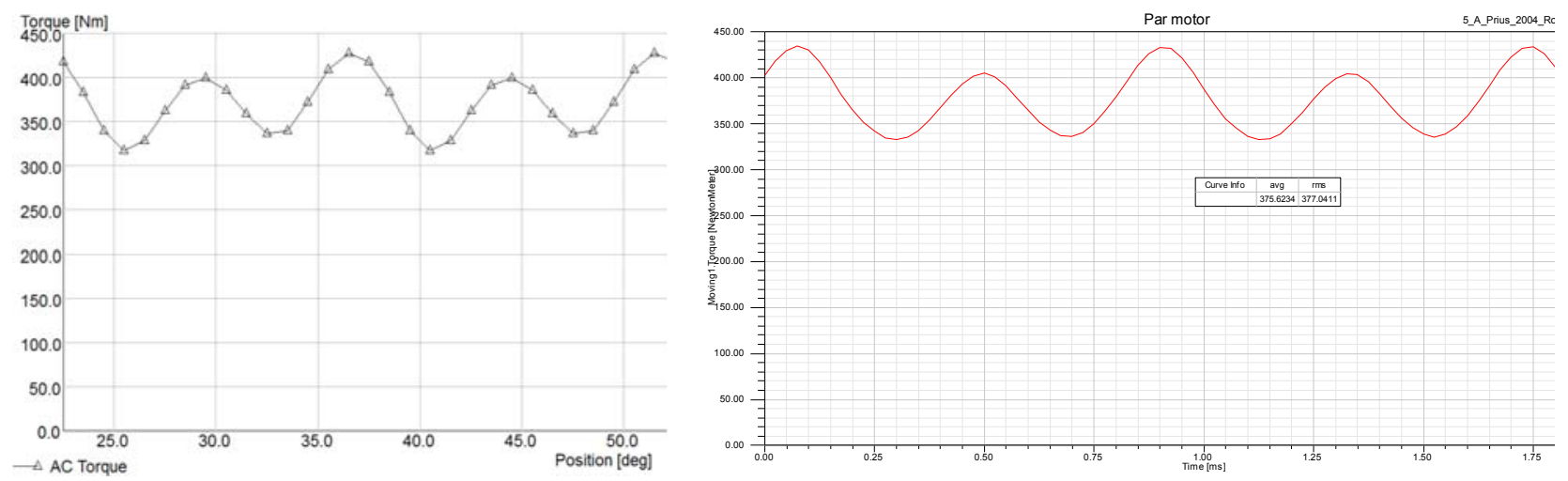

Figura III.11. Curvas de para 250 A y 3.000 rpm. OPERA[103] y modelo.

Por lo tanto, con las comparativas mostradas en este anexo respecto de otras fuentes, el autor concluye que los resultados de la modelación y análisis FEA son aceptables. 


\section{ANEXO IV. Vector de potencial magnético}


Se muestran en este anexo, para cada modelo desarrollado, un ejemplo de las líneas de flujo con la intensidad de 250 A en la fase A (amarillo) y el rotor en posición inicial. Se aprecia que el flujo de dispersión y la densidad de flujo en el puente tienen valores aceptables en nuestro modelo.
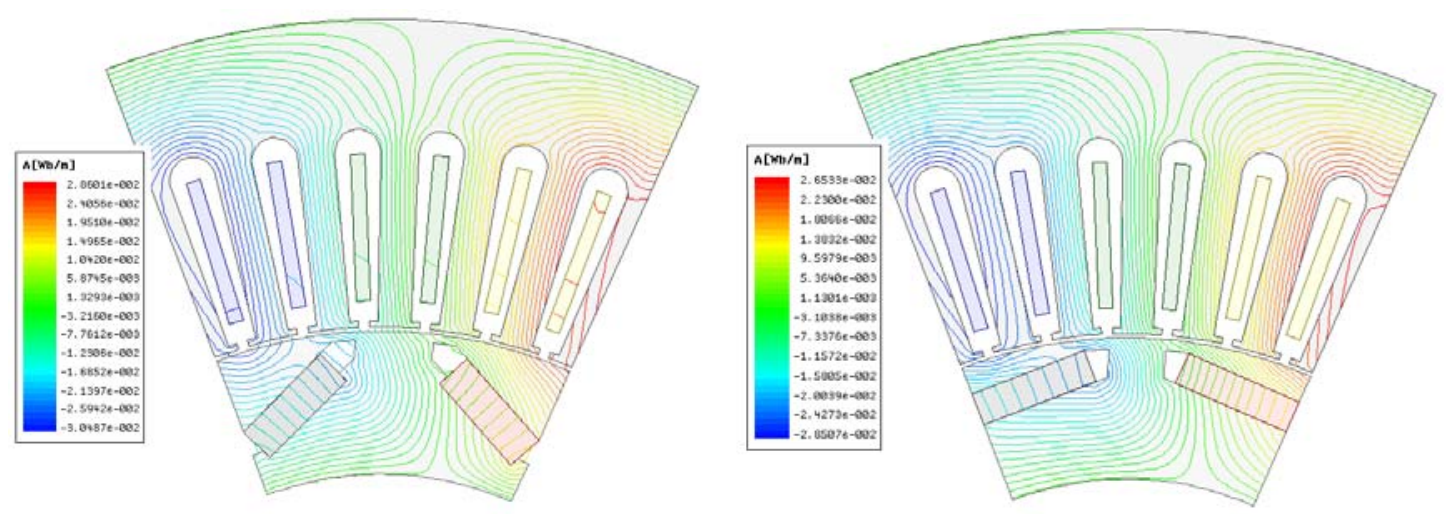

Figura IV.1. Modelos Prius 2004 y 2000
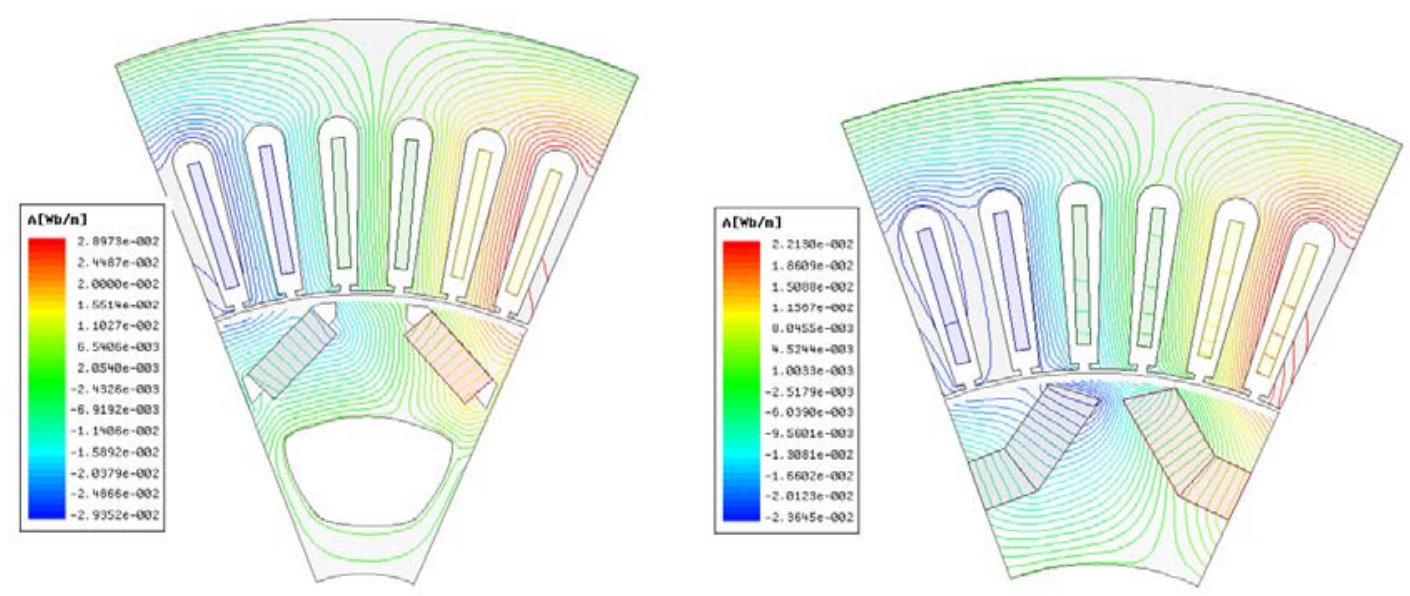

Figura IV.2. Modelos Prius 2010 y UQM
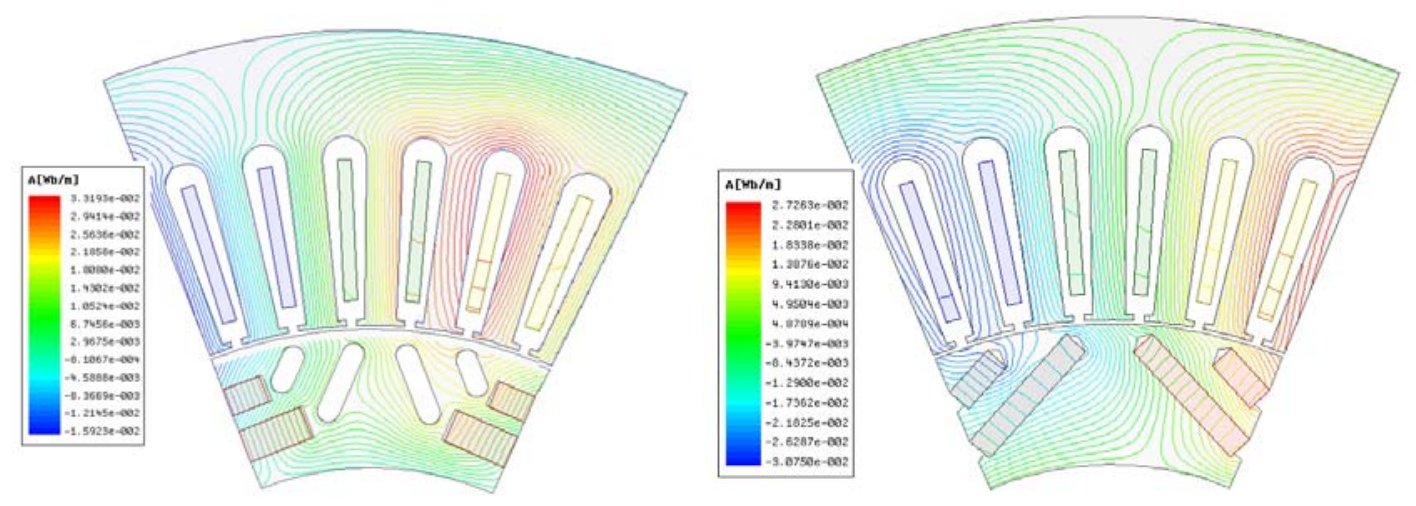

Figura IV.3. Modelos de doble capa planos 


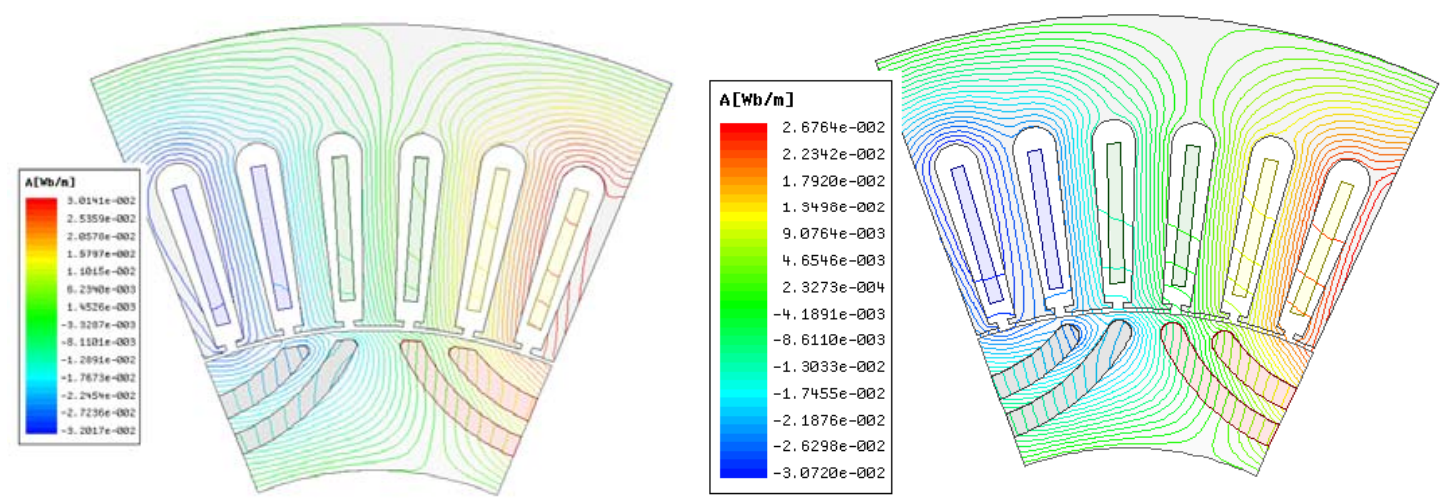

Figura IV.4. Modelos doble capa curvos 